Florida International University

FIU Digital Commons

$11-8-2013$

\title{
A Relationship Between the Florida Comprehensive Assessment Test 2.0 Mathematics Scores and Racial and Ethnic Concentrations when Considering Socio-Economic Status, ESOL Student Population
}

Marilys Galindo

Florida International University, marilys.galindo@gmail.com

DOI: $10.25148 /$ etd.FI13121201

Follow this and additional works at: https:// digitalcommons.fiu.edu/etd

Part of the Curriculum and Instruction Commons, and the Educational Assessment, Evaluation, and Research Commons

\section{Recommended Citation}

Galindo, Marilys, "A Relationship Between the Florida Comprehensive Assessment Test 2.0 Mathematics Scores and Racial and Ethnic Concentrations when Considering Socio-Economic Status, ESOL Student Population" (2013). FIU Electronic Theses and Dissertations. 1010.

https://digitalcommons.fiu.edu/etd/1010

This work is brought to you for free and open access by the University Graduate School at FIU Digital Commons. It has been accepted for inclusion in FIU Electronic Theses and Dissertations by an authorized administrator of FIU Digital Commons. For more information, please contact dcc@fiu.edu. 


\title{
FLORIDA INTERNATIONAL UNIVERSITY \\ Miami, Florida
}

\begin{abstract}
A RELATIONSHIP BETWEEN THE FLORIDA COMPREHENSIVE ASSESSMENT TEST 2.0 MATHEMATICS SCORES AND RACIAL AND ETHNIC CONCENTRATION WHEN CONSIDERING SOCIO-ECONOMIC STATUS, ESOL STUDENT POPULATION, AND SCHOOL CLIMATE
\end{abstract}

A dissertation submitted in partial fulfillment of the requirements for the degree of DOCTOR OF EDUCATION in CURRICULUM AND INSTRUCTION by Marilys Galindo 
To: Dean Delia Garcia

College of Education

This dissertation, written by Marilys Galindo, and entitled A Relationship Between the Florida Comprehensive Assessment Test 2.0 Mathematics Scores and Racial and Ethnic Concentrations when considering Socio-Economic Status, ESOL Student Population, and School Climate, having been approved in respect to style and intellectual content, is referred to you for judgment.

We have read this dissertation and recommend that it be approved.

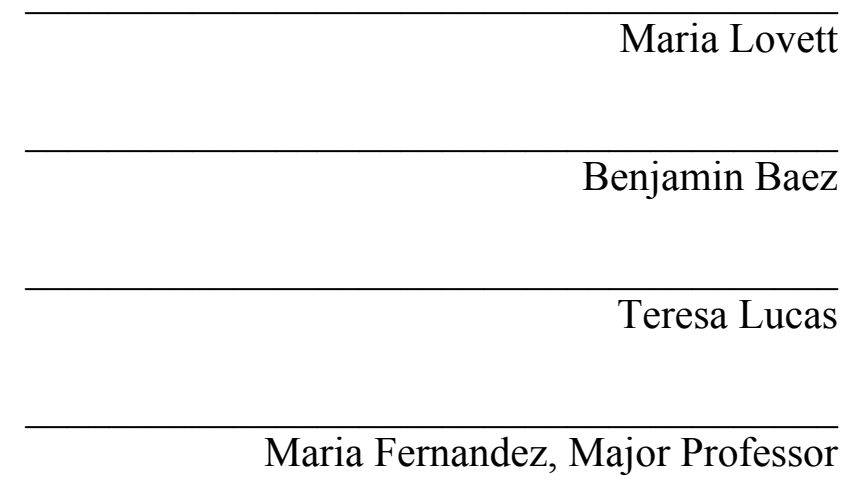

Date of Defense: November 8, 2013

The dissertation of Marilys Galindo is approved.

\begin{tabular}{r}
\hline $\begin{array}{r}\text { Dean Delia Garcia } \\
\text { College of Education }\end{array}$ \\
\hline Dean Lakshmi N. Reddi \\
University Graduate School
\end{tabular}

Florida International University, 2013 
C Copyright 2013 by Marilys Galindo

All rights reserved. 


\section{DEDICATION}

I dedicate this dissertation to my husband, parents, brother, and grandparents. Without their support, understanding, patience, and love, the completion of this degree would not have been possible. I am who I am today, thanks to you all! 


\section{ACKNOWLEDGMENTS}

Completing this education journey is a true blessing! To my Heavenly Father, thank you for being my shining light in the journey to this grand accomplishment.

To my husband, Fred Hernandez, a wholehearted thank you for inspiring me to travel this journey. Your infinite support, patience, and encouragement in this endeavor made it all possible. You always believed in me and offered reassurance throughout the process when I felt I would not finish. You gave me the strength and clarity to keep going. I could not have done this without you!

To my parents, Raul and Julie Galindo, thank you for your unwavering love and support throughout my life. From an early age, you instilled in me a desire to learn and achieve high, always giving me strength to reach for the stars and chase my dreams.

To my brother, Raul Galindo, thank you for being the reason to set an example. You were always there to listen and comfort me. Your endless support was priceless.

To my grandparents, Humberto and Esther Navarro, and Maria Berta Galindo, thank you for your prayers, which have helped make this dream a reality. To my late grandfather, Gilberto Galindo, thank you for blessing me from the heavens above.

To my ancestors, especially Dr. Juan Santiago Michelena, thank you for your inspiration and blessings from the heavens above that helped me accomplish this study.

To the professors who assisted me along the way, Dr. Maria Fernandez, Dr.

Teresa Lucas, Dr. Maria Lovett, Dr. Benjamin Baez, Dr. Linda Bliss, Dr. Isodore Newman, and Dr. Mohammed Farouk, thank you for your leadership during this journey. Finally, to my dog, Luna, thank you for your snuggles and kisses when I needed encouragement. 


\section{ABSTRACT OF THE DISSERTATION}

A RELATIONSHIP BETWEEN THE FLORIDA COMPREHENSIVE ASSESSMENT

TEST 2.0 MATHEMATICS SCORES AND RACIAL AND ETHNIC

CONCENTRATION WHEN CONSIDERING SOCIO-ECONOMIC STATUS, ESOL

STUDENT POPULATION, AND SCHOOL CLIMATE

by

Marilys Galindo

Florida International University, 2013

Miami, Florida

Professor Maria Fernandez, Major Professor

From the moment children are born, they begin a lifetime journey of learning about themselves and their surroundings. With the establishment of the No Child Left Behind Act of 2001, it mandates that all children receive a high-quality education in a positive school climate. Regardless of the school the child attends or the neighborhood in which the child lives, proper and quality education and resources must be provided and made available in order for the child to be academically successful.

The purpose of this ex post facto study was to investigate the relationship between the FCAT 2.0 mathematics scores of public middle school students in Miami-Dade County, Florida and the concentrations of a school's racial and ethnic make-up (Whites, Blacks, and Hispanics), English for Speakers of other Languages (ESOL) population, socio-economic status (SES), and school climate. The research question of this study was: Is there a significant relationship between the FCAT 2.0 Mathematics scores and racial and ethnic concentration of public middle school students in Miami-Dade County 
when controlling SES, ESOL student population, and school climate for the 2010-2011 school year?

The instruments used to collect the data were the FCAT 2.0 and Miami-Dade County Public Schools (M-DCPS) School Climate Survey. The study found that Economically Disadvantaged (SES) students socio-economic status had the strongest correlation with the FCAT 2.0 mathematics scores $(r=-.830)$. The next strongest correlation was with the number of students who agreed that their school climate was positive and helped them learn $(r=.741)$ and the third strongest correlation was a school percentage of White students $(r=.668)$. The study concluded that the FCAT 2.0 mathematics scores of M-DCPS middle school students have a significant relationship with socio-economic status, school climate, and racial concentration. 


\section{TABLE OF CONTENTS}

CHAPTER

PAGE

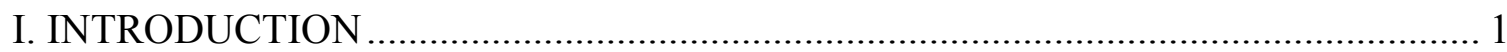

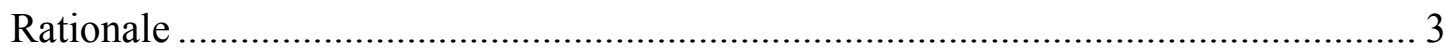

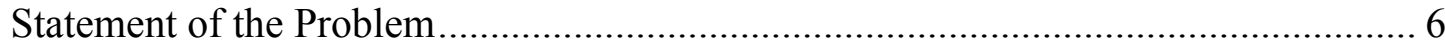

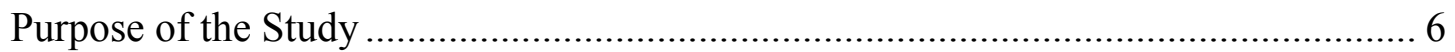

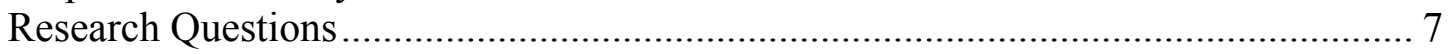

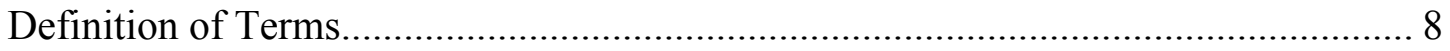

Conceptual Framework ...................................................................................... 13

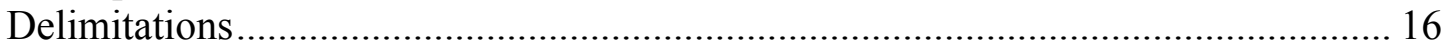

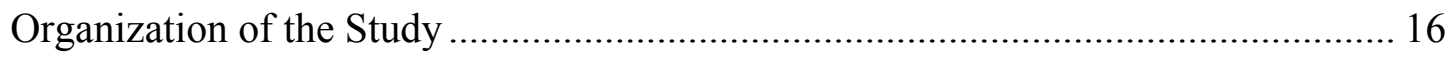

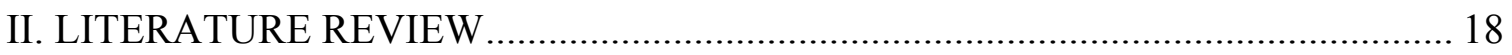

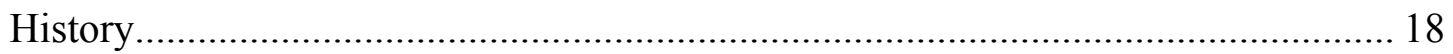

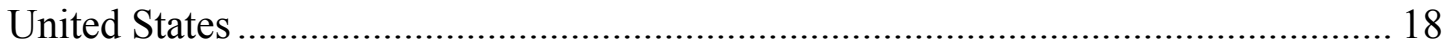

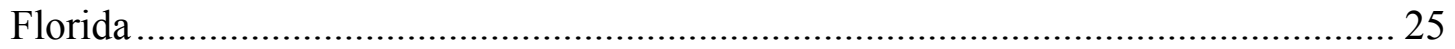

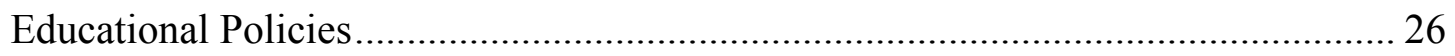

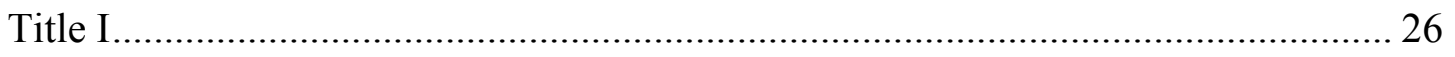

English for Speakers of Other Languages ............................................................. 27

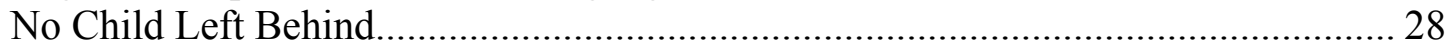

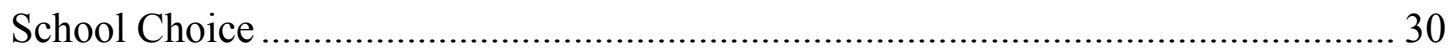

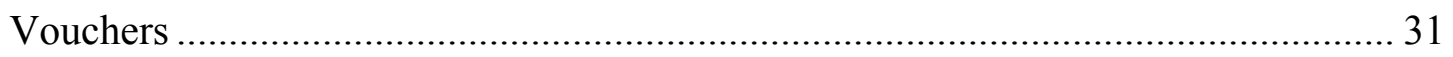

Magnet Programs …………………………………………………………. 33

Charter Schools .................................................................................................. 35

Academic Achievement and School Segregation ...................................................... 37

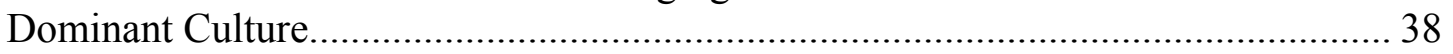

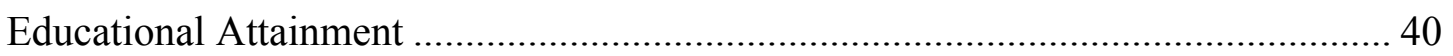

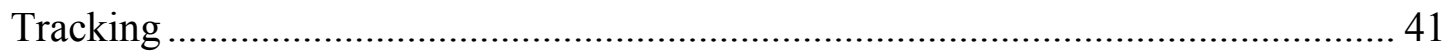

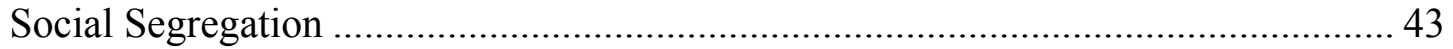

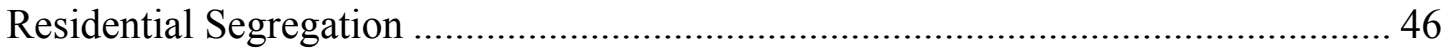

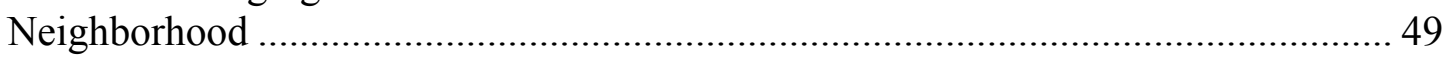

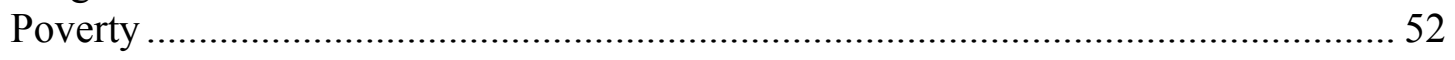

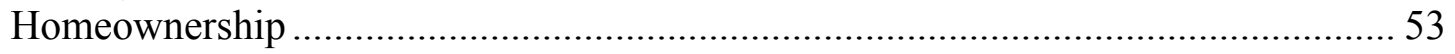

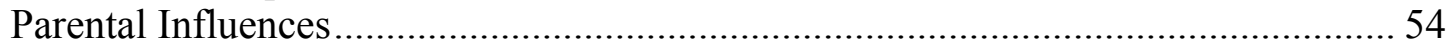

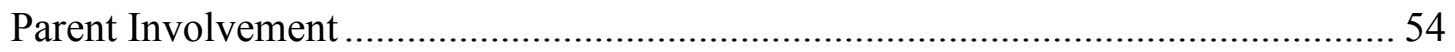

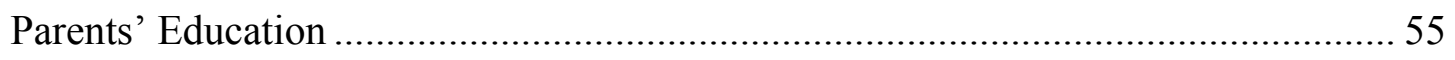

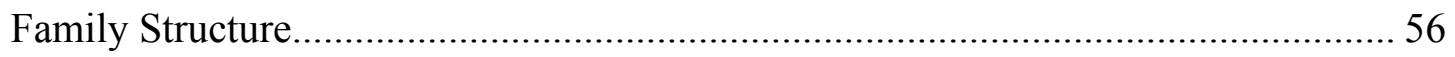

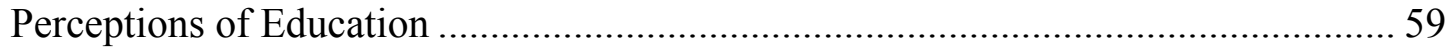

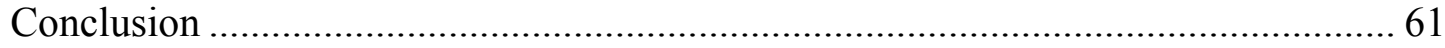

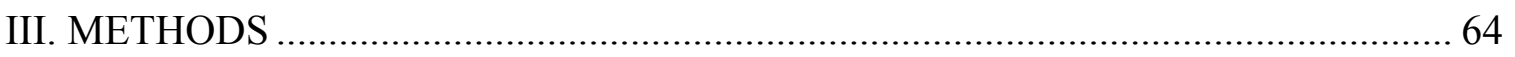

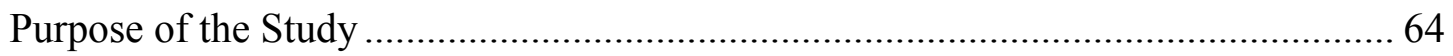

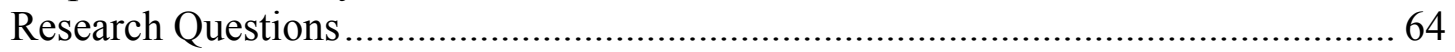




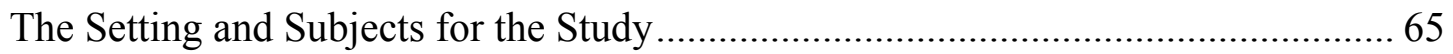

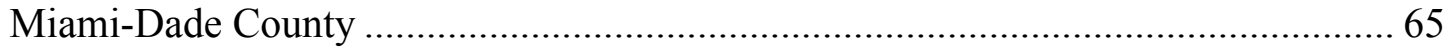

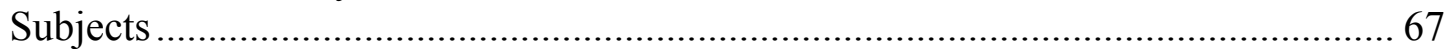

Florida Comprehensive Assessment Test (FCAT) ……………………………..... 68

School Climate Survey ……………………………….................................... 70

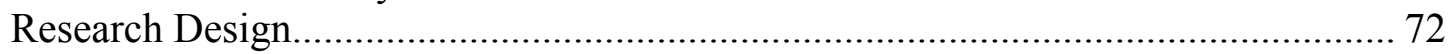

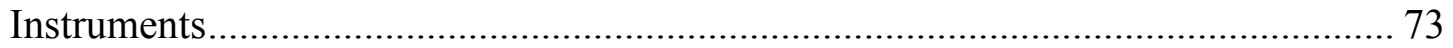

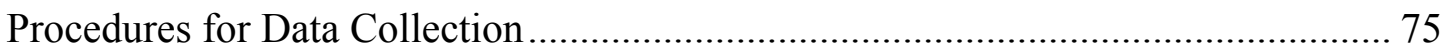

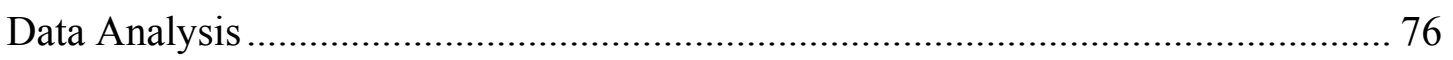

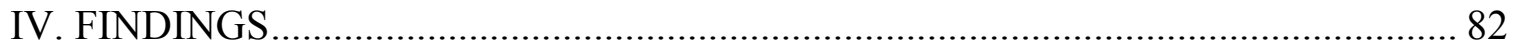

Relationship between FCAT 2.0 Mathematics Scores

and Racial and Ethnic Concentration when controlling

Socio-Economic Status, ESOL Student Population and

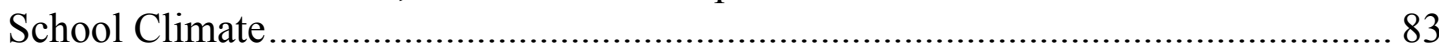

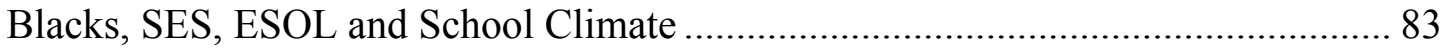

Blacks, Whites, ESOL and School Climate.......................................................... 96

Whites, Hispanics, ESOL and School Climate ...................................................... 108

Hispanics, ESOL and School Climate ………………….................................... 119

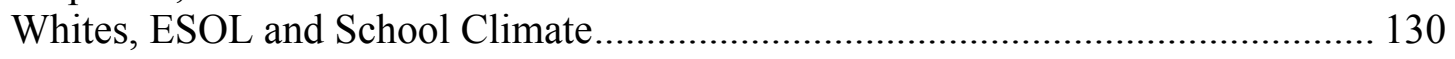

Relationship between Schools' Racial and Ethnic

Concentration and FCAT 2.0 Mathematics Scores when

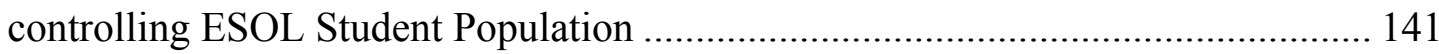

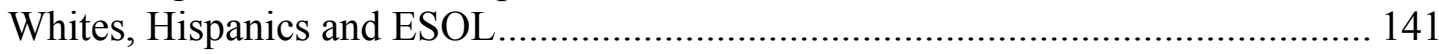

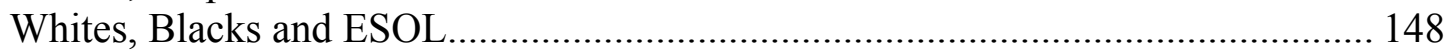

Relationship between FCAT 2.0 Mathematics Scores

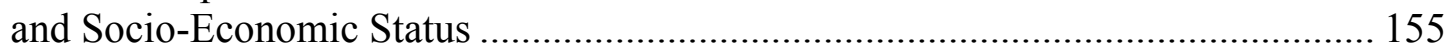

Relationship between FCAT 2.0 Mathematics Scores

and Socio-Economic Status when controlling Racial

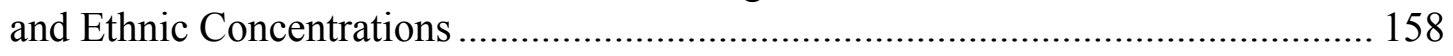

Whites, Hispanics and Socio-Economic Status …………..................................... 158

Whites, Blacks and Socio-Economic Status ........................................................... 165

Relationship between School Climate and FCAT 2.0

Mathematics Scores when controlling Racial and

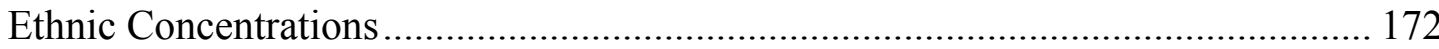

Whites, Hispanics and School Climate................................................................ 172

Whites, Blacks and School Climate...................................................................... 181

V. SUMMARY, DISCUSSION, AND RECOMMENDATIONS .................................. 191

Summary of Relationship between FCAT 2.0 Math

Scores and Racial and Ethnic Concentrations,

Socio-Economic Status, ESOL Student Population,

and School Climate.

Discussion and Implications for Improving Student

Performance on the FCAT 2.0 Mathematics Test 


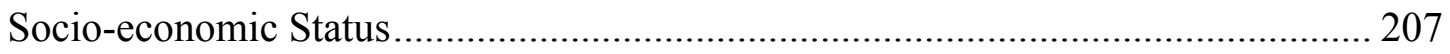

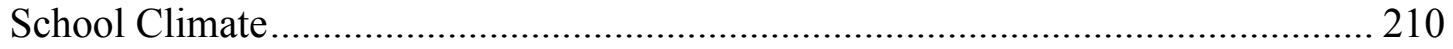

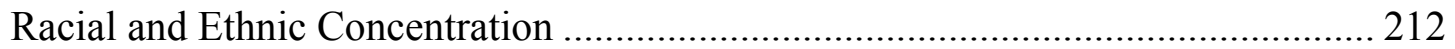

Recommendations for Improving Student Performance

on the FCAT 2.0 Mathematics Test.................................................................... 214

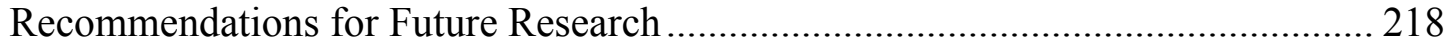

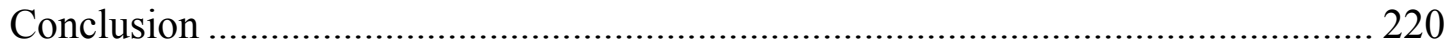

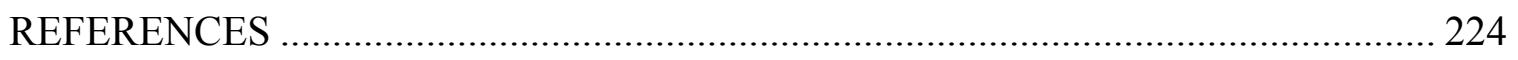

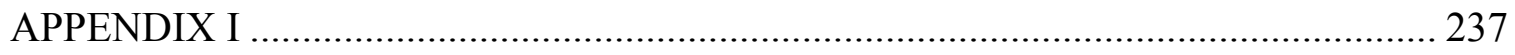

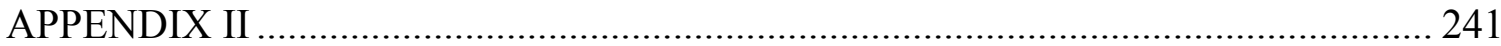

VITA................................................................ 283 


\section{LIST OF TABLES}

TABLE

PAGE

Table 1 FLDOE's 2011 AYP Report (2010-2011 Edition) Data .68

Table 2 MDCPS' School Climate Survey Individual Results (2010-2011 Edition) Data .68

Table 3 FCAT 2.0 Mathematics Equivalent Scale Score for $6^{\text {th }}, 7^{\text {th }}$, and $8^{\text {th }}$ grades

Table 4 FCAT 2.0 Mathematics Equivalent Scores

(Developmental Scale) for $6^{\text {th }}, 7^{\text {th }}$, and $8^{\text {th }}$ grade

Table 5 Pearson $r$ and Sig. (1-tailed) - Relationship of FCAT 2.0

Mathematics Scores and Racial and Ethnic Concentration (Blacks, Whites, Hispanics) when controlling Economically Disadvantaged (SES), ESOL Student Population, and School Climate.

Table 6 ANOVA $^{\text {a }}$ - Relationship of FCAT 2.0 Mathematics Scores and Racial and Ethnic Concentration (Blacks) when controlling Economically Disadvantaged (SES), ESOL Student Population, and School Climate.

Table 7 Coefficients - Relationship of FCAT 2.0 Mathematics Scores and Racial and Ethnic Concentration (Blacks) when controlling Economically Disadvantaged (SES), ESOL Student Population, and School Climate....

Table 8 Coefficients Continued - Relationship of FCAT 2.0 Mathematics Scores and Racial and Ethnic Concentration (Blacks) when controlling Economically Disadvantaged (SES), ESOL Student Population, and School Climate

Table 9 Pearson $r$ and Sig. (1-tailed) - Relationship of FCAT 2.0 Mathematics Scores and Racial and Ethnic Concentration (Blacks, Whites, Hispanics) when controlling Economically Disadvantaged (SES), ESOL Student Population, and School Climate.

Table 10 ANOVA - Relationship of FCAT 2.0 Mathematics Scores and Racial and Ethnic Concentration (Blacks, Whites) when controlling ESOL Student Population and School Climate 104 
Table 11 Coefficients - Relationship of FCAT 2.0 Mathematics Scores and Racial and Ethnic Concentration (Blacks, Whites) when controlling ESOL Student Population and School Climate.

Table 12 Coefficients Continued - Relationship of FCAT 2.0 Mathematics Scores and Racial and Ethnic Concentration (Blacks, Whites) when controlling ESOL Student Population and School Climate.

Table 13 Pearson $r$ and Sig. (1-tailed) - Relationship of Racial and Ethnic Concentration (Blacks, Whites, Hispanics) and FCAT 2.0 Mathematics Scores when controlling Economically

Disadvantaged (SES), ESOL Student Population, and School

Climate.

Table 14 ANOVA - Relationship of Racial and Ethnic Concentration (Whites, Hispanics) and FCAT 2.0 Mathematics Scores when controlling ESOL Student Population and School Climate.

Table 15 Coefficients - Relationship of Racial and Ethnic Concentration (Whites, Hispanics) and FCAT 2.0 Mathematics Scores when controlling ESOL Student Population and School Climate.

Table 16 Coefficients Continued - Relationship of Racial and Ethnic Concentration (Whites, Hispanics) and FCAT 2.0 Mathematics Scores when controlling ESOL Student Population and School Climate.

Table 17 Pearson $r$ and Sig. (1-tailed) - Relationship of Racial and

Ethnic Concentration (Blacks, Whites, Hispanics) and FCAT 2.0

Mathematics Scores when controlling Economically

Disadvantaged (SES), ESOL Student Population, and School

Climate.

Table 18 ANOVA - Relationship of Racial and Ethnic

Concentration (Hispanics) and FCAT 2.0 Mathematics Scores

when controlling ESOL Student Population, and School Climate

Table 19 Coefficients - Relationship of Racial and Ethnic Concentration (Hispanics) and FCAT 2.0 Mathematics Scores when controlling ESOL Student Population, and School Climate 
Table 20 Coefficients Continued - Relationship of Racial and Ethnic Concentration (Hispanics) and FCAT 2.0 Mathematics Scores when controlling ESOL Student Population, and School Climate.

Table 21 Pearson $r$ and Sig. (1-tailed) - Relationship of Racial and Ethnic Concentration (Blacks, Whites, Hispanics) and FCAT 2.0

Mathematics Scores when controlling Economically

Disadvantaged (SES), ESOL Student Population, and School

Climate

Table 22 ANOVA - Relationship of Racial and Ethnic Concentration (Whites) and FCAT 2.0 Mathematics Scores when controlling ESOL Student Population, and School Climate 138

Table 23 Coefficients - Relationship of Racial and Ethnic Concentration (Whites) and FCAT 2.0 Mathematics Scores when controlling ESOL Student Population, and School Climate

Table 24 Coefficients Continued - Relationship of Racial and Ethnic Concentration (Whites) and FCAT 2.0 Mathematics Scores when controlling ESOL Student Population, and School Climate

Table 25 Pearson $r$ and Sig. (1-tailed) - Relationship of Racial and Ethnic Concentration (Whites, Blacks, Hispanics) and FCAT 2.0 Mathematics Scores when controlling ESOL Student Population

Table 26 ANOVA - Relationship of Racial and Ethnic Concentration (Whites and Hispanics) and FCAT 2.0 Mathematics Scores when controlling ESOL Student Population....

Table 27 Coefficients - Relationship of Racial and Ethnic Concentration (Whites and Hispanics) and FCAT 2.0 Mathematics Scores when controlling ESOL Student Population

Table 28 Coefficients Continued - Relationship of Racial and Ethnic Concentration (Whites and Hispanics) and FCAT 2.0 Mathematics Scores when controlling ESOL Student Population 148

Table 29 Pearson $r$ and Sig. (1-tailed) - Relationship of Racial and Ethnic Concentration (Blacks, Whites, Hispanics) with the FCAT 2.0 Mathematics Scores when controlling the ESOL Student Population 150 
Table 30 ANOVA - Relationship of Racial and Ethnic

Concentration (Whites and Blacks) and FCAT 2.0 Mathematics

Scores when controlling ESOL Student Population

Table 31 Coefficients - Relationship of Racial and Ethnic

Concentration (Whites and Blacks) and FCAT 2.0 Mathematics

Scores when controlling ESOL Student Population

Table 32 Coefficients Continued - Relationship of Racial and

Ethnic Concentration (Whites and Blacks) and FCAT 2.0

Mathematics Scores when controlling ESOL Student Population

Table 33 Pearson $r$ and Sig. (1-tailed) - Relationship of FCAT 2.0

Mathematics Scores and Socio-Economic Status

Table 34 ANOVA - Relationship of FCAT 2.0 Mathematics

Scores and Socio-Economic Status.

Table 35 Coefficients - Relationship of FCAT 2.0 Mathematics

Scores and Socio-Economic Status..

Table 36 Coefficients Continued - Relationship of FCAT 2.0

Mathematics Scores and Socio-Economic Status

Table 37 Pearson $r$ and Sig. (1-tailed) - Relationship of FCAT 2.0

Mathematics Scores and Socio-Economic Status when controlling

Racial and Ethnic Concentration (Whites, Blacks, Hispanics).....

Table 38 ANOVA - Relationship of FCAT 2.0 Mathematics

Scores and Socio-Economic Status when controlling Racial and

Ethnic Concentration (Whites \& Hispanics)

Table 39 Coefficients - Relationship of FCAT 2.0 Mathematics

Scores and Socio-Economic Status when controlling Racial and

Ethnic Concentration (Whites \& Hispanics).

Table 40 Coefficients Continued - Relationship of FCAT 2.0

Mathematics Scores and Socio-Economic Status when controlling

Racial and Ethnic Concentration (Whites \& Hispanics).

Table 41 Pearson $r$ and Sig. (1-tailed) - Relationship of FCAT 2.0

Mathematics Scores and Socio-Economic Status when controlling

Racial and Ethnic Concentration (Whites, Blacks, Hispanics)

Table 42 ANOVA - Relationship of FCAT 2.0 Mathematics

Scores and Socio-Economic Status when controlling Racial and

Ethnic Concentration (Whites \& Blacks) 
Table 43 Coefficients - Relationship of FCAT 2.0 Mathematics

Scores and Socio-Economic Status when controlling Racial and

Ethnic Concentration (Whites \& Blacks)

Table 44 Coefficients Continued - Relationship of FCAT 2.0

Mathematics Scores and Socio-Economic Status when controlling

Racial and Ethnic Concentration (Whites \& Blacks)

Table 45 Pearson $r$ and Sig. (1-tailed) - Relationship of School

Climate and FCAT 2.0 Mathematics Scores when controlling

Racial and Ethnic Concentration (Whites, Blacks, \& Hispanics)

Table 46 ANOVA - Relationship of School Climate and FCAT

2.0 Mathematics Scores when controlling Racial and Ethnic

Concentration (Whites \& Hispanics)

Table 47 Coefficients - Relationship of School Climate and FCAT

2.0 Mathematics Scores when controlling Racial and Ethnic

Concentration (Whites \& Hispanics)

Table 48 Coefficients Continued - Relationship of School Climate

and FCAT 2.0 Mathematics Scores when controlling Racial and

Ethnic Concentration (Whites \& Hispanics).

Table 49 Pearson $r$ and Sig. (1-tailed) - Relationship of School

Climate and FCAT 2.0 Mathematics Scores when controlling

Racial and Ethnic Concentration (Whites, Blacks, \& Hispanics)

Table 50 ANOVA - Relationship of School Climate and FCAT

2.0 Mathematics Scores when controlling Racial and Ethnic

Concentration (Whites \& Blacks)

Table 51 Coefficients - Relationship of School Climate and FCAT

2.0 Mathematics Scores when controlling Racial and Ethnic

Concentration (Whites \& Blacks)

Table 52 Coefficients Continued - Relationship of School Climate and FCAT 2.0 Mathematics Scores when controlling Racial and Ethnic Concentration (Whites \& Black)

Table 53 Collinearity Statistics - Relationship of FCAT 2.0

Mathematics Scores and Racial and Ethnic Concentration (Blacks, Whites, Hispanics) when controlling Economically Disadvantaged (SES), ESOL Student Population, and School Climate 
Table 54 Descriptive Statistics - Relationship of FCAT 2.0

Mathematics Scores and Racial and Ethnic Concentration (Blacks)

when controlling Economically Disadvantaged (SES), ESOL

Student Population, and School Climate

Table 55 Model Summary - Relationship of FCAT 2.0

Mathematics Scores and Racial and Ethnic Concentration (Blacks)

when controlling Economically Disadvantaged (SES), ESOL

Student Population, and School Climate

Table 56 Collinearity Statistics - Relationship of FCAT 2.0

Mathematics Scores and Racial and Ethnic Concentration (Blacks,

Whites, Hispanics) when controlling Economically Disadvantaged

(SES), ESOL Student Population, and School Climate

Table 57 Descriptive Statistics - Relationship of FCAT 2.0

Mathematics Scores and Racial and Ethnic Concentration (Blacks,

Whites) when controlling ESOL Student Population and School

Climate.

Table 58 Model Summary - Relationship of FCAT 2.0

Mathematics Scores and Racial and Ethnic Concentration (Blacks, Whites) when controlling ESOL Student Population and School

Climate.

Table 59 Collinearity Statistics - Relationship of Racial and Ethnic

Concentration (Blacks, Whites, Hispanics) and FCAT 2.0

Mathematics Scores when controlling Economically

Disadvantaged (SES), ESOL Student Population, and School

Climate.

Table 60 Descriptive Statistics - Relationship of Racial and Ethnic

Concentration (Whites, Hispanics) and FCAT 2.0 Mathematics

Scores when controlling ESOL Student Population and School

Climate.

Table 61 Model Summary - Relationship of Racial and Ethnic

Concentration (Whites, Hispanics) and FCAT 2.0 Mathematics

Scores when controlling ESOL Student Population and School

Climate.

Table 62 Collinearity Statistics - Relationship of Racial and Ethnic

Concentration (Blacks, Whites, Hispanics) and FCAT 2.0

Mathematics Scores when controlling Economically

Disadvantaged (SES), ESOL Student Population, and School

Climate. 
Table 63 Descriptive Statistics - Relationship of Racial and Ethnic

Concentration (Hispanics) when controlling ESOL Student

Population, and School Climate with the FCAT 2.0 Mathematics

Scores

Table 64 Model Summary - Relationship of Racial and Ethnic Concentration (Hispanics) and FCAT 2.0 Mathematics Scores when controlling ESOL Student Population, and School Climate .255

Table 65 Collinearity Statistics - Relationship of Racial and Ethnic Concentration (Blacks, Whites, Hispanics) and FCAT 2.0

Mathematics Scores when controlling Economically

Disadvantaged (SES), ESOL Student Population, and School

Climate. .256

Table 66 Descriptive Statistics - Relationship of Racial and Ethnic Concentration (Whites) and FCAT 2.0 Mathematics Scores when controlling ESOL Student Population, and School Climate

Table 67 Model Summary - Relationship of Racial and Ethnic Concentration (Whites) and FCAT 2.0 Mathematics Scores when controlling ESOL Student Population, and School Climate.

Table 68 Collinearity Statistics - Relationship of Racial and Ethnic Concentration (Blacks, Whites, Hispanics) with the FCAT 2.0 Mathematics Scores when controlling the ESOL Student Population .260

Table 69 Descriptive Statistics - Relationship of Racial and Ethnic Concentration (Whites and Hispanics) and FCAT 2.0 Mathematics Scores when controlling ESOL Student Population .260

Table 70 Model Summary - Relationship of Racial and Ethnic Concentration (Whites and Hispanics) and FCAT 2.0 Mathematics

Scores when controlling ESOL Student Population .... .262

Table 71 Collinearity Statistics - Relationship of Racial and Ethnic Concentration (Blacks, Whites, Hispanics) with the FCAT 2.0 Mathematics Scores when controlling the ESOL Student Population .263

Table 72 Descriptive Statistics - Relationship of Racial and Ethnic Concentration (Blacks, Whites) with the FCAT 2.0 Mathematics Scores when controlling the ESOL Student Population 
Table 73 Model Summary - Relationship of Racial and Ethnic

Concentration (Whites and Blacks) and FCAT 2.0 Mathematics

Scores when controlling ESOL Student Population.....

Table 74 Descriptive Statistics - Relationship of FCAT 2.0

Mathematics Scores and Socio-Economic Status

Table 75 Model Summary - Relationship of FCAT 2.0

Mathematics Scores and Socio-Economic Status

Table 76 Collinearity Statistics - Relationship of the FCAT 2.0

Mathematics Scores and Socio-economic Status when controlling

Racial and Ethnic Concentration (Blacks, Whites, Hispanics).

Table 77 Descriptive Statistics - Relationship of FCAT 2.0

Mathematics Scores and Socio-Economic Status when controlling

Racial and Ethnic Concentration (Whites \& Hispanics).

Table 78 Model Summary - Relationship of FCAT 2.0

Mathematics Scores and Socio-Economic Status when controlling

Racial and Ethnic Concentration (Whites \& Hispanics).

Table 79 Collinearity Statistics - Relationship of the FCAT 2.0

Mathematics Scores and Socio-economic Status when controlling

Racial and Ethnic Concentration (Blacks, Whites, Hispanics)

Table 80 Descriptive Statistics - Relationship of FCAT 2.0

Mathematics Scores and Socio-Economic Status when controlling

Racial and Ethnic Concentration (Whites \& Blacks)

Table 81 Model Summary - Relationship of FCAT 2.0

Mathematics Scores and Socio-Economic Status when controlling

Racial and Ethnic Concentration (Whites \& Blacks)

Table 82 Collinearity Statistics - Relationship of the FCAT 2.0

Mathematics Scores and School Climate when controlling Racial

and Ethnic Concentration (Blacks, Whites, Hispanics)

Table 83 Descriptive Statistics - Relationship of School Climate and FCAT 2.0 Mathematics Scores when controlling Racial and Ethnic Concentration (Whites \& Hispanics).

Table 84 Model Summary - Relationship of School Climate and FCAT 2.0 Mathematics Scores when controlling Racial and Ethnic Concentration (Whites \& Hispanics) .278 
Table 85 Collinearity Statistics - Relationship of the FCAT 2.0 Mathematics Scores and School Climate when controlling Racial and Ethnic Concentration (Blacks, Whites, Hispanics)

Table 86 Descriptive Statistics - Relationship of School Climate and FCAT 2.0 Mathematics Scores when controlling Racial and Ethnic Concentration (Whites \& Blacks)

Table 87 Model Summary - Relationship of School Climate and FCAT 2.0 Mathematics Scores when controlling Racial and Ethnic Concentration (Whites \& Blacks). 


\section{ABBREVIATIONS AND ACRONYMS}

\begin{tabular}{|c|c|}
\hline ANOVA & Analysis of Variance \\
\hline AYP & Adequate Yearly Progress \\
\hline ELL & English Language Learners \\
\hline ESE & Exceptional Student Education \\
\hline ESL & English as a Second Language \\
\hline ESOL & English for Speaker of Other Languages \\
\hline FCAT & Florida Comprehensive Assessment Test \\
\hline FCAT 2.0 & Florida Comprehensive Assessment Test 2.0 \\
\hline FEFP & Florida Education Finance Program \\
\hline FIU & Florida International University \\
\hline FLDOE & Florida Department of Education \\
\hline IRB & Institutional Review Board \\
\hline M-DCPS & Miami-Dade County Public Schools \\
\hline MFP & Minimum Foundation Program \\
\hline MLR & Multiple Linear Regression \\
\hline NAACP & $\begin{array}{l}\text { National Association for the Advancement } \\
\text { of Colored People }\end{array}$ \\
\hline NCEE & National Commission on Excellence in Education \\
\hline NCLB & No Child Left Behind Act 2001 \\
\hline NDEA & National Defense Education Act \\
\hline NGSSS & Next Generation Sunshine State Standards \\
\hline PRE-K & Pre-Kindergarten \\
\hline $\mathrm{RCR}$ & Responsible Conduct of Research \\
\hline SES & Socio-Economic Status \\
\hline
\end{tabular}


SS

VIF

VPK

WASP
Sum of Squares

Variance Inflation Factor

Voluntary Pre-Kindergarten

White Anglo-Saxon Protestants 


\section{CHAPTER 1}

\section{INTRODUCTION}

It can be said that in American culture, all residents of the United States are connected in the sense that in exchange for living up to social responsibilities they are entitled to opportunity, rights, freedom, and justice. As stated by Moore (2002), American students, regardless of race, ethnicity, or religion, would be bonded by a common American culture, understand and accept the academic standards established by society and strive to fulfill their individual potential in a democratic society characterized by equal opportunity, individual rights, and responsibilities, freedom, and social justice. (p. 246)

Throughout history, the socio-economic status of different groups of people (with regard to their education, health, assets, and relationships) has created segregation among the country's population (Kahlenberg, 2000). Regardless of government efforts, segregation has continued to exist and reflects in the schools. Racial and ethnic minority families usually find themselves living in neighborhoods populated by other minorities. Moreover, the segregation of a school reflects the neighborhood's demographics; usually the more segregated the school, the lower the level of student achievement (Rumberger \& Palardy, 2005). Additionally, Rumberger and Palardy (2005) pointed out that "minority students are more likely to attend large, high-poverty urban schools with fewer qualified teachers and more traditional organizational features that inhibit student learning" (pp. 130-131). Schools that are in the same district, but located in neighborhoods of differing socio-economic status, display a large disparity in opportunities and quality of education offered to students. The students' academic achievement level has a relation to 
residential segregation. Residential segregation relates to the school's resources and materials, the students' preparation for standardized testing, the students' linguistic competency, the students' cultural experience, segregation, educational aspirations, parental involvement, and family structure (Moore, 2002).

Raley (1991) stated that the socio-economic status of neighborhoods relates to its children, their health, development, and academic achievement. The academic achievement of students living in low socio-economic areas has been limited by the lack of resources, funds, and parental support (Raley, 1991). With regards to race, W.E.B. Dubois wrote that an African American student "needs neither segregated schools nor mixed schools. What he needs is Education" (Coleman, 1935, p. 335). Every student needs to receive a quality education that meets their individual needs and learning styles, however, not all racial and ethnic minority children have the financial means to live in integrated neighborhoods or high socio-economic status neighborhoods with access to the higher quality education and opportunities. The responsibility lies with school districts and departments of education to provide all students with the necessities so that they are able to focus on obtaining an education for the benefit of their future. These necessities include the same amount of attention, exposure to knowledge, and resources found in schools located in higher socio-economic status neighborhoods. The socio-economic status into which students are born is beyond their control.

In 1974, Thurgood Marshall, a lawyer who contributed to the victory of Brown $v$ Board of Education and later served as a Supreme Court Justice, stated, we deal with the right of all children, whatever their race, to an equal state in life and to an equal opportunity to reach their full potential as citizens. Those 
children who have been denied that right in the past deserve better... our nation, I fear, will be ill served by the courts' refusal to remedy separate and unequal education for unless our children begin to learn together. (as cited in Chemerinsky, 2005, p. 32)

Regardless of the school the child attends or the neighborhood the child lives in, quality education and resources must be provided and made available in order for the child to be academically successful. From the moment children are born, they are learning; learning how to walk, read, talk, learning how to do everything (Chemerinsky, 2005). Besides, as implied by the name of the No Child Left Behind Act of 2001, no child should be left behind since it mandates that all children receive a high-quality education. "At the beginning of the twenty-first century, the issue is not education in general, but quality education" (Perry, T., 2010, p. xi). Are all children receiving the same high-quality education in a positive school climate?

This chapter provides background information on segregation and students' academic achievement, and, with regards to this study, the problem examined, the purpose, the research questions, the definition of terms, the significance of the study, the delimitations, and the organization of the study .

\section{Rationale}

The researcher has been interested in conducting this study since she began to complete her field experience hours for her Bachelor's degree from Florida International University in Miami-Dade County, Florida. The experience acquired first-hand intrigued the researcher. During her first set of 15 field hours back in the summer semester of 2004, the researcher was assigned to a Pre-Kindergarten (Pre-K) class at Jesse J. 
McCrary, Jr. Elementary School, formerly known as Little River Elementary School, during May and June of the school year. The school is located in a low socio-economic status neighborhood, in an area called Little Haiti due to the area's predominant population of Haitian immigrants. Approximately $84 \%$ of the student population was Black (Little River Elementary School Characteristic, 2004). During the researcher's experience at Jesse J. McCrary, Jr. Elementary School, she became troubled by the severe limitation to quality educational opportunities for these students. The resources and manipulatives (books, educational toys, etc.) in the classroom were old, broken, and limited. Classroom management needed improvement; there seemed to be some chaos since the children were always at play while the researcher was there. There was no evidence of a curriculum being followed. The researcher recalls the Pre-K teacher stating that she was content if her students were at least able to learn how to write their name by the end of the school year.

The researcher really noticed the difference when she went to complete her second set of 15 field hours at Sunset Park Elementary during the fall semester of 2004. The researcher was assigned to another Pre-Kindergarten class. This school is located in a middle to high socio-economic status neighborhood, in the Kendall area of Miami-Dade County. The majority of the student population was Hispanic, at $70 \%$, followed by White at 16\% and Black at 4\% (Sunset Park Elementary School Characteristic, 2005). Despite being the largest ethnic group in this school and school district, Hispanics are an ethnic minority in the United States.

During the researcher's experience at Sunset Park Elementary School, she directly observed the maximized learning experience received by those students. In contrast with 
the children at Jesse J. McCrary, Jr., the Sunset Park students had already mastered the ability to write their name by the time the researcher had started her field hours at the beginning of the school year in September. The class followed the curriculum adopted for Pre-Kindergarten in Miami-Dade County, the HighScope Curriculum, in which "children learn through direct, hands-on experiences with people, events and ideas" (HighScope Educational Research Foundation, 2011). The students were enthusiastically engaged and interested in the hands-on learning activities; it was a positive atmosphere for learning. The teacher led the students from activity to activity with smooth transitions, efficiently managing class time. The classroom management was well organized, and was reflected in the order and behavior of the students. There was an abundance of learning resources and manipulatives that seemed in relatively new condition. The researcher completed these 15 field hours during September and October, one school year after she visited Jesse J. McCrary, Jr. Elementary School.

After exposure to these contrasting classroom settings, the researcher became intrigued by the relationship between residential segregation and students' academic achievement. The experience raised many questions for her. Why are not all students in Miami-Dade County Public Schools (M-DCPS) receiving a high level of quality education? Why are all schools not providing the students with the same educational opportunities as mandated by the No Child Left Behind Act? What can be done about the inequality in the education system? How many more schools are in the same position as Jesse J. McCrary, Jr. Elementary School? It would be beneficial to education and policy makers to adjust or tailor educational policies to truly provide all students with quality education, and to hold those responsible for exercising high-quality education. 


\section{Statement of the Problem}

The problem examined in this study was if a significant relationship exists between the Florida Comprehensive Assessment Test 2.0 (FCAT 2.0) Mathematics scores and racial and ethnic concentrations (Blacks, Whites, and Hispanics) of public middle schools in Miami-Dade County when controlling socio-economic status, ESOL student population, and school climate for the 2010-2011 school year. Studies (Blazer, 2007; Borman, McNulty Eitle, Michael, \& Eitle, 2004; Chemerinsky, 2005; Conger, 2005; Kao \& Thompson, 2003; Moore 2002) on the relationship between achievement and segregation have been conducted, but a recent study focusing on Miami-Dade County will help better meet the needs of the students in the county. Additionally, not enough is currently known about the relationship of school segregation with the school climate, ESOL student population, and socio-economic status on the scores of middle school students in M-DCPS on the FCAT 2.0 Mathematics Test.

\section{Purpose of the Study}

The purpose of this study was to investigate the relationship between the FCAT 2.0 Mathematics scores of public middle school students in Miami-Dade County, Florida, the schools' racial and ethnic concentrations (Whites, Blacks, and Hispanics), ESOL student population, socio-economic status (SES), and school climate for the $2010-2011$

school year. The study was undertaken to demonstrate whether a significant relationship exists between mathematics achievement and racial and ethnic concentrations, socioeconomic status, ESOL student population, and school climate in Miami-Dade County Public Schools (M-DCPS). 


\section{Research Questions}

This study was driven by the following primary research question:

Is there a significant negative relationship between the FCAT 2.0 Mathematics scores and racial and ethnic concentration of public middle school students in Miami-Dade County when controlling SES, ESOL student population, and school climate for the 2010-2011 school year?

The study was also driven by these secondary research questions:

1. Is there a significant negative relationship between the FCAT 2.0 Mathematics scores and racial and ethnic concentrations when controlling the ESOL student population of the school?

2. Is there a significant negative relationship between the FCAT 2.0 Mathematics scores and SES?

3. Is there a significant negative relationship between the FCAT 2.0 Mathematics scores and SES when controlling racial and ethnic concentrations?

4. Is there a significant negative relationship between the FCAT 2.0 Mathematics scores and school climate when controlling racial and ethnic concentrations? 


\section{Definition of Terms}

\section{Black}

This term is used to describe individuals who according to the U.S. Census Bureau selected Black as their race on the Census form. Blacks are of different ethnicities and come from different areas of the world such as Africa, America, the Caribbean, and Latin America. A Black person is "a person having origins in any of the Black racial groups of Africa" (Race, 2000). The race category of Black can be divided into the country of origin of the person (e.g., Kenya, Nigeria, or Haiti).

\section{Cultural Capital}

This term was created by Pierre Bourdieu and Jean-Claude Passeron (1973) and refers to the knowledge, skills, education, and advantage a person gets from being wealthy.

\section{de facto Segregation}

This type of segregation is due to circumstances such as residential segregation and social segregation. It is difficult to control without violating the individual's rights. It usually occurs due to social or economic reasons (Moore, 2002).

\section{de jure Segregation}

This type of segregation of people is based on their race or ethnicity and it was imposed by the law (Moore, 2002).

\section{Desegregation}

This is when there are two or more different races in a neighborhood, school, or public area (Moore, 2002). This term has the same meaning as Integration. 


\section{Dominant Culture}

Specifically in the United States, it is the traits displayed by the White Anglo-Saxon Protestant social group. It is distinct from the culture of other groups such as Blacks and Hispanics. It established the U.S.'s government, values, economy, society, culture, etc.

\section{Economic Capital}

This is the monetary assets and properties an individual or family control.

\section{Ethnicity}

It is a quality of individuals who share traits that include customs, history, language, religion, and values.

\section{Financial Capital}

The term is used to measure the amount of income an individual has.

\section{Florida Comprehensive Assessment Test (FCAT)}

Also known as the FCAT, it is the state of Florida's standardized assessment, and is used to meet the requirements of the No Child Left Behind Act (NCLB).

\section{Florida Comprehensive Assessment Test (FCAT 2.0)}

This is the new version of FCAT. It was first administered on Wednesday April 13, 2011 in the subject areas of mathematics and reading only to test the students' mastery of the Next Generation Sunshine State Standards (NGSSS), which are the new academic standards in place for the state of Florida. 


\section{Hispanic}

This term is used to describe individuals who according to the U.S. Census Bureau identified themselves as Hispanic. "Persons of Hispanic origin, in particular, were those who indicated that their origin was Mexican, Puerto Rican, Cuban, Central or South American, or some other Hispanic origin. It should be noted that persons of Hispanic origin may be of any race"

(Race, 2000).

\section{Homophily}

This term is used to describe a person who prefers contact with someone of their race or ethnicity.

\section{Human Capital}

The term is used to measure an individual's education.

\section{Integration}

See Desegregation.

\section{Majority}

A part of a group consisting of more than half of its members and, specifically, when referring to the overall U.S. population, it means the White, non-Hispanic population in the U.S.

\section{Manipulatives}

Objects used for instruction that enhance a lesson by providing tactile or visual stimulation. 


\section{Math Achievement}

Since the establishment of the No Child Left Behind Act, the FCAT became the basis for measuring the students' achievement in all public schools in Florida. Students' scores on the FCAT 2.0 Mathematics Test is used to determine which level of mathematics they will be allowed to take the following year, without regard to the grade received in their mathematics course.

Also see Florida Comprehensive Assessment Test (FCAT) and FCAT 2.0.

\section{Middle Schools}

They are schools that house only sixth, seventh, and eighth grades. They are not considered a K-8 Center or a Combination School.

\section{Minority}

It is any ethnic or racial group of individuals not considered part of the majority, the White population. Specifically when referring to the overall U.S. population, it means the non-White groups of individuals in the U.S.

\section{Propinquity}

It is when a person has the opportunity for interracial contact.

\section{Race}

"The concept of race as used by the Census Bureau reflects self-identification by people according to the race or races with which they most closely identify. These categories, such as Black or White, are sociopolitical constructs and should not be interpreted as being scientific or anthropological in nature" (Race, 2000).

\section{Residence}

This is the building and neighborhood students and their families call home. 


\section{Residential Segregation}

This is the demographic patterns of race in neighborhoods, such as a majority White, Black, or Hispanic neighborhood.

\section{School Climate Survey}

It is a survey administered by Miami-Dade County Public Schools which allows the gathering of "information on the perceptions that students, their parents, and school staff hold concerning their schools and their performance" (School Climate Survey, 2010, p. i).

\section{School Segregation}

The separation of groups of students by race in schools due to the demographics of the neighborhood. In this study, a school is considered segregated if at least $80 \%$ of its student population belongs to a specific race or ethnicity (Moore, 2002).

\section{Segregation}

The separation of groups of individuals by race or ethnicity in society.

\section{Social Capital}

The term is used to measure the relations, interactions, and support an individual has.

\section{Social Segregation}

The separation of groups of students based on race or ethnicity within a school in social situations.

\section{Socio-economic Status (SES)}

The status of an individual based on their economic, social, and physical environments. It includes income, educational level, occupation, family, social status, and place of residence. 


\section{Tracking}

"Group[s] students into particular classes or programs based on their scores on the state standardized test," the FCAT (Moore, 2002, p. 26).

\section{White}

These are individuals who according to the U.S. Census Bureau selected White as their race on the Census form. "A person having origins in any of the original people of Europe, the Middle East, or North Africa” (e.g., Irish, German, Italian, Lebanese, Near Easterner, Arab, or Polish; Race, 2000).

\section{Conceptual Framework}

The conceptual framework of this study is socio-economic status. Socioeconomic status plays an important role in this study because it is an economic and social descriptor of an individual. Moore (2002) defined socioeconomic status as "an umbrella term which incorporates not only an economic and material description of a family, but the values, attitudes, skills, and behaviors that are critical components in achieving academic success” (p. 214). These characteristics (family structure, values, skills, and attitudes towards school and achievement) are all interrelated and relate to individuals' socio-economic status, hence influencing their lives.

The Coleman Report's findings were that the family's socioeconomic status was the most important factor in determining student achievement and educational attainment (Coleman, 1966). Additionally, socio-economic status may limit or enhance an individual's opportunities (e.g. career, educational, etc.) during their lifetime. "Residential and school segregation appear to be critical factors in limiting equal educational opportunities for minorities and explaining their lower levels of 
socioeconomic status and educational performance relative to the white majority" (Moore, 2002, p. 7). Schools dealing with residential and school segregation require more personnel and resources in order to provide their students with an equal educational opportunity. Students from middle and high socio-economic status are the most likely to succeed since they reflect the cultural and economic capital that schools value (Hong \& Youngs, 2008). Consequently, it is more difficult for students of low socio-economic status to be successful since they have less economic capital. These students have limited access to educational materials and resources as well as limited support from adults who are part of their life (Hong \& Youngs, 2008). Entwisle, Alexander, and Olson (1997) stated that "children from impoverished backgrounds do not stay in school as long as their better-off classmates" and "do not do as well as their better-off classmates on achievement tests" (p. 32). Families of high and middle socio-economic status have the financial ability to expose their children to various educational experiences, such as museums, tutors, libraries, manipulatives, resources, computers, and the Internet. Exposing children to various educational experiences may be more difficult for a low socio-economic status family due to limitations in resources (e.g. financial, time, etc.). Black and Hispanic families living in segregated neighborhoods find themselves struggling because of low socio-economic status, or low economic capital (Rumberger \& Palardy, 2005). They have a difficult time providing the basic necessities of life for their children. These families may not have the same education level or access to economic opportunities as high and middle socio-economic status families. Living in neighborhoods that are residentially segregated places limits on access to educational opportunities (Rumberger \& Palardy, 2005). These parents find themselves consumed by 
working extra hours or multiple jobs in order to provide for their families' living necessities, or lack the ability to participate at a high level in their children's education (for example, due to financial constraints, limited educational background, language barriers, etc.). On the other hand, many of the high and middle socio-economic status families have the skills to communicate and participate in their children's school and community. They have the education to assist their children with school assignments. They have the advantage of an income that allows them to provide more than just the necessities for their children, and which directly enhances their children's' learning experiences (Hallinan, 2001). Additionally, they have different perceptions and expectations of the school and the education system than that of low socio-economic status families.

"Educational attainment is strongly correlated with future occupational positions, income, and socio-economic status. A high level of education is viewed as a ticket to professional opportunities and economic success in an increasingly competitive and advanced society" (Moore, 2002, p. 52). Hence, it is vital that all schools provide students with the same quality education so that they are able to participate in professional opportunities and enjoy economic success.

Education is our most important public resource for overcoming family socioeconomic disparities, enhancing life opportunities, developing citizens, and promoting a genuine multiracial and multiethnic democracy. Segregated education negatively relates to all citizens and undermines the goal of constructing a multiracial and multiethnic democracy (Powell, 2005, p. 297). 


\section{Delimitations}

This study is delimited by the researcher in the following ways. Chapter 2 presents a literature review on various factors that are interrelated but will not be directly analyzed in this study. These factors include vouchers, magnet programs, charter schools, tracking, homeownership, parental influence, parental involvement, parents' education, and family structure. The decision to not directly analyze these factors delimits the study. The decision to conduct the study using only Miami-Dade County, Florida delimits the study. The study is then delimited to only the public middle schools of Miami-Dade County Public Schools. It does not include K-8 Centers or Combination Schools. Moreover, the study is delimited to just FCAT 2.0 Mathematics Test for the 2010-2011 school year. The study does not include any other subject area tested on the FCAT 2.0. Additionally, it is delimited to only one question of the School Climate Survey. Lastly, the study is delimited to the randomly selected students and their parents who participated in each school's School Climate Survey for the 2010-2011 school year.

\section{Organization of the Study}

Chapter 1 presented the background information on segregation and students' academic achievement, the problem to be examined, the purpose of the study, the research questions, the definition of terms, the significance of the study, the delimitations, and the organization of the study. Chapter 2 provides the review of the literature regarding segregation, and socio-economic status and its relationship to academic achievement, and perceptions of education. Chapter 3 discusses the methods in the study, which include the setting, the subjects, the research design, the instruments, the procedures for data collection, and data analysis. Chapter 4 demonstrates the relationship 
of the FCAT 2.0 Mathematics Test with the racial and ethnic concentrations, the results of the School Climate Survey, ESOL student population, and socio-economic status for the 2010-2011 school year in Miami-Dade County Public Schools. Chapter 5 summarizes the findings of the study and discusses the implications of the study for educational policy, theory, and further research. 


\section{CHAPTER 2}

\section{LITERATURE REVIEW}

The purpose of this study was to investigate the relationship between the FCAT 2.0 Mathematics scores of public middle school students in Miami-Dade County, Florida, the schools' racial and ethnic concentrations (Whites, Blacks, and Hispanics), ESOL student population, socio-economic status (SES), and school climate for the 2010 - 2011 school year. This study demonstrates the relationship that exists between mathematics achievement, racial and ethnic concentrations, perceptions of education (by students, parents and staff), ESOL student population, and socio-economic status in Miami-Dade County Public Schools. This study was driven by the following primary research question:

Is there a significant relationship between the FCAT 2.0 Mathematics scores and ethnic concentration of public middle schools in Miami-Dade County when controlling socio-economic status, ESOL student population, and school climate for the 2010-2011 school year?

\section{History}

\section{United States}

On July 4, 1776, the Declaration of Independence was passed and declared that "all men are created equal" (Independence Hall Association, 2010b). It was reinforced in 1789 with the Preamble to the United States Constitution that stated "to form a more perfect union, establish justice, insure domestic tranquility...promote the general welfare..." (Independence Hall Association, 2010a). These statements did not apply to the slaves; they were considered at the time as three-fifths of a person for purposes of 
apportioning representatives and taxation. About a century later, there was the American Civil War from 1861-1865. One of its causes was slavery and when the Thirteenth Amendment to the United States Constitution passed in 1865, slavery, as well as the three-fifths rule were abolished in the United States $\left(13^{\text {th }}\right.$ Amendment to the U.S. Constitution: Abolition of Slavery, n.d.).

In 1896, the Supreme Court decided that the case, Plessy v Ferguson, that dealt with racial segregation, and created "separate but equal" facilities and institutions (Moore, 2002, p. 8). This led to the separation of facilities and institutions for Whites and Blacks, such as separate water fountains, seating areas on public buses, and public schools. These facilities and institutions were separate and supposed to be equal. They were definitely separate, but time would prove them to be unequal.

During the time period of 1868 through 1931, states were addressing the matter of race in the schools (Moses, 2010). Eighteen states, composed of the Southern states as far North as Delaware and as far west as Arizona, mandated that White students and Black students attend separate schools. There were 10 states that forbade the separation of Whites and Blacks in public schools. These states were California, Illinois, Maine, Massachusetts, Nevada, New Jersey, Oregon, Pennsylvania, Rhode Island, and Washington (Moses, 2010).

Meanwhile, despite the laws and policies in place against racial discrimination, the practice was still thriving. Williams (1999) stated that “between 1900 and the 1940's, federal housing policies, the lending practices of banks, restrictive covenants, and discrimination by the real estate industry, individuals, and vigilant neighborhood organizations ensured that housing options for blacks were restricted to the least desirable 
residential areas" (p. 178). Blacks were able to buy property, but only in certain areas dealing with many extra requirements such as higher payments.

In 1938, the National Association for the Advancement of Colored People (NAACP) began "to demonstrate in courts of law that separate educational facilities and policies in local communities for Black and White populations were never equal" (Willie, 2005, p. 11). During this same year, in Gaines $v$ Canada, the court decided that not granting Lloyd Gaines admission violated his rights in the equal protection clause of the Fourteenth Amendment of the United States Constitution and consequently the University of Missouri's Law School must grant admission to African Americans (Wormser, 2002).

In 1954, through the Supreme Court's decision of the Brown v Board of Education case, everyone was given equal access to public education. As stated by Munoz, Clavijo, and Koven (1999), the Supreme Court ruled "that segregated public elementary and secondary schools were inherently unequal and damaged the educational future of African American students" (p. 5); de jure segregation was deemed illegal. Many schools started to become only superficially integrated because many were still, in practice, segregated. As Rivkin (2000) stated, students were "bused for desegregation purposes but they were not in the same classes as the white students" (p. 334); it was like there existed two schools in one. With this decision came many violent protests on behalf of Whites who did not want to be sharing classrooms, water fountains, and bus seating areas, among many other things, with Blacks.

Meanwhile, the launching of Sputnik 1 by the Soviet Union on October 4, 1957 marked the beginning of the Space Race. It was a competition between the United States 
and the Soviet Union. Since the United States was not the first country to launch a satellite into space, the United States' government began to analyze what was happening in their education system (Guillemette, n.d.). Soon after, the National Defense Education Act (NDEA) was passed that provided more funding to the United States' education system. It redesigned school curricula, emphasizing the sciences and mathematics. It also led to an increase in the number of students attending colleges and universities (The Federal Role in Education, 2010).

Under the presidency of Lyndon B. Johnson, the Civil Rights Act was passed by Congress in 1964, entitling all citizens to equal rights regardless of their age, color, handicap, national origin, race, religion, and sex. The Civil Rights Act went on to further emphasize the ruling of Brown $v$ Board of Education. As an incentive to eliminate discrimination and segregation, "the Department of Justice threatened to deny federal funds to segregated school systems" (Gray, 2005, p. 96). Unfortunately, based on today's school demographics, the Civil Rights Act was not so successful that all schools are now equally integrated. Schools seem to have resegregated (Williams, 1999).

In 1965, the Voting Rights Act was passed. It prohibited discriminatory voting practices that many states, especially in the South, were using. Such discrimination included taking a literacy test to obtain the right to vote. This act gave minorities, specifically Blacks, the right to vote but left many without obtaining that right because they were not literate (Voting Rights Act, n.d.).

Moreover, in 1966, James Coleman conducted a research study on the equality of education across all racial and ethnic groups and their academic achievements, known as The Coleman Report. Street (2005) stated that Coleman focused 
on the stressful danger and poverty of neighborhoods, the chaos of single-parent households, the absence of successful educated role models in homes and community, the missed breakfasts, the lack of privacy, and absence of books in homes and of bookstores and libraries in the community, the ubiquitous late night blare of the television, and the struggle of intermittently employed dropout mothers unable or unwilling to enforce reasonable sleeping and studying patterns for their children. (p. 122)

Coleman concluded that the family and neighborhood have more of a relationship with the students than the school (Berliner \& Biddle, 1995). In addition, he discovered that White students achieved higher than the other students, which were considered minorities. These racial and ethnic minority students were children of parents with little education. Coleman concluded that the American society must first desegregate itself in order for schools to truly become desegregated since students attend the school closest to their home.

In 1973, in the San Antonio School District v Rodriguez case, "the United States Supreme Court stated that public education is not a right granted to individuals by the Constitution" and "asserted that there is no constitutional right to education at all" (Perry, I., 2010, p. 34). Yet, the education of people is needed in order to keep the country running efficiently and effectively. "The denial of education was a signature feature of enslavement in the United States" and "teaching a slave to read was a criminal act" (Perry, I., 2010, p. 38). Education, along with property ownership and control of one's own life, became symbols of freedom. 
In 1974, in the Lau v Nichols case, "the U.S. Supreme Court called for providing meaningful participation in a public education program, regardless of a student's first language" (Misco \& Castañeda, 2009, p. 182). If it was not followed, the rights of a student, per the Civil Rights Act of 1964, would be violated. In 1982, in the Plyler v Doe case, it was made clear that illegal immigrants were also entitled to meaningful participation in a public education program. Since they too "are entitled to all the protections of the Fourteenth Amendment” (Misco \& Castañeda, 2009, p. 182).

In 1983 and under President Ronald Reagan, the National Commission on Excellence in Education (NCEE) published a report that analyzed the education system and performance of the country. A Nation at Risk: The Imperative of Educational Reform placed "nationwide attention to improve America's public schools and improve efforts to educate racial minority children" (Gray, 2005, p. 96). President Ronald Reagan used the findings of A Nation at Risk to explain "the 'failures' of American education and how those 'failures' were confirmed by 'evidence"' in his speech (Berliner \& Biddle, 1995, p. 3). Unless those failures were addressed, the nation would be damaged. According to the document, "American students never excelled in international comparisons of student achievement" which raised a red flag (Berliner \& Biddle, 1995, p.3). When comparing the American students' educational achievement to that of students in other industrialized countries, the American students ranked last (Gajendragadkar, 2006). Based on the censuses from the 1990s, many children were found living in poverty. Although "residential segregation by race declined slightly, racial and economic segregation in schools increased...we continue to segregate not only by race but also by income" (Powell, 2005, p. 284). Furthermore, the National School Boards Association reported 
that in the 1990s, nearly two-thirds of Black children attended segregated schools because it was their designated neighborhood school (Bankston \& Caldas, 1998). As a response to that report, the Goals 2000 legislation was passed.

Goals 2000 gave federal aid to the states, allowed the states to develop their own academic standards, defined levels of mastery, and measured students' learning through standardized testing. It also included the reauthorization of the Elementary and Secondary Education Act with provisions for more professional development for educators, instructional materials, resources, and parental involvement opportunities (Wang \& Kovach, 1995). This act provided grants and services to schools located in racial and ethnic minority neighborhoods. Low socio-economic status schools need extra funds to provide the support necessary for poor students to have an equal quality education (Berliner \& Biddle, 1995). They will need the support of school counselors and other personnel to cope with problems, social services, and programs that generate dignity and hope (Berliner \& Biddle, 1995). Programs such as Title I and Title VII were designed to help racial and ethnic minority students obtain the same academic achievement level as White students. The majority of students who qualify come from racial and ethnic minority households. A Title I school receives special federal funds to provide specific resources and services to the students. On the other hand, Title VII was established to help students acquire the English language.

In May 2000, the case Williams v State of California was filed in the California Supreme Court. It was due to a lack of "equal access to instructional materials, safe and decent school facilities, and qualified teachers" (The Williams Case, 2011). Settled four years later, it established funds for instructional materials and critical repair of school 
facilities in order to fulfill its constitutional obligation. "In California, education is a fundamental right" and the "California law also requires basic educational equality" (Oakes, 2010, p. 53).

Regardless, there has always been the "expectation that all people living in the nation, irrespective of color, race, and/or cultural background, will become part of one homogeneous culture" (Arora, 2005, p. 19). Unfortunately, this is still to occur, despite the federal efforts and policies. It has been almost 60 years since the decision of the Brown v Board of Education case, almost 50 years since the passage of The Civil Rights Act of 1964, and yet quality education does not exist for all children (Perry, T., 2010).

\section{Florida}

Former Governor Millard Caldwell established the Minimum Foundation Program (MFP) in 1945. Its purpose was "to equalize educational funding among districts based on the county's ability to support its schools" (Borman et al., 2004, p. 609). These funds were distributed as needed, regardless of the race or ethnic composition of the school's student population. Florida's politicians "hoped to prove that Black children would be provided an education equal to that provided to the state's White children, even if in separate schools" (Borman et al., p. 609). Florida's elected officials did not seem to accept the ruling of the Brown v Board of Education case because they devised a plan to circumvent it. In 1955, former Governor LeRoy Collins passed the Florida Pupil Assignment Law. This law "empowered county school boards to assign pupils to schools on the basis of sociological, psychological, and like intangible socioscientific factors" which later proved to be a "loophole for schools wishing to avoid desegregation" (Borman et al., p. 610). Finally, when the Civil Rights Act was passed in 
1964, Florida found itself obeying desegregation orders from the federal courts. Through transportation and the establishment of magnet schools, Florida was able to start meeting these mandates.

Years later, MFP was replaced by the Florida Education Finance Program (FEFP). It "restructured the funding formula based on full-time equivalency and local contributions" (Borman et al., 2004, p. 611). It "addressed the costs of different grades, special programs, cost of living differences in each county, and the cost of busing in rural areas" (Borman et al., p. 611). In 1999, the A+ Accountability Plan was passed in Florida. It was the foundation of school reform. It "required that students in grades 3-10 be tested annually in reading and mathematics on the state FCAT assessment" (Ladner, 2009, p. 11). This was the beginning of the Florida Comprehensive Assessment Test (FCAT).

Today, Florida's Constitution in Article IX, Section 1 states that "adequate provision shall be made by law for a uniform, efficient, safe, secure, and high quality system of free public schools that allows students to obtain a high quality equation" (State of Florida, 2013).

\section{Educational Policies}

\section{Title I}

From the Elementary and Secondary Education Act of 1965 came Title I. The purpose of Title I "is to ensure that all children have a fair, equal, and significant opportunity to obtain a high-quality education and reach, at a minimum, proficiency on challenging State academic achievement standard and State academic assessments" (U.S. Department of Education, 2004). The goal is to aid racial and ethnic minority students in 
the areas of health, nutrition, and educational resources (Borman, Stringfield, \& Slavin, 2001). Title I focuses on "helping eligible children meet the same challenging academic standards that states are required to establish for all children" (Miami-Dade County Public Schools, 2011b). Schools that have at least $40 \%$ of their student population qualify for free or reduced lunch (based on parents' income) receive Title I funds. It grants financial assistance to the state department of education and their school districts in order to help provide all students with a quality education. Title I provides these schools with extra funds to maximize the students' learning experience with programs, services, resources, and personnel. These funds are "used to provide educational services to students who are educationally disadvantaged or at risk of failing to meet state standards" (Education Week, 2004).

\section{English for Speakers of Other Languages}

From the reauthorization of the Elementary and Secondary Education Act in 1967 came Title VII, also known as the Bilingual Education Act. It "added a research agenda for English Language Learners (ELL), which was congressionally mandated and produced the beginnings of knowledge on and about the education of a Latino/a children" (Mercado \& Santamaria, 2005, p. 15). The English for Speakers of Other Languages (ESOL K-12) Program was established in the early 1960s for K-12 students whose primary language at home was not English. The ESOL (K-12) Program "is a Language Arts program that incorporates all aspects of Language Arts instruction, content, and language development" (Miami-Dade County Public Schools, 2011a). Students learn reading, literature, composition, vocabulary, word study, language, listening, speaking 
viewing, information literacy, study and test taking, and the culture of the English language (Miami-Dade County Public Schools, 2011a).

Every student is unique. "Each student brings to the classroom a multiplicity of intersecting experiences and a constellation of linguistic and cultural factors that will influence how the student responds to classroom conditions and to assigned work" (Zamel \& Spack, 2006, p. 126). Through educational programs like ESOL, the student's learning experience is improved.

\section{No Child Left Behind}

In 2001, former President George W. Bush signed the No Child Left Behind (NCLB) Act that has reformed education through accountability. NCLB's purpose is to ensure that all children have an equal opportunity to obtain high-quality education according to their state's academic standards. Kim and Sunderman (2005) pointed out that "it is intended to close the achievement gap between high- and low-performing children, especially the gaps between minority and non-minority students and disadvantaged children and their more advantaged peers" (p. 3). NCLB provided and required more professional development for teachers in order to classify them as highlyqualified. It also made the information about teachers' qualifications public. NCLB redesigned curricula to focus on the concepts expected to appear on standardized tests. Complying with the NCLB mandates, state departments of education have turned to standardized tests as a way of holding districts accountable for the education students are receiving. States have to follow the NCLB mandates in order to continue to receive federal funding. 
There are certain requirements in place that allow for the gathering of accurate data to measure if the school made adequate yearly progress (AYP). "NCLB requires $95 \%$ of students overall and $95 \%$ of each subgroup of students within a school to take the standardized reading and mathematics tests" (Kim \& Sunderman, 2005, p. 3). The purpose of AYP status is to ensure that there is improvement in school performance, especially among the subgroups. Subgroups include racial and ethnic students, Title I students, special needs students, and ESL (English as a second language) students (Hong \& Youngs, 2008). When AYP status is not met, it forces districts and schools to implement additional educational strategies and supports such as reviews, tutoring, reinforcement, educational technology, support personnel, and professional development to help raise the students test scores. If a school fails to meet AYP in any of its subgroups, it will not be granted AYP status for that school year. "Schools that fail to make AYP for two or more consecutive years are identified as "in need for improvement" (Kim \& Sunderman, 2005, p. 3). On the other hand, another way to obtain AYP is through safe harbor. If the amount of students below proficiency is reduced by at least $10 \%$ and there is improvement in another factor such as the school's attendance rate, then the school is granted AYP status (Kim \& Sunderman, 2005, p. 3).

Lee (2004) stated that even though this is an incentive for schools, "there has been evidence that high stakes tests, rather than promote educational excellence for all children, disadvantage typically underrepresented students who are disproportionately found among those who fail to meet the cutoff scores" (p. 3). Hence, these standardized tests seem to be modeled according to the cultural and economic capital theories, favoring the knowledge, skills, and education of the students in middle or high socio- 
economic status, instead of providing all students a quality education. Street (2005) stated that "the NCLB responded to the achievement gap by mandating rigorous testing standards for all racial, ethnic, and socio-economic student groups" and that schools that fail to do so are being threatened to lose federal funding by 2014 (p. 145). Teachers, parents, students, and stakeholders believe lessons seem to be drilling students with just the basics and not allowing time for them to discover the concepts in-depth and get to truly teach them hands-on (Gonzalez, 2005). Gonzalez (2005) stated that teachers "are teaching to the test rather than providing students with the full range of curriculum" because there is a specific amount of material that needs to be covered before the standardized test is administered (p. 173). This standardized testing is actually having students dislike school (Street, 2005).

With the establishment of NCLB came the creation of various other education programs targeted at meeting the needs of the students. Voluntary Pre-Kindergarten (VPK) was created in certain states with Title I funds and it gives the opportunity to all four year olds to start attending school free with the goal of helping them achieve a high academic level and reducing the achievement gap. Additionally, the creation of the Florida Virtual School offers over 90 online classes to middle and high school students for free, allowing them to get ahead or reinforce any subject area (Ladner \& Lips, 2009).

\section{School Choice}

NCLB, along with other educational policies, is aimed at reducing the achievement gap. Since "so many schools in poor neighborhoods are deficient and resistant to improvement, many see school choice as the best choice for improving education opportunities for poor children" (Archbald, 2004, p. 285). It provides families, 
especially low socio-economic status families, with options, if they are not satisfied with the neighborhood's public schools. School choice "serves as a route to better school options for disadvantaged students otherwise consigned to underperforming districts and could thereby shape school attendance patterns based on students' interests, rather than home addresses" (Lubienski \& Weitzel, 2009, p. 354). For these families, it might not be an option to move to an integrated neighborhood or higher socio-economic status neighborhood but at least they can decide to send their children to a school that maximizes their learning. For many families, it has provided their child with a better learning experience and brighter future. "School choice aims to provide these students and their parents with the choice options that middle and upper class families already have in substance through residential selectivity" (Lubienski \& Weitzel, 2009, p. 373). It "will not only provide a mechanism for students seeking to improve the quality of their own education but also engender competition that will lead to improvements in the quality of education for students who remain in traditional public schools" (Sass, 2006, p. 92).

Public schools are finding themselves seeking magnet programs and establishing unique educational programs to maintain their current students and attract new ones from outside their attendance boundary. They are making their education more appealing so parents and students pick them. Through vouchers, magnet programs, and charter schools, parents are given more options with respect to their child's education.

\section{Vouchers}

Vouchers were originally created in the 1960 s and they enabled "parents to choose either a public or private school for their children to attend" (Gajendragadkar, 
2006, p. 148). Removing the monopoly power of local public schools, now students can attend certain private schools using this coupon (Barrow \& Rouse, 2008, p. 2). Poor families have the opportunity "to choose private schools over their neighborhood public schools" (Barrow \& Rouse, 2008, p. 11). These families have the opportunity to send their child to a religious-driven and/or smaller classroom settings school. Vouchers allow low socio-economic status families to send their child to a private school without having to pay the tuition, in hopes of providing a better education for their child. "Children from poorer families are captives in neighborhood schools in inner cities or rural areas" and need choices in order to attend a high-achieving school (Levin, 1998, p. 379). Vouchers give parents more control of their child's education "because they allow parents to find the right particular school for each individual child" from the participating schools only (Forster, 2008, p. 11). Vouchers are also aimed at assisting in integrating schools and neighborhoods, allowing low socio-economic status families to send their child to a private school. Forster (2008) stated that "in other service areas, from grocery stores to health care, if a service provider isn't getting the job done people can switch to another provider simply by making the decision to do so" (p. 11). With the voucher, qualifying students' parents do not have to pay for school twice: first through property taxes and second through tuition. Selecting this school choice will not cost parents any more money than what they already contribute through property taxes, if they own property. Unfortunately, not all private schools participate in the program. Many of the best private schools do not accept vouchers. These public school students must also pass the particular private school's entrance exam. Plus, vouchers are not fixing the quality of 
education in public schools; they are just giving a ticket out to certain students to leave the problem behind.

\section{Magnet Programs}

As a response to the ruling of the Brown v Board of Education case, magnet schools were created mainly to attract White students to high racial and ethnic minority enrollment schools and to enhance the schools' curriculum. They were meant to integrate segregated schools and provide opportunities for other students to attend a school outside of their neighborhood. A magnet school attracts students from other neighborhoods just like a magnet attracts metal objects (West, 1994). Parents are able to choose to send their child there or not, instead of being forced to, as long as the child is accepted to the magnet program. To attract White parents to magnet schools located in segregated neighborhoods, specializations in curricula such as foreign language, the arts, science, and technology or the establishment of programs like the International Baccalaureate and Advanced Placement are used (Gersti-Pepin, 2002). Besides the specialized curriculum, they have innovative practices. Students are exposed to learning opportunities that have been made possible because of the magnet program. These magnet programs add diversity to highly segregated schools. Dr. Martin Luther King Jr. stated "desegregation is eliminative and negative...integration is the positive acceptance of desegregation and the welcomed participation of Negroes in the total range of human activities" (Orfield, 2007, p. 25). Through these efforts, it is hoped that minority students will benefit from the high-quality education found in white schools.

In order for magnet schools to attract students from outside the neighborhood, the school has to be appealing and enticing (West, 1994). The school is marketed, making it 
seem a school for the gifted or for superior students (West, 1994). In some cases, neighborhood students are placed into courses that are separate and often in a lower academic track as compared with higher track courses offered to transferring students; this is not the quality of education originally envisioned. West (1994) also added that racial and ethnic minority students experience more disciplinary punishments than majority students. Such scenarios create feelings of inferiority for the racial and ethnic minority students.

There are two types of magnet programs, partial-site and full-site. The full-site magnet program has all the students in the school in the magnet program. On the other hand, the partial-site magnet involves only the students transferring into the school for the magnet program. The partial-site magnet program is more prone to segregating the students within the school because "nonmagnet students are denied the company of the magnet students; they are also denied the special attention, financial support, and superior educational opportunity the magnet students receive" (West, 1994, p. 2570).

Not all magnet schools provide all their students with the same educational opportunities. Metz (1988) stated that magnet programs create two separate schools within one because some students benefit from the magnet resources while others do not. It creates segregation within a school, contrary to its magnet program's purpose of desegregating the school. Gersti-Pepin (2002) stated that "policymakers often develop policy under the guise of making schools better, but in effect they often lose sight of insuring that all students receive a good education regardless of gender, race, or class distinctions" (p. 47). 
Regardless of the intentions of the Brown v Board of Education Supreme Court case, the Civil Rights Act, Goals 2000, and the No Child Left Behind Act, segregation has not been totally eliminated and quality education does not exist in schools. "Residential segregation has led to the concentration of poverty in residential areas and thus the concentration of poverty in the classroom (Williams, 1999, p. 179). Residential segregation, which is reflected in the schools' population, continues to make education separate and unequal, even with the efforts of magnet schools, mandatory busing, and rezoning of areas. These efforts have helped reduce but have not completely eliminated segregation and surely not established quality education in all schools. According to the Harvard Civil Rights Project, schools are becoming segregated once again because housing segregation has increased. In 2004, the White enrollment was at $60 \%$, lower than what it was in 1968 at $80 \%$. In that same year, the Black and Hispanic school enrollment was 17\% each, in comparison to five percent in 1968 (Lee, 2004). The amount of White students enrolled has decreased while the amount of Black and Hispanic students enrolled has increased since 1968. This study brought forth any existing relationship between school segregation, the scores of middle school students on the FCAT 2.0 Mathematics Test, the results of the School Climate Survey, ESOL student population, and socio-economic status.

\section{Charter Schools}

In 1991, charter schools were created, starting off in the State of Minnesota. "Charter schools are independent schools of choice that are publicly funded, freed from regulations governing traditional public schools, and contractually accountable for performance such as student achievement on state assessment tests" (Gajendragadkar, 
2006, pp. 144-145). They were created to offer parents and their children another option in regards to schooling. Charter schools do not have attendance boundaries and offer rigorous and specialized curriculum, but students must choose to enroll and then be accepted. Such specified curriculum is what makes the charter school attractive to students not from the neighborhood. This has been a path many parents have taken if they have felt that the neighborhood's public school is not providing their child with a maximized learning opportunity. Charter schools have "fostered competition that will lead to increases in the quality of traditional public schools" (Sass, 2006, p. 96).

It was believed that charter schools would desegregate neighborhoods but, unfortunately, that has not yet happened. According to Gajendragadker (2006), "charter schools increase racial isolation because White charter school students are less likely than other racial group students to attend schools with large minority populations" (p. 154). The Civil Rights Project at Harvard University discovered that " $70 \%$ of African Americans in charter schools attend an intensely segregated minority school compared to 34\% of African American public school students" (Levy, 2010, p. 44). Levy (2010) added that to many, it seems that charter schools are starting up the "white flight" again and returning to the "separate but equal" doctrine or maybe separate but unequal (p. 50). Charter schools are not establishing quality education in all schools. While some students are leaving to charter schools, the problem is being left behind in the public schools and not getting fixed. The students who remain in public schools continue to deal with the low-quality education. Since there are no attendance boundaries, parents can send their child to any charter school as long as the child is accepted. White parents are moving their children from their designated traditional public school and placing 
them in a charter school where Whites are the majority of the student population (Levy, 2010). This applies to all races in the same way and is the same as students attending only a designated neighborhood public school: Students are still faced with social segregation, tracking, simplified curriculum, few highly-qualified teachers, and more of the same problems as in a system with designated schools.

To address this issue, some states have passed laws to racially balance the student population in charter schools, but these laws are not addressing the quality of education in public schools. Overall, charter schools provide a choice to families for obtaining a better education for their children under the efforts of "increased accountability, heightened parental engagement, and inspired curricular innovation" (Gajendragadkar, 2006, p. 180). They "have the potential to counteract attendance patterns based on segregated neighborhoods and create school communities based on common areas of interest and values" while following laws that racially balance the student population (Lubienski \& Weitzel, 2009, p. 354).

\section{Academic Achievement and School Segregation}

The theorist Paulo Freire (1970) stated that "money is the measure of all things", especially of one's socio-economic status (p. 44). It is reflective of one's success. Kahlenberg (2006) added that "education is supposed to be the prime engine for social mobility in America" (p. 1). Unfortunately, for many, obtaining a high socio-economic status is difficult because of the challenges brought forth by the various factors such as dominant culture, school segregation, residential segregation, poverty, family structure, and parents' education that hinder receiving a high-quality education, seen as the path to success (Street, 2005). "Black and Hispanic students are much more likely to attend low- 
income schools than Whites" (Blazer, 2007, p. 4). But, it is the school's job to educate so that these factors are eliminated. As stated by Dr. Martin Luther King Jr. "the job of the school is to teach so well that family background is no longer an issue" (Rouse \& Barrow, 2006, p. 100). This study investigates what a relationship, if any, exists between school segregation, academic achievement, perceptions of education, ESOL student population, and socio-economic status.

\section{Dominant Culture}

Public institutions have established racism and White supremacy.

"Institutionalized racism is the extent to which racism is embedded in the dominant organizations and power structure of society resulting in distinctive patterns of social disadvantages" (Hardaway \& McLoyd, 2009, p. 247). We have all "received the message that the lighter or whiter people's skin is, the better, the smarter, more moral and deserving they are" (Berlak, 2008, p. 12). It has trickled throughout, taking a subconscious role in everyday life. "Children are particularly susceptible to the media's assaults on the intelligence, morality, and motivation of people who look like them" and "internalize these beliefs about themselves" (Delpit, 2010, p. 174). These markers of race and ethnicity perpetuate the racial inequality that still exists today in the United States despite the efforts that have been put in motion to end it (Berlak, 2008).

Public institutions like schools reflect the values, goals, and interests of dominant economic and political institutions. Delpit (1995) stated that "the culture of the school is based on the culture of the upper and middle classes - of those in power" and are reflective of the knowledge, skills, and education of those with a higher position in society, usually the White supremacy, according to cultural capital theory (p. 25). These 
public institutions must be examined in order to understand the gap in educational performance between the dominant White population and various racial and ethnic minority groups. This examination will bring forth ways to improve educational performance since the public institutions relate to the formation of attitudes, values, skills, and knowledge related to school performance (Moore, 2002). According to Delpit and Dowdy (2002), the results of standardized testing favor children who speak common American English simply because these children are able to respond to questions that are couched in a familiar language based upon familiar experiences. Since the 'right children' - upper class, wealthy - tend to get the top scores, it is assumed that the I.Q., reading speech, language acquisition, and other tests are valid. (p.98) All other students who do not share familiar language base or familiar experiences must be educated and tested according to such guidelines. Unfortunately, test creators fail "to develop assessment instruments that could accurately and adequately distinguish between language disabilities and language differences" (Perry, Steele, \& Hilliard, 2003, p. 54).

The predominant culture of White Anglo-Saxon Protestants (WASPs) reinforces the idea that its values, attitudes, beliefs, traditions, customs, and morals are the only acceptable and normal behavior. Divergence from these cultural traits is perceived as abnormal and, in cases of extreme differences, different cultures can be perceived as deviant and degenerate. Inequality toward minority groups is tolerated, so long as social conventions continue to benefit the majority. Moore (2002) stated that "multiculturalists assert that the gap in educational performance exists because minority students have been the victims of racism and discrimination by educational institutions dominated by White Anglo-Saxon Protestant (WASP) values, attitudes, behaviors, and goals” (p. 70). As 
stated by Freire (1970), "the oppressor, what is worthwhile is to have more - always more - even at the cost of the oppressed having less or having nothing. For them, to be is to have and to be the class of the "haves"' (p. 44). In essence, the majority will always want more power and more control. Society reflects their values, goals, and interests, despite how discriminatory or unfair it may be to the rest of the population.

\section{Educational Attainment}

According to Moore (2002), the gap of educational attainment between Whites and racial and ethnic minority groups has decreased during the last forty years, but it continues to exist. Also, the population of racial and ethnic minority students in schools has been increasing through the years. Standardized tests, according to critics, are culturally biased against racial and ethnic minority groups; they are not based on the linguistic competency and cultural experiences of the races and ethnicities of all students taking the tests. "A much lower percentage of students passed the FCAT in Black segregated schools than in White segregated schools" (Borman et al., 2004, p. 625).

Valencia (1997) stated that students attending segregated schools live in poverty, have high drop-out rates, have less qualified teachers, have fewer teachers who mirror the diversity of students, are in more remedial courses, are less exposed to pre-collegiate courses, have low educational aspirations, have low college enrollment, have low scores on standardized tests, have unmet educational needs, have cultural/language exclusion, and have low parental involvement. "By the time students reach the $12^{\text {th }}$ grade, very few students of color are included in upper-level mathematics courses" (Diamond, 2006, p. 500). Borman et al. (2004) stated that "as the percentage of Black students increased [in 
a school], there was an expected decrease in the percentage of students passing the

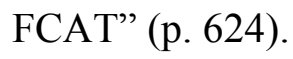

On the other hand, students attending mainly White schools are offered more precollegiate courses, have more highly-skilled teachers, have a more rigorous curriculum, have higher educational aspirations, and have higher parental involvement. Crain (1970)

and Boozer, Krueger, and Wolkon (1992) concluded that the higher the White enrollment in a school, the greater the chances for academic achievement, probability of attending college, higher wages, and working in an integrated environment. This finding justifies the purpose of this study to investigate if a relationship exists between the scores of middle school students on the FCAT 2.0 Mathematics Test, racial and ethnic concentrations, the results of the School Climate Survey, ESOL student population, and socio-economic status.

The educational attainment of students relates not only to the quality of education they receive but also the atmosphere found in their homes, socio-economic status, participation in cultural activities, residential segregation, and resources available in and outside of school. Individual differences attributed to experiences, places lived, and culture, among other things, relate to who the child is, their abilities, attitudes, behavior, goals, and values and who they can become (Valencia, 1997).

\section{Tracking}

Through curriculum differentiation, students are placed according to their academic abilities (Valencia, 1997). This teaching method has led to segregation within schools. "Even in integrated schools, Black students are disproportionately allocated or tracked into low-ability and non-college preparatory classes that are characterized by a 
less demanding curriculum and lower teacher expectations" (William, 1999, p. 179). This separation of students according to their academic preparation is "referred to as tracking, ability grouping, or gifted and talented programming" and does not provide quality education for all students (Conger, 2005, p. 226). From the elementary school grades, the students are being tracked based on their mathematics and reading abilities, steering them towards higher or lower levels of education. Tracking may lead to the permanent placement of students at a low-level, never challenging them to their true potential (Aberger, Brown, Mantil, \& Perkins, 2009, p. 17). There are many factors that relate to a child's understanding. This goes on to relate to the students' belief in themselves, their self-esteem, and what they are capable of achieving. According to Moore (2002), racial and ethnic minority groups tend to be less educated than Whites, and "nationwide, minorities are overrepresented in special education and remedial classes and underrepresented in advanced classes" (p. 12). "Minority and White students with similar academic abilities are often assigned to different tracks, with Black and Hispanic students disproportionately found in lower tracks" (Blazer, 2007, p. 8).

Additionally, schools located in residentially segregated and low socio-economic status neighborhoods do not offer the same amount of honors and Advanced Placement courses as schools located in predominantly White and high socio-economic status neighborhoods (Kao \& Thompson, 2003). When students are placed in classes according to their academic level, the student population is being segregated since the majority of the racial and ethnic minority groups are placed in remedial and regular level classes while the majority of Whites are placed in honors and Advanced Placement level classes. This limits the students' exposure and opportunities, not providing quality education to 
all students. Students placed in the "lower educational tracks are typically taught by less qualified teachers using instructional materials and strategies that are less challenging and engaging and therefore, ultimately, learn less" (Diamond, 2006, p. 501). Moreover, tracking increases social segregation, limiting the interaction of racial and ethnic minority groups with the majority in social settings. Not having the same linguistic competency and cultural experiences of the dominant culture can prevent racial and ethnic minority students from achieving a high academic level and being able to be enrolled in honors and Advanced Placement level classes (Kao \& Thompson, 2003).

On the other hand, detracking has been created to counteract the relation of tracking (Blazer, 2007). These heterogeneous classrooms increase classroom diversity and decreased within school segregation (Blazer, 2007). Detracking is a method used to combat school segregation.

\section{Social Segregation}

Residential segregation leads to school segregation which then creates social segregation. Social segregation is present in schools through propinquity and homophily. Propinquity, when a person has the opportunity for interracial contact, is highly available to students attending integrated schools or schools in middle or high socio-economic status neighborhoods (Mouw \& Entwisle, 2006). Individuals who exhibit homophily, the tendency to prefer contact with one's own race or ethnicity, have this trait reinforced when attending a school with a high concentration of their race or ethnicity, due to fewer opportunities to interact with members of other social groups (Mouw \& Entwisle, 2006). Social segregation can result from residential segregation of the school's neighborhood. If the neighborhood is heavily populated by Hispanics, there is a high chance the makeup 
of the local school's student population will be Hispanic. Consequently, students attending such a school will most likely interact socially with Hispanics (Moody, 2001). The tendency toward homophily leads students to become friends with other individuals who share similar social traits. The similarities are usually found in academic performance, behavior, and socio-economic status (Moody, 2001). Additionally, sometimes parents decide on a school based on the racial and ethnic concentrations of the student population, even if the school is of lower academic quality (Lubienski \& Weitzel, 2009). These parents' priority is for their child to be surrounded by children similar to them so that they fit in and feel comfortable.

Furthermore, even when the overall demographics suggest that a school is integrated, social groups within the school may still not be integrated with each other. "Schools that seem integrated on paper do not always have integrated classrooms or common areas" (Blazer, 2007, p. 7). Around many school campuses, each racial and ethnic group has its own territory where it socializes. Despite the level of integration in classrooms, students will segregate themselves in the cafeteria, extracurricular activities, and playground (Clotfeller, 2002; Schofield \& Sagar, 1977; Tatum, 1997; p. 225). This adds to the segregation among the student population, leading to strained relations among the different racial and ethnic groups. This also limits the interaction between students racially and ethnically different from each other.

In contrast, extracurricular activities give students the opportunity to interact with students of different ethnicities and race (Moody, 2001). Students participating in sports, school government, drama, music, clubs, and the school newspaper are exposed to opportunities that promote interracial friendships. Participation in extracurricular 
activities is a challenge to racial and ethnic minority students who are learning the English language and culture since they are not able to interact socially (Romo, 1997). They feel timid and embarrassed about how they speak English and how less knowledgeable they are about the American way of life. According to Romo (1997), "cooperative learning methods create thoughtful, equitable interactions needed to promote positive racial attitudes...students of different races and ethnicities work together in groups, which receive rewards, recognition, or evaluation based on how much they improve each member's academic performance" (p. 5). All students need to be exposed to information about different racial and ethnic groups in order to respect and better relate to each other. A racial and ethnic minority student who becomes literate in English is able to learn and understand the knowledge necessary to be promoted from grade to grade. On the other hand, these racial and ethnic minority students usually deal with being bullied and ridiculed. They suffer from stereotype threat which is "being viewed through the lens of a negative stereotype" that deals with their race or ethnicity "or the fear of doing something that might inadvertently confirm that stereotype" (Diamond, 2006, p. 501). They become timid and afraid of representing and displaying their culture. Sometimes they might be faced with conflicting choices between a perceived loyalty to their social group and their desire to be successful in school. There also exists the case in which the racial and ethnic minority student has decided not to learn English or adopt the American culture, having created a connotative definition to achieving high academically; they see getting good grades as "acting White" (Romo, 1997, p. 2). Thus, they refuse to abandon their native culture and do everything that does not make them "White". These issues stem from the segregation that exists in the 
students environment and can lead to the squandering of the educational capabilities of minority students that struggle with these social pressures.

Ainsworth (2002) stated that usually children in segregated neighborhoods have no admiration of older peers who have completed high school, while instead they hold in high esteem those who drop out of school. They will eventually not put forth maximum effort and stop caring about their education. This lack of interest and effort is seen with a weak academic preparation noticeable through low grades and test scores. Suspension and grade retention also have a long term relationship on racial and ethnic minority students, leading to low self-esteem and lack of interest and motivation, to then possibly dropping out of high school (Kao \& Thompson, 2003). Students are more likely to drop out of high school if the school is predominately Black or Hispanic (Mayer, 1991). Dropping out of high school tends to lead to lower paying jobs, greater chance for unemployment, dependency on welfare, higher crime rate, teenage pregnancy, and greater chance for their children being disadvantaged (Jargowsky \& Bane, 1991; Massey \& Denton, 1993; Wilson, 1997, 2012). All these conditions seem to be predominant in segregated neighborhoods. The children are the future of the country; hence they need to receive the proper academic preparation today necessary for them to be successful leaders tomorrow.

\section{Residential Segregation}

"Racial and economic inequalities shape children's experiences from very early on and as a result, on average, Black and White children face very different life chances" (Magnuson \& Waldfogel, 2008, p. 1). Residential segregation has led to institutional inequalities. "Many believe that the dramatic differences between Blacks and Whites in 
achievement are due, in part, to school segregation" (Echenique, Fryer Jr., \& Kaufman, 2006, p. 265). School segregation is reflective of the segregation that exists in the neighborhood, residential segregation which is de facto segregation. Since a school's population is largely based on its surrounding boundaries, whoever lives within that boundary attends the school. Schools in a racial and ethnic minority neighborhood will have high enrollments of racial and ethnic minority students (Kim \& Sunderman, 2005). "School attendance boundaries are largely determined by neighborhood of residence and because families of different socio-economic status backgrounds live in different neighborhoods, children from more and less advantaged backgrounds attend different schools" (Rouse \& Barrow, 2006, p. 116). Racial and ethnic minority students, who are the ones in need of the most support and resources, find themselves exposed to the least because of where they live and where the school they attend is located. In these circumstances, students do not receive quality education.

Majority neighborhoods have better schools, better facilities, and better resources while racial and ethnic minority neighborhoods have lower-quality schools, worse facilities, and inadequate resources. Significant numbers of racial and ethnic minorities live and go to school in isolation from the majority, receiving an inferior education (Cobb \& Glass, 2009). Luckily, there are still the few that succeed. In the case of Brown $v$ Board of Education, Brown stated "segregation has no place in public education because segregation often leads to discrimination. And discrimination has no place in a free, open, and democratic society" (Willie, 2005, p. 13). Inequalities in residential areas have led to discrimination since not all schools offer the same exposure and opportunities. 
Residential segregation creates "a barrier for the establishment of successful school programs" (Stretesky \& Hogan, 2005, p. 412). Between the lack of funds, materials, and resources, negative attitude, and low expectations from the community, residential segregation impedes success in the schools. Racial and ethnic minority students would have better educational opportunities and resources if they attend a high majority enrollment school, since many of their schools do not offer the same quality education. Such "access to predominantly White institutions would enhance the social mobility and life chances" for minorities (Borman et al., 2004, p. 607). The social and economic disadvantages of residential segregation make it difficult for children to overcome the challenges of inequality.

Residential segregation creates different neighborhoods with different needs and resources. Regardless of policies and community programs that have been created to meet these needs, many needs are still to be met. Poverty still prevails in segregated neighborhoods and equality of residential areas and their schools is far from existing. The characteristics of the families in segregated neighborhoods, their assets, attitudes, education, employment, and income play a key part in the success of the students. Echenique et al. (2006) stated that "Black children enter kindergarten lagging behind White children, and these differences grow throughout the school years" (p. 265). This is common among racial and ethnic minorities due to the limited exposure these children have to education before starting school.

It is these circumstances that drove the purpose of this study, to identify the relationship between school segregation, academic achievement, perceptions of education, ESOL student population, and socio-economic status. It is in the interest of 
the country to provide segregated schools with the necessary funds, resources, materials, and personnel to provide those students with a high-quality education as per NCLB (Gray, 2005).

\section{Neighborhood}

Middle and high socio-economic status families often decide the school their children will attend, "either private schools or good public schools in neighborhoods their parents have chosen to live in" (Archbald, 2004, p. 285). On the other hand, "poor and minority children are more often enrolled in schools not because they have chosen them, but because of the restricted choices about where they can live; restrictions that are imposed by housing policies, lending practices, and societal prejudices" (Archbald, 2004, p. 285). Other restrictions are self-imposed by the individuals, such as obtaining a good education to have a stable career and be successful.

According to Charles Clotfeller, a leading desegregation researcher, "more than a third (37.4\%) of the nation's black students in 2000 attended schools that were ninety to a hundred percent nonwhite and nearly three-fourths (72\%) attended schools that were at least fifty percent nonwhite" (Street, 2005, p. 15). Scott (2005) added that "low-income, high-needs, and minority children are concentrated in urban centers, while higherincome, better educated, white families are typically found in the suburbs and private schools" (p. 9). "White and wealthier students will take steps to maintain their social status by distancing themselves from groups that they perceive to be of lowering standing" (Saporito \& Sohoni, 2006, p. 82). They are willing to relocate as long as racial and ethnic minorities do not relate to their social status. They are aware that a community's attitude, behavior, socio-economic status, and values have a deep relation to 
children's educational attainment. "The concentration of poor students and non-White students depresses achievement and magnifies the average likelihood of dropping out" ( $\mathrm{p}$. 2138). In essence, the majority does not want to send their child to a school with low achievement and high drop-out rates.

Neighborhood conditions relate to the child's academic achievement, shaping who the child is and will become. As stated by Moore (2002) "a neighborhood, much like a family, is an organic entity that can through its community values, behaviors, attitudes, and adult role models exert a profound relationship, positive or negative, on the children who reside in the community" (p. 212). Growing up in a neighborhood with a high crime rate negatively relates to the child's life, just as growing up in a neighborhood with a low crime rate positively relates to the child's life. "In concentrated poverty neighborhoods, children may be less exposed to adults and peers who speak Standard English and also less exposed to hearing language, in general, because of restrictions on social interaction imposed by parents concerned about safety" (Sastry \& Pebley, 2008, p. 8). Wilson (1997) concluded that "neighborhoods where most adults have steady jobs, foster behaviors and attitudes that are conducive to success" (p. 119). Children are raised seeing the examples of model adults, with norms, structure, and values. Also, they are exposed to other opportunities presented through information, networks, and resources. Without these positive examples, the children are growing up in social isolation that lacks role models and various other exposures (Stretesky \& Hogan, 2005, p. 407).

Children living in communities that negatively relate to them are more likely to have broken families, health problems, hunger, welfare dependency, crime exposure, and learning disabilities. Their opportunities to succeed become limited. With the lack of 
role models, children have less constructive ways to spend their time, lending themselves to unproductive activities, displaying lack of interest for schoolwork and their future, and being disrespectful towards adults (Wacquant, 1996). Street (2005) added that "children cannot grow up to be healthy and successful adults unless basic needs of security, nutrition, housing, honoring, and recognition of self, etc. are met" (p. 144). These needs are present in the lives of all children doing well in school and they come from the home.

On the other hand, it is not just White parents who send their children to schools with high White enrollment. Racial and ethnic minority parents also look for schools that will allow their child to feel welcomed and part of a whole. Berliner and Biddle (1995) stated that "racial and ethnic minorities would like the schools attended by their children to offer curricula that honor their cultural heritages" (p. 226). Sending their child to a school that has a high White enrollment will only make them feel like an outsider. "Minority parents, who fear their children will be isolated or have other difficulties in predominantly White schools, will search for schools where the student body is predominantly minority" (Tedin \& Weiher, 2004, p. 1110). Also, living in residential segregated neighborhoods can limit the English skills students are acquiring in school. They lack the interactions that lead to the practice and further development of English because they do not find themselves needing to communicate in English. Additionally, residential segregation can be "attributed in part to people's preferences over the race of their neighbors" (Bayer, McMillan, \& Rueben, 2001, p. 3). Many parents feel more comfortable raising their children in a neighborhood where they share the same race and ethnicity with others than in a neighborhood that they do not. Unfortunately, this action 
on behalf of racial and ethnic minority parents only leads to further residential segregation and hinders their child's success.

\section{Poverty}

Due to economic reasons, minorities tend to live in segregated and low socioeconomic neighborhoods where poverty prevails. "Segregation is a key determinant of the quality of life in neighborhoods", placing limits on access and opportunities (Williams, 1999, p. 183). Racial and ethnic minority groups "continue to face considerable prejudice and discrimination in U.S. housing markets and therefore remain considerably unable to freely choose where they wish to live" (Street, 2005, p. 32). Schools in these neighborhoods have low achievement levels and lack the resources and opportunities offered by schools in middle and high socio-economic status neighborhoods. "Teachers and schools must accept, believe, and act upon the belief that children of poverty area learners, have been learning since birth, are ready to learn at anytime, and will learn" (Delpit \& Dowdy, 2002, p. 135). Teachers and schools must set high expectations, be positive, show that they believe in the students, and provide the adequate resources and review for the students. This reinforces the idea that these students deserve a quality education.

Poverty relates to children thoroughly, from birth till death; even if they end up being successful, poverty has hindered their life in one way or another in their earlier years. "If children come to school hungry, sick, homeless, scared, or with uncorrected vision problems or if they come from homes warmed by high-sulfur heating oil or with inadequate sanitation systems, their education is compromised" (Cortes, Jr., 2010, p. 97). Overall, racial and ethnic minority groups usually attend schools whose overall 
achievement is low (Wang \& Kovach, 1995). These schools lack the necessary personnel and resources in order to improve the school's overall achievement. All students should have the textbooks and supplies necessary for their classes, and incentives should be offered to attract highly-qualified teachers to such schools. Through effective instruction, students are able to academically achieve higher. All students need to explore the world around them through complex, hands-on projects. Their education must be a continuous accrual of knowledge.

Furthermore, the deterioration of the family, religion, and community has placed a great amount of pressure on school districts to solve social problems like segregation, student behavior, crime, and drug abuse. Many racial and ethnic minority families face poverty and life-threatening problems. They rely on community resources like counseling, financial assistance, and medical treatment to overcome these situations. Children who were raised in a household that received financial assistance are less likely to graduate from high school than children who were raised in a household that did not receive any financial assistance (Raley, 1991).

\section{Homeownership}

Some families find themselves homeless and living in cars parked in abandoned lots. Homeless children are prone to having poor cognitive and physical development and exhibit more health problems than students who have a place to call home (HartShegos, 1999). They have a higher probability of suffering from anxiety, depression, asthma, anemia, stunted growth, lead poisoning, and poor nutrition (Hart-Shegos, 1999). Their academic success is also hindered. "In schools with greater student mobility and a higher percentage of students in poverty, fewer students passed the math and reading 
portions of the FCAT" (Borman et al., 2004, p. 623). On the other hand, parents who are homeowners provide their children with a more stable home environment. Unlike renters, there is a greater chance of not moving from house to house. Children are able to grow up attending the schools in the same neighborhood, not removing them from instructional time to pack, move, and unpack. Usually students fall out of place in the curriculum when moving from one school to another, causing confusion if they have not acquired the necessary skills on the concept being taught at their new school.

Additionally, homeowners are willing to invest more money in their home unlike renters, providing their children with a higher quality living environment (Haurin, Parcel, \& Haurin, 2001). This increases the economic capital of the household which positively relates to the success of the children (Haurin et al.).

\section{Parental Influences}

\section{Parent Involvement}

Parents contribute to their children's education by providing three types of capital: financial, human and social capital. A family's financial capital is measured by their amount of income. The larger the income, the more comfortable life the children will have. The family's human capital is measured by the parents' education. The higher education the parents have, the larger income they will receive. The family's social capital is measured by the relations, interactions, and support of the parents with the child. The more networking and resources the parents are exposed to due to their social position, the better off the children will be.

Muller (1995) stated that the more involved a parent is in their child's education, the higher the child will achieve academically. "Students with the most supportive 
parents not only have higher proficiency levels, but also more positive attitudes towards mathematics than those students with the least supportive parents" (Cai, Moyer, \& Wang, 1999, p. 15). In fact, it "not only increases educational outcomes for individual children but for the entire school" (Aberger et al., 2009, p. 12). Parents who have more access to educational information and social networks are able to provide their children with the best education possible (Scott, 2005). Muller (1995) added that when mothers are not employed full-time, they are able to dedicate more time to their child's education. With increased involvement from the mother, the father also tends to increase their involvement in their child's education. Parents in these circumstances become more aware of school functions and increase their participation. They assist their child more with homework and studying. There is also a higher chance of them knowing the parents of their child's friends. Additionally, households in which the mother is not employed full time usually have a stricter, regulated environment, such as television restrictions and homework checks.

\section{Parents' Education}

Moreover, parents' education level has a relation with students' socio-economic status and academic achievement. According to Sarane Boocock, an educational sociologist, "the family characteristic that is the most powerful predictor of school performance is socio-economic: the higher the socio-economic status of the student's family, the higher his academic achievement" (Moore, 2002, p. 62). Part of the family characteristic is the parents' education. Children whose parents are well educated and older spend more time studying and watch less television than children of less educated and younger parents (Hofferth \& Sandberg, 2001). Usually, families with higher socio- 
economic status select a neighborhood to live in based on the elementary school's reputation. Students coming from a majority neighborhood have parents who are able to provide them with more than just the basic necessities. Books, computers, educational centers, games, museum visits, summer camps, tutoring, library visits, and zoo visits are all resources that families with higher socio-economic status can provide for their children. Such parents also have more time to be involved in their child's education. Rivkin (2000) added that Blacks who are educated, involved in their children's education, and have resources are more likely to send their children to a high White enrollment school for them to obtain a better education and have more opportunities.

\section{Family Structure}

Since the 1960s, the number of children growing up in a single-parent household, due to divorce or being born out of wedlock, continues to increase. Kelly and Emery (2003) stated that "children in divorced families have lower academic performance and achievement test scores compared with children in continuously married families" (p. 356). Their chances of dropping out of high school are two to three times greater (Kelly \& Emery, 2003). A divorce is a stressful situation for children. They often find themselves feeling that the divorce is their fault. They deal with loyalty issues with each parent. Plenty of children lose contact with their birth father after a divorce (Kelly \& Emery, 2003). Since the father is usually absent in these cases, these children grow up without a male role model. This is particularly hard for boys since the father is usually absent in their lives. Younger children relate more to the absence of a parent than older children, since the older children are more independent, mature, and able to understand. By the time these children are finishing high school, many decide not to attend college 
because of the economic hardship they have and are still undergoing because of their parents' divorce (Amato, 2000). Overall, these students tend to have fewer years of education than students whose parents are not divorced (Keith \& Finlay, 1988). Additionally, children whose parents divorce usually move from home to home and switch schools more frequently than children whose parents are married (Sandell \& Plutzer, 2005). This causes instability in the child's life.

As Mulkey, Crain, and Harrington (1992) reported, "students from one-parent households have significantly lower grades and test scores than do students from twoparent households" (p. 176). Children who grow up in a single-parent household (mother or father) are more likely to be single-parents themselves and typically they do not have high academic achievement. A single-parent home often comes with economic deprivation. These single-parents often need to work multiple jobs or long hour days just to get by. Usually, the children take on more responsibilities at younger ages, interfering with their education (Hofferth \& Sandberg, 2001). These children end up suffering since they do not receive the amount of attention and supervision they need. These children usually find themselves home alone and struggling on homework assignments. Usually, parental support is nonexistent.

Furthermore, belonging to a poor family with a large number of children also relates to student achievement. The household income needs to be used to pay for the living expenses of more individuals. If money is lacking, parents find themselves not being able to provide their children with what is needed to be healthy and successful in school. Health care, medicine, vitamins, and proper nutrition might be minimal. Educational resources and support such as books, computers, Internet, trips to museums 
and libraries, and tutors might be lacking. Additionally, usually parental support is nonexistent. The majority of these parents may be working extra to be able to earn more money to pay the bills (Roscigno, Tomaskovie-Devey, \& Crowley, 2006, p. 2139). According to Raley (1991), families who are headed by the mother are usually economically disadvantaged. In such a situation, when the child is old enough to work, they may quit school to help with the financial difficulties or if the child stays in school the job may start burdening the child's education. Mothers who are single-parents sometimes turn to their children for emotional support in regards to their personal problems (Raley, 1991). The mother will share her feelings and transmit her emotions to her child, including bitter feelings towards her ex-husband, frustration towards men, or experiences with her new significant other (Glenwick \& Mowrey, 1986). When children take on responsibilities that may be too advanced for their age such as providing emotional support to their mother, the parent and child are role reversing. This turns the parent-child relationship into more of a friendship, which can improve communication between the parent and child but also make it harder for the parent to discipline the child. Also, children may experience stress when their parent remarries. But, on the contrary, sometimes children whose parents remarry have a higher graduation rate than children whose parents do not remarry since two caring adults bring more stability to a child's life (Raley, 1991, p. 5). In order for racial and ethnic minority groups to overcome the hardships they face, parents and children alike have to "accept responsibility for positive outcomes" versus denying "responsibility for negative outcomes" (Miller, Reynolds, \& Weiner, 2003, p. 106). They need to focus on all the factors that contribute to their child's education and try to limit the negative relations. 
Racial and ethnic minority students need to have high self-esteem, establish goals, and be given the opportunity to achieve them in order to be educationally successful. They should have self-efficacy, the knowledge of their ability to succeed in reaching a specific goal. Students, regardless of their race and ethnicity, need to have capacity and control beliefs. Students with capacity beliefs have confidence in their own capabilities. Also, students with control beliefs know they control the factors that relate to their ability to succeed. Students need to be aware and understand that everything is attainable if they put their maximum effort into it. Sometimes, racial and ethnic minority groups have suffered so much hardship and ridicule that the children develop what is called "learned helplessness" (Miller et al., 2003, p. 106). These children find themselves in this condition, with difficulties in school and feel "there is no opportunity for change" (Miller et al., p. 106). In reality, it is never too late to change and take advantage of the new opportunities that present themselves.

Therefore, limited exposure to role models succeeding with the dominant culture, restricted career and employment opportunities, and unsupportive or unhelpful social networks are among the explanations for the relation of disadvantaged neighborhoods on academic achievement (Ainsworth, 2002). Residential segregation, socio-economic status, poverty, homeownership, parent involvement, parents' education, and family structure are factors that are related to each other and can hinder the academic achievement of students.

\section{Perceptions of Education}

School climate is a pattern of shared perceptions about the characteristics of an organization (Keefe, Kelley, \& Miller, 1985). A positive school climate is vital to the 
school's success. "Safety, trust, respect, fairness, high expectations, a welcoming

environment - these elements add up to a positive school climate" (Perkins-Gough, 2008, p. 89). The students, parents, and school staff need to feel and experience this positive school climate in order for them to have positive perceptions of education and the school they attend, their child attends, or they work. Sweeney (1988) stated "a winning school climate provides the very foundation for a sound educational program" (p. 1). Sweeney (1988) added "when the climate is right, people are inspired to do their best. Teachers and students...do what needs to be done to stimulate learning, and achievement generally rises" (p. 1). Everything that occurs at the school or related to the school relates to the perceptions of education and school climate. A school's climate "is the quality and consistency of interpersonal interactions within the school community that influences children's cognitive, social, and psychological development" (Hoy \& Sabo, 1998, p. 322). It can be a positive relation or a significant barrier to the students' learning and performance of staff members. "School climate is reflected in every interaction and in every decision adults and students make" which include inspiring students to maintain and protect school property, and helping your child with homework and studies (Noonan, 2004, pp. 61-62).

School districts, such as Miami-Dade County Public Schools, conduct a School Climate Survey every school year to assess the perceptions of education of the participating students, their parents, and the entire school staff. The data collected is used "to promote meaningful staff, family, and student engagement- and to enhance the social, emotional, ethical, civic, and intellectual skills and dispositions that contribute to success in school and in life" (Cohen, Pickeral, \& McCloskey, 2009, p. 45). Various different 
questions bring to light the perceptions of each, the students, the parents, and the school staff. It assists in bringing forth the areas in need of improvement in the school, district and in education.

The perceptions the students, parents, and school staff have of the school and education eventually reflect upon the school climate, which in turn reflects upon students' academic achievement as well as the school's success. These perceptions are based on previous and current experiences with the school, district and education. These experiences can deal with finance, support, and discrimination (Rubie-Davis, Peterson, Irving, Widdowson, \& Dixon, 2010). "School climate may be one of the most important ingredients of a successful instructional program" (Heck, 2000, pp.513 - 522). Negative attitudes or low expectations are reflected on the students' academic achievement and the school's success. "The climate of a school has always been, and continues to be, essential to a school's success in educating its children and preparing them for a life beyond its corridors" (Noonan, 2004, p. 61).

\section{Conclusion}

According to Flores (2005),

as we enter the $21^{\text {st }}$ century, we face ultra-conservative movements (English Only, Back-to-Basics, standardization of curricula, high-stakes standardized testing, etc.), public policies (banning of bilingual education in states such as California, Massachusetts, New York; high school exit exams; No Child Left Behind), and big corporate interests (McGraw-Hill, Houghton Mifflen, Open Court) in the effort to continue these deficit views and schooling practices of Latinos and children of color in general. (p. 91) 
There are currently many forces against acts and policies that support meeting the needs of racial and ethnic minority students in education. It is vital for the country to educate every child, because today's children will be the ones leading the development of society in the future. Every child needs to receive a quality education from a positive school climate.

According to Freire (1970), to meet the needs of minorities, "the solution is not to 'integrate' them into the structure of oppression, but to transform that structure so that they can become "beings for themselves"' (p. 61). Transforming the structure is having all schools provide a quality education and be held accountable for it. Despite the school segregation, racial and ethnic minority children need to have equal educational opportunities so they can grow into successful adults and look past all their hardships. All children, despite their ethnicity or race, "have the right to their own language, their own culture" and the system must be fought so "that children be allowed to express themselves in their own language style" (Delpit, 1995, p. 37). Delpit (1995) added "it is not they, the children, who must change, but the schools" (p. 37). Their individual learning needs and styles need to be met so they can grow up into successful adults. Districts, schools, and teachers must maintain high standards for all students, especially minorities, to push them forth academically. These structures or public institutions need to be transformed to meet the needs of all students. Wang and Kovach (1995) believe that by "magnifying the 'positives' in the lives of urban children and youth, we can rekindle hope for progress in addressing the deep-rooted problem of the achievement gap" (p. 5). Public schools, where the majority of children receive their education, is vital for the future of the United States. It is important that the education that the children 
receive is the best possible and tailored to all racial and ethnic and socio-economic groups of students.

We share a common destiny. That destiny does not rely solely upon the White community - or professional - but upon the performance of our entire citizenry. We need an educated population and competent work force across all occupations. Remember the words of Dr. Martin Luther King: 'The quality, not the longevity of one's life, is what's important.' (Lisack, 1987, p. 32)

The students' academic achievement level relates to school segregation and the advantages and disadvantages that come with it. Despite the number of years since the ruling of the Brown v Board of Education case, much work still needs to be done in assuring that all schools are providing an educational opportunity and high-quality education in a positive school climate to the students. School districts must be held accountable for it, like they are with the state standardized tests. Educational equality is still to be realized (Echenique et al., 2006). Hence, the children's future depends upon the performance of the entire country to end segregation so that students, regardless of their socio-economic status, receive the same quality education and opportunities in order to be academically successful. "The educational and social benefits of desegregation begin only when students from different racial and ethnic backgrounds are learning together, in classes with diverse populations (Orfield, 2007, p. 10). 


\section{CHAPTER 3}

\section{METHODS}

This chapter briefly touches upon the purpose of the study and research question again. Additionally, this chapter focuses on the setting and subjects for the study, the research design, the statistical instruments used, and the procedures for data collection and conducting data analysis.

\section{Purpose of the Study}

The purpose of this study was to investigate the relationship between the FCAT 2.0 Mathematics scores of public middle school students in Miami-Dade County, Florida, racial and ethnic concentrations (Whites, Blacks, and Hispanics), ESOL student population, socio-economic status, and school climate for the $2010-2011$ school year. The study was undertaken to demonstrate whether a significant relationship exists between mathematics achievement and racial and ethnic concentrations, socio-economic status, ESOL student population, and school climate in Miami-Dade County Public Schools (M-DCPS).

\section{Research Questions}

This study was driven by the following primary research question:

Is there a significant negative relationship between the FCAT 2.0 Mathematics scores and racial and ethnic concentration of public middle school students in Miami-Dade County when controlling SES, ESOL student population, and school climate for the 2010-2011 school year? 
The study was also driven by these secondary research questions:

1. Is there a significant negative relationship between the FCAT 2.0 Mathematics scores and racial and ethnic concentrations when controlling the ESOL student population of the school?

2. Is there a significant negative relationship between the FCAT 2.0 Mathematics scores and SES?

3. Is there a significant negative relationship between the FCAT 2.0 Mathematics scores and SES when controlling racial and ethnic concentrations?

4. Is there a significant negative relationship between the FCAT 2.0 Mathematics scores and school climate when controlling racial and ethnic concentrations?

\section{The Setting and Subjects for the Study}

\section{Miami-Dade County}

MacDonald and Monkman (2005) stated that "although Brown v Board of Education had ruled segregation illegal in 1954, Miami, like most urban areas, still practiced racial segregation in the 1960s" (p. 67). Miami is home to immigrants, some highly successful, while others struggle daily to meet their needs. According to the U.S. Census Bureau, in 2010, the population of Miami-Dade county was 2,496,435 (2010a). In Miami, Hispanics are the demographic majority and Spanish is spoken everywhere. The U.S. Census Bureau reported that $65 \%$ of the population is Hispanic, while $18.9 \%$ is Black Non-Hispanic, and 15.4\% is White Non-Hispanic (2010b). Furthermore, $70.3 \%$ of households have another language other than English spoken at home, 58.3\% own their home and $17.1 \%$ live in poverty (U.S. Census Bureau, 2010a). 
Currently, M-DCPS is the fourth largest public school system in the nation (Miami-Dade County Public Schools, 2013). According to M-DCPS Statistical Highlights for the 2010-2011 school year, they had a total of 435 schools, 347,133 students, and 20,322 teachers (2011). In sixth grade, they had 2,359 White Non-Hispanic students, 6,596 Black Non-Hispanic students, and 17,651 Hispanic students (Miami-Dade County Public Schools, 2011c). In seventh grade, they had 2,357 White Non-Hispanic students, 6,653 Black Non-Hispanic students, and 17,637 Hispanic students (Miami-Dade County Public Schools, 2011c). In eighth grade, they had 2,534 White Non-Hispanic students, 6,626 Black Non-Hispanic students, and 17,700 Hispanic students (Miami-Dade County Public Schools, 2011c). There were 62,838 students enrolled in the English for Speakers of Other Languages (K-12) Program (Miami-Dade County Public Schools, 2011c). There were 187,481 students using Spanish as their home language, followed by 16,789 students using Haitian Creole as their home language (Miami-Dade County Public Schools, 2011c). Of the total number of public middle school students, $75.5 \%$ were eligible for free/reduced lunch compared to Miami-Dade County Public Schools' district average of 70.2\% for all schools (Miami-Dade County Public Schools, 2011c).

M-DCPS has been able to desegregate a considerable number of the schools. As of June 30, 2002, M-DCPS was granted unitary status by the United States District Court for the Southern District of Florida, meaning it was no longer considered segregated based on the district's demographics (Blazer, 2007). In recent years, the number of White students attending predominantly Black and Hispanic schools has increased due to the efforts of decreasing segregation in M-DCPS through the establishment and promotion of several new magnet programs in schools throughout the district as well as 
the rezoning of school boundaries (Blazer, 2007). Magnet programs, charter schools, and vouchers have given students the ability to attend other schools besides their home school in hopes of offering them varied opportunities for becoming successful.

\section{Subjects}

For the 2010-2011 school year, there were a total of 59 public middle schools that were part of Miami-Dade County Public Schools and all of them were used in this study. The scores obtained by each of the 59 public middle schools for the FCAT 2.0 Mathematics Test in the 2010-2011 school year were used in the study, as well as the results of racial and ethnic concentration, ESOL student population, socio-economic status, and the School Climate Survey. The scores on the FCAT 2.0 Mathematics Test for the 2010-2011 school year were analyzed. Those exams were collected at the schools, then collected by M-DCPS, and sent to be graded following the guidelines and orders of Florida's Department of Education.

Moreover, the results of the School Climate Survey for each participating public middle school were analyzed. These surveys were collected by teachers and administrators and then submitted to M-DCPS to be compiled and analyzed. The data on racial and ethnic concentration, ESOL student population, and socio-economic status were compiled by M-DCPS’ Department of Research Services.

FLDOE's 2011 AYP Report (2010-2011 Edition) provided data from the 59 different public middle schools on the number of students tested by race/ethnicity, Title I students, and English Language Learners. MDCPS' School Climate Survey Individual Results (2010-2011 Edition) provided the results of the school climate survey given randomly to selected students and their parents, along with all of the staff from the 59 
different public middle schools. Table 1 displays the total number of White students, Black students, and Hispanic students, along with the total of these three categories and their corresponding percentages from the total. Moreover, the table displays the total number of Economically Disadvantaged (SES) students and ESOL students, along with their corresponding percentages from the total. Lastly, Table 2 displays the total number of School Climate Parent Surveys returned, School Climate Student Surveys returned, and School Climate Staff Surveys returned along with the total of these three categories and their corresponding percentages from the total.

Table 1

FLDOE's 2011 AYP Report (2010-2011 Edition) Data

\begin{tabular}{|c|c|c|c|c|c|c|c|c|c|c|c|}
\hline & White & Black & Hispanic & $\begin{array}{l}\text { Eco. } \\
\text { Dis. }\end{array}$ & ESOL & $\begin{array}{c}\text { Total } \\
(\mathrm{B}+ \\
\mathrm{W}+ \\
\mathrm{H}) \\
\end{array}$ & $\begin{array}{c}\% \\
\text { White }\end{array}$ & $\begin{array}{c}\% \\
\text { Black }\end{array}$ & $\begin{array}{c}\% \\
\text { Hispanic }\end{array}$ & $\begin{array}{c}\% \\
\text { Eco. } \\
\text { Dis. }\end{array}$ & $\begin{array}{c}\% \\
\text { ESOL }\end{array}$ \\
\hline Total & 4330 & 14896 & 35025 & 43044 & 7306 & 54251 & $8.0 \%$ & $27.5 \%$ & $64.6 \%$ & $79.3 \%$ & $13.5 \%$ \\
\hline
\end{tabular}

Table 2

MDCPS' School Climate Survey Individual Results (2010-2011 Edition) Data

\begin{tabular}{cccccccc}
\hline & $\begin{array}{c}\text { Parents } \\
\text { Forms } \\
\text { Returned }\end{array}$ & $\begin{array}{c}\text { Students } \\
\text { Forms } \\
\text { Returned }\end{array}$ & $\begin{array}{c}\text { Staff Forms } \\
\text { Returned }\end{array}$ & $\begin{array}{c}\text { Total } \\
\text { Forms } \\
\text { Returned }\end{array}$ & $\begin{array}{c}\% \\
\text { Parents }\end{array}$ & $\begin{array}{c}\% \\
\text { Students }\end{array}$ & $\begin{array}{c}\% \\
\text { Staff }\end{array}$ \\
\hline Total & 4776 & 5585 & 2298 & 12659 & $37.7 \%$ & $44.1 \%$ & $18.2 \%$ \\
\hline
\end{tabular}

\section{Florida Comprehensive Assessment Test (FCAT)}

The Florida Comprehensive Assessment Test, also known as the FCAT, has been administered in the state of Florida since 1998. Since the establishment of the 2001 No Child Left Behind Act, it is the basis for the school accountability program in Florida. The test's purposes are to measure the students' abilities in mathematics, reading, science, and writing, and assure that high standards are being implemented. The test is 
criterion-referenced. Students take the FCAT Writing, Mathematics, Reading, and Science in the spring each school year and students are tested in specific subject areas depending on their grade-level. All public school students, including charter school students, are required to take the FCAT. There are cases in which English Language Learner (ELL) students or Exceptional Student Education (ESE) students can be excluded from taking the FCAT, but certain requirements must be met and guidelines must be followed. Other ELL students or ESE students may be eligible for certain accommodations and are provided these accommodations during the test.

Students are examined in mathematics and reading from third through $10^{\text {th }}$ grade. Students are examined in science in fifth, eighth, and $11^{\text {th }}$ grade. Last, students are examined in writing in fourth, eighth, and $10^{\text {th }}$ grade. "Students in grade three must achieve an FCAT Equivalent Score at level two or higher [of five levels] in reading, or show good cause, to be eligible for promotion" (Florida Department of Education, February 2011). In $10^{\text {th }}$ grade, students are required to pass the mathematics and reading portions of the test in order to receive their high school diploma upon the completion of high school. The students who entered ninth grade in the 2009-2010 school year, need a score of at least 1889 in mathematics in order to graduate high school (Florida Department of Education, February 2011). Additionally, the students need a score of at least 1926 in reading in order to graduate high school (Florida Department of Education, February 2011). If they do not pass the exam in $10^{\text {th }}$ grade, they have additional opportunities during $11^{\text {th }}$ and $12^{\text {th }}$ grade to pass the exam. If they still do not pass, they will only receive a certificate of completion of high school instead of a high school diploma. 
With new academic content standards in place at the start of the 2010-2011 school year, the FCAT has changed. These new academic content standards are the Next Generation Sunshine State Standards (NGSSS). The Florida Department of Education has modified the FCAT to the FCAT 2.0 in order to measure students' achievement of the NGSSS. Mathematics and reading were the first to make the transition. The FCAT 2.0 for sixth, seventh, and eighth grade mathematics was administered to all Florida students on Wednesday April 13, 2011. Science was first administered on April 2012 and only to fifth and eighth graders.

The results of the FCAT 2.0 exam for the 2010-2011 school year were released and published by the Florida Department of Education during summer of 2011. These documents compare school districts to each other as well as schools within a school district to each other. Besides the FCAT 2.0 scores, it also includes demographics information about the schools (socio-economic status, racial and ethnic concentration, and ESOL student population).

\section{School Climate Survey}

Since the early 1990s, M-DCPS has been administering yearly the School Climate Survey which allows the gathering of "information on the perceptions that students, their parents, and school staff hold concerning their schools and their performance" (School Climate Surveys, 2011, p. i). It gathers "information regarding what these groups think about the school and their perceptions concerning how the school can be improved" (School Climate Surveys, 2011, p. 1). Unlike school staff, not all students and parents participate. M-DCPS' Department of Research Services uses the random number generator from Microsoft Excel software to randomly select the students and their parents 
who will participate in the School Climate Survey (T. Froman, personal communication, May 24, 2011). All the homeroom classrooms at each school are assigned a random number. The homeroom classrooms are then placed in order according to their assigned random number. These numbers are entered in Microsoft Excel and then homeroom classrooms are chosen at each school until at least 200 students have been randomly selected (T. Froman, personal communication, May 24, 2011). These students and their parents are asked to participate in the School Climate Survey. Unfortunately, not all surveys distributed are returned.

There are three different surveys, one for each type of recipient: student, parent, and school staff. They are each tailored to obtain the individual perceptions of the students, parents, and school staff on the school, its performance, and areas in need of improvement. For each item, the participant must answer "strongly agree", "agree", "undecided/unknown", "disagree", and "strongly disagree".

The School Climate Survey is given during the months of January and February of every school year and is collected by teachers and administrators to then be sent in to M-DCPS' Department of Research Services. The data are compiled, analyzed, and then released publicly in August. Documents are released for each school, presenting its results by type of survey (Parent, Student, or Staff), question, and response. The responses are published as a percentage. In the same report, the school's individual results are compared to all other schools.

For this study, the one item present in each of the three different surveys (student, parent, and school staff) was used in order to test the same perception of education from these different views. Additionally, for this study only the percentages from those who 
responded "strongly agree" or "agree" on the School Climate Survey for students, parents, and staff were used. These two percentages were added together to obtain one percentage to represent how many students, parents, or staff agree that the school is positive and helps the students learn. For the students' School Climate Survey, the variable being tested (listed with its corresponding number from the survey) was as follows:

26. The overall climate or feeling at my school is positive and helps me learn. (School Climate Surveys, 2011, p. 11).

For the parents' School Climate Survey, the variable being tested (listed with its corresponding number from the survey) was as follows:

34. The overall climate or atmosphere at my child's school is positive and helps my child learn. (School Climate Surveys, 2011, p. 10).

For the school staffs' School Climate Survey, the variable being tested (listed with its corresponding number from the survey) was as follows:

34. The overall climate or atmosphere at my school is positive and helps students learn. (School Climate Surveys, 2011, p. 12).

For this study, from this point forth the item is referred to as the positive school climate question.

\section{Research Design}

This study was an ex post facto research because there was "no direct control of independent variables because their manifestations have already occurred or because they are inherently not manipulable" (Kerlinger, 1973, p. 379). It allowed for the discovery of a relationship among the variables. The independent variables in this study are racial and 
ethnic concentrations (Blacks, Hispanics, and Whites), ESOL student population, socioeconomic status, and the results of the positive school climate question of the public middle schools in Miami-Dade County. These are all pre-existing conditions and cannot be manipulated. The dependent variable in this study is the scores of the middle school students on the FCAT 2.0 Mathematics Test for the 2010-2011 school year. These scores and results have already occurred and cannot be manipulated. Since the variables cannot be manipulated, then causal inferences cannot be made.

In this study, the dependent variable, middle school students' scores on the FCAT 2.0 Mathematics Test, was tested for differences on the independent variables, racial and ethnic concentration, the results of the positive school climate question, the ESOL student population, and the socio-economic status of the students for the 2010-2011 school year. The ex post facto research design "begins with a given effect and seeks the experimental factor that brought it about" (Mouly, 1970, p. 340).

\section{Instruments}

For this study, various instruments were used to obtain the necessary data that were analyzed. The instruments were the FCAT 2.0 and M-DCPS' School Climate Survey. The FCAT 2.0 was the instrument that measured the middle school students' academic achievement. This data were collected, graded, and made available by Florida Department of Education at the end of the 2010 - 2011 school year.

The FCAT 2.0 scores are categorized by levels one through five. In order to obtain a passing score, the students must score at least a level three or higher on the FCAT Mathematics Equivalent Scale Scores (Table 3) and on the FCAT Mathematics Equivalent Scores (Developmental Scale Scores; Table 4). For this school year, two sets 
of scores were used because they are transitioning from the Equivalent Scale Scores (Table 3) of the original FCAT to the Developmental Scale Scores of the FCAT 2.0 (Table 4; Florida Department of Education, 2011d). If the students score a level 1 or 2, they are considered as having failed the FCAT 2.0 Mathematics Test.

Table 3

FCAT 2.0 Mathematics Equivalent Scale Score for $6^{\text {th }}, 7^{\text {th }}$, and $8^{\text {th }}$ grades

\begin{tabular}{lccccc}
\hline Grade & Level 1 & Level 2 & Level 3 & Level 4 & Level 5 \\
\hline 6 & $100-282$ & $283-314$ & $315-353$ & $354-390$ & $391-500$ \\
7 & $100-274$ & $275-305$ & $306-343$ & $344-378$ & $379-500$ \\
8 & $100-279$ & $280-309$ & $310-346$ & $347-370$ & $371-500$ \\
\hline
\end{tabular}

Table 4

FCAT 2.0 Mathematics Equivalent Scores (Developmental Scale) for $6^{\text {th }}$, $7^{\text {th }}$, and $8^{\text {th }}$ grade

\begin{tabular}{lccccc}
\hline Grade & Level 1 & Level 2 & Level 3 & Level 4 & Level 5 \\
\hline 6 & $770-1553$ & $1554-1691$ & $1692-1859$ & $1860-2018$ & $2019-2492$ \\
7 & $958-1660$ & $1661-1785$ & $1786-1938$ & $1939-2079$ & $2080-2572$ \\
8 & $1025-1732$ & $1733-1850$ & $1851-1997$ & $1998-2091$ & $2092-2605$ \\
\hline
\end{tabular}

The Florida Department of Education grades its public middle schools by awarding "one point for each percent of students who score proficient or higher on the FCAT and who make annual learning gains" (Florida Department of Education, July 2011). The highest number of points a school may earn is 800 , which includes 400 points from the learning gains components. The performance components include "percent of full-year-enrolled students scoring at level 3 or higher on FCAT Reading” for 100 points maximum (Florida Department of Education, July 2011). The same applies for FCAT Mathematics, FCAT Science, and FCAT Writing, each 100 points maximum. The learning gains components include "percent of full-year-enrolled students who made 
learning gains in reading" and mathematics (100 points maximum for each) and the "percent of full-year-enrolled students in the lowest performing 25\% who made learning gains in reading" and mathematics (100 points maximum for each; Florida Department of Education, July 2011). The schools are awarded a grade based on the score earned. An " $\mathrm{A}$ " is considered at least 525 points, a " $\mathrm{B}$ " is between 495 and 524 points, a " $\mathrm{C}$ " is between 435 and 494 points, a " $\mathrm{D}$ " is between 395 and 434 points, and an "F" is less than 395 points" (Florida Department of Education, July 2011).

The School Climate Survey was the instrument that measured the perceptions of education from students, parents, and school staff. After responding "strongly agree", “agree", "undecided/unknown", "disagree”, or "strongly disagree” for each item, the responses to these surveys were collected by teachers and administrators and submitted to M-DCPS' Department of Research Services. The results were compiled and different reports were released including by school, by variable, and by entire school district among many.

\section{Procedures for Data Collection}

For this study, the guidelines of Florida International University's (FIU) Institutional Review Board (IRB) and Responsible Conduct of Research (RCR) were followed as expected by FIU and M-DCPS. The trainings of IRB and RCR were completed. Once the researcher's dissertation proposal was defended, the study was submitted to the IRB, with a Form A1 waiver since no individual human beings participated in the study. Upon FIU IRB's approval, data were collected.

Florida Department of Education (FLDOE) and M-DCPS have published several documents analyzing various aspects of the school district. These documents are 
available to the public. For this study, FLDOE's FCAT School Accountability Report (2010-2011 Edition), FLDOE's 2011 AYP Report (2010-2011 Edition), and MDCPS' School Climate Survey Individual Results (2010-2011 Edition) were used to collect the necessary data.

FLDOE's School Accountability Report (2010-2011 Edition) provided data on the percentage of the students passing the FCAT 2.0 Mathematics Test (achievement levels 3 through 5). FLDOE's 2011 AYP Report (2010-2011 Edition) provided data on the number of students tested by race/ethnicity, Title I students, and English Language Learners by individual middle school. This document further presented information on the individual middle schools such as their FCAT school grade, if they met AYP status, and if they had Title I status. MDCPS' School Climate Survey Individual Results (20102011 Edition) provided the results of the school climate survey given to randomly selected students and their parents, along with all of the staff at each individual middle school. The survey gathered the perceptions of education at the school for those stakeholders.

\section{Data Analysis}

In this study, five research hypotheses regarding the relationship between the FCAT 2.0 Mathematics scores and racial and ethnic concentration of public middle schools in Miami-Dade County when controlling socio-economic status, ESOL student population, and school climate for the 2010-2011 school year were tested. Since these research hypotheses are specifying the direction of the correlation, they are all one-tailed research hypotheses (directional). The following research hypotheses were tested: 
H1. There is a significant negative relationship between the FCAT 2.0 Mathematics scores and racial and ethnic concentration of public middle schools in Miami-Dade County when controlling socio-economic status, ESOL student population, and school climate for the 2010-2011 school year.

H2. There is a significant negative relationship between the FCAT 2.0

Mathematics scores and racial and ethnic concentration when controlling the ESOL student population of the school.

H3. There is a significant negative relationship between the FCAT 2.0 Mathematics scores and SES.

H4. There is a significant negative relationship between the FCAT 2.0 Mathematics scores and SES when controlling racial and ethnic concentrations.

H5. There is a significant negative relationship between the FCAT 2.0 Mathematics scores and school climate when controlling racial and ethnic concentrations.

The research questions and hypotheses were formulated based on the literature review. The independent variables of racial and ethnic concentrations, socio-economic status, ESOL student population, and school climate are present in several different studies and literature as having a relationship to academic achievement. These studies and literature include Coleman (1966); Berliner and Biddle (1995); Lubienski and Weitzel (2009); Levin (1998), Williams (1999); Freire (1970); Blazer (2007); Delpit (1995); Perry et al. (2003); Borman et al. (2004); Cortes, Jr. (2010); Perkins-Gough (2008); Sweeney (1988); Hoy and Sabo (1998); and Heck (2000). This study's research 
questions and hypotheses were designed to search for a relationship between the FCAT 2.0 Mathematics scores, racial and ethnic concentrations, socio-economic status, ESOL student population, and school climate in Miami-Dade County, Florida.

For the primary research question and first hypothesis, since racial and ethnic concentrations have a relation to socio-economic status, ESOL student population, and school climate, these variables were controlled in order to analyze the unique variance between racial and ethnic concentrations and the FCAT 2.0 Mathematics scores. Socioeconomic status, ESOL student population, and school climate are interrelated to racial and ethnic concentrations, so the ability to analyze them individually was sought. (Coleman, 1966; Blazer, 2007; Borman et al., 2004)

For the first secondary research question and second hypothesis, since racial and ethnic concentrations can have a relation to ESOL student population, ESOL student population was controlled in order to analyze the unique variance between racial and ethnic concentrations and the FCAT 2.0 Mathematics scores. ESOL student population was interrelated to racial and ethnic concentrations, so the ability to analyze them individually was sought. (Coleman, 1966; Blazer, 2007; Borman et al., 2004)

For the second secondary research question and third hypothesis, a relationship between FCAT 2.0 Mathematics scores and socio-economic status is sought. Socioeconomic status was interrelated to academic achievement, so the ability to analyze it was sought. (Levin, 1998; Williams, 1999; Freire, 1970; Delpit, 1995; Cortes, Jr. 2010)

For the third secondary question and fourth hypothesis, since socio-economic status and racial and ethnic concentrations have a relation, racial and ethnic concentrations were controlled in order to analyze the unique variance between socio- 
economic status and the FCAT 2.0 Mathematics scores. Socio-economic status was interrelated to racial and ethnic concentrations, so the ability to analyze them individually was sought. (Levin, 1998; Williams, 1999; Freire, 1970; Delpit, 1995; Cortes, Jr. 2010)

For the fourth secondary question and fifth hypothesis, racial and ethnic concentrations were controlled in order to analyze the relationship between school climate and the FCAT 2.0 Mathematics scores. Racial and ethnic concentrations were interrelated to school climate so the ability to analyze them individually was sought. (Perkins-Gough, 2008; Sweeney, 1988; Hoy \& Sabo, 1998; Heck, 2000)

Multiple Linear Regression (MLR), also known as General Linear Model (GLM), was used to test the hypotheses. It brought forth if there was a significant relationship between middle school students' mathematics scores on the FCAT 2.0 and racial and ethnic concentration when controlling the socio-economic status, the ESOL student population, and the school climate. "Multiple Linear Regression is a method used to model the linear relationship between a dependent variable and one or more independent variables" (Meko, 2011, p. 1).

Moreover, Multiple Linear Regression provided flexibility and benefits for the purposes of this study. Multiple Linear Regression can be used to test the majority of research hypotheses. Additionally, Multiple Linear Regression "generates an $R^{2}$ coefficient that allows the research to account for a significant amount of variance on the criterion variable" (Lindemer, 2006, p. 96).

Furthermore, for the purpose of this study, an alpha level, $P_{\text {crit }}$, of 0.01 was used. Using an alpha level of 0.01 allows the study to be replicated $72 \%$ of the time (Newman, McNeil, \& Fraas, 2003). Studies using a 0.05 alpha level can only be replicated $50 \%$ of 
the time. The software that was used to perform the statistical analyses is IBM SPSS Statistics 20 .

The 2010-2011 school year FCAT 2.0 Mathematics results, the dependent variable, were presented as percentages in FLDOE's School Accountability Report (20102011 Edition). These percentages represent the percentages of the students passing the FCAT 2.0 by obtaining achievement levels 3,4 , and 5 . The racial and ethnic concentration data, an independent variable, was presented in FLDOE's 2011 AYP Report (2010-2011 Edition) as the percentages of Black, Hispanic, and White students that test at each school. The socio-economic status, an independent variable, was represented by the percentage of Title I students, meaning the percentage of students receiving free or reduced lunch as presented by FLDOE's 2011 AYP Report (2010-2011 Edition). The ESOL student population data, an independent variable, was presented as the percentage of ESOL student population tested at each school in FLDOE's 2011 AYP Report (2010-2011 Edition). Lastly, MDCPS' School Climate Survey Individual Results (2010-2011 Edition), an independent variable, presented the data on perceptions of education of students, parents, and school staff. A percentage represents the total amount from the answer choices "strongly agree" and "agree" from the item used from the survey. The item used is referred to as the positive school climate question.

Chapter 3 presented the setting and subjects for the study, the research design, statistical instruments used, and the procedures for data collection and conducting data analysis. Next, Chapter 4 presents the relationship between the scores of the FCAT 2.0 Mathematics Test and the racial and ethnic concentrations, the ESOL student population, socio-economic status, and the results of the positive school climate question. Last, 
Chapter 5 summarizes the findings of the study and discusses the implications of the study for educational policy, theory, and further research. 


\section{CHAPTER 4}

\section{FINDINGS}

The primary purpose of this chapter is to investigate the relationship between the FCAT 2.0 Mathematics scores of public middle school students in Miami-Dade County, Florida and the schools' racial and ethnic concentrations (Whites, Blacks, and Hispanics), ESOL student population, socio-economic status (SES), and school climate for the 2010 - 2011 school year. The chapter includes an analysis of the relationships between the scores of the FCAT 2.0 Mathematics Test and the racial and ethnic concentrations, the ESOL student population, socio-economic status, and the results of the positive school climate question from the School Climate Survey.

The major findings of this study on Miami-Dade County Public Schools were analyzed in light of current research to help explain if the FCAT 2.0 Mathematics scores of public middle school students have a relationship with racial and ethnic concentrations (Whites, Blacks, and Hispanics), ESOL student population, socio-economic status, and the results of the positive school climate question. Further analysis of the data is found in Appendix II (Collinearity Statistics, Descriptive Statistics, and Model Summary tables). Caution must be used when interpreting the results of this study because measuring educational performance relies on complex and complicated variables such as racial and ethnic concentration, socio-economic status, and perceptions of education (Moore, 2002). These variables interact with each other in ways that can challenge expectations and predictions. Hence, multicollinearity was present in various occasions when testing the hypotheses. 
Multicollinearity occurs when two or more independent variables are highly correlated with each other (Hinton, Brownlow, McMurray, \& Cozens, 2004). The presence of multicollinearity makes it difficult to analyze the individual contribution of each independent variable in predicting the dependent variable. If multicollinearity exists, in the Coefficient Table, under the column of Collinearity Statistics, the Tolerance results would be less than 0.10 and the VIF results would be greater than ten. In order to analyze the individual contribution of each independent variable on the dependent variable, one or more of the highly correlated variables were removed each time multicollinearity was present.

\section{Relationship between FCAT 2.0 Mathematics Scores and Racial and Ethnic}

\section{Concentration when controlling Socio-Economic Status, ESOL Student Population and School Climate}

\section{Blacks, SES, ESOL and School Climate}

The study was driven by a primary research question which tested the relationship between the FCAT 2.0 Mathematics scores and racial and ethnic concentration (Blacks) of public middle schools in Miami-Dade County when controlling socio-economic status, ESOL student population, and school climate for the $2010-2011$ school year. For this particular test, there was a high correlation between the White student population, the Black student population, and the Hispanic student population; thus, the White student population and the Hispanic student population were left out in order to eliminate multicollinearity (Appendix II, Table 53). On the other hand, the independent variables of the White student population and the Hispanic student population were only kept in for 
the Pearson $r$ and Sig. Table (Table 5) so that the correlation of those variables would be known.

Correlations of the independent variables with the dependent variable were also calculated. Pearson correlation, $r$, measures how much the scores of the two variables vary together, and then contrasts it with how much they vary individually (Hinton et al., 2004). It describes the linear relationship between two variables. The $r$ represents a value between negative one and positive one. A strong correlation has a $r$ that measures between 0.7 and 1 , while a moderate correlation has a $r$ that measures between 0.3 and 0.7, and a weak correlation has a $r$ that measures between 0 and 0.3 (DiMaria, 2000). The closer the value is to zero, the weaker the correlation. A weak correlation represents scattered points and a lot of error while a strong correlation represents the majority of points lying on a regression line and a small amount of error. Additionally, a positive correlation is when both values are increasing while a negative correlation is when one value is increasing and the other is decreasing. (Hinton et al.)

As shown in Table 5, the correlations have different strengths. The Black student population has a -0.597 correlation with the percentage of the students passing the FCAT 2.0 Mathematics Test. It is a negative correlation meaning that as the Black student population increased, the percentage of the students passing the FCAT 2.0 Mathematics Test decreased. It is a moderate correlation because the $r$ is between -0.3 and -0.7 . The Hispanic student population has a 0.429 correlation with the percentage of the students passing the FCAT 2.0 Mathematics Test. It is a positive correlation meaning that as the Hispanic student population increased, the percentage of the students passing the FCAT 2.0 Mathematics Test increased. It is a moderate correlation because the $r$ is between 0.3 
and 0.7 . The White student population has a 0.668 correlation with the students passing the FCAT 2.0 Mathematics Test. It is a positive correlation meaning that as the White student population increased, the percentage of the students passing the FCAT 2.0 Mathematics Test increased. It is a moderate correlation because the $r$ is between 0.3 and 0.7. The ESOL student population has a -0.134 correlation with the percentage of the students passing the FCAT 2.0 Mathematics Test. It is a weak correlation since the $r$ is is between 0 and -0.3 .It is a negative correlation meaning that as the ESOL student population increased, the percentage of the students passing the FCAT 2.0 Mathematics Test decreased. The Economically Disadvantaged (SES) student population has a -0.830 correlation with the percentage of the students passing the FCAT 2.0 Mathematics Test. It is a strong correlation since $r$ is between -0.7 and -1 but, it is also a negative correlation meaning that as the Economically Disadvantaged (SES) increased, the percentage of the students passing the FCAT 2.0 Mathematics Test decreased. The parents agreeing that the school climate is positive and helps students learn has a 0.595 correlation with the percentage of the students passing the FCAT 2.0 Mathematics Test. It is a positive correlation meaning that as more parents agree that the school climate is positive and helps students learn, the higher the percentage of the students passing the FCAT 2.0 Mathematics Test. It is a moderate correlation because the $r$ is between 0.3 and 0.7 . The students agreeing that the school climate is positive and helps them learn has a 0.741 correlation with the percentage of the students passing the FCAT 2.0 Mathematics Test. It is a strong correlation since the $r$ is between 0.7 and 1 but, it is also a positive correlation meaning that as more students agree that the school climate is positive and helps them learn, the higher percentage of the students passing the FCAT 2.0 
Mathematics Test. The staff agreeing that the school climate is positive and helps students learn has a 0.605 correlation with the percentage of the students passing the FCAT 2.0 Mathematics Test. It is a moderate correlation since the $r$ is between 0.3 and 0.7 but it is also a positive correlation meaning that the more staff agree that the school climate is positive and helps students learn increased, the students higher the percentage of the students passing the FCAT 2.0 Mathematics Test. 
Table 5

Pearson r and Sig. (1-tailed) - Relationship of FCAT 2.0 Mathematics Scores and Racial and Ethnic Concentration (Blacks, Whites, Hispanics) when controlling Economically Disadvantaged (SES), ESOL Student Population, and School Climate

\begin{tabular}{|c|c|c|c|c|c|c|c|c|c|c|}
\hline \multicolumn{2}{|c|}{ Total $\%{ }^{\mathrm{a}}$} & $\begin{array}{c}\text { Passing } \\
\text { FCAT } \\
\text { Math }\end{array}$ & Blacks & Hispanics & Whites & ESOL & $\begin{array}{c}\text { Economically } \\
\text { Disadvantaged } \\
(\mathrm{SES})\end{array}$ & $\begin{array}{l}\text { School } \\
\text { Climate } \\
\text { (Parent) }\end{array}$ & $\begin{array}{c}\text { School } \\
\text { Climate } \\
\text { (Student) }\end{array}$ & $\begin{array}{c}\text { School } \\
\text { Climate } \\
\text { (Staff) }\end{array}$ \\
\hline \multirow{9}{*}{ 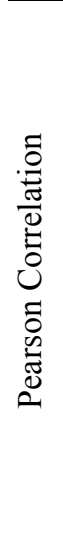 } & Passing FCAT Math & 1.000 & -.597 & .429 & .668 & -.134 & -.830 & .595 & .741 & .605 \\
\hline & Blacks & -.597 & 1.000 & -.959 & -.351 & -.328 & .407 & -.546 & -.511 & -.478 \\
\hline & Hispanics & .429 & -.959 & 1.000 & .073 & .472 & -.161 & .464 & .410 & .417 \\
\hline & Whites & .668 & -.351 & .073 & 1.000 & -.394 & -.891 & .376 & .417 & .289 \\
\hline & ESOL & -.134 & -.328 & .472 & -.394 & 1.000 & .435 & .085 & .062 & -.027 \\
\hline & Economically Disadvantaged (SES) & -.830 & .407 & -.161 & -.891 & .435 & 1.000 & -.429 & -.529 & -.429 \\
\hline & School Climate (Parent) & .595 & -.546 & .464 & .376 & .085 & -.429 & 1.000 & .624 & .474 \\
\hline & School Climate (Student) & .741 & -.511 & .410 & .417 & .062 & -.529 & .624 & 1.000 & .554 \\
\hline & School Climate (Staff) & .605 & -.478 & .417 & .289 & -.027 & -.429 & .474 & .554 & 1.000 \\
\hline \multirow{9}{*}{ 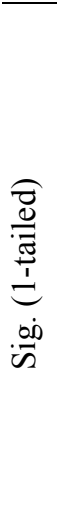 } & Passing FCAT Math & . & .000 & .000 & .000 & .156 & .000 & .000 & .000 & .000 \\
\hline & Blacks & .000 & . & .000 & .003 & .006 & .001 & .000 & .000 & .000 \\
\hline & Hispanics & .000 & .000 & . & .290 & .000 & .111 & .000 & .001 & .001 \\
\hline & Whites & .000 & .003 & .290 & . & .001 & .000 & .002 & .001 & .013 \\
\hline & ESOL & .156 & .006 & .000 & .001 & . & .000 & .263 & .324 & .419 \\
\hline & Economically Disadvantaged (SES) & .000 & .001 & .111 & .000 & .000 & . & .000 & .000 & .000 \\
\hline & School Climate (Parent) & .000 & .000 & .000 & .002 & .263 & .000 & . & .000 & .000 \\
\hline & School Climate (Student) & .000 & .000 & .001 & .001 & .324 & .000 & .000 & . & .000 \\
\hline & Schonal Climate (Staff) & $n n n$ & $n \cap n$ & $n n$ & $n$ & n & $n \cap n$ & $n \cap n$ & $n \cap n$ & \\
\hline
\end{tabular}


For the primary research question, the independent variables with the strongest correlations to the dependent variable were the Economically Disadvantaged (SES) students and the results of the positive school climate question on the student survey. The independent variable with the weakest correlation to the dependent variable was the ESOL student population. The independent variables with moderate correlations were the Black student population, the Hispanic student population, the White student population, the results of the positive school climate question on the parent survey, and the results of the positive school climate question on the staff survey. The independent variables with a negative relationship with the dependent variable were the Black student population, the ESOL student population and the Economically Disadvantaged (SES) student population, meaning that as the value of these variables increased, a lower percentage of the students pass the FCAT 2.0 Mathematics Test. The independent variables with a positive relationship with the dependent variable were the Hispanic student population, the White student population, the results of the positive school climate question on the parent survey, the results of the positive school climate question on the student survey, and the results of the positive school climate question on the staff survey, meaning that as the value of these variables increased, a higher percentage of students pass the FCAT 2.0 Mathematics Test.

Table 5 shows the results of the research hypothesis (H1). The $P_{\text {crit }}$ established for this study is 0.01 . The $P_{\text {calc }}$ for the Black student population is $p<0.001$, making it statistically significant since it is less than 0.01 and not rejecting the research hypothesis (H1), meaning a significant negative relationship exists between the FCAT 2.0 mathematics scores and the racial and ethnic concentrations of public middle schools in 
Miami-Dade County when controlling socio-economic status, ESOL student population, and the school climate for the $2010-2011$ school year. The $P_{\text {calc }}$ for the Hispanic student population is $p<0.001$, making it statistically significant since it is less than 0.01 and not rejecting the research hypothesis (H1), meaning a significant negative relationship exists between the FCAT 2.0 mathematics scores and the racial and ethnic concentrations of public middle schools in Miami-Dade County when controlling socioeconomic status, ESOL student population, and the school climate for the $2010-2011$ school year. The $P_{\text {calc }}$ for the White student population is $p<0.001$, making it statistically significant since it is less than 0.01 and not rejecting the research hypothesis (H1), meaning a significant negative relationship exists between the FCAT 2.0 mathematics scores and the racial and ethnic concentrations of public middle schools in Miami-Dade County when controlling socio-economic status, ESOL student population, and the school climate for the $2010-2011$ school year. The $P_{\text {calc }}$ for the ESOL student population is 0.156 , making it not statistically significant since 0.156 is not less than 0.01 so the research hypothesis (H1) is rejected, meaning no significant negative relationship exists between the FCAT 2.0 mathematics scores and the racial and ethnic concentrations of public middle schools in Miami-Dade County when controlling socio-economic status, ESOL student population, and the school climate for the $2010-2011$ school year. The $P_{\text {calc }}$ for the Economically Disadvantaged (SES) student population is $p<0.001$, making it statistically significant since it is less than 0.01 and not rejecting the research hypothesis (H1), meaning a significant negative relationship exists between the FCAT 2.0 mathematics scores and the racial and ethnic concentrations of public middle schools in Miami-Dade County when controlling socio-economic status, ESOL student 
population, and the school climate for the $2010-2011$ school year. The $P_{\text {calc }}$ for parents agreeing that the school climate is positive and helps students learn is $p<0.001$, making it statistically significant since it is less than 0.01 and not rejecting the research hypothesis (H1), meaning a significant negative relationship exists between the FCAT 2.0 mathematics scores and the racial and ethnic concentrations of public middle schools in Miami-Dade County when controlling socio-economic status, ESOL student population, and the school climate for the $2010-2011$ school year. The $P_{\text {calc }}$ for students agreeing that the school climate is positive and helps them learn is $p<0.001$, making it statistically significant since it is less than 0.01 and not rejecting the research hypothesis (H1), meaning a significant negative relationship exists between the FCAT 2.0 mathematics scores and the racial and ethnic concentrations of public middle schools in Miami-Dade County when controlling socio-economic status, ESOL student population, and the school climate for the $2010-2011$ school year. The $P_{\text {calc }}$ for staff agreeing that the school climate is positive and helps students learn is $p<0.001$, making it statistically significant since it is less than 0.01 and not rejecting the research hypothesis $(\mathrm{H} 1)$, meaning a significant negative relationship exists between the FCAT 2.0 mathematics scores and the racial and ethnic concentrations of public middle schools in Miami-Dade County when controlling socio-economic status, ESOL student population, and the school climate for the $2010-2011$ school year.

For each research hypothesis not rejected, a Type I Error has been made if any research hypothesis ends up being incorrect. A one percent chance exists of that happening. Moreover, for the primary research question, there was only one independent 
variable that was not statistically significant, the percentage of the ESOL student population.

As shown in Table 6, there are two models because Model 1 is controlling the ESOL student population, socio-economic status, and school climate while Model 2 incorporates all the independent variables. Table 6 shows the Sum of Squares (SS) Total for both models is 14379.222 , which represents all the variance in the data. It measures how dispersed the data points are, in other words all the variance in the data. For Model 1, the Sum of Squares (SS) Regression is 12236.586 , which is the unique variance that can be explained. For Model 2, the Sum of Squares (SS) Regression is 12456.304. SS Regression is also known as SS Between, SS Model, and SS Explained. For Model 1, the Sum of Squares (SS) Residual is 2142.635, which is the variance that cannot be explained. For Model 2, the Sum of Squares (SS) Residual is 2076.892. SS Residual is also known as SS Unexplained, SS Error, SS Within, Group Variance, and Error Variance. For Model 1, Degrees of Freedom, $d f$, for Regression is five and for Residual is 51 , for a total of $56 d f$. For Model 2, Degrees of Freedom, $d f$, for Regression is six and for Residual is 50 , for a total of $56 d f$. The Mean Square is the variance in the ANOVA. It calculates the variance estimates by dividing the Sum of Squares by respective Degrees of Freedom. For Model 1, for Regression, it is 2447.317 and for Residual, it is 42.012. For Model 2, for Regression, it is 2050.388 and for Residual, it is 41.538. For Model 1, the $F$ value is 58.252 which is the test statistic $\left(T S_{\text {calc or }} F_{\text {calc }}\right)$, testing the significance of $R, R^{2}$, and of the entire regression model. For Model 2, the $F$ value is 49.362. Calculated by dividing the Regression Mean Square by the Residual Mean Square, the $F$ value provides the ratio between the two variances. For the Significant column, $P_{\text {calc }}$, Model 1 
is statistically significant because $p<0.001$, hence it is less than 0.01 , as well as in Model 2 , thus it does not reject the research hypothesis (H1), meaning a significant negative relationship exists between the FCAT 2.0 Mathematics scores and racial and ethnic concentrations when controlling socio-economic status, ESOL student population, and school climate of public middle schools in Miami-Dade County for the 2010 - 2011 school year (Hinton et al, 2004). Hence, it indicates the presence of a negative relationship in Model 1 and Model 2 between the independent variables and dependent variable. The independent variables may have overlapped in creating this relationship with the dependent variables.

Table 6

ANOVA ${ }^{a}$ - Relationship of FCAT 2.0 Mathematics Scores and Racial and Ethnic Concentration (Blacks) when controlling Economically Disadvantaged (SES), ESOL Student Population, and School Climate

\begin{tabular}{llccccc}
\hline Model & Sum of Squares & df & Mean Square & F & Sig. \\
\hline \multirow{2}{*}{1} & Regression & 12236.586 & 5 & 2447.317 & 58.252 & $.000^{\mathrm{b}}$ \\
& Residual & 2142.635 & 51 & 42.012 & & \\
& Total & 14379.222 & 56 & & & \\
\hline \multirow{2}{*}{2} & Regression & 12302.330 & 6 & 2050.388 & 49.362 & $.000^{\mathrm{c}}$ \\
& Residual & 2076.892 & 50 & 41.538 & & \\
& Total & 14379.222 & 56 & & & \\
\hline
\end{tabular}

Note a. Dependent Variable: \% Passing FCAT Math

b. Predictors: (Constant), \% of School Climate (Parent), \% of ESOL student population, $\%$ School Climate (Staff), \% School Climate (Student), \% of Economically

Disadvantaged (SES)

c. Predictors: (Constant), \% of School Climate (Parent), \% of ESOL student population, $\%$ School Climate (Staff), \% of Black student population, \% School Climate (Student), \% of Economically Disadvantaged (SES)

Table 7 shows how much each variable contributes to the research question for this particular test. The Standardized Coefficients column presents the contribution that the independent variable makes to the model. The Beta is the average amount that the 
dependent variable increases when the independent variable increases by one standard deviation and all other independent variables are held constant. According to the Beta results, the strongest contribution on the passing of the FCAT 2.0 Mathematics Test comes from the students that are Economically Disadvantaged (SES), -0.657 in Model 1 and from the students that are Economically Disadvantaged (SES), -0.610 in Model 2.

For the Sig. column in Table 7, if the value is $<0.01$, the variable makes a significant contribution to the prediction of the dependent variable. If the value is $>0.01$, the variable does not make a significant contribution to the prediction of the dependent variable. For Model 1, the independent variables that make a significant contribution to the dependent variable were the Economically Disadvantaged (SES) student population $(p<0.001)$ and the results of the positive school climate question on the student survey (0.002). For Model 2, the independent variables that make a significant contribution to the dependent variable were the Economically Disadvantaged (SES) student population $(p<0.001)$ and the results of the positive school climate question on the student survey (0.002). For Model 1, the independent variables that do not make a significant contribution to the dependent variable were the ESOL student population (0.047), the results of the positive school climate question on the parent survey (0.347), and the results of the positive school climate question on the staff survey (0.029). For Model 2, the independent variables not making a significant contribution to the dependent variable were the Black student population (0.214), the ESOL student population (0.299), the results of the positive school climate question on the parent survey (0.535), and the results of the positive school climate question on the staff survey ( 0.063 ; Hinton et al., 2004). 
Table 7

Coefficients - Relationship of FCAT 2.0 Mathematics Scores and Racial and Ethnic Concentration (Blacks) when controlling Economically Disadvantaged (SES), ESOL Student Population, and School Climate

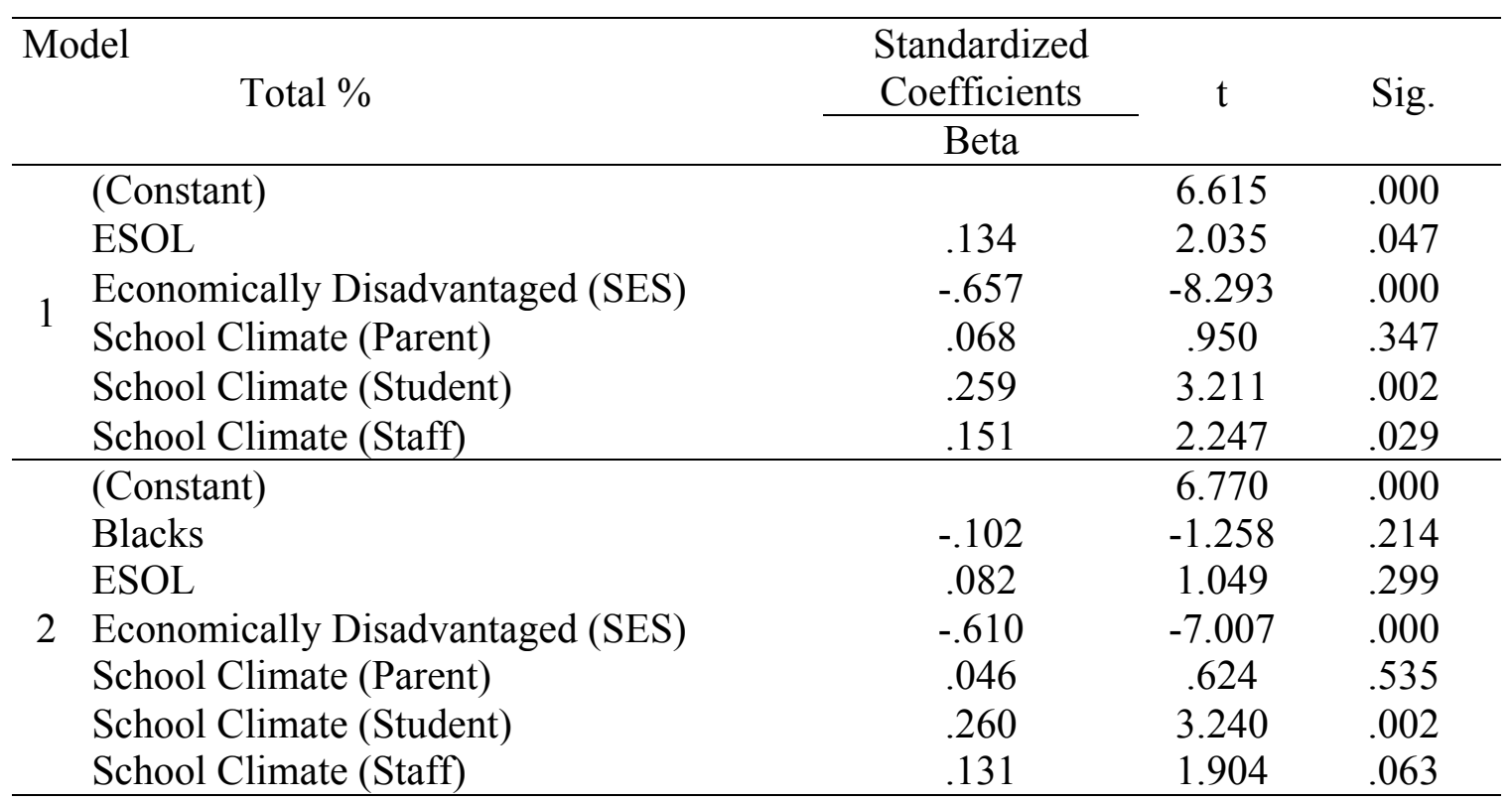

Moreover, Table 8's Part column under Correlations, when the values are squared, it indicates the contribution each independent variable has to the total $R^{2}$ (Pallant, 2010). These values also represent the total variance each independent variable explains in the dependent variable and how much the $R^{2}$ drops when it is not included in the model. In Model 1, the ESOL student population contributes $1.21 \%$ to the dependent variable, meaning it also explains $1.21 \%$ of the unique variance in the dependent variable and will cause the $R^{2}$ to drop $1.21 \%$ if it is not included in the model. The Economically Disadvantaged (SES) student population contributes $20.1 \%$ to the dependent variable, meaning it also explains $20.1 \%$ of the unique variance in the dependent variable and will cause the $R^{2}$ to drop $20.1 \%$ if it is not included in the model. The parents agreeing that the school climate is positive and help students learn contributes $0.26 \%$ to the dependent 
variable, meaning it also explains $0.26 \%$ of the unique variance in the dependent variable and will cause the $R^{2}$ to drop $0.26 \%$ if it is not included in the model. The students agreeing that the school climate is positive and helps them learn contributes $3.03 \%$ to the dependent variable, meaning it also explains $3.03 \%$ of the unique variance in the dependent variable and will cause the $R^{2}$ to drop $3.03 \%$ if it is not included in the model. The staff agreeing that the school climate is positive and helps students learn contributes $1.46 \%$ to the dependent variable, meaning it also explains $1.46 \%$ of the unique variance in the dependent variable and will cause the $R^{2}$ to drop $1.46 \%$ if it is not included in the model. On the other hand, for Model 2, the Black student population contributes $0.46 \%$ to the dependent variable, meaning it also explains $0.46 \%$ of variance in the dependent variable and will cause the $R^{2}$ to drop $0.46 \%$ if it is not included in the model. The ESOL student population contributes $0.31 \%$ to the dependent variable, meaning it also explains $0.31 \%$ of variance in the dependent variable and will cause the $R^{2}$ to drop $0.31 \%$ if it is not included in the model. The Economically Disadvantaged (SES) student population contributes $14.2 \%$ to the dependent variable, meaning it also explains $14.2 \%$ of variance in the dependent variable and will cause the $R^{2}$ to drop $14.2 \%$ if it is not included in the model. The parents agreeing that the school climate is positive and help students learn contributes $0.12 \%$ to the dependent variable, meaning it also explains $0.12 \%$ of variance in the dependent variable and will cause the $R^{2}$ to drop $0.12 \%$ if it is not included in the model. The students agreeing that the school climate is positive and helps them learn contributes $3.03 \%$ to the dependent variable, meaning it also explains $3.03 \%$ of variance in the dependent variable and will cause the $R^{2}$ to drop $3.03 \%$ if it is not included in the model. The staff agreeing that the school climate is positive and helps students learn 
contributes $1.04 \%$ to the dependent variable, meaning it also explains $1.04 \%$ of variance in the dependent variable and will cause the $R^{2}$ to drop $1.04 \%$ if it is not included in the model. The strongest contribution to the dependent variable of the passing of the FCAT 2.0 Mathematics Test comes from the Economically Disadvantaged (SES) students (20.1\%) in Model 1, followed by the Economically Disadvantaged (SES) students (14.2\%) in Model 2. (See Appendix II for the Collinearity Statistics explanation) Table 8

Coefficients Continued - Relationship of FCAT 2.0 Mathematics Scores and Racial and Ethnic Concentration (Blacks) when controlling Economically Disadvantaged (SES), ESOL Student Population, and School Climate

\begin{tabular}{llcc}
\hline Model & \multicolumn{2}{c}{ Correlations } & \multicolumn{2}{c}{ Collinearity Statistics } \\
\cline { 2 - 4 } Total \% & Part & Tolerance & VIF \\
\hline ESonstant) & .110 & & \\
ESOL & -.448 & .671 & 1.490 \\
Economically & .051 & .466 & 2.147 \\
Disadvantaged (SES) & .174 & .563 & 1.777 \\
School Climate (Parent) & .121 & .450 & 2.224 \\
School Climate (Student) & & .647 & 1.546 \\
School Climate (Staff) & -.068 & .436 & 2.291 \\
\hline (Constant) & .056 & .477 & 2.096 \\
Blacks & -.377 & .381 & 2.624 \\
ESOL & .034 & .530 & 1.886 \\
Economically & .174 & .450 & 2.224 \\
Disadvantaged (SES) & .102 & .612 & 1.635 \\
School Climate (Parent) & & & \\
School Climate (Student) & & & \\
School Climate (Staff) & & &
\end{tabular}

\section{Blacks, Whites, ESOL and School Climate}

The primary research question was further tested using a combination of different variables. Due to the presence of multicollinearity, the independent variables of the Hispanic student population and the Economically Disadvantaged (SES) student population were removed in order to be able to analyze the individual contribution of 
each independent variable to the dependent variable (Appendix II, Table 56). On the other hand, the independent variable of the Hispanic student population was only kept in for the Pearson $r$ and Sig. Table (Table 9) so that the correlation of those variables would be known.

As shown in Table 9, the correlations have different strengths. The Black student population has a -0.597 correlation with the percentage of the students passing the FCAT 2.0 Mathematics Test. It is a negative correlation meaning that as the Black student population increased, the percentage of the students passing the FCAT 2.0 Mathematics Test decreased. It is a moderate correlation because the $r$ is between -0.3 and -0.7 . The Hispanic student population has a 0.429 correlation with the percentage of the students passing the FCAT 2.0 Mathematics Test. It is a positive correlation meaning that as the Hispanic student population increased, the percentage of the students passing the FCAT 2.0 Mathematics Test increased. It is a moderate correlation because the $r$ is between 0.3 and 0.7 . The White student population has a 0.668 correlation with the percentage of the students passing the FCAT 2.0 Mathematics Test. It is a positive correlation meaning that as the White student population increased, the percentage of the students passing the FCAT 2.0 Mathematics Test increased. It is a moderate correlation because the $r$ is between 0.3 and 0.7 . The ESOL student population has a -0.134 correlation with the percentage of the students passing the FCAT 2.0 Mathematics Test. It is a weak correlation since the $r$ is between 0 and -0.3 but, it is also a negative correlation meaning that as the ESOL student population increased, the percentage of the students passing the FCAT 2.0 Mathematics Test decreased. The Economically Disadvantaged (SES) student population has a -0.830 correlation with the percentage of the students passing the FCAT 
2.0 Mathematics Test. It is a strong correlation since the $r$ is between -0.7 and -1 but, it is also a negative correlation meaning that as the Economically Disadvantaged (SES) increased, the percentage of the students passing the FCAT 2.0 Mathematics Test decreased. The parents agreeing that the school climate is positive and helps students learn has a 0.595 correlation with the percentage of the students passing the FCAT 2.0 Mathematics Test. It is a positive correlation meaning that as the parents agreeing that the school climate is positive and helps students learn increased, the percentage of the students passing the FCAT 2.0 Mathematics Test also increased. It is a moderate correlation because the $r$ is between 0.3 and 0.7 . The students agreeing that the school climate is positive and helps them learn has a 0.741 correlation with the percentage of the students passing the FCAT 2.0 Mathematics Test. It is a strong correlation since the $r$ is between 0.7 and 1 but, it is also a positive correlation meaning that as the students agreeing that the school climate is positive and helps them learn increased, the percentage of the students passing the FCAT 2.0 Mathematics Test also increased. The staff agreeing that the school climate is positive and helps students learn has a 0.605 correlation with the percentage of the students passing the FCAT 2.0 Mathematics Test. It is a moderate correlation since the $r$ is between 0.3 and 0.7 but it is also a positive correlation meaning that as the staff agreeing that the school climate is positive and helps students learn increased, of the students passing the FCAT 2.0 Mathematics Test also increased. 
Table 9

Pearson r and Sig. (1-tailed) - Relationship of FCAT 2.0 Mathematics Scores and Racial and Ethnic Concentration (Blacks, Whites, Hispanics) when controlling Economically Disadvantaged (SES), ESOL Student Population, and School Climate

\begin{tabular}{|c|c|c|c|c|c|c|c|c|c|c|}
\hline \multicolumn{2}{|c|}{ Total $\%{ }^{\mathrm{a}}$} & $\begin{array}{l}\text { Passing } \\
\text { FCAT } \\
\text { Math }\end{array}$ & Blacks & Hispanics & Whites & ESOL & $\begin{array}{c}\text { Economically } \\
\text { Disadvantaged } \\
\text { (SES) }\end{array}$ & $\begin{array}{l}\text { School } \\
\text { Climate } \\
\text { (Parent) }\end{array}$ & $\begin{array}{l}\text { School } \\
\text { Climate } \\
\text { (Student) } \\
\end{array}$ & $\begin{array}{c}\text { School } \\
\text { Climate } \\
\text { (Staff) }\end{array}$ \\
\hline \multirow{8}{*}{ 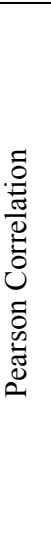 } & Passing FCAT Math & 1.000 & -.597 & .429 & .668 & -.134 & -.830 & .595 & .741 & .605 \\
\hline & Blacks & -.597 & 1.000 & -.959 & -.351 & -.328 & .407 & -.546 & -.511 & -.478 \\
\hline & Hispanics & .429 & -.959 & 1.000 & .073 & .472 & -.161 & .464 & .410 & .417 \\
\hline & Whites & .668 & -.351 & .073 & 1.000 & -.394 & -.891 & .376 & .417 & .289 \\
\hline & Economically Disadvantaged (SES) & -.830 & .407 & -.161 & -.891 & .435 & 1.000 & -.429 & -.529 & -.429 \\
\hline & School Climate (Parent) & .595 & -.546 & .464 & .376 & .085 & -.429 & 1.000 & .624 & .474 \\
\hline & School Climate (Student) & .741 & -.511 & .410 & .417 & .062 & -.529 & .624 & 1.000 & .554 \\
\hline & School Climate (Staff) & .605 & -.478 & .417 & .289 & -.027 & -.429 & .474 & .554 & 1.000 \\
\hline \multirow{8}{*}{ 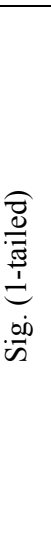 } & Passing FCAT Math & . & .000 & .000 & .000 & .156 & .000 & .000 & .000 & .000 \\
\hline & Hispanics & .000 & .000 & . & .290 & .000 & .111 & .000 & .001 & .001 \\
\hline & Whites & .000 & .003 & .290 & . & .001 & .000 & .002 & .001 & .013 \\
\hline & ESOL & .156 & .006 & .000 & .001 & . & .000 & .263 & .324 & .419 \\
\hline & Economically Disadvantaged (SES) & .000 & .001 & .111 & .000 & .000 & . & .000 & .000 & .000 \\
\hline & School Climate (Parent) & .000 & .000 & .000 & .002 & .263 & .000 & . & .000 & .000 \\
\hline & School Climate (Student) & .000 & .000 & .001 & .001 & .324 & .000 & .000 & . & .000 \\
\hline & School Climate (Staff) & .000 & .000 & .001 & .013 & .419 & .000 & .000 & .000 & . \\
\hline
\end{tabular}

Note. ${ }^{a} n=59$. 
For the primary research question, the independent variables with the strongest correlations to the dependent variable were the Economically Disadvantaged (SES) students and the results of the positive school climate question on the student survey. The independent variable with the weakest correlation to the dependent variable was the ESOL student population. The independent variables with moderate correlations were the Black student population, the Hispanic student population, the White student population, the results of the positive school climate question on the parent survey, and the results of the positive school climate question on the staff survey. The independent variables with a negative relationship with the dependent variable were the Black student population, the ESOL student population and the Economically Disadvantaged (SES) student population, meaning that as the values of these variables increased, a lower percentage of students passed the FCAT 2.0 Mathematics Test. The independent variables with a positive relationship with the dependent variable were the Hispanic student population, the White student population, the results of the positive school climate question on the parent survey, the results of the positive school climate question on the student survey, and the results of the positive school climate question on the staff survey, meaning that as they increased in size, a higher percentage of students passed the FCAT 2.0 Mathematics Test.

Table 9 shows the results of the research hypothesis (H1). The $P_{\text {crit }}$ established for this study is 0.01 . The $P_{\text {calc }}$ for the Black student population is $p<0.001$, making it statistically significant since it is less than 0.01 and not rejecting the research hypothesis (H1), meaning a significant negative relationship exists between the FCAT 2.0 Mathematics scores and the racial and ethnic concentrations of public middle schools in 
Miami-Dade County when controlling socio-economic status, ESOL student population, and the school climate for the $2010-2011$ school year. The $P_{\text {calc }}$ for the Hispanic student population is $p<0.001$, making it statistically significant since it is less than 0.01 and not rejecting the research hypothesis (H1), meaning a significant negative relationship exists between the FCAT 2.0 Mathematics scores and the racial and ethnic concentrations of public middle schools in Miami-Dade County when controlling socioeconomic status, ESOL student population, and the school climate for the 2010 - 2011 school year. The $P_{\text {calc }}$ for the White student population is $p<0.001$, making it statistically significant since it is less than 0.01 and not rejecting the research hypothesis (H1), meaning a significant negative relationship exists between the FCAT 2.0 Mathematics scores and the racial and ethnic concentrations of public middle schools in Miami-Dade County when controlling socio-economic status, ESOL student population, and the school climate for the 2010 - 2011 school year. The $P_{\text {calc }}$ for the ESOL student population is 0.156 , making it not statistically significant since 0.156 is not less than 0.01 so the research hypothesis (H1) is rejected, meaning no significant negative relationship exists between the FCAT 2.0 Mathematics scores and the racial and ethnic concentrations of public middle schools in Miami-Dade County when controlling socio-economic status, ESOL student population, and the school climate for the $2010-2011$ school year. The $P_{\text {calc }}$ for the Economically Disadvantaged (SES) student population is $p<0.001$, making it statistically significant since it is less than 0.01 and not rejecting the research hypothesis (H1), meaning a significant negative relationship exists between the FCAT 2.0 Mathematics scores and the racial and ethnic concentrations of public middle schools in Miami-Dade County when controlling socio-economic status, ESOL student 
population, and the school climate for the $2010-2011$ school year. The $P_{\text {calc }}$ for parents agreeing that the school climate is positive and helps students learn is $p<0.001$, making it statistically significant since it is less than 0.01 and not rejecting the research hypothesis (H1), meaning a significant negative relationship exists between the FCAT 2.0 Mathematics scores and the racial and ethnic concentrations of public middle schools in Miami-Dade County when controlling socio-economic status, ESOL student population, and the school climate for the $2010-2011$ school year. The $P_{\text {calc }}$ for students agreeing that the school climate is positive and helps them learn is $p<0.001$, making it statistically significant since it is less than 0.01 and not rejecting the research hypothesis (H1), meaning a significant negative relationship exists between the FCAT 2.0 Mathematics scores and the racial and ethnic concentrations of public middle schools in Miami-Dade County when controlling socio-economic status, ESOL student population, and the school climate for the $2010-2011$ school year. The $P_{\text {calc }}$ for staff agreeing that the school climate is positive and helps students learn is $p<0.001$, making it statistically significant since it is less than 0.01 and not rejecting the research hypothesis $(\mathrm{H} 1)$, meaning a significant negative relationship exists between the FCAT 2.0 Mathematics scores and the racial and ethnic concentrations of public middle schools in Miami-Dade County when controlling socio-economic status, ESOL student population, and the school climate for the $2010-2011$ school year.

For each research hypothesis not rejected, a Type I Error has been made if any research hypothesis ends up being incorrect. There is a one percent chance of that happening. Moreover, for the primary research question, there was only one independent 
variable that was not statistically significant, the percentage of the ESOL student population.

As shown in Table 10, there are two models because Model 1 is controlling the ESOL student population and school climate while Model 2 incorporates all the independent variables. Table 10 demonstrates the Sum of Squares (SS) Total for both models is 14379.222 , which represents all the variance in the data. For Model 1, the Sum of Squares (SS) Regression is 9346.894, which is the unique variance that can be explained. For Model 2, the Sum of Squares (SS) Regression is 11108.853. For Model 1, the Sum of Squares (SS) Residual is 5032.328, which is the variance that cannot be explained. For Model 2, the Sum of Squares (SS) Residual is 3270.369. For Model 1, Degrees of Freedom, $d f$, for Regression is four and for Residual is 52 , for a total of $56 d f$. For Model 2, Degrees of Freedom, $d f$, for Regression is six and for Residual is 50, for a total of $56 d f$. The Mean Square is the variance in the ANOVA. The Mean Square for Model 1's Regression is 2336.723 and for Residual, it is 96.776 . The Mean Square for Model 2's Regression is 1851.475 and for Residual, it is 65.407. For Model 1, the $F$ value is 24.146 which is the test statistic $\left(T S_{\text {calc or }} F_{\text {calc }}\right)$, testing the significance of $R, R^{2}$, and of the entire regression model. For Model 2, the $F$ value is 28.307. For the Significant column, $P_{\text {calc }}$, Model 1 is statistically significant because $p<0.001$, hence it is less than 0.01, as well as in Model 2, thus it does not reject the research hypothesis (H1), meaning a significant negative relationship exists between the FCAT 2.0 Mathematics scores and racial and ethnic concentrations when controlling socio-economic status, ESOL student population, and school climate of public middle schools in Miami-Dade County for the $2010-2011$ school year (Hinton et al., 2004). Hence, it indicates the 
presence of a negative relationship in Model 1 and Model 2 between the independent variables and dependent variable. The independent variables may have overlapped in creating this relationship with the dependent variables.

Table 10

ANOVA - Relationship of FCAT 2.0 Mathematics Scores and Racial and Ethnic Concentration (Blacks, Whites) when controlling ESOL Student Population and School Climate

\begin{tabular}{llccccc}
\hline Model & Sum of Squares & df & Mean Square & F & Sig. \\
\hline \multirow{2}{*}{1} & Regression & 9346.894 & 4 & 2336.723 & 24.146 & $.000^{\mathrm{b}}$ \\
& Residual & 5032.328 & 52 & 96.776 & & \\
& Total & 14379.222 & 56 & & & \\
\hline 2 & Regression & 11108.853 & 6 & 1851.475 & 28.307 & $.000^{\mathrm{c}}$ \\
& Residual & 3270.369 & 50 & 65.407 & & \\
& Total & 14379.222 & 56 & & & \\
\hline
\end{tabular}

Note a. Dependent Variable: \% Passing FCAT Math

b. Predictors: (Constant), \% of School Climate (Parent), \% of ESOL student population, $\%$ School Climate (Staff), \% School Climate (Student)

c. Predictors: (Constant), $\%$ of School Climate (Parent), $\%$ of ESOL student population, $\%$ School Climate (Staff), \% of Black student population, \% School Climate (Student), \% of White student population

Table 11 shows how much each variable contributes to the research question for this particular test. According to the Beta results, the strongest contribution on the passing of the FCAT 2.0 Mathematics Test comes from the positive school climate question of the student survey, -0.511 in Model 1 and also from the positive school climate question of the student survey, .374 in Model 2.

For the Sig. column in Table 11, for Model 1, the independent variable making a significant contribution to the dependent variable was the results of the positive school climate question on the student survey $(p<0.001)$. For Model 2 , the independent variables making a significant contribution to the dependent variable were the White 
student population (0.001) and the results of the positive school climate question on the student survey $(p<0.001)$. For Model 1 , the independent variable not making a significant contribution to the dependent variable were the ESOL student population (0.039), the results of the positive school climate question on the parent survey (0.097), and the results of the positive school climate question on the staff survey $(0.026)$. For Model 2, the independent variables not making a significant contribution to the dependent variable were the Black student population (0.039), the ESOL student population (0.296), the results of the positive school climate question on the staff survey (0.047), and the results of the positive school climate question on the parent survey (0.631; Hinton et al., 2004).

Table 11

Coefficients - Relationship of FCAT 2.0 Mathematics Scores and Racial and Ethnic Concentration (Blacks, Whites) when controlling ESOL Student Population and School Climate

\begin{tabular}{|c|c|c|c|c|}
\hline \multicolumn{2}{|c|}{ Model } & \multicolumn{3}{|l|}{ Standardized } \\
\hline \multicolumn{2}{|r|}{ Total $\%$} & Coefficients & $\mathrm{t}$ & Sig. \\
\hline \multirow{5}{*}{1} & (Constant) & & -.302 & .764 \\
\hline & ESOL & -.175 & -2.113 & .039 \\
\hline & School Climate (Parent) & .182 & 1.690 & .097 \\
\hline & School Climate (Student) & .511 & 4.504 & .000 \\
\hline & School Climate (Staff) & .232 & 2.294 & .026 \\
\hline \multirow{7}{*}{2} & (Constant) & & 1.915 & .061 \\
\hline & Blacks & -.212 & -2.125 & .039 \\
\hline & Whites & .333 & 3.597 & .001 \\
\hline & ESOL & -.094 & -1.056 & .296 \\
\hline & School Climate (Parent) & .045 & .484 & .631 \\
\hline & School Climate (Student) & .374 & 3.862 & .000 \\
\hline & School Climate (Staff) & .177 & 2.039 & .047 \\
\hline
\end{tabular}

Moreover, in Table 12's Part column under Correlations, in Model 1, after squaring the values, the ESOL student population contributes $2.99 \%$ to the dependent 
variable, meaning it also explains $2.99 \%$ of the unique variance in the dependent variable and will cause the $R^{2}$ to drop $2.99 \%$ if it is not included in the model. The parents agreeing that the school climate is positive and help students learn contributes $1.93 \%$ to the dependent variable, meaning it also explains $1.93 \%$ of the unique variance in the dependent variable and will cause the $R^{2}$ to drop $1.93 \%$ if it is not included in the model. The students agreeing that the school climate is positive and helps them learn contributes $13.69 \%$ to the dependent variable, meaning it also explains $13.69 \%$ of the unique variance in the dependent variable and will cause the $R^{2}$ to drop $13.69 \%$ if it is not included in the model. The staff agreeing that the school climate is positive and helps students learn contributes $3.53 \%$ to the dependent variable, meaning it also explains $3.53 \%$ of the unique variance in the dependent variable and will cause the $R^{2}$ to drop $3.53 \%$ if it is not included in the model. On the other hand, for Model 2, the Black student population contributes $2.04 \%$ to the dependent variable, meaning it also explains $2.04 \%$ of variance in the dependent variable and will cause the $R^{2}$ to drop $2.04 \%$ if it is not included in the model. The White student population contributes $5.90 \%$ to the dependent variable, meaning it also explains $5.90 \%$ of variance in the dependent variable and will cause the $R^{2}$ to drop $5.90 \%$ if it is not included in the model. The ESOL student population contributes $0.50 \%$ to the dependent variable, meaning it also explains $0.50 \%$ of variance in the dependent variable and will cause the $R^{2}$ to drop $0.50 \%$ if it is not included in the model. The parents agreeing that the school climate is positive and help students learn contributes $0.11 \%$ to the dependent variable, meaning it also explains $0.11 \%$ of variance in the dependent variable and will cause the $R^{2}$ to drop $0.11 \%$ if it is not included in the model. The students agreeing that the school climate is positive and 
helps them learn contributes $6.76 \%$ to the dependent variable, meaning it also explains $6.76 \%$ of variance in the dependent variable and will cause the $R^{2}$ to drop $6.76 \%$ if it is not included in the model. The staff agreeing that the school climate is positive and helps students learn contributes $1.88 \%$ to the dependent variable, meaning it also explains $1.88 \%$ of variance in the dependent variable and will cause the $\mathrm{R}^{2}$ to drop $1.88 \%$ if it is not included in the model. The strongest contribution to the dependent variable of the passing of the FCAT 2.0 Mathematics Test comes from the students agreeing that the school climate is positive and helps them learn $(13.69 \%)$, followed by the students agreeing that the school climate is positive and helps them learn (6.76\%) in Model 2. (See Appendix II for the Collinearity Statistics explanation)

Table 12

Coefficients Continued - Relationship of FCAT 2.0 Mathematics Scores and Racial and Ethnic Concentration (Blacks, Whites) when controlling ESOL Student Population and School Climate

\begin{tabular}{lccc}
\hline Model & \multicolumn{2}{c}{ Correlations } & \multicolumn{2}{c}{ Collinearity Statistics } \\
\cline { 2 - 4 } \multicolumn{1}{c}{ Total \% } & Part & Tolerance & VIF \\
\hline (Constant) & & & \\
ESOL & -.173 & .985 & 1.015 \\
$1 \quad$ School Climate (Parent) & .139 & .584 & 1.713 \\
School Climate (Student) & .370 & .524 & 1.909 \\
School Climate (Staff) & .188 & .661 & 1.514 \\
\hline (Constant) & & & \\
Blacks & -.068 & .436 & 2.291 \\
Whites & .243 & .532 & 1.880 \\
ESOL & -.071 & .569 & 1.757 \\
School Climate (Parent) & .033 & .527 & 1.898 \\
School Climate (Student) & .260 & .484 & 2.066 \\
School Climate (Staff) & .137 & .606 & 1.651 \\
\hline
\end{tabular}




\section{Whites, Hispanics, ESOL and School Climate}

The primary research question was further tested using a combination of different variables. Due to the presence of multicollinearity, the independent variables of the Black student population and the Economically Disadvantaged (SES) student population were removed in order to be able to analyze the individual contribution of each independent variable to the dependent variable (Appendix II, Table 59). On the other hand, the independent variables of the Black student population and the Economically Disadvantaged (SES) student population were only kept for the Pearson $r$ and Sig. Table (Table 13) so that the correlation of those variables would be known.

As shown in Table 13, the correlations have different strengths. The Black student population has a -0.597 correlation with the percentage of the students passing the FCAT 2.0 Mathematics Test. It is a negative correlation meaning that as the Black student population increased, the percentage of the students passing the FCAT 2.0 Mathematics Test decreased. It is a moderate correlation because the $r$ is between -0.3 and -0.7. The Hispanic student population has a 0.429 correlation with the percentage of the students passing the FCAT 2.0 Mathematics Test. It is a positive correlation meaning that as the Hispanic student population increased, the percentage of the students passing the FCAT 2.0 Mathematics Test increased. It is a moderate correlation because the $r$ is between 0.3 and 0.7 . The White student population has a 0.668 correlation with the percentage of the students passing the FCAT 2.0 Mathematics Test. It is a positive correlation meaning that as the White student population increased, the percentage of the students passing the FCAT 2.0 Mathematics Test increased. It is a moderate correlation because the $r$ is between 0.3 and 0.7 . The ESOL student population has a -0.134 
correlation with the percentage of the students passing the FCAT 2.0 Mathematics Test. It is a weak correlation since the $r$ is between 0 and -0.3 but, it is also a negative correlation meaning that as the ESOL student population increased, the percentage of the students passing the FCAT 2.0 Mathematics Test decreased. The Economically Disadvantaged (SES) student population has a -0.830 correlation with the percentage of the students passing the FCAT 2.0 Mathematics Test. It is a strong correlation since the $r$ is between -0.7 and -1 but, it is also a negative correlation meaning that as the Economically Disadvantaged (SES) increased, the percentage of the students passing the FCAT 2.0 Mathematics Test decreased. The parents agreeing that the school climate is positive and helps students learn has a 0.595 correlation with the percentage of the students passing the FCAT 2.0 Mathematics Test. It is a positive correlation meaning that as the parents agreeing that the school climate is positive and helps students learn increased, the percentage of the students passing the FCAT 2.0 Mathematics Test also increased. It is a moderate correlation because the $r$ is between 0.3 and 0.7 . The students agreeing that the school climate is positive and helps them learn has a 0.741 correlation with the percentage of the students passing the FCAT 2.0 Mathematics Test. It is a strong correlation since the $r$ is between 0.7 and 1 but, it is also a positive correlation meaning that as the students agreeing that the school climate is positive and helps them learn increased, the percentage of the students passing the FCAT 2.0 Mathematics Test also increased. The staff agreeing that the school climate is positive and helps students learn has a 0.605 correlation with the percentage of the students passing the FCAT 2.0 Mathematics Test. It is a moderate correlation since the $r$ is between 0.3 and 0.7 but it is also a positive correlation meaning that as the staff agreeing that the school climate is 
positive and helps students learn increased, of the students passing the FCAT 2.0

Mathematics Test also increased. 
Table 13

Pearson r and Sig. (1-tailed) - Relationship of Racial and Ethnic Concentration (Blacks, Whites, Hispanics) and FCAT 2.0 Mathematics Scores when controlling Economically Disadvantaged (SES), ESOL Student Population, and School Climate

\begin{tabular}{|c|c|c|c|c|c|c|c|c|c|c|}
\hline \multicolumn{2}{|c|}{ Total $\%^{\mathrm{a}}$} & $\begin{array}{l}\text { Passing } \\
\text { FCAT } \\
\text { Math }\end{array}$ & Blacks & Hispanics & Whites & ESOL & $\begin{array}{c}\text { Economically } \\
\text { Disadvantaged } \\
(\mathrm{SES})\end{array}$ & $\begin{array}{l}\text { School } \\
\text { Climate } \\
\text { (Parent) }\end{array}$ & $\begin{array}{l}\text { School } \\
\text { Climate } \\
\text { (Student) }\end{array}$ & $\begin{array}{c}\text { School } \\
\text { Climate } \\
\text { (Staff) }\end{array}$ \\
\hline \multirow{8}{*}{ 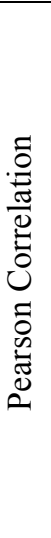 } & Passing FCAT Math & 1.000 & -.597 & .429 & .668 & -.134 & -.830 & .595 & .741 & .605 \\
\hline & Blacks & -.597 & 1.000 & -.959 & -.351 & -.328 & .407 & -.546 & -.511 & -.478 \\
\hline & Hispanics & .429 & -.959 & 1.000 & .073 & .472 & -.161 & .464 & .410 & .417 \\
\hline & Whites & .668 & -.351 & .073 & 1.000 & -.394 & -.891 & .376 & .417 & .289 \\
\hline & Economically Disadvantaged (SES) & -.830 & .407 & -.161 & -.891 & .435 & 1.000 & -.429 & -.529 & -.429 \\
\hline & School Climate (Parent) & .595 & -.546 & .464 & .376 & .085 & -.429 & 1.000 & .624 & .474 \\
\hline & School Climate (Student) & .741 & -.511 & .410 & .417 & .062 & -.529 & .624 & 1.000 & .554 \\
\hline & School Climate (Staff) & .605 & -.478 & .417 & .289 & -.027 & -.429 & .474 & .554 & 1.000 \\
\hline \multirow{8}{*}{ 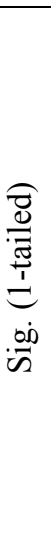 } & Passing FCAT Math & . & .000 & .000 & .000 & .156 & .000 & .000 & .000 & .000 \\
\hline & Hispanics & .000 & .000 & . & .290 & .000 & .111 & .000 & .001 & .001 \\
\hline & Whites & .000 & .003 & .290 & . & .001 & .000 & .002 & .001 & .013 \\
\hline & ESOL & .156 & .006 & .000 & .001 & . & .000 & .263 & .324 & .419 \\
\hline & Economically Disadvantaged (SES) & .000 & .001 & .111 & .000 & .000 & . & .000 & .000 & .000 \\
\hline & School Climate (Parent) & .000 & .000 & .000 & .002 & .263 & .000 & . & .000 & .000 \\
\hline & School Climate (Student) & .000 & .000 & .001 & .001 & .324 & .000 & .000 & . & .000 \\
\hline & School Climate (Staff) & .000 & .000 & .001 & .013 & .419 & .000 & .000 & .000 & . \\
\hline
\end{tabular}

Note. ${ }^{a} n=59$. 
For the primary research question, the independent variables with the strongest correlations to the dependent variable were the Economically Disadvantaged (SES) student population and the results of the positive school climate question on the student survey. The independent variable with the weakest correlation to the dependent variable was the ESOL student population. The independent variables with moderate correlations were the Black student population, the Hispanic student population, the White student population, the results of the positive school climate question on the parent survey, and the results of the positive school climate question on the staff survey. The independent variables with a negative relationship with the dependent variable were the Black student population, the ESOL student population and the Economically Disadvantaged (SES) student population, meaning that as the value of these variables increased, a lower percentage of students passed the FCAT 2.0 Mathematics Test. The independent variables with a positive relationship with the dependent variable were the Hispanic student population, the White student population, the results of the positive school climate question on the parent survey, the results of the positive school climate question on the student survey, and the results of the positive school climate question on the staff survey, meaning that as value of these variables increased, a higher percentage of students passed the FCAT 2.0 Mathematics Test.

Table 13 shows the results of the research hypothesis (H1). The $P_{\text {crit }}$ established for this study is 0.01 . The $P_{\text {calc }}$ for the Black student population is $p<0.001$, making it statistically significant since it is less than 0.01 and not rejecting the research hypothesis (H1), meaning a significant negative relationship exists between the FCAT 2.0 mathematics scores and the racial and ethnic concentrations of public middle schools in 
Miami-Dade County when controlling socio-economic status, ESOL student population, and the school climate for the $2010-2011$ school year. The $P_{\text {calc }}$ for the Hispanic student population is $p<0.001$, making it statistically significant since it is less than 0.01 and not rejecting the research hypothesis (H1), meaning a significant negative relationship exists between the FCAT 2.0 mathematics scores and the racial and ethnic concentrations of public middle schools in Miami-Dade County when controlling socioeconomic status, ESOL student population, and the school climate for the $2010-2011$ school year. The $P_{\text {calc }}$ for the White student population is $p<0.001$, making it statistically significant since it is less than 0.01 and not rejecting the research hypothesis (H1), meaning a significant negative relationship exists between the FCAT 2.0 mathematics scores and the racial and ethnic concentrations of public middle schools in Miami-Dade County when controlling socio-economic status, ESOL student population, and the school climate for the $2010-2011$ school year. The $P_{\text {calc }}$ for the ESOL student population is 0.156 , making it not statistically significant since 0.156 is not less than 0.01 so the research hypothesis (H1) is rejected, meaning no significant negative relationship exists between the FCAT 2.0 mathematics scores and the racial and ethnic concentrations of public middle schools in Miami-Dade County when controlling socio-economic status, ESOL student population, and the school climate for the $2010-2011$ school year. The $P_{\text {calc }}$ for the Economically Disadvantaged (SES) student population is $p<0.001$, making it statistically significant since it is less than 0.01 and not rejecting the research hypothesis (H1), meaning a significant negative relationship exists between the FCAT 2.0 mathematics scores and the racial and ethnic concentrations of public middle schools in Miami-Dade County when controlling socio-economic status, ESOL student 
population, and the school climate for the $2010-2011$ school year. The $P_{\text {calc }}$ for parents agreeing that the school climate is positive and helps students learn is $p<0.001$, making it statistically significant since it is less than 0.01 and not rejecting the research hypothesis (H1), meaning a significant negative relationship exists between the FCAT 2.0 mathematics scores and the racial and ethnic concentrations of public middle schools in Miami-Dade County when controlling socio-economic status, ESOL student population, and the school climate for the $2010-2011$ school year. The $P_{\text {calc }}$ for students agreeing that the school climate is positive and helps them learn is $p<0.001$, making it statistically significant since it is less than 0.01 and not rejecting the research hypothesis (H1), meaning a significant negative relationship exists between the FCAT 2.0 mathematics scores and the racial and ethnic concentrations of public middle schools in Miami-Dade County when controlling socio-economic status, ESOL student population, and the school climate for the $2010-2011$ school year. The $P_{\text {calc }}$ for staff agreeing that the school climate is positive and helps students learn is $p<0.001$, making it statistically significant since it is less than 0.01 and not rejecting the research hypothesis $(\mathrm{H} 1)$, meaning a significant negative relationship exists between the FCAT 2.0 mathematics scores and the racial and ethnic concentrations of public middle schools in Miami-Dade County when controlling socio-economic status, ESOL student population, and the school climate for the $2010-2011$ school year.

For each research hypothesis not rejected, a Type I Error has been made if any research hypothesis ends up being incorrect. There was a one percent chance of that happening. Moreover, for the primary research question, there was only one independent 
variable that was not statistically significant, the percentage of the ESOL student population.

As shown in Table 14, the Sum of Squares (SS) Total for both models is 14379.222, which represents all the variance in the data. For Model 1, the Sum of Squares (SS) Regression is 9346.894 , which is the unique variance that can be explained. For Model 2, the Sum of Squares (SS) Regression is 11096.910. For Model 1, the Sum of Squares (SS) Residual is 5032.328, which is the variance that cannot be explained. For Model 2, the Sum of Squares (SS) Residual is 3282.312. For Model 1, Degrees of Freedom, $d f$, for Regression is four and for Residual is 52 , f or a total of $56 d f$. For Model 2, Degrees of Freedom, $d f$, for Regression is six and for Residual is 50, for a total of $56 d f$. The Mean Square is the variance in the ANOVA. The Mean Square for Model 1's Regression is 2336.723 and for Residual, it is 96.776 . The Mean Square for Model 2's Regression is 1849.485 and for Residual, it is 65.646. For Model 1, the $F$ value is 24.146 which is the test statistic $\left(T S_{\text {calc or }} F_{\text {calc }}\right)$, testing the significance of $R, R^{2}$, and of the entire regression model. For Model 2, the $F$ value is 28.174. For the Significant column, $P_{\text {calc }}$, Model 1 is statistically significant because $p<0.001$ hence it is less than 0.01, as well as Model 2, thus it does not reject the research hypothesis (H1), meaning a significant negative relationship exists between the FCAT 2.0 mathematics scores and racial and ethnic concentrations when controlling socio-economic status, ESOL student population, and school climate of public middle schools in Miami-Dade County for the 2010 - 2011 school year (Hinton et al., 2004). Hence, it indicates the presence of a negative relationship in Model 1 and Model 2 between the independent variables and 
dependent variable. The independent variables may have overlapped in creating this relationship with the dependent variables.

Table 14

ANOVA - Relationship of Racial and Ethnic Concentration (Whites, Hispanics) and FCAT 2.0 Mathematics Scores when controlling ESOL Student Population and School Climate

\begin{tabular}{llccccc}
\hline Model & Sum of Squares & df & Mean Square & F & Sig. \\
\hline \multirow{2}{*}{1} & Regression & 9346.894 & 4 & 2336.723 & 24.146 & $.000^{\mathrm{b}}$ \\
& Residual & 5032.328 & 52 & 96.776 & & \\
& Total & 14379.222 & 56 & & & \\
\hline 2 & Regression & 11096.910 & 6 & 1849.485 & 28.174 & $.000^{\mathrm{c}}$ \\
& Residual & 3282.312 & 50 & 65.646 & & \\
& Total & 14379.222 & 56 & & & \\
\hline
\end{tabular}

Note a. Dependent Variable: \% Passing FCAT Math

b. Predictors: (Constant), \% of School Climate (Parent), \% of ESOL student population, $\%$ School Climate (Staff), \% School Climate (Student)

c. Predictors: (Constant), \% of School Climate (Parent), \% of ESOL student population, $\%$ School Climate (Staff), \% of Hispanic student population, \% School Climate (Student), \% of White student population

Table 15 shows how much each variable contributes to the research question for this particular test. According to the Beta results, the strongest contribution on the passing of the FCAT 2.0 Mathematics Test comes from the positive school climate question of the student survey, -0.511 in Model 1 and also from the White student population, .391 in Model 2.

For the Sig. column in Table 15, for Model 1, the independent variable making a significant contribution to the dependent variable was the results of the positive school climate question on the student survey $(p<0.001)$. For Model 2 , the independent variables making a significant contribution to the dependent variable were the White student population $(p<0.001)$ and the results of the positive school climate question on 
the student survey $(p<0.001)$. For Model 1 , the independent variable not making a significant contribution to the dependent variable were the ESOL student population (0.039), the results of the positive school climate question on the staff survey (0.026), and the results of the positive school climate question on the parent survey (0.097). For Model 2, the independent variables not making a significant contribution to the dependent variable are the Hispanic student population (0.043), the ESOL student population (0.301), the results of the positive school climate question on the staff survey (0.046), and the results of the positive school climate question on the parent survey (0.619; Hinton et al., 2004).

Table 15

Coefficients - Relationship of Racial and Ethnic Concentration (Whites, Hispanics) and FCAT 2.0 Mathematics Scores when controlling ESOL Student Population and School Climate

\begin{tabular}{|c|c|c|c|c|}
\hline \multicolumn{2}{|c|}{ Model } & \multicolumn{3}{|l|}{ Standardized } \\
\hline \multicolumn{2}{|r|}{ Total \% } & Coefficients & $\mathrm{t}$ & Sig. \\
\hline \multirow{5}{*}{1} & (Constant) & & -.302 & .764 \\
\hline & ESOL & -.175 & -2.113 & .039 \\
\hline & School Climate (Parent) & .182 & 1.690 & .097 \\
\hline & School Climate (Student) & .511 & 4.504 & .000 \\
\hline & School Climate (Staff) & .232 & 2.294 & .026 \\
\hline \multirow{7}{*}{2} & (Constant) & & 1.276 & .208 \\
\hline & Hispanics & .194 & 2.078 & .043 \\
\hline & Whites & .391 & 4.533 & .000 \\
\hline & ESOL & -.094 & -1.045 & .301 \\
\hline & School Climate (Parent) & .047 & .500 & .619 \\
\hline & School Climate (Student) & .377 & 3.881 & .000 \\
\hline & School Climate (Staff) & .178 & 2.050 & .046 \\
\hline
\end{tabular}

Moreover, in Table 16's Part column under Correlations, in Model 1, after squaring the values, the ESOL student population contributes $2.99 \%$ to the dependent variable, meaning it also explains $2.99 \%$ of the unique variance in the dependent variable 
and will cause the $R^{2}$ to drop $2.99 \%$ if it is not included in the model. The parents agreeing that the school climate is positive and help students learn contributes $1.93 \%$ to the dependent variable, meaning it also explains $1.93 \%$ of the unique variance in the dependent variable and will cause the $R^{2}$ to drop $1.93 \%$ if it is not included in the model. The students agreeing that the school climate is positive and helps them learn contributes $13.69 \%$ to the dependent variable, meaning it also explains $13.69 \%$ of the unique variance in the dependent variable and will cause the $R^{2}$ to drop $13.69 \%$ if it is not included in the model. The staff agreeing that the school climate is positive and helps students learn contributes $3.53 \%$ to the dependent variable, meaning it also explains $3.53 \%$ of the unique variance in the dependent variable and will cause the $R^{2}$ to drop $3.53 \%$ if it is not included in the model. On the other hand, for Model 2, the Hispanic student population contributes $1.96 \%$ to the dependent variable, meaning it also explains $1.96 \%$ of variance in the dependent variable and will cause the $R^{2}$ to drop $1.96 \%$ if it is not included in the model. The White student population contributes $9.36 \%$ to the dependent variable, meaning it also explains $9.36 \%$ of variance in the dependent variable and will cause the $R^{2}$ to drop $9.36 \%$ if it is not included in the model. The ESOL student population contributes $0.50 \%$ to the dependent variable, meaning it also explains $0.50 \%$ of variance in the dependent variable and will cause the $R^{2}$ to drop $0.50 \%$ if it is not included in the model. The parents agreeing that the school climate is positive and help students learn contributes $0.12 \%$ to the dependent variable, meaning it also explains $0.12 \%$ of variance in the dependent variable and will cause the $R^{2}$ to drop $0.12 \%$ if it is not included in the model. The students agreeing that the school climate is positive and helps them learn contributes $6.86 \%$ to the dependent variable, meaning it also explains 
$6.86 \%$ of variance in the dependent variable and will cause the $R^{2}$ to drop $6.86 \%$ if it is not included in the model. The staff agreeing that the school climate is positive and helps students learn contributes $1.90 \%$ to the dependent variable, meaning it also explains $1.90 \%$ of variance in the dependent variable and will cause the $R^{2}$ to drop $1.90 \%$ if it is not included in the model. The strongest contribution to the dependent variable of the passing of the FCAT 2.0 Mathematics Test comes from the students agreeing that the school climate is positive and helps them learn (13.69\%), followed by the White student population (9.36\%) in Model 2. (See Appendix II for the Collinearity Statistics explanation)

Table 16

Coefficients Continued - Relationship of Racial and Ethnic Concentration (Whites, Hispanics) and FCAT 2.0 Mathematics Scores when controlling ESOL Student Population and School Climate

\begin{tabular}{llccc}
\hline \multirow{2}{*}{ Model } & \multicolumn{2}{c}{ Correlations } & \multicolumn{2}{c}{ Collinearity Statistics } \\
\cline { 2 - 4 } & \multicolumn{2}{c}{ Part } & Tolerance & VIF \\
\hline (Constant) & & & \\
ESOL & -.173 & .985 & 1.015 \\
1 School Climate (Parent) & .139 & .584 & 1.713 \\
& School Climate (Student) & .370 & .524 & 1.909 \\
School Climate (Staff) & .188 & .661 & 1.514 \\
\hline (Constant) & & & \\
Hispanics & .140 & .523 & 1.913 \\
Whites & .306 & .614 & 1.628 \\
ESOL & -.071 & .565 & 1.771 \\
School Climate (Parent) & .034 & .528 & 1.895 \\
School Climate (Student) & .262 & .485 & 2.064 \\
School Climate (Staff) & .138 & .606 & 1.651 \\
\hline
\end{tabular}

\section{Hispanics, ESOL and School Climate}

The primary research question was further tested using a combination of different variables. Due to the presence of multicollinearity, the independent variables of the 
Black student population, the White student population, and the Economically Disadvantaged (SES) student population were removed in order to be able to analyze the individual contribution of each independent variable to the dependent variable (Appendix II, Table 62). On the other hand, the independent variables of the Black student population, the White student population, and the Economically Disadvantaged (SES) student population were only kept for the Pearson $r$ and Sig. Table (Table 17) so that the correlation of those variables would be known.

As shown in Table 17, the correlations have different strengths. The Black student population has a -0.597 correlation with the percentage of the students passing the FCAT 2.0 Mathematics Test. It is a negative correlation meaning that as the Black student population increased, the percentage of the students passing the FCAT 2.0 Mathematics Test decreased. It is a moderate correlation because the $r$ is between -0.3 and -0.7 . The Hispanic student population has a 0.429 correlation with the percentage of the students passing the FCAT 2.0 Mathematics Test. It is a positive correlation meaning that as the Hispanic student population increased, the percentage of the students passing the FCAT 2.0 Mathematics Test increased. It is a moderate correlation because the $r$ is between 0.3 and 0.7 . The White student population has a 0.668 correlation with the percentage of the students passing the FCAT 2.0 Mathematics Test. It is a positive correlation meaning that as the White student population increased, the percentage of the students passing the FCAT 2.0 Mathematics Test increased. It is a moderate correlation because the $r$ is between 0.3 and 0.7 . The ESOL student population has a -0.134 correlation with the percentage of the students passing the FCAT 2.0 Mathematics Test. It is a weak correlation since the $r$ is between 0 and -0.3 but, it is also a negative 
correlation meaning that as the ESOL student population increased, the percentage of the students passing the FCAT 2.0 Mathematics Test decreased. The Economically Disadvantaged (SES) student population has a -0.830 correlation with the percentage of the students passing the FCAT 2.0 Mathematics Test. It is a strong correlation since the $r$ is -0.7 and -1 but, it is also a negative correlation meaning that as the Economically Disadvantaged (SES) increased, the percentage of the students passing the FCAT 2.0 Mathematics Test decreased. The parents agreeing that the school climate is positive and helps students learn has a 0.595 correlation with the percentage of the students passing the FCAT 2.0 Mathematics Test. It is a positive correlation meaning that as the parents agreeing that the school climate is positive and helps students learn increased, the percentage of the students passing the FCAT 2.0 Mathematics Test also increased. It is a moderate correlation because the $r$ is between 0.3 and 0.7 . The students agreeing that the school climate is positive and helps them learn has a 0.741 correlation with the percentage of the students passing the FCAT 2.0 Mathematics Test. It is a strong correlation since the $r$ is between 0.7 and 1 but, it is also a positive correlation meaning that as the students agreeing that the school climate is positive and helps them learn increased, the percentage of the students passing the FCAT 2.0 Mathematics Test also increased. The staff agreeing that the school climate is positive and helps students learn has a 0.605 correlation with the percentage of the students passing the FCAT 2.0 Mathematics Test. It is a moderate correlation since the $r$ is between 0.3 and 0.7 but it is also a positive correlation meaning that as the staff agreeing that the school climate is positive and helps students learn increased, of the students passing the FCAT 2.0 Mathematics Test also increased. 
Table 17

Pearson r and Sig. (1-tailed) - Relationship of Racial and Ethnic Concentration (Blacks, Whites, Hispanics) and FCAT 2.0 Mathematics Scores when controlling Economically Disadvantaged (SES), ESOL Student Population, and School Climate

\begin{tabular}{|c|c|c|c|c|c|c|c|c|c|c|}
\hline \multicolumn{2}{|c|}{ Total $\%{ }^{\mathrm{a}}$} & $\begin{array}{c}\text { Passing } \\
\text { FCAT } \\
\text { Math } \\
\end{array}$ & Blacks & Hispanics & Whites & ESOL & $\begin{array}{c}\text { Economically } \\
\text { Disadvantaged } \\
\text { (SES) }\end{array}$ & $\begin{array}{l}\text { School } \\
\text { Climate } \\
\text { (Parent) }\end{array}$ & $\begin{array}{c}\text { School } \\
\text { Climate } \\
\text { (Student) } \\
\end{array}$ & $\begin{array}{c}\text { School } \\
\text { Climate } \\
\text { (Staff) }\end{array}$ \\
\hline \multirow{8}{*}{ 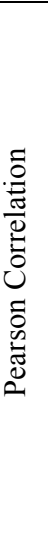 } & Passing FCAT Math & 1.000 & -.597 & .429 & .668 & -.134 & -.830 & .595 & .741 & .605 \\
\hline & Blacks & -.597 & 1.000 & -.959 & -.351 & -.328 & .407 & -.546 & -.511 & -.478 \\
\hline & Hispanics & .429 & -.959 & 1.000 & .073 & .472 & -.161 & .464 & .410 & .417 \\
\hline & Whites & .668 & -.351 & .073 & 1.000 & -.394 & -.891 & .376 & .417 & .289 \\
\hline & Economically Disadvantaged (SES) & -.830 & .407 & -.161 & -.891 & .435 & 1.000 & -.429 & -.529 & -.429 \\
\hline & School Climate (Parent) & .595 & -.546 & .464 & .376 & .085 & -.429 & 1.000 & .624 & .474 \\
\hline & School Climate (Student) & .741 & -.511 & .410 & .417 & .062 & -.529 & .624 & 1.000 & .554 \\
\hline & School Climate (Staff) & .605 & -.478 & .417 & .289 & -.027 & -.429 & .474 & .554 & 1.000 \\
\hline \multirow{8}{*}{ 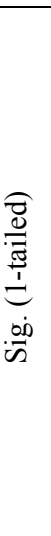 } & Passing FCAT Math & . & .000 & .000 & .000 & .156 & .000 & .000 & .000 & .000 \\
\hline & Hispanics & .000 & .000 & . & .290 & .000 & .111 & .000 & .001 & .001 \\
\hline & Whites & .000 & .003 & .290 & . & .001 & .000 & .002 & .001 & .013 \\
\hline & ESOL & .156 & .006 & .000 & .001 & . & .000 & .263 & .324 & .419 \\
\hline & Economically Disadvantaged (SES) & .000 & .001 & .111 & .000 & .000 & . & .000 & .000 & .000 \\
\hline & School Climate (Parent) & .000 & .000 & .000 & .002 & .263 & .000 & . & .000 & .000 \\
\hline & School Climate (Student) & .000 & .000 & .001 & .001 & .324 & .000 & .000 & . & .000 \\
\hline & School Climate (Staff) & .000 & .000 & .001 & .013 & .419 & .000 & .000 & .000 & . \\
\hline
\end{tabular}

Note. ${ }^{a} n=59$. 
For the primary research question, the independent variables with the strongest correlations to the dependent variable were the Economically Disadvantaged (SES) students and the results of the positive school climate question on the student survey. The independent variable with the weakest correlation to the dependent variable was the ESOL student population. The independent variables with moderate correlations were the Black student population, the Hispanic student population, the White student population, the results of the positive school climate question on the parent survey, and the results of the positive school climate question on the staff survey. The independent variables with a negative relationship with the dependent variable were the Black student population, the ESOL student population and the Economically Disadvantaged (SES) student population, meaning that as the value of these variables increased, a lower percentage of students passed the FCAT 2.0 Mathematics Test. The independent variables with a positive relationship with the dependent variable were the Hispanic student population, the White student population, the results of the positive school climate question on the parent survey, the results of the positive school climate question on the student survey, and the results of the positive school climate question on the staff survey, meaning that as the value of these variables increased, a higher percentage of students passed the FCAT 2.0 Mathematics Test.

Table 17 shows the results of the research hypothesis (H1). The $P_{\text {crit }}$ established for this study is 0.01 . The $P_{\text {calc }}$ for the Black student population is $p<0.001$, making it statistically significant since it is less than 0.01 and not rejecting the research hypothesis (H1), meaning a significant negative relationship exists between the FCAT 2.0 mathematics scores and the racial and ethnic concentrations of public middle schools in 
Miami-Dade County when controlling socio-economic status, ESOL student population, and the school climate for the $2010-2011$ school year. The $P_{\text {calc }}$ for the Hispanic student population is $p<0.001$, making it statistically significant since it is less than 0.01 and not rejecting the research hypothesis (H1), meaning a significant negative relationship exists between the FCAT 2.0 mathematics scores and the racial and ethnic concentrations of public middle schools in Miami-Dade County when controlling socioeconomic status, ESOL student population, and the school climate for the $2010-2011$ school year. The $P_{\text {calc }}$ for the White student population is $\mathrm{p}<0.001$, making it statistically significant since it is less than 0.01 and not rejecting the research hypothesis (H1), meaning a significant negative relationship exists between the FCAT 2.0 mathematics scores and the racial and ethnic concentrations of public middle schools in Miami-Dade County when controlling socio-economic status, ESOL student population, and the school climate for the $2010-2011$ school year. The $P_{\text {calc }}$ for the ESOL student population is 0.156 , making it not statistically significant since 0.156 is not less than 0.01 so the research hypothesis (H1) is rejected, meaning no significant negative relationship exists between the FCAT 2.0 mathematics scores and the racial and ethnic concentrations of public middle schools in Miami-Dade County when controlling socio-economic status, ESOL student population, and the school climate for the $2010-2011$ school year. The $P_{\text {calc }}$ for the Economically Disadvantaged (SES) student population is $p<0.001$, making it statistically significant since it is less than 0.01 and not rejecting the research hypothesis (H1), meaning a significant negative relationship exists between the FCAT 2.0 mathematics scores and the racial and ethnic concentrations of public middle schools in Miami-Dade County when controlling socio-economic status, ESOL student 
population, and the school climate for the $2010-2011$ school year. The $P_{\text {calc }}$ for parents agreeing that the school climate is positive and helps students learn is $p<0.001$, making it statistically significant since it is less than 0.01 and not rejecting the research hypothesis (H1), meaning a significant negative relationship exists between the FCAT 2.0 mathematics scores and the racial and ethnic concentrations of public middle schools in Miami-Dade County when controlling socio-economic status, ESOL student population, and the school climate for the $2010-2011$ school year. The $P_{\text {calc }}$ for students agreeing that the school climate is positive and helps them learn is $p<0.001$, making it statistically significant since it is less than 0.01 and not rejecting the research hypothesis (H1), meaning a significant negative relationship exists between the FCAT 2.0 mathematics scores and the racial and ethnic concentrations of public middle schools in Miami-Dade County when controlling socio-economic status, ESOL student population, and the school climate for the $2010-2011$ school year. The $P_{\text {calc }}$ for staff agreeing that the school climate is positive and helps students learn is $p<0.001$, making it statistically significant since it is less than 0.01 and not rejecting the research hypothesis $(\mathrm{H} 1)$, meaning a significant negative relationship exists between the FCAT 2.0 mathematics scores and the racial and ethnic concentrations of public middle schools in Miami-Dade County when controlling socio-economic status, ESOL student population, and the school climate for the $2010-2011$ school year.

For each research hypothesis not rejected, a Type I Error has been made if any research hypothesis ends up being incorrect. There was a one percent chance of that happening. Moreover, for the primary research question, there was only one independent 
variable that was not statistically significant, the percentage of the ESOL student population.

As shown in Table 18, the Sum of Squares (SS) Total for both models is 14379.222, which represents all the unique variance in the data. For Model 1, the Sum of Squares (SS) Regression is 9346.894, which is the variance that can be explained. For Model 2, the Sum of Squares (SS) Regression is 9747.905. For Model 1, the Sum of Squares (SS) Residual is 5032.328, which is the variance that cannot be explained. For Model 2, the Sum of Squares (SS) Residual is 4631.317. For Model 1, Degrees of Freedom, $d f$, for Regression is four and for Residual is 52 , for a total of $56 d f$. For Model 2, Degrees of Freedom, $d f$, for Regression is five and for Residual is 51 , for a total of 56 $d f$. The Mean Square is the variance in the ANOVA. The Mean Square for Model 1's Regression is 2336.723 and for Residual, it is 96.776. The Mean Square for Model 2's Regression is 1949.581 and for Residual, it is 90.810 . For Model 1, the $F$ value is 24.146 which is the test statistic $\left(T S_{\text {calc or }} F_{\text {calc }}\right.$ ), testing the significance of $R, R^{2}$, and of the entire regression model. For Model 2, the $F$ value is 21.469. For the Significant column, $P_{\text {calc }}$, Model 1 is statistically significant because $p<0.001$ hence they are less than 0.01 , as well as Model 2, thus it does not reject the research hypothesis (H1), meaning a significant negative relationship exists between the FCAT 2.0 mathematics scores and racial and ethnic concentrations when controlling socio-economic status, ESOL student population, and school climate of public middle schools in Miami-Dade County for the 2010 - 2011 school year (Hinton et al., 2004). Hence, it indicates the presence of a negative relationship in Model 1 and Model 2 between the independent variables and 
dependent variable. The independent variables may have overlapped in creating this relationship with the dependent variables.

Table 18

ANOVA - Relationship of Racial and Ethnic Concentration (Hispanics) and FCAT 2.0 Mathematics Scores when controlling ESOL Student Population, and School Climate

\begin{tabular}{llccccc}
\hline Model & Sum of Squares & df & Mean Square & F & Sig. \\
\hline \multirow{2}{*}{1} & Regression & 9346.894 & 4 & 2336.723 & 24.146 & $.000^{\mathrm{b}}$ \\
& Residual & 5032.328 & 52 & 96.776 & & \\
& Total & 14379.222 & 56 & & & \\
\hline \multirow{2}{*}{2} & Regression & 9747.905 & 5 & 1949.581 & 21.469 & $.000^{\mathrm{c}}$ \\
& Residual & 4631.317 & 51 & 90.810 & & \\
& Total & 14379.222 & 56 & & & \\
\hline
\end{tabular}

Note a. Dependent Variable: \% Passing FCAT Math

b. Predictors: (Constant), \% of School Climate (Parent), \% of ESOL student population, $\%$ School Climate (Staff), \% School Climate (Student)

c. Predictors: (Constant), $\%$ of School Climate (Parent), \% of ESOL student population, $\%$ School Climate (Staff), \% School Climate (Student), \% of Hispanic student population

Table 19 shows how much each variable contributes to the research question for this particular test. According to the Beta results, the strongest contribution on the passing of the FCAT 2.0 Mathematics Test comes from the positive school climate question of the student survey, -0.511 in Model 1 and also from the positive school climate question of the student survey, .493 in Model 2.

For the Sig. column for Model 1, the independent variable making a significant contribution to the dependent variable was the results of the positive school climate question on the student survey $(p<0.001)$. For Model 2 , the independent variable making a significant contribution to the dependent variable was the results of the positive school climate question on the student survey $(p<0.001)$. For Model 1 , the independent variables not making a significant contribution to the dependent variable were the ESOL 
student population (0.039), the results of the positive school climate question on the parent survey $(0.097)$, and the results of the positive school climate question on the staff survey (0.026). For Model 2, the independent variables not making a significant contribution to the dependent variable were the Hispanic student population $(0.041)$, the ESOL student population (0.005), the results of the positive school climate question on the parent survey $(0.254)$, and the results of the positive school climate question on the staff survey (0.102; Hinton et al., 2004).

Table 19

Coefficients - Relationship of Racial and Ethnic Concentration (Hispanics) and FCAT 2.0 Mathematics Scores when controlling ESOL Student Population, and School Climate

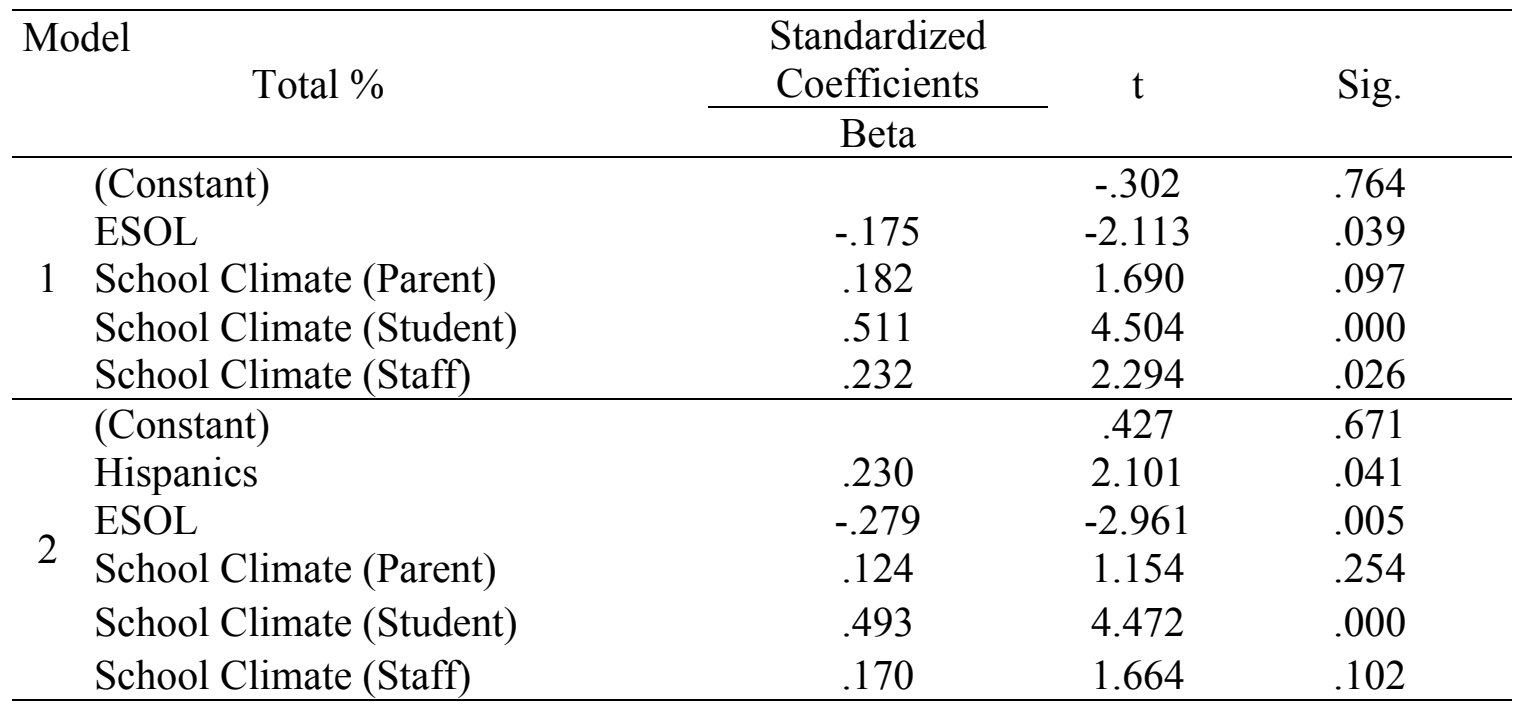

Moreover, in Table 20's Part column under Correlations, in Model 1, after squaring the values, the ESOL student population contributes $2.99 \%$ to the dependent variable, meaning it also explains $2.99 \%$ of the unique variance in the dependent variable and will cause the $R^{2}$ to drop $2.99 \%$ if it is not included in the model. The parents agreeing that the school climate is positive and help students learn contributes $1.93 \%$ to the dependent variable, meaning it also explains $1.93 \%$ of the unique variance in the 
dependent variable and will cause the $R^{2}$ to drop $1.93 \%$ if it is not included in the model. The students agreeing that the school climate is positive and helps them learn contributes $13.69 \%$ to the dependent variable, meaning it also explains $13.69 \%$ of the unique variance in the dependent variable and will cause the $R^{2}$ to drop $13.69 \%$ if it is not included in the model. The staff agreeing that the school climate is positive and helps students learn contributes $3.53 \%$ to the dependent variable, meaning it also explains $3.53 \%$ of the unique variance in the dependent variable and will cause the $R^{2}$ to drop $3.53 \%$ if it is not included in the model. On the other hand, for Model 2, the Hispanic student population contributes $2.79 \%$ to the dependent variable, meaning it also explains $2.79 \%$ of variance in the dependent variable and will cause the $R^{2}$ to drop $2.79 \%$ if it is not included in the model. The ESOL student population contributes $5.52 \%$ to the dependent variable, meaning it also explains $5.52 \%$ of variance in the dependent variable and will cause the $R^{2}$ to drop $5.52 \%$ if it is not included in the model. The parents agreeing that the school climate is positive and help students learn contributes $0.85 \%$ to the dependent variable, meaning it also explains $0.85 \%$ of variance in the dependent variable and will cause the $R^{2}$ to drop $0.85 \%$ if it is not included in the model. The students agreeing that the school climate is positive and helps them learn contributes $12.6 \%$ to the dependent variable, meaning it also explains $12.6 \%$ of variance in the dependent variable and will cause the $R^{2}$ to drop $12.6 \%$ if it is not included in the model. The staff agreeing that the school climate is positive and helps students learn contributes $1.74 \%$ to the dependent variable, meaning it also explains $1.74 \%$ of variance in the dependent variable and will cause the $R^{2}$ to drop $1.74 \%$ if it is not included in the model. The strongest contribution to the dependent variable of the passing of the FCAT 2.0 
Mathematics Test comes from the students agreeing that the school climate is positive and helps them learn (13.69\%), followed by the students agreeing that the school climate is positive and helps them learn $(12.6 \%)$ in Model 2. (See Appendix II for the Collinearity Statistics explanation)

Table 20

Coefficients Continued - Relationship of Racial and Ethnic Concentration (Hispanics) and FCAT 2.0 Mathematics Scores when controlling ESOL Student Population, and School Climate

\begin{tabular}{llcc}
\hline \multirow{2}{*}{ Model } & \multicolumn{2}{c}{ Correlations } & \multicolumn{2}{c}{ Collinearity Statistics } \\
\cline { 2 - 4 } & Part & Tolerance & VIF \\
\hline \multirow{2}{*}{ (Constant) } & & & \\
ESOL & -.173 & .985 & 1.015 \\
1 School Climate (Parent) & .139 & .584 & 1.713 \\
School Climate (Student) & .370 & .524 & 1.909 \\
School Climate (Staff) & .188 & .661 & 1.514 \\
\hline (Constant) & & & \\
Hispanics & .167 & .526 & 1.900 \\
ESOL & -.235 & .711 & 1.406 \\
School Climate (Parent) & .092 & .546 & 1.831 \\
School Climate (Student) & .355 & .521 & 1.921 \\
School Climate (Staff) & .132 & .606 & 1.650 \\
\hline
\end{tabular}

\section{Whites, ESOL and School Climate}

The primary research question was further tested using a combination of different variables. Due to the presence of multicollinearity, the independent variables of the Hispanic student population, the Black student population, and the Economically Disadvantaged (SES) student population were removed in order to be able to analyze the individual contribution of each independent variable to the dependent variable (Appendix II, Table 65). On the other hand, the independent variables of the Hispanic student population, the Black student population, and the Economically Disadvantaged (SES) 
student population were only kept for the Pearson $r$ and Sig. Table (Table 21) so that the correlation of those variables would be known.

As shown in Table 21, the correlations have different strengths. The Black student population has a -0.597 correlation with the percentage of the students passing the FCAT 2.0 Mathematics Test. It is a negative correlation meaning that as the Black student population increased, the percentage of the students passing the FCAT 2.0 Mathematics Test decreased. It is a moderate correlation because the $r$ is between -0.3 and -0.7. The Hispanic student population has a 0.429 correlation with the percentage of the students passing the FCAT 2.0 Mathematics Test. It is a positive correlation meaning that as the Hispanic student population increased, the percentage of the students passing the FCAT 2.0 Mathematics Test increased. It is a moderate correlation because the $r$ is between 0.3 and 0.7 . The White student population has a 0.668 correlation with the percentage of the students passing the FCAT 2.0 Mathematics Test. It is a positive correlation meaning that as the White student population increased, the percentage of the students passing the FCAT 2.0 Mathematics Test increased. It is a moderate correlation because the $r$ is between 0.3 and 0.7 . The ESOL student population has a -0.134 correlation with the percentage of the students passing the FCAT 2.0 Mathematics Test. It is a weak correlation since the $r$ is between 0 and -0.3 but, it is also a negative correlation meaning that as the ESOL student population increased, the percentage of the students passing the FCAT 2.0 Mathematics Test decreased. The Economically Disadvantaged (SES) student population has a -0.830 correlation with the percentage of the students passing the FCAT 2.0 Mathematics Test. It is a strong correlation since the $r$ is between -0.7 and -1 but, it is also a negative correlation meaning that as the 
Economically Disadvantaged (SES) increased, the percentage of the students passing the FCAT 2.0 Mathematics Test decreased. The parents agreeing that the school climate is positive and helps students learn has a 0.595 correlation with the percentage of the students passing the FCAT 2.0 Mathematics Test. It is a positive correlation meaning that as the parents agreeing that the school climate is positive and helps students learn increased, the percentage of the students passing the FCAT 2.0 Mathematics Test also increased. It is a moderate correlation because the $r$ is between 0.3 and 0.7 . The students agreeing that the school climate is positive and helps them learn has a 0.741 correlation with the percentage of the students passing the FCAT 2.0 Mathematics Test. It is a strong correlation since the $r$ is between 0.7 and 1 but, it is also a positive correlation meaning that as the students agreeing that the school climate is positive and helps them learn increased, the percentage of the students passing the FCAT 2.0 Mathematics Test also increased. The staff agreeing that the school climate is positive and helps students learn has a 0.605 correlation with the percentage of the students passing the FCAT 2.0 Mathematics Test. It is a moderate correlation since the $r$ is between 0.3 and 0.7 but it is also a positive correlation meaning that as the staff agreeing that the school climate is positive and helps students learn increased, of the students passing the FCAT 2.0 Mathematics Test also increased. 
Table 21

Pearson r and Sig. (1-tailed) - Relationship of Racial and Ethnic Concentration (Blacks, Whites, Hispanics) and FCAT 2.0 Mathematics Scores when controlling Economically Disadvantaged (SES), ESOL Student Population, and School Climate

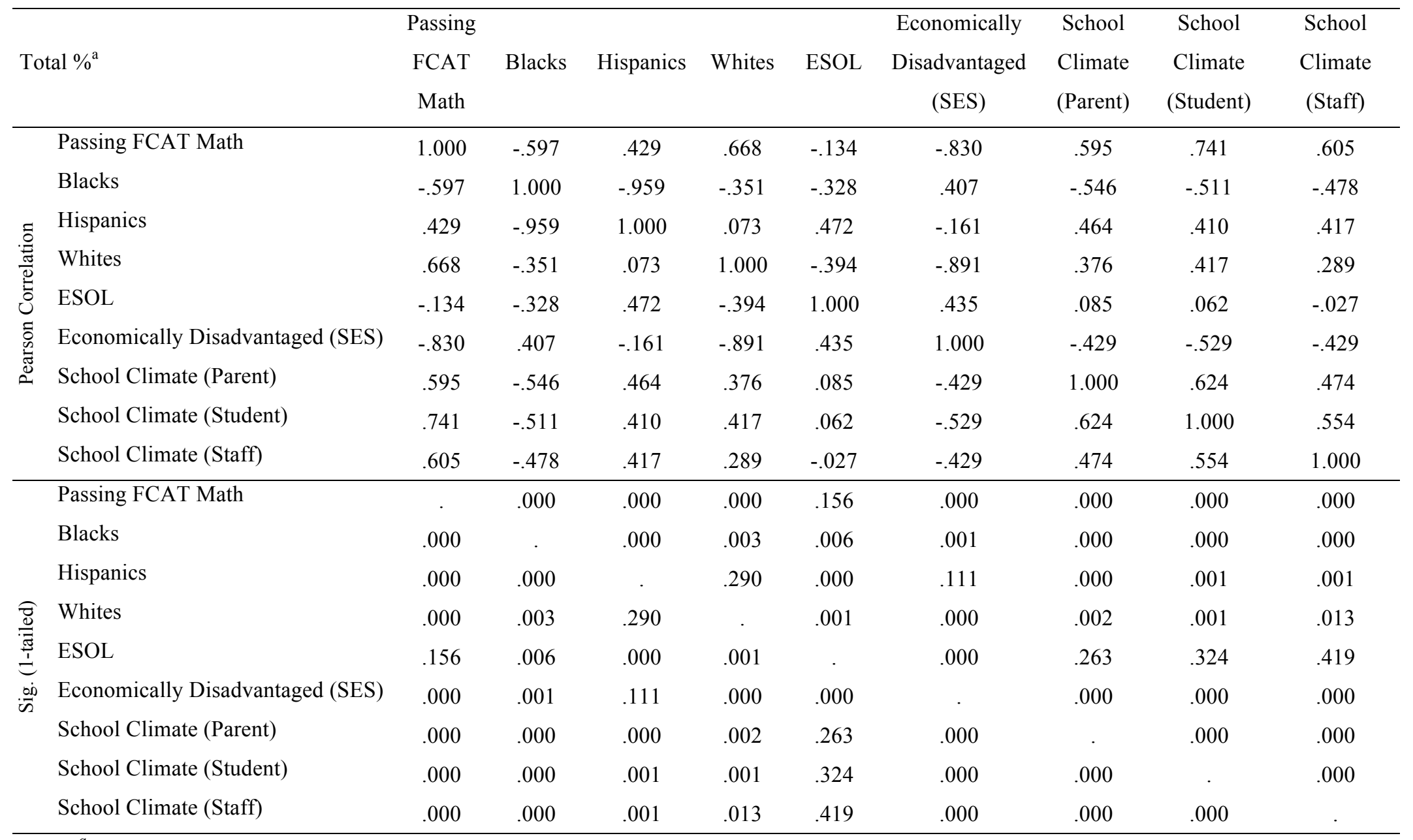

Note. ${ }^{a} n=59$. 
For the primary research question, the independent variables with the strongest correlations to the dependent variable were the Economically Disadvantaged (SES) students and the results of the positive school climate question on the student survey. The independent variable with the weakest correlation to the dependent variable was the ESOL student population. The independent variables with moderate correlations were the Black student population, the Hispanic student population, the White student population, the results of the positive school climate question on the parent survey, and the results of the positive school climate question on the staff survey. The independent variables with a negative relationship with the dependent variable were the Black student population, the ESOL student population and the Economically Disadvantaged (SES) student population, meaning that as the value of these variables increased, a lower percentage of students passed the FCAT 2.0 Mathematics Test. The independent variables with a positive relationship with the dependent variable were the Hispanic student population, the White student population, the results of the positive school climate question on the parent survey, the results of the positive school climate question on the student survey, and the results of the positive school climate question on the staff survey, meaning that as the value of these variables increased, a higher percentage of students passed the FCAT 2.0 Mathematics Test.

Table 21 shows the results of the research hypothesis (H1). The $P_{\text {crit }}$ established for this study is 0.01 . The $P_{\text {calc }}$ for the Black student population is $p<0.001$, making it statistically significant since it is less than 0.01 and not rejecting the research hypothesis (H1), meaning a significant negative relationship exists between the FCAT 2.0 mathematics scores and the racial and ethnic concentrations of public middle schools in 
Miami-Dade County when controlling socio-economic status, ESOL student population, and the school climate for the $2010-2011$ school year. The $P_{\text {calc }}$ for the Hispanic student population is $p<0.001$, making it statistically significant since it is less than 0.01 and not rejecting the research hypothesis (H1), meaning a significant negative relationship exists between the FCAT 2.0 mathematics scores and the racial and ethnic concentrations of public middle schools in Miami-Dade County when controlling socioeconomic status, ESOL student population, and the school climate for the $2010-2011$ school year. The $P_{\text {calc }}$ for the White student population is $p<0.001$, making it statistically significant since it is less than 0.01 and not rejecting the research hypothesis (H1), meaning a significant negative relationship exists between the FCAT 2.0 mathematics scores and the racial and ethnic concentrations of public middle schools in Miami-Dade County when controlling socio-economic status, ESOL student population, and the school climate for the $2010-2011$ school year. The $P_{\text {calc }}$ for the ESOL student population is 0.156 , making it not statistically significant since 0.156 is not less than 0.01 so the research hypothesis (H1) is rejected, meaning no significant negative relationship exists between the FCAT 2.0 mathematics scores and the racial and ethnic concentrations of public middle schools in Miami-Dade County when controlling socio-economic status, ESOL student population, and the school climate for the $2010-2011$ school year. The $P_{\text {calc }}$ for the Economically Disadvantaged (SES) student population is $p<0.001$, making it statistically significant since it is less than 0.01 and not rejecting the research hypothesis (H1), meaning a significant negative relationship exists between the FCAT 2.0 mathematics scores and the racial and ethnic concentrations of public middle schools in Miami-Dade County when controlling socio-economic status, ESOL student 
population, and the school climate for the $2010-2011$ school year. The $P_{\text {calc }}$ for parents agreeing that the school climate is positive and helps students learn is $p<0.001$, making it statistically significant since it is less than 0.01 and not rejecting the research hypothesis (H1), meaning a significant negative relationship exists between the FCAT 2.0 mathematics scores and the racial and ethnic concentrations of public middle schools in Miami-Dade County when controlling socio-economic status, ESOL student population, and the school climate for the $2010-2011$ school year. The $P_{\text {calc }}$ for students agreeing that the school climate is positive and helps them learn is $p<0.001$, making it statistically significant since it is less than 0.01 and not rejecting the research hypothesis (H1), meaning a significant negative relationship exists between the FCAT 2.0 mathematics scores and the racial and ethnic concentrations of public middle schools in Miami-Dade County when controlling socio-economic status, ESOL student population, and the school climate for the $2010-2011$ school year. The $P_{\text {calc }}$ for staff agreeing that the school climate is positive and helps students learn is $p<0.001$, making it statistically significant since it is less than 0.01 and not rejecting the research hypothesis $(\mathrm{H} 1)$, meaning a significant negative relationship exists between the FCAT 2.0 mathematics scores and the racial and ethnic concentrations of public middle schools in Miami-Dade County when controlling socio-economic status, ESOL student population, and the school climate for the $2010-2011$ school year.

For each research hypothesis not rejected, a Type I Error has been made if any research hypothesis ends up being incorrect. There was a one percent chance of that happening. Moreover, for the primary research question, there was only one independent 
variable that was not statistically significant, the percentage of the ESOL student population.

As shown in Table 22, the Sum of Squares (SS) Total for both models is 14379.222, which represents all the variance in the data. For Model 1, the Sum of Squares (SS) Regression is 9346.894 , which is the unique variance that can be explained. For Model 2, the Sum of Squares (SS) Regression is 10813.531. For Model 1, the Sum of Squares (SS) Residual is 5032.328, which is the variance that cannot be explained. For Model 2, the Sum of Squares (SS) Residual is 3565.691. For Model 1, Degrees of Freedom, $d f$, for Regression is four and for Residual is 52 , for a total of $56 d f$. For Model 2, Degrees of Freedom, $d f$, for Regression is five and for Residual is 51, for a total of 56 $d f$. The Mean Square is the variance in the ANOVA. The Mean Square for Model 1's Regression is 2336.723 and for Residual, it is 96.776. The Mean Square for Model 2's Regression is 2162.706 and for Residual, it is 69.916. For Model 1, the $F$ value is 24.146 which is the test statistic $\left(T S_{\text {calc or }} F_{\text {calc }}\right.$ ), testing the significance of $R, R^{2}$, and of the entire regression model. For Model 2, the $F$ value is 30.933. For the Significant column, $P_{\text {calc }}$, Model 1 is statistically significant because $p<0.001$ hence they are less than 0.01 , as well as Model 2, thus it does not reject the research hypothesis (H1), meaning a significant negative relationship exists between the FCAT 2.0 mathematics scores and racial and ethnic concentrations when controlling socio-economic status, ESOL student population, and school climate of public middle schools in Miami-Dade County for the 2010 - 2011 school year (Hinton et al., 2004). Hence, it indicates the presence of a negative relationship in Model 1 and Model 2 between the independent variables and 
dependent variable. The independent variables may have overlapped in creating this relationship with the dependent variables.

Table 22

ANOVA - Relationship of Racial and Ethnic Concentration (Whites) and FCAT 2.0 Mathematics Scores when controlling ESOL Student Population, and School Climate

\begin{tabular}{llccccc}
\hline Model & Sum of Squares & df & Mean Square & F & Sig. \\
\hline \multirow{2}{*}{1} & Regression & 9346.894 & 4 & 2336.723 & 24.146 & $.000^{\mathrm{b}}$ \\
& Residual & 5032.328 & 52 & 96.776 & & \\
& Total & 14379.222 & 56 & & & \\
\hline \multirow{2}{*}{2} & Regression & 10813.531 & 5 & 2162.706 & 30.933 & $.000^{\mathrm{c}}$ \\
& Residual & 3565.691 & 51 & 69.916 & & \\
& Total & 14379.222 & 56 & & & \\
\hline
\end{tabular}

Note a. Dependent Variable: \% Passing FCAT Math

b. Predictors: (Constant), \% of School Climate (Parent), \% of ESOL student population, $\%$ School Climate (Staff), \% School Climate (Student)

c. Predictors: (Constant), \% of School Climate (Parent), \% of ESOL student population, $\%$ School Climate (Staff), \% School Climate (Student), \% of White student population

Table 23 shows how much each variable contributes to the research question for this particular test. According to the Beta results, the strongest contribution on the passing of the FCAT 2.0 Mathematics Test comes from the positive school climate question of the student survey, -0.511 in Model 1 and also from the White student population, .406 in Model 2.

For the Sig. column in Table 23, for Model 1, the independent variable making a significant contribution to the dependent variable was the results of the positive school climate question on the student survey $(p<0.001)$. For Model 2 , the independent variables making a significant contribution to the dependent variable were the White student population $(p<0.001)$, the results of the positive school climate question on the student survey ( $p<0.001$ ), and the results of the positive school climate question on the 
staff survey $(0.010)$. For Model 1, the independent variables not making a significant contribution to the dependent variable were the ESOL student population (0.039), the results of the positive school climate question on the staff survey (0.026), and the results of the positive school climate question on the parent survey (0.097). For Model 2, the independent variables not making a significant contribution to the dependent variable were the ESOL student population (0.993) and the results of the positive school climate question on the parent survey (0.331; Hinton et al., 2004).

Table 23

Coefficients - Relationship of Racial and Ethnic Concentration (Whites) and FCAT 2.0 Mathematics Scores when controlling ESOL Student Population, and School Climate

\begin{tabular}{|c|c|c|c|c|}
\hline \multirow[t]{2}{*}{ Mode } & \multirow[b]{2}{*}{ Total \% } & \multirow{2}{*}{$\begin{array}{c}\text { Standardized } \\
\text { Coefficients } \\
\text { Beta }\end{array}$} & \multirow[b]{2}{*}{$\mathrm{t}$} & \multirow[b]{2}{*}{ Sig. } \\
\hline & & & & \\
\hline \multirow{5}{*}{1} & (Constant) & & -.302 & .764 \\
\hline & ESOL & -.175 & -2.113 & .039 \\
\hline & School Climate (Parent) & .182 & 1.690 & .097 \\
\hline & School Climate (Student) & .511 & 4.504 & .000 \\
\hline & School Climate (Staff) & .232 & 2.294 & .026 \\
\hline \multirow{6}{*}{2} & (Constant) & & .621 & .537 \\
\hline & Whites & .406 & 4.580 & .000 \\
\hline & ESOL & .001 & .009 & .993 \\
\hline & School Climate (Parent) & .092 & .981 & .331 \\
\hline & School Climate (Student) & .387 & 3.872 & .000 \\
\hline & School Climate (Staff) & .230 & 2.679 & .010 \\
\hline
\end{tabular}

Moreover, Table 24's Part column under Correlations, in Model 1, after squaring the values, the ESOL student population contributes $2.99 \%$ to the dependent variable, meaning it also explains $2.99 \%$ of the unique variance in the dependent variable and will cause the $R^{2}$ to drop $2.99 \%$ if it is not included in the model. The parents agreeing that the school climate is positive and help students learn contributes $1.93 \%$ to the dependent variable, meaning it also explains $1.93 \%$ of the unique variance in the dependent variable 
and will cause the $R^{2}$ to drop $1.93 \%$ if it is not included in the model. The students agreeing that the school climate is positive and helps them learn contributes $13.69 \%$ to the dependent variable, meaning it also explains $13.69 \%$ of the unique variance in the dependent variable and will cause the $R^{2}$ to drop $13.69 \%$ if it is not included in the model. The staff agreeing that the school climate is positive and helps students learn contributes $3.53 \%$ to the dependent variable, meaning it also explains $3.53 \%$ of the unique variance in the dependent variable and will cause the $R^{2}$ to drop $3.53 \%$ if it is not included in the model. On the other hand, for Model 2, the White student population contributes $10.2 \%$ to the dependent variable, meaning it also explains $10.2 \%$ of variance in the dependent variable and will cause the $R^{2}$ to drop $10.2 \%$ if it is not included in the model. The ESOL student population contributes $0.00 \%$ to the dependent variable, meaning it also explains $0.00 \%$ of variance in the dependent variable and will cause the $R^{2}$ to drop $0.00 \%$ if it is not included in the model. The parents agreeing that the school climate is positive and help students learn contributes $0.46 \%$ to the dependent variable, meaning it also explains $0.46 \%$ of variance in the dependent variable and will cause the $R^{2}$ to drop $0.46 \%$ if it is not included in the model. The students agreeing that the school climate is positive and helps them learn contributes $7.29 \%$ to the dependent variable, meaning it also explains $7.29 \%$ of variance in the dependent variable and will cause the $R^{2}$ to drop $7.29 \%$ if it is not included in the model. The staff agreeing that the school climate is positive and helps students learn contributes $3.50 \%$ to the dependent variable, meaning it also explains $3.50 \%$ of variance in the dependent variable and will cause the $R^{2}$ to drop $3.50 \%$ if it is not included in the model. The strongest contribution to the dependent variable of the passing of the FCAT 2.0 Mathematics Test comes from the students agreeing that the 
school climate is positive and helps them learn (13.69\%) in Model 1, followed by the White student population (10.2\%) in Model 2. (See Appendix II for the Collinearity Statistics explanation)

Table 24

Coefficients Continued - Relationship of Racial and Ethnic Concentration (Whites) and FCAT 2.0 Mathematics Scores when controlling ESOL Student Population, and School Climate

\begin{tabular}{lccc}
\hline \multirow{2}{*}{ Model } & \multicolumn{2}{c}{ Correlations } & \multicolumn{2}{c}{ Collinearity Statistics } \\
\cline { 2 - 4 } & Part & Tolerance & VIF \\
\hline \multirow{2}{*}{ (Constant) } & & & \\
ESOL & -.173 & .985 & 1.015 \\
1 School Climate (Parent) & .139 & .584 & 1.713 \\
School Climate (Student) & .370 & .524 & 1.909 \\
School Climate (Staff) & .188 & .661 & 1.514 \\
\hline (Constant) & & & \\
Whites & .319 & .619 & 1.617 \\
ESOL & .001 & .760 & 1.317 \\
School Climate (Parent) & .068 & .558 & 1.792 \\
School Climate (Student) & .270 & .486 & 2.058 \\
School Climate (Staff) & .187 & .661 & 1.514 \\
\hline
\end{tabular}

Relationship between Schools' Racial and Ethnic Concentration and FCAT 2.0 Mathematics Scores when controlling ESOL Student Population

\section{Whites, Hispanics and ESOL}

The study is driven by secondary research questions which tests different relationships between the dependent variable and independent variables. For this particular test, significant unique variance is sought between the schools' racial and ethnic concentration and the FCAT 2.0 Mathematics scores when controlling the ESOL student population. There was a high correlation between the White student population, the Black student population, and the Hispanic student population, and so the Black student population was left out in order to eliminate the multicollinearity (Appendix II, 
Table 68). On the other hand, the independent variable of Black student population was kept for the Pearson $r$ and Sig. Table (Table 25) so that the correlation of this variable would be known.

As shown in Table 25, the correlations have different strengths. The ESOL student population has a -0.134 correlation with the percentage of the students passing the FCAT 2.0 Mathematics Test. It is a weak correlation since the $r$ is between 0 and -0.3 but, it is also a negative correlation meaning that as the ESOL student population increased, the percentage of the students passing the FCAT 2.0 Mathematics Test decreased. The White student population has a 0.668 correlation with the percentage of the students passing the FCAT 2.0 Mathematics Test. It is a moderate correlation since the $r$ is between 0.3 and 0.7 but, it is also a positive correlation meaning that as the White student population increased, the percentage of the students passing the FCAT 2.0 Mathematics Test increased. The Hispanic student population has a 0.429 correlation with the percentage of the students passing the FCAT 2.0 Mathematics Test. It is a positive correlation meaning that as the Hispanic student population increased, the percentage of the students passing the FCAT 2.0 Mathematics Test increased. It is a moderate correlation because the $r$ is between 0.3 and 0.7 . The Black student population has a -0.597 correlation with the percentage of the students passing the FCAT 2.0 Mathematics Test. It is a negative correlation meaning that as the Black student population increased, the percentage of the students passing the FCAT 2.0 Mathematics Test decreased. It is a moderate correlation because the $r$ is between -0.3 and -0.7 . 
Table 25

Pearson r and Sig. (1-tailed) - Relationship of Racial and Ethnic Concentration (Whites, Blacks, Hispanics) and FCAT 2.0 Mathematics Scores when controlling ESOL Student Population

\begin{tabular}{|c|c|c|c|c|c|c|}
\hline Total & & $\begin{array}{l}\text { Passing } \\
\text { FCAT }\end{array}$ & ESOL & Blacks & Whites & Hispanics \\
\hline & Passing FCAT Math & 1.000 & -.134 & -.597 & .668 & .429 \\
\hline 무ㅇㅛㅛ & ESOL & -.134 & 1.000 & -.328 & -.394 & .472 \\
\hline$\frac{\pi}{0}$ & Blacks & -.597 & -.328 & 1.000 & -.351 & -.959 \\
\hline$\approx$ & Whites & .668 & -.394 & -.351 & 1.000 & .073 \\
\hline & Hispanics & .429 & .472 & -.959 & .073 & 1.000 \\
\hline & Passing FCAT Math & & .156 & .000 & .000 & .000 \\
\hline$\neq 0$ & ESOL & .156 & . & .006 & .001 & .000 \\
\hline 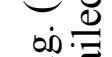 & Blacks & .000 & .006 & . & .003 & .000 \\
\hline$\ddot{\omega} \Xi$ & Whites & .000 & .001 & .003 & $\cdot$ & .290 \\
\hline & Hispanics & .000 & .000 & .000 & .290 & . \\
\hline
\end{tabular}

Note. $a=59$.

For this secondary research question, there was no independent variable with a strong correlation to the dependent variable. The independent variable with the weakest correlation to the dependent variable was the ESOL student population. The independent variables with moderate correlations were the Hispanic student population, the Black student population, and the White student population. The independent variable with a negative relationship with the dependent variable were the Black student population and the ESOL student population, meaning that as the value of these variables increased, a lower percentage of students passed the FCAT 2.0 Mathematics Test. The independent variables with a positive relationship with the dependent variable were the White student population and the Hispanic student population, meaning that as the value of these variables increased, a higher percentage of students passed the FCAT 2.0 Mathematics Test. 
Table 25 shows the results of the research hypothesis (H2). The $P_{\text {crit }}$ established for this study is 0.01 . The $P_{\text {calc }}$ for the ESOL student population is 0.156 , making it not statistically significant since 0.156 is not less than 0.01 so the research hypothesis is rejected (H2), meaning no significant negative relationship exists between racial and ethnic concentrations and the FCAT 2.0 mathematics scores when controlling the ESOL student population. The $P_{\text {calc }}$ for the White student population is $p<0.001$, making it statistically significant since it is less than 0.01 and not rejecting the research hypothesis (H2), meaning a significant negative relationship exists between racial and ethnic concentrations and the FCAT 2.0 mathematics scores when controlling the ESOL student population. The $P_{\text {calc }}$ for the Hispanic student population is $p<0.001$, making it statistically significant since it is less than 0.01 and not rejecting the research hypothesis $(\mathrm{H} 2)$, meaning a significant negative relationship exists between racial and ethnic concentrations and the FCAT 2.0 mathematics scores when controlling the ESOL student population. The $P_{\text {calc }}$ for the Black student population is $p<0.001$, making it statistically significant since it is less than 0.01 and not rejecting the research hypothesis $(\mathrm{H} 2)$, meaning a significant negative relationship exists between racial and ethnic concentrations and the FCAT 2.0 mathematics scores when controlling the ESOL student population.

For each research hypothesis that is rejected, a Type I Error has been made if any research hypothesis ends up being incorrect. There was a one percent chance of that happening. Moreover, for this secondary research question, there was only one independent variable that was not statistically significant, the ESOL student population. 
As shown in Table 26, the Sum of Squares (SS) Total for both models is 14892.765, representing all the variance in the data. For Model 1, the Sum of Squares (SS) Regression is 267.392 , the unique variance that can be explained. For Model 2, the Sum of Squares (SS) Regression is 8906.996 , which is the variance that can be explained. For Model 1, the Sum of Squares (SS) Residual is 14625.373 , the variance that cannot be explained. For Model 2, the Sum of Squares (SS) Residual is 5985.770, the variance that cannot be explained. For Model 1, Degrees of Freedom, $d f$, for Regression is one and for Residual is 57 , for a total of $58 d f$. For Model 2, Degrees of Freedom, $d f$, for Regression is three and for Residual is 55, for a total of $58 d f$. The Mean Square is the variance in the ANOVA. For Regression of Model 1, it is 267.392 and for Residual, it is 256.585. For Regression of Model 2, it is 2968.999 and for Residual, it is 108.832. For Model 1, the $F$ value is 1.042 which is the test statistic $\left(T S_{\text {calc }}\right.$ or $\left.F_{\text {calc }}\right)$. For Model 2, the $F$ value is 27.281 which is the test statistic $\left(T S_{\text {calc }}\right.$ or $\left.F_{\text {calc }}\right)$. For the Significant column, $P_{\text {calc }}$, Model 1 is not statistically significant since 0.312 is not less than 0.01 , thus it does reject the research hypothesis (H2), meaning no significant negative relationship exists between racial and ethnic concentrations and the FCAT 2.0 mathematics scores when controlling the ESOL student population. Model 2 is statistically significant because $p<0.001$ hence it is less than 0.01 , thus it does not reject the research hypothesis (H2), meaning a significant negative relationship exists between racial and ethnic concentrations and the FCAT 2.0 mathematics scores when controlling the ESOL student population. (Hinton et al., 2004) 
Table 26

ANOVA - Relationship of Racial and Ethnic Concentration (Whites and Hispanics) and FCAT 2.0 Mathematics Scores when controlling ESOL Student Population

\begin{tabular}{llccccc}
\hline Model & Sum of Squares & df & Mean Square & F & Sig. \\
\hline \multirow{4}{*}{1} & Regression & 267.392 & 1 & 267.392 & 1.042 & $.312^{\text {b }}$ \\
& Residual & 14625.373 & 57 & 256.585 & & \\
& Total & 14892.765 & 58 & & & \\
\hline \multirow{2}{*}{2} & Regression & 8906.996 & 3 & 2968.999 & 27.281 & $.000^{\mathrm{c}}$ \\
& Residual & 5985.770 & 55 & 108.832 & & \\
& Total & 14892.765 & 58 & & & \\
\hline
\end{tabular}

Note. a. Dependent Variable: \% Passing FCAT Math

b. Predictor: (Constant), \% of ESOL student population

c. Predictors: (Constant), \% of ESOL student population, \% of White student population, $\%$ of Hispanic student population

Table 27 shows how much each variable contributes to the research question for this particular test. According to the Beta results, the strongest contribution on the passing of the FCAT 2.0 Mathematics Test comes from the White student population, 0.595, in Model 2.

For the Sig. column, the independent variables making a significant contribution to the dependent variable were the White student population $(p<0.000)$ and the Hispanic student population $(p<0.000)$ in Model 2. The independent variable not making a significant contribution to the dependent variable was the ESOL student population in Model 1 (0.312) and Model 2 (0.351). 
Table 27

Coefficients - Relationship of Racial and Ethnic Concentration (Whites and Hispanics) and FCAT 2.0 Mathematics Scores when controlling ESOL Student Population

\begin{tabular}{llcccc}
\hline \multirow{2}{*}{ Model } & Total \% & \multicolumn{2}{c}{$\begin{array}{c}\text { Standardized } \\
\text { Coefficients }\end{array}$} & $\mathrm{t}$ & Sig. \\
\cline { 3 - 3 } & & Beta & & \\
\hline \multirow{2}{*}{1} & (Constant) & & 15.983 & .000 \\
& ESOL & -.134 & -1.021 & .312 \\
\hline \multirow{2}{*}{2} & (Constant) & & & 11.674 & .000 \\
& ESOL & -.104 & & -.940 & .351 \\
& Whites & .595 & 6.061 & .000 \\
& Hispanics & .434 & 4.243 & .000 \\
\hline
\end{tabular}

Moreover, Table 28's Part column under Correlations, for Model 1, the ESOL student population contributes $1.80 \%$ to the dependent variable, meaning it also explains $1.80 \%$ of the unique variance in the dependent variable and will cause the $R^{2}$ to drop $1.80 \%$ if it is not included in the model. On the other hand, for Model 2, the ESOL student population contributes $0.64 \%$ to the dependent variable, meaning it also explains $0.64 \%$ of variance in the dependent variable and will cause the $R^{2}$ to drop $0.64 \%$ if it is not included in the unique model. The White student population contributes $26.8 \%$ to the dependent variable, meaning it also explains $26.8 \%$ of the variance in the dependent variable and will cause the $R^{2}$ to drop $26.8 \%$ if it is not included in the model. The Hispanic student population contributes $13.2 \%$ to the dependent variable, meaning it also explains $13.2 \%$ of the variance in the dependent variable and will cause the $\mathrm{R}^{2}$ to drop $13.2 \%$ if it is not included in the model. The strongest contribution to the dependent variable of the passing of the FCAT 2.0 Mathematics Test comes from the White student population (26.8\%), followed by the Hispanic student population (13.2\%). (See Appendix II for the Collinearity Statistics explanation) 
Table 28

Coefficients Continued - Relationship of Racial and Ethnic Concentration (Whites and Hispanics) and FCAT 2.0 Mathematics Scores when controlling ESOL Student Population

\begin{tabular}{|c|c|c|c|c|}
\hline \multirow{2}{*}{\multicolumn{2}{|c|}{ Model }} & \multirow{2}{*}{$\begin{array}{c}\text { Correlations } \\
\text { Part }\end{array}$} & \multicolumn{2}{|c|}{ Collinearity Statistics } \\
\hline & & & Tolerance & VIF \\
\hline \multirow{2}{*}{1} & (Constant) & & & \\
\hline & ESOL & -.134 & 1.000 & 1.000 \\
\hline \multirow{4}{*}{2} & (Constant) & & & \\
\hline & ESOL & -.080 & .592 & 1.690 \\
\hline & Whites & .518 & .758 & 1.320 \\
\hline & Hispanics & .363 & .697 & 1.435 \\
\hline
\end{tabular}

\section{Whites, Blacks and ESOL}

The secondary research question was further tested using a combination of different variables. For this particular test, significant unique variance is sought between the schools' racial and ethnic concentration and the FCAT 2.0 Mathematics scores when controlling the ESOL student population. There was a high correlation between the White student population, the Black student population, and the Hispanic student population, and so the Hispanic student population was left out in order to eliminate the multicollinearity (Appendix II, Table 71). On the other hand, the independent variable of the Hispanic student population was kept for the Pearson $r$ and Sig. Table (Table 29) so that the correlation of this variable would be known.

As shown in Table 29, the correlations have different strengths. The ESOL student population has a -0.134 correlation with the percentage of the students passing the FCAT 2.0 Mathematics Test. It is a weak correlation since the $r$ is between 0 and -0.3 but, it is also a negative correlation meaning that as the ESOL student population increased, the percentage of the students passing the FCAT 2.0 Mathematics Test 
decreased. The White student population has a 0.668 correlation with the percentage of the students passing the FCAT 2.0 Mathematics Test. It is a moderate correlation since the $r$ is between 0.3 and 0.7 but, it is also a positive correlation meaning that as the White student population increased, the percentage of the students passing the FCAT 2.0 Mathematics Test increased. The Hispanic student population has a 0.429 correlation with the percentage of the students passing the FCAT 2.0 Mathematics Test. It is a positive correlation meaning that as the Hispanic student population increased, the percentage of the students passing the FCAT 2.0 Mathematics Test increased. It is a moderate correlation because the $r$ is between 0.3 and 0.7. The Black student population has a -0.597 correlation with the percentage of the students passing the FCAT 2.0 Mathematics Test. It is a negative correlation meaning that as the Black student population increased, the percentage of the students passing the FCAT 2.0 Mathematics Test decreased. It is a moderate correlation because the $r$ is between -0.3 and -0.7 . 
Table 29

Pearson r and Sig. (1-tailed) - Relationship of Racial and Ethnic Concentration (Blacks, Whites, Hispanics) with the FCAT 2.0 Mathematics Scores when controlling the ESOL Student Population

\begin{tabular}{|c|c|c|c|c|c|c|}
\hline Total & & $\begin{array}{c}\text { Passing } \\
\text { FCAT }\end{array}$ & ESOL & Blacks & Whites & Hispanics \\
\hline & Passing FCAT Math & 1.000 & -.134 & -.597 & .668 & .429 \\
\hline 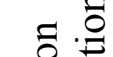 & ESOL & -.134 & 1.000 & -.328 & -.394 & .472 \\
\hline$\frac{\pi}{\pi}$ & Blacks & -.597 & -.328 & 1.000 & -.351 & -.959 \\
\hline$\stackrel{0}{0}$ & Whites & .668 & -.394 & -.351 & 1.000 & .073 \\
\hline & Hispanics & .429 & .472 & -.959 & .073 & 1.000 \\
\hline & Passing FCAT Math & & .156 & .000 & .000 & .000 \\
\hline$\perp \Rightarrow$ & ESOL & .156 & . & .006 & .001 & .000 \\
\hline $\sin :=$ & Blacks & .000 & .006 & . & .003 & .000 \\
\hline 政 & Whites & .000 & .001 & .003 & - & .290 \\
\hline & Hispanics & .000 & .000 & .000 & .290 & \\
\hline
\end{tabular}

Note. $a=59$.

For this secondary research question, there was no independent variable with a strong correlation to the dependent variable. The independent variable with the weakest correlation to the dependent variable was the ESOL student population. The independent variables with moderate correlations were the Hispanic student population, the Black student population, and the White student population. The independent variable with a negative relationship with the dependent variable were the Black student population and the ESOL student population, meaning that as the value of these variables increased, a lower percentage of students passed the FCAT 2.0 Mathematics Test. The independent variables with a positive relationship with the dependent variable were the White student population and the Hispanic student population, meaning that as the value of these variables increased, a higher percentage of students passed the FCAT 2.0 Mathematics Test. 
Table 29 shows the results of the research hypothesis (H2). The $P_{\text {crit }}$ established for this study is 0.01 . The $P_{\text {calc }}$ for the ESOL student population is 0.156 , making it not statistically significant since 0.156 is not less than 0.01 so the research hypothesis is rejected (H2), meaning no significant negative relationship exists between racial and ethnic concentrations and the FCAT 2.0 mathematics scores when controlling the ESOL student population. The $P_{\text {calc }}$ for the White student population is $p<0.001$, making it statistically significant since it is less than 0.01 and not rejecting the research hypothesis (H2), meaning a significant negative relationship exists between racial and ethnic concentrations and the FCAT 2.0 mathematics scores when controlling the ESOL student population. The $P_{\text {calc }}$ for the Hispanic student population is $p<0.001$, making it statistically significant since it is less than 0.01 and not rejecting the research hypothesis $(\mathrm{H} 2)$, meaning a significant negative relationship exists between racial and ethnic concentrations and the FCAT 2.0 mathematics scores when controlling the ESOL student population. The $P_{\text {calc }}$ for the Black student population is $p<0.001$, making it statistically significant since it is less than 0.01 and not rejecting the research hypothesis $(\mathrm{H} 2)$, meaning a significant negative relationship exists between racial and ethnic concentrations and the FCAT 2.0 mathematics scores when controlling the ESOL student population.

For each research hypothesis not rejected, a Type I Error has been made if any research hypothesis ends up being incorrect. There was a one percent chance of that happening. Moreover, for this secondary research question, there was only one independent variable that was not statistically significant, the ESOL student population. 
As shown in Table 30, the Sum of Squares (SS) Total for both models is 14892.765, representing all the variance in the data. For Model 1, the Sum of Squares (SS) Regression is 267.392 , which is the unique variance that can be explained. For Model 2, the Sum of Squares (SS) Regression is 8988.996, the variance that can be explained. For Model 1, the Sum of Squares (SS) Residual is 14625.373, the variance that cannot be explained. For Model 2, the Sum of Squares (SS) Residual is 5903.769, the variance that cannot be explained. For Model 1, Degrees of Freedom, $d f$, for Regression is one and for Residual is 57, for a total of $58 d f$. For Model 2, Degrees of Freedom, $d f$, for Regression is three and for Residual is 55 , for a total of $58 d f$. The Mean Square is the variance in the ANOVA. For Regression of Model 1, it is 267.392 and for Residual, it is 256.585. For Regression of Model 2, it is 2996.332 and for Residual, it is 107.341. For Model 1 , the $F$ value is 1.042 which is the test statistic $\left(T S_{\text {calc }}\right.$ or $\left.F_{\text {calc }}\right)$. For Model 2, the $F$ value is 27.914 which is the test statistic $\left(T S_{\text {calc }}\right.$ or $\left.F_{\text {calc }}\right)$. For the Significant column, $P_{\text {calc, }}$, Model 1 is not statistically significant since 0.312 is not less than 0.05 , thus it does reject the research hypothesis $(\mathrm{H} 2)$, meaning no significant negative relationship exists between racial and ethnic concentrations and the FCAT 2.0 Mathematics scores when controlling the ESOL student population. Model 2 is statistically significant because $p<0.001$ hence it is less than 0.01 , thus it does not reject the research hypothesis $(\mathrm{H} 2)$, meaning a significant negative relationship exists between racial and ethnic concentrations and the FCAT 2.0 Mathematics scores when controlling the ESOL student population. (Hinton et al., 2004) 
Table 30

ANOVA - Relationship of Racial and Ethnic Concentration (Whites and Blacks) and FCAT 2.0 Mathematics Scores when controlling ESOL Student Population

\begin{tabular}{llccccc}
\hline Model & Sum of Squares & df & Mean Square & F & Sig. \\
\hline \multirow{2}{*}{1} & Regression & 267.392 & 1 & 267.392 & 1.042 & $.312^{\mathrm{b}}$ \\
& Residual & 14625.373 & 57 & 256.585 & & \\
& Total & 14892.765 & 58 & & & \\
\hline \multirow{2}{*}{2} & Regression & 8988.996 & 3 & 2996.332 & 27.914 & $.000^{\mathrm{c}}$ \\
& Residual & 5903.769 & 55 & 107.341 & & \\
& Total & 14892.765 & 58 & & & \\
\hline
\end{tabular}

Note. a. Dependent Variable: \% Passing FCAT Math

b. Predictor: (Constant), \% of ESOL student population

c. Predictors: (Constant), \% of ESOL student population, $\%$ of White student population, $\%$ of Black student population

Table 31 shows how much each variable contributes to the research question for this particular test. According to the Beta results, the strongest contribution on the passing of the FCAT 2.0 Mathematics Test comes from the Black student population, -0.471 and the White student population, 0461 in Model 2.

For the Sig. column, the independent variables making a significant contribution to the dependent variable were the White student population $(p<0.001)$ and the Black student population $(p<0.001)$ in Model 2. The independent variable not making a significant contribution to the dependent variable was the ESOL student population in Model 1 (0.312) and Model 2 (0.336). 
Table 31

Coefficients - Relationship of Racial and Ethnic Concentration (Whites and Blacks) and FCAT 2.0 Mathematics Scores when controlling ESOL Student Population

\begin{tabular}{|c|c|c|c|c|}
\hline \multirow[t]{2}{*}{ Model } & \multirow{2}{*}{ Total \% } & $\begin{array}{l}\text { Standardized } \\
\text { Coefficients }\end{array}$ & \multirow[t]{2}{*}{$\mathrm{t}$} & \multirow[t]{2}{*}{ Sig. } \\
\hline & & Beta & & \\
\hline \multirow{2}{*}{1} & (Constant) & & 15.983 & .000 \\
\hline & ESOL & -.134 & -1.021 & .312 \\
\hline \multirow{4}{*}{2} & (Constant) & & 12.236 & .000 \\
\hline & ESOL & -.107 & -.970 & .336 \\
\hline & Whites & .461 & 4.156 & .000 \\
\hline & Blacks & -.471 & -4.361 & .000 \\
\hline
\end{tabular}

Moreover, Table 32's Part column under Correlations, for Model 1, the ESOL student population contributes $1.80 \%$ to the dependent variable, meaning it also explains $1.80 \%$ of the unique variance in the dependent variable and will cause the $R^{2}$ to drop $1.80 \%$ if it is not included in the model. On the other hand, for Model 2, the ESOL student population contributes $0.67 \%$ to the dependent variable, meaning it also explains $0.67 \%$ of variance in the dependent variable and will cause the $R^{2}$ to drop $0.67 \%$ if it is not included in the model. The White student population contributes $12.5 \%$ to the dependent variable, meaning it also explains $12.5 \%$ of variance in the dependent variable and will cause the $R^{2}$ to drop $12.5 \%$ if it is not included in the model. The Black student population contributes $13.69 \%$ to the dependent variable, meaning it also explains $13.69 \%$ of variance in the dependent variable and will cause the $R^{2}$ to drop $13.69 \%$ if it is not included in the model. The strongest contribution to the dependent variable of the passing of the FCAT 2.0 Mathematics Test comes from the Black student population (13.69\%), followed by the White student population (12.5\%). (See Appendix II for the Collinearity Statistics explanation) 
Table 32

Coefficients Continued - Relationship of Racial and Ethnic Concentration (Whites and Blacks) and FCAT 2.0 Mathematics Scores when controlling ESOL Student Population

\begin{tabular}{llccc}
\hline \multirow{2}{*}{ Model } & & \multicolumn{2}{c}{ Correlations } & \multicolumn{2}{c}{ Collinearity Statistics } \\
\cline { 3 - 5 } 1 & & Part & Tolerance & VIF \\
\hline \multirow{2}{*}{2} & (Constant) & & & \\
& ESOL & -.134 & 1.000 & 1.000 \\
\hline \multirow{2}{*}{2} & (Constant) & & & \\
& ESOL & -.082 & .596 & 1.678 \\
& Whites & .353 & .586 & 1.707 \\
& Blacks & -.370 & .619 & 1.616 \\
\hline
\end{tabular}

\section{Relationship between FCAT 2.0 Mathematics Scores and Socio-Economic Status}

The study is driven by another secondary research question which tests the relationships between the dependent variable and one independent variable. For this particular test, significant variance is sought between the FCAT 2.0 Mathematics scores of the public middle school students and socio-economic status (SES).

As shown in Table 33, the correlation between of the students passing the FCAT 2.0 Mathematics Test and the Economically Disadvantaged (SES) student population is -0.830 . It is a strong correlation because the $r$ is between -0.7 and -1 but, it is also a negative correlation meaning that as the Economically Disadvantaged student population increased, the percentage of the students passing the FCAT 2.0 Mathematics Test decreased.

Table 33 shows the result of the research hypothesis (H3). The $P_{\text {crit }}$ established for this study is 0.01 . The $P_{\text {calc }}$ for the relationship between the Economically Disadvantaged (SES) student population and the students passing the FCAT 2.0 Mathematics Test is $p<0.001$, making it statistically significant since it is less than 0.01 and not rejecting the research hypothesis $(\mathrm{H} 3)$, meaning a significant negative 
relationship exists between the FCAT 2.0 Mathematics scores and socio-economic status. A Type I Error has been made if the research hypothesis ends up being incorrect. There was a one percent chance of that happening.

Table 33

Pearson r and Sig. (1-tailed) - Relationship of FCAT 2.0 Mathematics Scores and SocioEconomic Status

\begin{tabular}{llcc}
\hline Total $\%^{a}$ & & $\begin{array}{c}\text { Passing } \\
\text { FCAT Math }\end{array}$ & $\begin{array}{c}\text { Economically } \\
\text { Disadvantaged }\end{array}$ \\
\hline Pearson & Passing FCAT Math & 1.000 & -.830 \\
Correlation & Economically Disadvantaged & -.830 & 1.000 \\
\hline Sig. $(1-$ & Passing FCAT Math &. & .000 \\
tailed) & Economically Disadvantaged & .000 &. \\
\hline
\end{tabular}

Note. $a=59$.

As shown in 34, the Sum of Squares (SS) Total is 14892.765, representing all the variance in the data. The Sum of Squares (SS) Regression is 10250.929, the variance that can be explained. The Sum of Squares (SS) Residual is 4641.837, the variance that cannot be explained. The Degrees of Freedom, $d f$, for Regression is one and for Residual is 57 , for a total of $58 d f$. The Mean Square is the variance in the ANOVA. For Regression, it is 10250.929 and for Residual, it is 81.436 . The $F$ value is 125.878 which is the test statistic $\left(T S_{\text {calc }}\right.$ or $\left.F_{\text {calc }}\right)$. For the Significant column, $P_{\text {calc }}$, it is statistically significant because $p<0.001$ hence it is less than 0.01 , thus it does not reject the research hypothesis (H3), meaning a significant negative relationship exists between the FCAT 2.0 mathematics scores and socio-economic status. (Hinton et al., 2004) 
Table 34

ANOVA - Relationship of FCAT 2.0 Mathematics Scores and Socio-Economic Status

\begin{tabular}{llccccc}
\hline & Model & Sum of Squares & df & Mean Square & F & Sig. \\
\hline \multirow{2}{*}{1} & Regression & 10250.929 & 1 & 10250.929 & 1215.878 & $.000^{\mathrm{b}}$ \\
& Residual & 4641.837 & 57 & 81.436 & & \\
& Total & 14892.765 & 58 & & & \\
\hline
\end{tabular}

Note. a. Dependent Variable: \% Passing FCAT Math

b. Predictor: (Constant), \% of Economically Disadvantage student population

Table 35 shows how much the variable contributes to the research question for

this particular test. According to the Beta results, the Economically Disadvantaged (SES) student population has a strong contribution on the passing of the FCAT 2.0 Mathematics Test. For the Sig. column, the Economically Disadvantaged (SES) student population makes a significant contribution to the dependent variable $(p<0.001)$.

Table 35

Coefficients - Relationship of FCAT 2.0 Mathematics Scores and Socio-Economic Status

\begin{tabular}{|c|c|c|c|c|}
\hline \multirow[t]{2}{*}{ Model } & \multirow{2}{*}{ Total \% } & $\begin{array}{c}\text { Standardized } \\
\text { Coefficients }\end{array}$ & \multirow[t]{2}{*}{$\mathrm{t}$} & \multirow[t]{2}{*}{ Sig. } \\
\hline & & Beta & & \\
\hline \multirow[b]{2}{*}{1} & (Constant) & & 20.583 & .000 \\
\hline & $\begin{array}{l}\text { Economically } \\
\text { Disadvantaged (SES) }\end{array}$ & -.830 & -11.220 & .000 \\
\hline
\end{tabular}

Moreover, Table 36's Part column under Correlations, after squaring the values the Economically Disadvantaged student population contributes $68.89 \%$ to the dependent variable, meaning it also explains $68.89 \%$ of variance in the dependent variable and will cause the $R^{2}$ to drop $68.89 \%$ if it is not included in the model. (See Appendix II for the Collinearity Statistics explanation) 
Table 36

Coefficients Continued - Relationship of FCAT 2.0 Mathematics Scores and SocioEconomic Status

\begin{tabular}{clccc}
\hline \multirow{2}{*}{ Model } & & Correlations & \multicolumn{2}{c}{ Collinearity Statistics } \\
\cline { 3 - 5 } & & Part & Tolerance & VIF \\
\hline \multirow{2}{*}{1} & $\begin{array}{l}\text { (Constant) } \\
\text { Economically } \\
\text { Disadvantaged }\end{array}$ & -.830 & & \\
\hline
\end{tabular}

\section{Relationship between FCAT 2.0 Mathematics Scores and Socio-Economic Status} when controlling Racial and Ethnic Concentrations

\section{Whites, Hispanics and Socio-Economic Status}

The study is driven by secondary research questions which tests different relationships between the dependent variable and independent variables. For this particular test, significant variance is sought between the FCAT 2.0 Mathematics scores and socio-economic status when controlling the racial and ethnic concentrations (Whites and Hispanics). There was a high correlation between the White student population, the Black student population, and the Hispanic student population, and so the Black student population was left out in order to eliminate the multicollinearity (Appendix II, Table 76). On the other hand, the independent variable of the Black student population was kept for the Pearson $r$ and Sig. Table (Table 37) so that the correlation of this variable would be known.

As shown inTable 37, the correlations have different strengths. The White student population has a 0.668 correlation with the percentage of the students passing the FCAT 2.0 Mathematics Test. It is a moderate correlation since the $r$ is between 0.3 and 0.7 but, it is also a positive correlation meaning that as the White student population 
increased, the percentage of the students passing the FCAT 2.0 Mathematics Test increased. The Hispanic student population has a 0.429 correlation with the percentage of the students passing the FCAT 2.0 Mathematics Test. It is a positive correlation meaning that as the Hispanic student population increased, the percentage of the students passing the FCAT 2.0 Mathematics Test increased. It is a moderate correlation since the $r$ is between 0.3 and 0.7 . The Black student population has a -0.597 correlation with the percentage of the students passing the FCAT 2.0 Mathematics Test. It is a negative correlation meaning that as the Black student population increased, the percentage of the students passing the FCAT 2.0 Mathematics Test decreased. It is a moderate correlation since the $r$ is between -0.3 and -0.7 . The Economically Disadvantaged (SES) student population has a -0.830 correlation with the percentage of the students passing the FCAT 2.0 Mathematics Test. It is a negative correlation meaning that as the Economically Disadvantaged (SES) student population increased, the percentage of the students passing the FCAT 2.0 Mathematics Test decreased. It is a strong correlation because the $r$ is between -0.7 and -1 . 
Table 37

Pearson r and Sig. (1-tailed) - Relationship of FCAT 2.0 Mathematics Scores and SocioEconomic Status when controlling Racial and Ethnic Concentration (Whites, Blacks, Hispanics)

\begin{tabular}{|c|c|c|c|c|c|c|}
\hline \multicolumn{2}{|c|}{ Total $\%{ }^{\mathrm{a}}$} & \multirow{2}{*}{$\begin{array}{c}\text { Passing } \\
\text { FCAT } \\
\text { Math } \\
1.000\end{array}$} & Whites & Hispanics & Blacks & $\begin{array}{l}\text { Economically } \\
\text { Disadvantaged }\end{array}$ \\
\hline \multirow{5}{*}{ 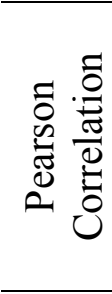 } & Passing FCAT Math & & .668 & .429 & -.597 & -.830 \\
\hline & Whites & .668 & 1.000 & .073 & -.351 & -.891 \\
\hline & Hispanics & .429 & .073 & 1.000 & -.959 & -.161 \\
\hline & Blacks & -.597 & -.351 & -.959 & 1.000 & .407 \\
\hline & $\begin{array}{l}\text { Economically } \\
\text { Disadvantaged (SES) }\end{array}$ & -.830 & -.891 & -.161 & .407 & 1.000 \\
\hline \multirow{5}{*}{ 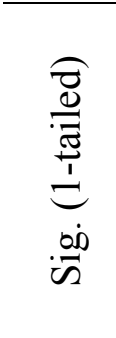 } & Passing FCAT Math & & .000 & .000 & .000 & .000 \\
\hline & Whites & .000 & $\cdot$ & .290 & .003 & .000 \\
\hline & Hispanics & .000 & .290 & 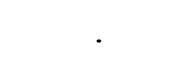 & .000 & .111 \\
\hline & Blacks & .000 & .003 & .000 & $\cdot$ & .001 \\
\hline & $\begin{array}{l}\text { Economically } \\
\text { Disadvantaged } \\
\text { (SES) }\end{array}$ & .000 & .000 & .111 & .001 & 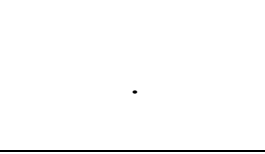 \\
\hline
\end{tabular}

Note. $a=59$.

For this secondary research question, the independent variable with the strongest correlation to the dependent variable was the Economically Disadvantaged (SES) student population, followed by the White student population. The independent variables with the moderate correlation to the dependent variable were the Hispanic student population and the Black student population. The independent variables with a negative relationship with the dependent variable were the Black student population and the Economically Disadvantaged (SES) student population, meaning that as the value of these variables increased, a lower percentage of students passed the FCAT 2.0 Mathematics Test. The independent variables with a positive relationship with the dependent variable were the White student population and the Hispanics student population, meaning that as the value 
of these variables increased, a higher percentage of students passed the FCAT 2.0 Mathematics Test.

Table 37 displays the results of the research hypothesis (H4). The $P_{\text {crit }}$ established for this study is 0.01 . The $P_{\text {calc }}$ for the White student population is $p<0.001$, making it statistically significant since it is less than 0.01 and not rejecting the research hypothesis (H4), meaning a significant negative relationship exists between the FCAT 2.0 Mathematics scores and socio-economic status when controlling racial and ethnic concentrations. The $P_{\text {calc }}$ for the Hispanic student population is $p<0.001$, making it statistically significant since it is less than 0.01 and not rejecting the research hypothesis (H4), meaning a significant negative relationship exists between the FCAT 2.0 Mathematics scores and socio-economic status when controlling racial and ethnic concentrations. The $P_{\text {calc }}$ for the Black student population is $p<0.001$, making it statistically significant since it is less than 0.01 and not rejecting the research hypothesis (H4), meaning a significant negative relationship exists between the FCAT 2.0 Mathematics scores and socio-economic status when controlling racial and ethnic concentrations. The $P_{\text {calc }}$ for the Economically Disadvantaged student population is $p<$ 0.001 , making it statistically significant since it is less than 0.01 and not rejecting the research hypothesis $(\mathrm{H} 4)$, meaning a significant negative relationship exists between the FCAT 2.0 Mathematics scores and socio-economic status when controlling racial and ethnic concentrations.

For each research hypothesis that is rejected, a Type I Error has been made if any research hypothesis ends up being incorrect. There was a one percent chance of that 
happening. Moreover, for this secondary research question, all variables were statistically significant.

As shown in Table 38, the Sum of Squares (SS) Total for both models is 14892.765, which represents all the variance in the data. For Model 1, the Sum of Squares (SS) Regression is 8810.772 , which is the unique variance that can be explained. For Model 2, the Sum of Squares (SS) Regression is 11762.765, which is the variance that can be explained. For Model 1, the Sum of Squares (SS) Residual is 6081.993, which is the variance that cannot be explained. For Model 2, the Sum of Squares (SS) Residual is 3130.000 , which is the variance that cannot be explained. For Model 1, Degrees of Freedom, $d f$, for Regression is two and for Residual is 56, for a total of $58 d f$. For Model 2, Degrees of Freedom, $d f$, for Regression is three and for Residual is 55, for a total of $58 d f$. The Mean Square is the variance in the ANOVA. For Regression of Model 1, it is 4405.386 and for Residual, it is 108.607. For Regression of Model 2, it is 3920.922 and for Residual, it is 56.909. For Model 1 , the $F$ value is 40.563 which is the test statistic $\left(T S_{\text {calc }}\right.$ or $\left.F_{\text {calc }}\right)$. For Model 2, the $F$ value is 68.898 which is the test statistic $\left(T S_{\text {calc }}\right.$ or $\left.F_{\text {calc }}\right)$. For the Significant column, $P_{\text {calc, }}$, Model 1 is statistically significant since $p<0.001$ hence it is less than 0.01 , thus it does not reject the research hypothesis (H4), meaning a significant negative relationship exists between the FCAT 2.0 Mathematics scores and socio-economic status when controlling racial and ethnic concentrations. Model 2 is statistically significant because $p<0.001$ hence it is less than 0.01 , thus it does not reject the research hypothesis (H4), meaning a significant negative relationship exists between the FCAT 2.0 Mathematics scores and socio-economic status when controlling racial and ethnic concentrations. (Hinton et al., 2004) 
Table 38

ANOVA - Relationship of FCAT 2.0 Mathematics Scores and Socio-Economic Status when controlling Racial and Ethnic Concentration (Whites \& Hispanics)

\begin{tabular}{llccccc}
\hline Model & Sum of Squares & df & Mean Square & F & Sig. \\
\hline \multirow{2}{*}{1} & Regression & 8810.772 & 2 & 4405.386 & 40.563 & $.000^{\mathrm{b}}$ \\
& Residual & 6081.993 & 56 & 108.607 & & \\
& Total & 14892.765 & 58 & & & \\
\hline \multirow{2}{*}{2} & Regression & 11762.765 & 3 & 3920.922 & 68.898 & $.000^{\mathrm{c}}$ \\
& Residual & 3130.000 & 55 & 56.909 & & \\
& Total & 14892.765 & 58 & & & \\
\hline
\end{tabular}

Note. a. Dependent Variable: \% Passing FCAT Math

b. Predictor: (Constant), \% of White student population, $\%$ of Hispanic student population

c. Predictors: (Constant), \% of White student population, \% of Hispanic student population, $\%$ of Economically Disadvantaged student population

Table 39 shows how much each variable contributes to the research question for this particular test. According to the Beta results, the strongest contribution on the passing of the FCAT 2.0 Mathematics Test comes from the Economically Disadvantaged (SES) student population, -1.002, in Model 2, followed by the White student population, 0.640 , in Model 1.

For the Sig. column, the independent variables making a significant contribution to the dependent variable are the Economically Disadvantaged (SES) student population $(p<0.001)$ and the Hispanic student population $(p<0.001)$ in Model 2. The independent variable not making a significant contribution to the dependent variable is the White student population in Model 2 (0.080), but it does make a significant contribution in Model 1, $p<0.001$. (Hinton et al., 2004) 
Table 39

Coefficients - Relationship of FCAT 2.0 Mathematics Scores and Socio-Economic Status when controlling Racial and Ethnic Concentration (Whites \& Hispanics)

\begin{tabular}{|c|c|c|c|c|}
\hline \multicolumn{2}{|c|}{ Model } & \multirow{2}{*}{$\begin{array}{c}\begin{array}{c}\text { Standardized } \\
\text { Coefficients }\end{array} \\
\text { Beta } \\
\end{array}$} & \multirow[t]{2}{*}{$\mathrm{t}$} & \multirow{2}{*}{ Sig. } \\
\hline & Total \% & & & \\
\hline \multirow{3}{*}{1} & (Constant) & & 12.830 & .000 \\
\hline & Whites & .640 & 7.478 & .000 \\
\hline & Hispanics & .382 & 4.458 & .000 \\
\hline \multirow{4}{*}{2} & (Constant) & & 10.007 & .000 \\
\hline & Whites & -.245 & -1.781 & .080 \\
\hline & Hispanics & .285 & 4.499 & .000 \\
\hline & Economically Disadvantaged (SES) & -1.002 & -7.202 & .000 \\
\hline
\end{tabular}

Moreover, Table 40's Part column under Correlations, for Model 1, the White student population contributes $40.8 \%$ to the dependent variable, meaning it also explains $40.8 \%$ of the unique variance in the dependent variable and will cause the $R^{2}$ to drop $40.8 \%$ if it is not included in the model. The Hispanic student population contributes $14.5 \%$ to the dependent variable, meaning it also explains $14.5 \%$ of the unique variance in the dependent variable and will cause the $R^{2}$ to drop $14.5 \%$ if it is not included in the model. On the other hand, for Model 2, the White student population contributes $1.21 \%$ to the dependent variable, meaning it also explains $1.21 \%$ of variance in the dependent variable and will cause the $R^{2}$ to drop $1.21 \%$ if it is not included in the model. The Hispanic student population contributes $7.73 \%$ to the dependent variable, meaning it also explains $7.73 \%$ of variance in the dependent variable and will cause the $R^{2}$ to drop $7.73 \%$ if it is not included in the model. The Economically Disadvantaged (SES) student population contributes $19.8 \%$ to the dependent variable, meaning it also explains $19.8 \%$ of variance in the dependent variable and will cause the $R^{2}$ to drop $19.8 \%$ if it is not included in the model. The strongest contribution to the dependent variable of the passing 
of the FCAT 2.0 Mathematics Test comes from the White student population $(40.8 \%)$ in Model 1 and Economically Disadvantaged (SES) student population (19.8\%) in Model 2. (See Appendix II for the Collinearity Statistics explanation).

Table 40

Coefficients Continued - Relationship of FCAT 2.0 Mathematics Scores and SocioEconomic Status when controlling Racial and Ethnic Concentration (Whites \& Hispanics)

\begin{tabular}{llccc}
\hline \multirow{2}{*}{ Model } & Correlations & \multicolumn{2}{c}{ Collinearity Statistics } \\
\cline { 2 - 5 } & (Constant) & Part & Tolerance & VIF \\
\hline Whites & & & \\
& Hispanics & .639 & .995 & 1.005 \\
\hline & (Constant) & .381 & .995 & 1.005 \\
\hline Whites & & & \\
2 & Hispanics & -.110 & .202 & 4.961 \\
& Economically Disadvantaged & .278 & .950 & 1.052 \\
(SES) & -.445 & .197 & 5.066 \\
\hline
\end{tabular}

\section{Whites, Blacks and Socio-Economic Status}

The secondary research question was further tested using a combination of different variables. For this particular test, significant variance is sought between the FCAT 2.0 Mathematics scores and socio-economic status when controlling the racial and ethnic concentrations (Whites and Blacks). There was a high correlation between the White student population, the Black student population, and the Hispanic student population, and so the Hispanic student population was left out in order to eliminate the multicollinearity (Appendix II, Table 79). On the other hand, the independent variable of the Hispanic student population was kept for the Pearson $r$ and Sig. Table (Table 41) so that the correlation of this variable is known. 
As shown in Table 41, the correlations have different strengths. The White student population has a 0.668 correlation with the percentage of the students passing the FCAT 2.0 Mathematics Test. It is a moderate correlation since the $r$ is between 0.3 and 0.7 but, it is also a positive correlation meaning that as the White student population increased, the percentage of the students passing the FCAT 2.0 Mathematics Test increased. The Hispanic student population has a 0.429 correlation with the percentage of the students passing the FCAT 2.0 Mathematics Test. It is a positive correlation meaning that as the Hispanic student population increased, the percentage of the students passing the FCAT 2.0 Mathematics Test increased. It is a moderate correlation since the $r$ is between 0.3 and 0.7 . The Black student population has a -0.597 correlation with the percentage of the students passing the FCAT 2.0 Mathematics Test. It is a negative correlation meaning that as the Black student population increased, the percentage of the students passing the FCAT 2.0 Mathematics Test decreased. It is a moderate correlation since the $r$ is between -0.3 and -0.7 . The Economically Disadvantaged (SES) student population has a -0.830 correlation with the percentage of the students passing the FCAT 2.0 Mathematics Test. It is a negative correlation meaning that as the Economically Disadvantaged (SES) student population increased, the percentage of the students passing the FCAT 2.0 Mathematics Test decreased. It is a strong correlation because the $r$ is between -0.7 and -1 . 
Table 41

Pearson r and Sig. (1-tailed) - Relationship of FCAT 2.0 Mathematics Scores and SocioEconomic Status when controlling Racial and Ethnic Concentration (Whites, Blacks, Hispanics)

\begin{tabular}{|c|c|c|c|c|c|c|}
\hline \multicolumn{2}{|c|}{ Total $\%{ }^{\mathrm{a}}$} & \multirow{2}{*}{$\begin{array}{c}\text { Passing } \\
\text { FCAT } \\
\text { Math }\end{array}$} & Whites & Hispanics & Blacks & $\begin{array}{l}\text { Economically } \\
\text { Disadvantaged }\end{array}$ \\
\hline \multirow{5}{*}{ 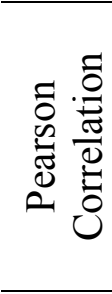 } & Passing FCAT Math & & .668 & .429 & -.597 & -.830 \\
\hline & Whites & .668 & 1.000 & .073 & -.351 & -.891 \\
\hline & Hispanics & .429 & .073 & 1.000 & -.959 & -.161 \\
\hline & Blacks & -.597 & -.351 & -.959 & 1.000 & .407 \\
\hline & $\begin{array}{l}\text { Economically } \\
\text { Disadvantaged (SES) }\end{array}$ & -.830 & -.891 & -.161 & .407 & 1.000 \\
\hline \multirow{5}{*}{ 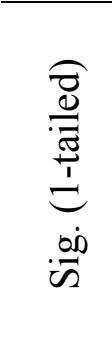 } & Passing FCAT Math & . & .000 & .000 & .000 & .000 \\
\hline & Whites & .000 & 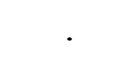 & .290 & .003 & .000 \\
\hline & Hispanics & .000 & .290 & . & .000 & .111 \\
\hline & Blacks & .000 & .003 & .000 & . & .001 \\
\hline & $\begin{array}{l}\text { Economically } \\
\text { Disadvantaged } \\
\text { (SES) }\end{array}$ & .000 & .000 & .111 & .001 & . \\
\hline
\end{tabular}

Note. $a=59$.

For this secondary research question, the independent variable with the strongest correlation to the dependent variable was the Economically Disadvantaged (SES) student population, followed by the White student population. The independent variables with the moderate correlation to the dependent variable were the Hispanic student population and the Black student population. The independent variables with a negative relationship with the dependent variable were the Black student population and the Economically Disadvantaged (SES) student population, meaning that as the value of these variables increased, a lower percentage of students passed the FCAT 2.0 Mathematics Test. The independent variables with a positive relationship with the dependent variable were the White student population and the Hispanics student population, meaning that as the value 
of these variables increased, a higher percentage of students passed the FCAT 2.0 Mathematics Test.

Table 41 displays the results of the research hypothesis (H4). The $P_{\text {crit }}$ established for this study is 0.01 . The $P_{\text {calc }}$ for the White student population is $p<0.001$, making it statistically significant since it is less than 0.01 and not rejecting the research hypothesis (H4), meaning a significant negative relationship exists between the FCAT 2.0 Mathematics scores and socio-economic status when controlling racial and ethnic concentrations. The $P_{\text {calc }}$ for the Hispanic student population is $p<0.001$, making it statistically significant since it is less than 0.01 and not rejecting the research hypothesis (H4), meaning a significant negative relationship exists between the FCAT 2.0 Mathematics scores and socio-economic status when controlling racial and ethnic concentrations. The $P_{\text {calc }}$ for the Black student population is $p<0.001$, making it statistically significant since it is less than 0.01 and not rejecting the research hypothesis (H4), meaning a significant negative relationship exists between the FCAT 2.0 Mathematics scores and socio-economic status when controlling racial and ethnic concentrations. The $P_{\text {calc }}$ for the Economically Disadvantaged student population is $p<$ 0.001 , making it statistically significant since it is less than 0.01 and not rejecting the research hypothesis $(\mathrm{H} 4)$, meaning a significant negative relationship exists between the FCAT 2.0 Mathematics scores and socio-economic status when controlling racial and ethnic concentrations.

For each research hypothesis not rejected, a Type I Error has been made if any research hypothesis ends up being incorrect. There is a one percent chance of that 
happening. Moreover, for this secondary research question, all variables were statistically significant.

As shown in Table 42, the Sum of Squares (SS) Total for both models is 14892.765, representing all the variance in the data. For Model 1, the Sum of Squares (SS) Regression is 8888.069 , which is the unique variance that can be explained. For Model 2, the Sum of Squares (SS) Regression is 11785.185 , the variance that can be explained. For Model 1, the Sum of Squares (SS) Residual is 6004.696, the variance that cannot be explained. For Model 2, the Sum of Squares (SS) Residual is 3107.580, the variance that cannot be explained. For Model 1, Degrees of Freedom, $d f$, for Regression is two and for Residual is 56, for a total of $58 d f$. For Model 2, Degrees of Freedom, $d f$, for Regression is three and for Residual is 55 , for a total of $58 d f$. The Mean Square is the variance in the ANOVA. For Regression of Model 1, it is 4444.034 and for Residual, it is 107.227. For Regression of Model 2, it is 3928.395 and for Residual, it is 56.501 . For Model 1, the $F$ value is 41.445 which is the test statistic $\left(T S_{\text {calc }}\right.$ or $\left.F_{\text {calc }}\right)$. For Model 2, the $F$ value is 69.527 which is the test statistic $\left(T S_{\text {calc }}\right.$ or $\left.F_{\text {calc }}\right)$. For the Significant column, $P_{\text {calc }}$, Model 1 is statistically significant since $p<0.001$ hence it is less than 0.01 , thus it does not reject the research hypothesis (H4), meaning a significant negative relationship exists between the FCAT 2.0 Mathematics scores and socio-economic status when controlling racial and ethnic concentrations. Model 2 is statistically significant because $p<0.001$ hence it is less than 0.01 , thus it does not reject the research hypothesis (H4), meaning a significant negative relationship exists between the FCAT 2.0 Mathematics scores and socio-economic status when controlling racial and ethnic concentrations. (Hinton et al., 2004) 
Table 42

ANOVA - Relationship of FCAT 2.0 Mathematics Scores and Socio-Economic Status when controlling Racial and Ethnic Concentration (Whites \& Blacks)

\begin{tabular}{llccccc}
\hline Model & Sum of Squares & df & Mean Square & F & Sig. \\
\hline \multirow{2}{*}{1} & Regression & 8888.069 & 2 & 4444.034 & 41.445 & $.000^{\mathrm{b}}$ \\
& Residual & 6004.696 & 56 & 107.227 & & \\
& Total & 14892.765 & 58 & & & \\
\hline \multirow{2}{*}{2} & Regression & 11785.185 & 3 & 3928.395 & 69.527 & $.000^{\mathrm{c}}$ \\
& Residual & 3107.580 & 55 & 56.501 & & \\
& Total & 14892.765 & 58 & & & \\
\hline
\end{tabular}

Note. a. Dependent Variable: \% Passing FCAT Math

b. Predictor: (Constant), $\%$ of White student population, $\%$ of Black student population

c. Predictors: (Constant), \% of White student population, $\%$ of Black student population, $\%$ of Economically Disadvantaged student population

Table 43 shows how much each variable contributes to the research question for this particular test. According to the Beta results, the strongest contribution on the passing of the FCAT 2.0 Mathematics Test comes from the Economically Disadvantaged (SES) student population, -0.995, in Model 2, followed by the White student population, 0.523, in Model 1.

For the Sig. column, the independent variables that make a significant contribution to the dependent variable were the Black student population $(p<0.001)$ and the Economically Disadvantaged (SES) student population $(p<0.001)$ in Models 1 and 2 . The White student population makes a significant contribution to the dependent variable in Model $1(p<0.001)$ but, not in Model $2(0.020)$. 
Table 43

Coefficients - Relationship of FCAT 2.0 Mathematics Scores and Socio-Economic Status when controlling Racial and Ethnic Concentration (Whites \& Blacks)

\begin{tabular}{|c|c|c|c|c|}
\hline \multicolumn{2}{|c|}{ Model } & \multirow{2}{*}{$\begin{array}{c}\begin{array}{c}\text { Standardized } \\
\text { Coefficients }\end{array} \\
\text { Beta } \\
\end{array}$} & \multirow{2}{*}{$\mathrm{t}$} & \multirow{2}{*}{ Sig. } \\
\hline & Total $\%$ & & & \\
\hline \multirow{3}{*}{1} & (Constant) & & 23.020 & .000 \\
\hline & Whites & .523 & 5.771 & .000 \\
\hline & Blacks & -.414 & -4.567 & .000 \\
\hline \multirow{4}{*}{2} & (Constant) & & 11.696 & .000 \\
\hline & Whites & -.326 & -2.403 & .020 \\
\hline & Blacks & -.307 & -4.559 & .000 \\
\hline & Economically Disadvantaged (SES) & -.995 & -7.161 & .000 \\
\hline
\end{tabular}

Moreover, Table 44's Part column under Correlations, for Model 1, the White student population contributes $24 \%$ to the dependent variable, meaning it also explains $24 \%$ of the unique variance in the dependent variable and will cause the $R^{2}$ to drop $24 \%$ if it is not included in the model. The Black student population contributes $15 \%$ to the dependent variable, meaning it also explains $15 \%$ of the unique variance in the dependent variable and will cause the $R^{2}$ to drop $15 \%$ if it is not included in the model. On the other hand, for Model 2, the White student population contributes $2.19 \%$ to the dependent variable, meaning it also explains $2.19 \%$ of variance in the dependent variable and will cause the $R^{2}$ to drop $2.19 \%$ if it is not included in the model. The Black student population contributes $7.90 \%$ to the dependent variable, meaning it also explains $7.90 \%$ of variance in the dependent variable and will cause the $R^{2}$ to drop $7.90 \%$ if it is not included in the model. The Economically Disadvantaged (SES) student population contributes $19.4 \%$ to the dependent variable, meaning it also explains $19.4 \%$ of variance in the dependent variable and will cause the $R^{2}$ to drop $19.4 \%$ if it is not included in the model. The strongest contribution to the dependent variable of the passing of the FCAT 
2.0 Mathematics Test comes from the White student population (24\%) in Model 1 and Economically Disadvantaged (SES) student population (19.4\%) in Model 2. (See Appendix II for the Collinearity Statistics explanation)

Table 44

Coefficients Continued - Relationship of FCAT 2.0 Mathematics Scores and SocioEconomic Status when controlling Racial and Ethnic Concentration (Whites \& Blacks)

\begin{tabular}{llccc}
\hline \multirow{2}{*}{ Model } & \multicolumn{2}{c}{ Correlations } & \multicolumn{2}{c}{ Collinearity Statistics } \\
\cline { 3 - 5 } & (Constant) & Part & Tolerance & VIF \\
\hline \multirow{2}{*}{$1 \quad$ Whites } & & & \\
& Blacks & .490 & .877 & 1.141 \\
& (Constant) & -.387 & .877 & 1.141 \\
\hline \multirow{2}{*}{2} & Whites & -.148 & .206 & 4.844 \\
& Blacks & -.281 & .834 & 1.199 \\
& Economically Disadvantaged (SES) & -.441 & .197 & 5.087 \\
\hline
\end{tabular}

Relationship between School Climate and FCAT 2.0 Mathematics Scores when controlling Racial and Ethnic Concentrations

\section{Whites, Hispanics and School Climate}

The study is driven by secondary research questions which tests different relationships between the dependent variable and independent variables. For this particular test, significant variance is sought between school climate and the FCAT 2.0 Mathematics scores when controlling the racial and ethnic concentrations (Whites and Hispanics). There was a high correlation between the White student population, the Black student population, and the Hispanic student population thus, the Black student population were left out in order to eliminate the multicollinearity (Appendix II, Table 82). On the other hand, the independent variable of the Black student population was 
kept for the Pearson $r$ and Sig. Table (Table 45) so that the correlation of this variable would be known.

As shown in Table 45, the correlations have different strengths. The White student population has a 0.668 correlation with the percentage of the students passing the FCAT 2.0 Mathematics Test. It is a moderate correlation since the $r$ is between 0.3 and 0.7 but, it is also a positive correlation meaning that as the White student population increased, the percentage of the students passing the FCAT 2.0 Mathematics Test increased. The Hispanic student population has a 0.429 correlation with the percentage of the students passing the FCAT 2.0 Mathematics Test. It is a positive correlation meaning that as the Hispanic student population increased, the percentage of the students passing the FCAT 2.0 Mathematics Test increased. It is a moderate correlation since the $r$ is between 0.3 and 0.7 . The Black student population has a -0.597 correlation with the percentage of the students passing the FCAT 2.0 Mathematics Test. It is a negative correlation meaning that as the Black student population increased, the percentage of the students passing the FCAT 2.0 Mathematics Test decreased. It is a moderate correlation since the $r$ is between -0.3 and -0.7 . The parents agreeing that the school climate is positive and helps students learn has a 0.595 correlation with the percentage of the students passing the FCAT 2.0 Mathematics Test. It is a positive correlation meaning that as the parents agreeing that the school climate is positive and helps students learn increased while the percentage of the students passing the FCAT 2.0 Mathematics Test also increased. It is a moderate correlation since the $r$ is between 0.3 and 0.7 . The students agreeing that the school climate is positive and helps them learn has a 0.741 correlation with the percentage of the students passing the FCAT 2.0 Mathematics Test. 
It is a strong correlation since the $r$ is between 0.7 and 1 but, it is also a positive correlation meaning that as the students agreeing that the school climate is positive and helps them learn increased while the percentage of the students passing the FCAT 2.0 Mathematics Test also increased. The staff agreeing that the school climate is positive and helps students learn has a 0.605 correlation with the percentage of the students passing the FCAT 2.0 Mathematics Test. It is a moderate correlation since the $r$ is between 0.3 and 0.7 but it is also a positive correlation meaning that as the staff agreeing that the school climate is positive and helps students learn increased while the percentage of the students passing the FCAT 2.0 Mathematics Test also increased. 
Table 45

Pearson r and Sig. (1-tailed) - Relationship of School Climate and FCAT 2.0 Mathematics Scores when controlling Racial and Ethnic Concentration (Whites, Blacks, \& Hispanics)

\begin{tabular}{|c|c|c|c|c|c|c|c|c|}
\hline \multicolumn{2}{|c|}{ Total $\%{ }^{\mathrm{a}}$} & $\begin{array}{c}\text { Passing } \\
\text { FCAT } \\
\text { Math }\end{array}$ & Whites & Hispanics & Blacks & $\begin{array}{c}\text { School } \\
\text { Climate } \\
\text { (Parent) }\end{array}$ & $\begin{array}{c}\text { School } \\
\text { Climate } \\
\text { (Student) }\end{array}$ & $\begin{array}{c}\text { School } \\
\text { Climate } \\
\text { (Staff) }\end{array}$ \\
\hline \multirow{9}{*}{ 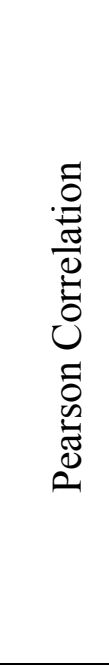 } & $\begin{array}{l}\text { Passing } \\
\text { FCAT Math }\end{array}$ & 1.000 & .668 & .429 & -.597 & .595 & .741 & .605 \\
\hline & Whites & .668 & 1.000 & .073 & -.351 & .376 & .417 & .289 \\
\hline & Hispanics & .429 & .073 & 1.000 & -.959 & .464 & .410 & .417 \\
\hline & Blacks & -.597 & -.351 & -.959 & 1.000 & -.546 & -.511 & -.478 \\
\hline & School & & & & & & & \\
\hline & $\begin{array}{l}\text { Climate } \\
\text { (Parent) }\end{array}$ & .595 & .376 & .464 & -.546 & 1.000 & .624 & .474 \\
\hline & $\begin{array}{l}\text { School } \\
\text { Climate } \\
\text { (Student) }\end{array}$ & .741 & .417 & .410 & -.511 & .624 & 1.000 & .554 \\
\hline & School & & & & & & & \\
\hline & $\begin{array}{l}\text { Climate } \\
\text { (Staff) }\end{array}$ & .605 & .289 & .417 & -.478 & .474 & .554 & 1.000 \\
\hline \multirow{10}{*}{ 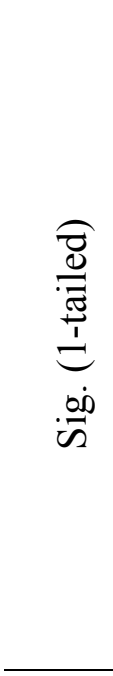 } & $\begin{array}{l}\text { Passing } \\
\text { FCAT Math }\end{array}$ & - & .000 & .000 & .000 & .000 & .000 & .000 \\
\hline & Whites & .000 & . & .290 & .003 & .002 & .001 & .013 \\
\hline & Hispanics & .000 & .290 & . & .000 & .000 & .001 & .001 \\
\hline & Blacks & .000 & .003 & .000 & . & .000 & .000 & .000 \\
\hline & School & & & & & & & \\
\hline & $\begin{array}{l}\text { Climate } \\
\text { (Parent) }\end{array}$ & .000 & .002 & .000 & .000 & . & .000 & .000 \\
\hline & School & & & & & & & \\
\hline & (Student) & .000 & .001 & .001 & .000 & .000 & . & .000 \\
\hline & School & & & & & & & \\
\hline & $\begin{array}{l}\text { Climate } \\
\text { (Staff) }\end{array}$ & .000 & .013 & .001 & .000 & .000 & .000 & . \\
\hline
\end{tabular}

Note. $a=59$.

For this secondary research question, the independent variable with the strongest correlation to the dependent variable was percentage of students agreeing that the school climate is positive and helps them learn. The other independent variables had moderate 
correlations to the dependent variable: the White student population, the Hispanic student population, the Black student population, the parents agreeing that the school climate is positive and helps students learning, and staff agreeing that the school climate is positive and helps students learning. All independent variables had a positive relationship with the dependent variable, meaning that as the value of these variables increased, a higher percentage of students passed the FCAT 2.0 Mathematics Test, except for the Black student population that had a negative relationship.

Table 45 displays the results of the research hypothesis (H5). The $P_{\text {crit }}$ established for this study is 0.01 . The $P_{\text {calc }}$ for the White student population is $p<0.001$, making it statistically significant since it is less than and not rejecting the research hypothesis (H5), meaning a significant negative relationship exists between school climate and the FCAT 2.0 Mathematics scores when controlling racial and ethnic concentrations. The $P_{\text {calc }}$ for the Hispanic student population is $p<0.001$, making it statistically significant since it is less than 0.01 and not rejecting the research hypothesis (H5), meaning a significant negative relationship exists between school climate and the FCAT 2.0 Mathematics scores when controlling racial and ethnic concentrations. The $P_{\text {calc }}$ for the Black student population is $p<0.001$, making it statistically significant since it is less than 0.01 and not rejecting the research hypothesis (H5), meaning a significant negative relationship exists between school climate and the FCAT 2.0 Mathematics scores when controlling racial and ethnic concentrations. The $P_{\text {calc }}$ for the parents agreeing that the school climate is positive and helps students learn is $p<0.001$, making it statistically significant since it is less than 0.01 and not rejecting the research hypothesis (H5), meaning a significant negative relationship exists between school climate and the FCAT 2.0 Mathematics 
scores when controlling racial and ethnic concentrations. The $P_{\text {calc }}$ for the students agreeing that the school climate is positive and helps them learn is $p<0.001$, making it statistically significant since it is less than 0.01 and not rejecting the research hypothesis (H5), meaning a significant negative relationship between school climate and the FCAT 2.0 Mathematics scores when controlling racial and ethnic concentrations. The $P_{\text {calc }}$ for the staff agreeing that the school climate is positive and helps students learn is $p<0.001$, making it statistically significant since it is less than 0.01 and not rejecting the research hypothesis (H5), meaning a significant negative relationship exists between school climate and the FCAT 2.0 Mathematics scores when controlling racial and ethnic concentrations.

For each research hypothesis not rejected, a Type I Error has been made if any research hypothesis ends up being incorrect. There is a one percent chance of that happening. Moreover, for this secondary research question, all variables were statistically significant.

As shown in Table 46, the Sum of Squares (SS) Total for both models is 14379.222, representing all the variance in the data. For Model 1, the Sum of Squares (SS) Regression is 8506.953 , which is the unique variance that can be explained. For Model 2, the Sum of Squares (SS) Regression is 11025.213, the variance that can be explained. For Model 1, the Sum of Squares (SS) Residual is 5872.269, the variance that cannot be explained. For Model 2, the Sum of Squares (SS) Residual is 3354.009, the variance that cannot be explained. For Model 1, Degrees of Freedom, $d f$, for Regression is two and for Residual is 54, for a total of $56 d f$. For Model 2, Degrees of Freedom, $d f$, for Regression is five and for Residual is 51 , for a total of $56 d f$. The 
Mean Square is the variance in the ANOVA. For Regression of Model 1, it is 4253.476 and for Residual, it is 108.746. For Regression of Model 2, it is 2205.043 and for Residual, it is 65.765 . For Model 1, the $F$ value is 39.114 which is the test statistic $\left(T S_{\text {calc }}\right.$ or $\left.F_{\text {calc }}\right)$. For Model 2, the $F$ value is 33.529 which is the test statistic $\left(T S_{\text {calc }}\right.$ or $\left.F_{c a l c}\right)$. For the Significant column, $P_{c a l c}$, Model 1 is statistically significant since $p<$ 0.001 hence it is less than 0.01 , thus it does not reject the research hypothesis (H5), meaning a significant negative relationship exists between school climate and the FCAT 2.0 Mathematics scores when controlling racial and ethnic concentrations. Model 2 is statistically significant because $p<0.001$ hence it is less than 0.01 , thus it does not reject the research hypothesis (H5), meaning a significant negative relationship exists between school climate and the FCAT 2.0 Mathematics scores when controlling racial and ethnic concentrations. (Hinton et al., 2004)

Table 46

ANOVA - Relationship of School Climate and FCAT 2.0 Mathematics Scores when controlling Racial and Ethnic Concentration (Whites \& Hispanics)

\begin{tabular}{llccccc}
\hline \multirow{2}{*}{ Model } & $\begin{array}{c}\text { Sum of } \\
\text { Squares }\end{array}$ & df & Mean Square & F & \multirow{2}{*}{ Sig. } \\
\hline \multirow{2}{*}{1} & Regression & 8506.953 & 2 & 4253.476 & 39.114 & $.000^{\mathrm{b}}$ \\
& Residual & 5872.269 & 54 & 108.746 & & \\
& Total & 14379.222 & 56 & & & \\
\hline \multirow{2}{*}{2} & Regression & 11025.213 & 5 & 2205.043 & 33.529 & $.000^{\mathrm{c}}$ \\
& Residual & 3354.009 & 51 & 65.765 & & \\
& Total & 14379.222 & 56 & & & \\
\hline
\end{tabular}

Note. a. Dependent Variable: \% Passing FCAT Math

b. Predictor: (Constant), \% of White student population, $\%$ of Hispanic student population

c. Predictors: (Constant), \% of White student population, $\%$ of Hispanic student population, School Climate 
Table 47 shows how much each variable contributes to the research question for this particular test. According to the Beta results, the strongest contribution on the passing of the FCAT 2.0 Mathematics Test comes from the White student population, 0.640 in Model 1 and 0.432 in Model 2.

For the Sig. column, the independent variables making a significant contribution to the dependent variable were the White student population $(p<0.001)$ and the Hispanic student population $(p<0.001)$ in Model 1 , as well as the White student population $(p<$ $0.001)$ and the positive school climate question of the student survey $(p<0.001)$ in Model 2. The independent variables not making a significant contribution to the dependent variable were the Hispanic student population (0.079), the positive school climate question of the staff survey $(0.025)$, and the positive school climate question of the parent survey $(0.635)$ in Model 2.

Table 47

Coefficients - Relationship of School Climate and FCAT 2.0 Mathematics Scores when controlling Racial and Ethnic Concentration (Whites \& Hispanics)

\begin{tabular}{|c|c|c|c|c|}
\hline \multicolumn{2}{|c|}{ Model } & $\begin{array}{c}\text { Standardized } \\
\text { Coefficients } \\
\text { Beta } \\
\end{array}$ & $\mathrm{t}$ & Sig. \\
\hline \multirow{3}{*}{1} & (Constant) & & 12600 & $0 \Omega 0$ \\
\hline & Whites & .640 & 7.343 & .000 \\
\hline & Hispanics & .382 & 4.378 & .000 \\
\hline \multirow{6}{*}{2} & (Constant) & & 1.105 & .274 \\
\hline & Whites & .432 & 5.615 & .000 \\
\hline & Hispanics & .145 & 1.794 & .079 \\
\hline & School Climate (Parent) & .045 & .478 & .635 \\
\hline & School Climate (Student) & .365 & 3.782 & .000 \\
\hline & School Climate (Staff) & .197 & 2.315 & .025 \\
\hline
\end{tabular}

Moreover, Table 48's Part column under Correlations, for Model 1, the White student population contributes $40.8 \%$ to the dependent variable, meaning it also explains 
$40.8 \%$ of the unique variance in the dependent variable and will cause the $R^{2}$ to drop $40.8 \%$ if it is not included in the model. The Hispanic student population contributes $14.5 \%$ to the dependent variable, meaning it also explains $14.5 \%$ of the unique variance in the dependent variable and will cause the $R^{2}$ to drop $14.5 \%$ if it is not included in the model. On the other hand, for Model 2, the White student population contributes $14.4 \%$ to the dependent variable, meaning it also explains $14.4 \%$ of variance in the dependent variable and will cause the $R^{2}$ to drop $14.4 \%$ if it is not included in the model. The Hispanic student population contributes $1.46 \%$ to the dependent variable, meaning it also explains $1.46 \%$ of variance in the dependent variable and will cause the $R^{2}$ to drop $1.46 \%$ if it is not included in the model. The positive school climate question of the parent survey contributes $0.10 \%$ to the dependent variable, meaning it also explains $0.10 \%$ of variance in the dependent variable and will cause the $R^{2}$ to drop $0.10 \%$ if it is not included in the model. The positive school climate question of the student survey contributes $6.55 \%$ to the dependent variable, meaning it also explains $6.55 \%$ of variance in the dependent variable and will cause the $R^{2}$ to drop $6.55 \%$ if it is not included in the model. The positive school climate question of the staff survey contributes $2.46 \%$ to the dependent variable, meaning it also explains $2.46 \%$ of variance in the dependent variable and will cause the $R^{2}$ to drop $2.46 \%$ if it is not included in the model. The strongest contribution to the dependent variable of the passing of the FCAT 2.0 Mathematics Test comes from the White student population (40.8\%) in Model 1, followed by the Hispanic student population (14.5\%) in Model 1. (See Appendix II for the Collinearity Statistics explanation) 
Table 48

Coefficients Continued - Relationship of School Climate and FCAT 2.0 Mathematics Scores when controlling Racial and Ethnic Concentration (Whites \& Hispanics)

\begin{tabular}{llccc}
\hline \multirow{2}{*}{ Model } & \multicolumn{2}{c}{ Correlations } & \multicolumn{2}{c}{ Collinearity Statistics } \\
\cline { 2 - 4 } & Part & Tolerance & VIF \\
\hline \multirow{2}{*}{1 (Constant) } & Whites & .639 & .995 & 1.005 \\
& Hispanics & .381 & .995 & 1.005 \\
\hline \multicolumn{1}{l}{ (Constant) } & & & \\
Whites & .380 & .774 & 1.293 \\
Hispanics & .121 & .703 & 1.422 \\
School Climate & .032 & .528 & 1.895 \\
(Parent) & & & \\
School Climate & .256 & .491 & 2.036 \\
(Student) & .157 & .633 & 1.580 \\
School Climate (Staff) & & &
\end{tabular}

\section{Whites, Blacks and School Climate}

This secondary research question was further tested using a combination of different variables. For this particular test, significant variance is sought between school climate and the FCAT 2.0 Mathematics scores when controlling the racial and ethnic concentrations (Whites and Blacks). There was a high correlation between the White student population, the Black student population, and the Hispanic student population thus, the Hispanic student population were left out in order to eliminate the multicollinearity (Appendix II, Table 85). On the other hand, the independent variable of the Hispanic student population was kept for the Pearson $r$ and Sig. Table (Table 49) so that the correlation of this variable would be known.

As shown in Table 49, the correlations have different strengths. The White student population has a 0.668 correlation with the percentage of the students passing the FCAT 2.0 Mathematics Test. It is a moderate correlation since the $r$ is between 0.3 and 
0.7 but, it is also a positive correlation meaning that as the White student population increased, the percentage of the students passing the FCAT 2.0 Mathematics Test increased. The Hispanic student population has a 0.429 correlation with the percentage of the students passing the FCAT 2.0 Mathematics Test. It is a positive correlation meaning that as the Hispanic student population increased, the percentage of the students passing the FCAT 2.0 Mathematics Test increased. It is a moderate correlation since the $r$ is between 0.3 and 0.7 . The Black student population has a -0.597 correlation with the percentage of the students passing the FCAT 2.0 Mathematics Test. It is a negative correlation meaning that as the Black student population increased, the percentage of the students passing the FCAT 2.0 Mathematics Test decreased. It is a moderate correlation since the $r$ is between -0.3 and -0.7 . The parents agreeing that the school climate is positive and helps students learn has a 0.595 correlation with the percentage of the students passing the FCAT 2.0 Mathematics Test. It is a positive correlation meaning that as the parents agreeing that the school climate is positive and helps students learn increased while the percentage of the students passing the FCAT 2.0 Mathematics Test also increased. It is a moderate correlation since the $r$ is between 0.3 and 0.7 . The students agreeing that the school climate is positive and helps them learn has a 0.741 correlation with the percentage of the students passing the FCAT 2.0 Mathematics Test. It is a strong correlation since the $r$ is between 0.7 and 1 but, it is also a positive correlation meaning that as the students agreeing that the school climate is positive and helps them learn increased while the percentage of the students passing the FCAT 2.0 Mathematics Test also increased. The staff agreeing that the school climate is positive and helps students learn has a 0.605 correlation with the percentage of the students 
passing the FCAT 2.0 Mathematics Test. It is a moderate correlation since the $r$ is between 0.3 and 0.7 but it is also a positive correlation meaning that as the staff agreeing that the school climate is positive and helps students learn increased while the percentage of the students passing the FCAT 2.0 Mathematics Test also increased. 
Table 49

Pearson r and Sig. (1-tailed) - Relationship of School Climate and FCAT 2.0 Mathematics Scores when controlling Racial and Ethnic Concentration (Whites, Blacks, \& Hispanics)

\begin{tabular}{|c|c|c|c|c|c|c|c|c|}
\hline \multicolumn{2}{|c|}{ Total $\%{ }^{\mathrm{a}}$} & $\begin{array}{c}\text { Passing } \\
\text { FCAT } \\
\text { Math }\end{array}$ & Whites & Hispanics & Blacks & $\begin{array}{c}\text { School } \\
\text { Climate } \\
\text { (Parent) }\end{array}$ & $\begin{array}{c}\text { School } \\
\text { Climate } \\
\text { (Student) }\end{array}$ & $\begin{array}{c}\text { School } \\
\text { Climate } \\
\text { (Staff) }\end{array}$ \\
\hline \multirow{9}{*}{ 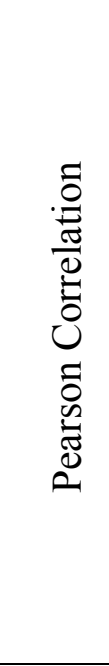 } & $\begin{array}{l}\text { Passing } \\
\text { FCAT Math }\end{array}$ & 1.000 & .668 & .429 & -.597 & .595 & .741 & .605 \\
\hline & Whites & .668 & 1.000 & .073 & -.351 & .376 & .417 & .289 \\
\hline & Hispanics & .429 & .073 & 1.000 & -.959 & .464 & .410 & .417 \\
\hline & Blacks & -.597 & -.351 & -.959 & 1.000 & -.546 & -.511 & -.478 \\
\hline & School & & & & & & & \\
\hline & $\begin{array}{l}\text { Climate } \\
\text { (Parent) }\end{array}$ & .595 & .376 & .464 & -.546 & 1.000 & .624 & .474 \\
\hline & $\begin{array}{l}\text { School } \\
\text { Climate } \\
\text { (Student) }\end{array}$ & .741 & .417 & .410 & -.511 & .624 & 1.000 & .554 \\
\hline & School & & & & & & & \\
\hline & $\begin{array}{l}\text { Climate } \\
\text { (Staff) }\end{array}$ & .605 & .289 & .417 & -.478 & .474 & .554 & 1.000 \\
\hline \multirow{10}{*}{ 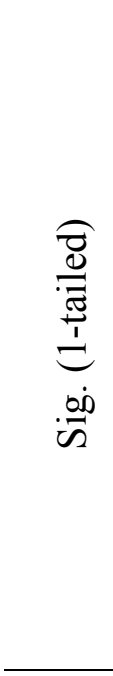 } & $\begin{array}{l}\text { Passing } \\
\text { FCAT Math }\end{array}$ & - & .000 & .000 & .000 & .000 & .000 & .000 \\
\hline & Whites & .000 & . & .290 & .003 & .002 & .001 & .013 \\
\hline & Hispanics & .000 & .290 & . & .000 & .000 & .001 & .001 \\
\hline & Blacks & .000 & .003 & .000 & . & .000 & .000 & .000 \\
\hline & School & & & & & & & \\
\hline & $\begin{array}{l}\text { Climate } \\
\text { (Parent) }\end{array}$ & .000 & .002 & .000 & .000 & . & .000 & .000 \\
\hline & School & & & & & & & \\
\hline & (Student) & .000 & .001 & .001 & .000 & .000 & . & .000 \\
\hline & School & & & & & & & \\
\hline & $\begin{array}{l}\text { Climate } \\
\text { (Staff) }\end{array}$ & .000 & .013 & .001 & .000 & .000 & .000 & . \\
\hline
\end{tabular}

Note. $a=59$.

For this secondary research question, the independent variable with the strongest correlation to the dependent variable was percentage of students agreeing that the school climate is positive and helps them learn. The independent variables with moderate 
correlations to the dependent variable were the White student population, the Hispanic student population, the Black student population, the parents agreeing that the school climate is positive and helps students learning, and staff agreeing that the school climate is positive and helps students learning. All independent variables had a positive relationship with the dependent variable, meaning that as the value of these variables increased, a higher percentage of students passed the FCAT 2.0 Mathematics Test, except for the Black student population that had a negative relationship.

Table 49 displays the results of the research hypothesis (H5). The $P_{\text {crit }}$ established for this study is 0.01 . The $P_{\text {calc }}$ for the White student population is $p<0.001$, making it statistically significant since it is less than 0.01 and not rejecting the research hypothesis (H5), meaning a significant negative relationship exists between school climate and the FCAT 2.0 Mathematics scores when controlling racial and ethnic concentrations. The $P_{\text {calc }}$ for the Hispanic student population $p<0.001$, making it statistically significant since it is less than 0.01 and not rejecting the research hypothesis (H5), meaning a significant negative relationship exists between school climate and the FCAT 2.0 Mathematics scores when controlling racial and ethnic concentrations. The $P_{\text {calc }}$ for the Black student population is $p<0.001$, making it statistically significant since it is less than 0.01 and not rejecting the research hypothesis (H5), meaning a significant negative relationship exists between school climate and the FCAT 2.0 Mathematics scores when controlling racial and ethnic concentrations. The $P_{\text {calc }}$ for the parents agreeing that the school climate is positive and helps students learn is $p<0.001$, making it statistically significant since it is less than 0.01 and not rejecting the research hypothesis (H5), meaning a significant negative relationship exists between school climate and the FCAT 
2.0 Mathematics scores when controlling racial and ethnic concentrations. The $P_{\text {calc }}$ for the students agreeing that the school climate is positive and helps them learn is $p<0.001$, making it statistically significant since it is less than 0.01 and not rejecting the research hypothesis (H5), meaning a significant negative relationship exists between school climate and the FCAT 2.0 Mathematics scores when controlling racial and ethnic concentrations. The $P_{\text {calc }}$ for the staff agreeing that the school climate is positive and helps students learn is $p<0.001$, making it statistically significant since it is less than 0.01 and not rejecting the research hypothesis (H5), meaning a significant negative relationship exists between school climate and the FCAT 2.0 Mathematics scores when controlling racial and ethnic concentrations.

For each research hypothesis not rejected, a Type I Error has been made if any research hypothesis ends up being incorrect. There is a one percent chance of that happening. Moreover, for this secondary research question, all variables were statistically significant.

As shown in Table 50, the Sum of Squares (SS) Total for both models is 14379.222, which represents all the variance in the data. For Model 1, the Sum of Squares (SS) Regression is 8581.584 , which is the unique variance that can be explained. For Model 2, the Sum of Squares (SS) Regression is 11035.906, which is the variance that can be explained. For Model 1, the Sum of Squares (SS) Residual is 5797.638, which is the variance that cannot be explained. For Model 2, the Sum of Squares (SS) Residual is 3343.316 , which is the variance that cannot be explained. For Model 1, Degrees of Freedom, $d f$, for Regression is two and for Residual is 54, for a total of $56 d f$. For Model 2, Degrees of Freedom, $d f$, for Regression is five and for Residual is 51, for a 
total of $56 d f$. The Mean Square is the variance in the ANOVA. For Regression of Model 1, it is 4290.792 and for Residual, it is 107.364. For Regression of Model 2, it is 2207.181 and for Residual, it is 65.555 . For Model 1 , the $F$ value is 39.965 which is the test statistic $\left(T S_{\text {calc }}\right.$ or $\left.F_{\text {calc }}\right)$. For Model 2, the $F$ value is 33.669 which is the test statistic $\left(T S_{\text {calc }}\right.$ or $\left.F_{\text {calc }}\right)$. For the Significant column, $P_{\text {calc }}$, Model 1 is statistically significant since $p<0.001$ hence it is less than 0.01 , thus it does not reject the research hypothesis (H5), meaning a significant negative relationship exists between school climate and the FCAT 2.0 Mathematics scores when controlling racial and ethnic concentrations. Model 2 is statistically significant because $p<0.001$ hence it is less than 0.01 , thus it does not reject the research hypothesis (H5), meaning a significant negative relationship exists between school climate and the FCAT 2.0 Mathematics scores when controlling racial and ethnic concentrations. (Hinton et al., 2004)

Table 50

ANOVA - Relationship of School Climate and FCAT 2.0 Mathematics Scores when controlling Racial and Ethnic Concentration (Whites \& Blacks)

\begin{tabular}{llccccc}
\hline \multicolumn{2}{l}{ Model } & Sum of Squares & df & $\begin{array}{c}\text { Mean } \\
\text { Square }\end{array}$ & F & Sig. \\
\hline \multirow{2}{*}{1} & Regression & 8581.584 & 2 & 4290.792 & 39.965 & $.000^{\mathrm{b}}$ \\
& Residual & 5797.638 & 54 & 107.364 & & \\
& Total & 14379.222 & 56 & & & \\
\hline \multirow{2}{*}{2} & Regression & 11035.906 & 5 & 2207.181 & 33.669 & $.000^{\mathrm{c}}$ \\
& Residual & 3343.316 & 51 & 65.555 & & \\
& Total & 14379.222 & 56 & & & \\
\hline
\end{tabular}

Note. a. Dependent Variable: \% Passing FCAT Math

b. Predictor: (Constant), $\%$ of White student population, $\%$ of Black student population

c. Predictors: (Constant), $\%$ of White student population, $\%$ of Black student population, School Climate 
Table 51 shows how much each variable contributes to the research question for this particular test. According to the Beta results, the strongest contribution on the passing of the FCAT 2.0 Mathematics Test comes from the White student population, 0.523 in Model 1 and 0.388 in Model 2.

For the Sig. column, the independent variables making a significant contribution to the dependent variable were the White student population $(p<0.001)$ and the Black student population $(p<0.001)$ in Model 1 , as well as the White student population $(p<$ $0.001)$, and the positive school climate question of the student survey $(p<0.001)$ in Model 2. The independent variable not making a significant contribution to the dependent variable is the Black student population (0.071) and the positive school climate question of the parent survey (0.647), and the positive school climate question of the staff survey (0.025) in Model 2.

Table 51

Coefficients - Relationship of School Climate and FCAT 2.0 Mathematics Scores when controlling Racial and Ethnic Concentration (Whites \& Blacks)

\begin{tabular}{|c|c|c|c|c|}
\hline \multicolumn{2}{|c|}{ Model } & \multirow{2}{*}{$\begin{array}{c}\begin{array}{c}\text { Standardized } \\
\text { Coefficients }\end{array} \\
\text { Beta } \\
\end{array}$} & \multirow[t]{2}{*}{$\mathrm{t}$} & \multirow[t]{2}{*}{ Sig. } \\
\hline \multirow{4}{*}{1} & & & & \\
\hline & (Constant) & & 22.608 & .000 \\
\hline & Whites & .523 & 5.667 & .000 \\
\hline & Blacks & -.414 & -4.484 & .000 \\
\hline \multirow{6}{*}{2} & (Constant) & & 1.646 & .106 \\
\hline & Whites & .388 & 5.112 & .000 \\
\hline & Blacks & -.159 & -1.842 & .071 \\
\hline & School Climate (Parent) & .043 & .461 & .647 \\
\hline & School Climate (Student) & .363 & 3.763 & .000 \\
\hline & School Climate (Staff) & .196 & 2.304 & .025 \\
\hline
\end{tabular}

Moreover, Table 52's Part column under Correlations, for Model 1, the White student population contributes $24 \%$ to the dependent variable, meaning it also explains 
$24 \%$ of the unique variance in the dependent variable and will cause the $R^{2}$ to drop $24 \%$ if it is not included in the model. The Black student population contributes $15 \%$ to the dependent variable, meaning it also explains $15 \%$ of the unique variance in the dependent variable and will cause the $R^{2}$ to drop $15 \%$ if it is not included in the model. On the other hand, for Model 2, the White student population contributes 11.9\% to the dependent variable, meaning it also explains $11.9 \%$ of variance in the dependent variable and will cause the $R^{2}$ to drop $11.9 \%$ if it is not included in the model. The Black student population contributes $1.54 \%$ to the dependent variable, meaning it also explains $1.54 \%$ of variance in the dependent variable and will cause the $R^{2}$ to drop $1.54 \%$ if it is not included in the model. The positive school climate question of the parent survey contributes $0.10 \%$ to the dependent variable, meaning it also explains $0.10 \%$ of variance in the dependent variable and will cause the $R^{2}$ to drop $0.10 \%$ if it is not included in the model. The positive school climate question of the student survey contributes $6.45 \%$ to the dependent variable, meaning it also explains $6.45 \%$ of variance in the dependent variable and will cause the $R^{2}$ to drop $6.45 \%$ if it is not included in the model. The positive school climate question of the staff survey contributes $2.43 \%$ to the dependent variable, meaning it also explains $2.43 \%$ of variance in the dependent variable and will cause the $R^{2}$ to drop $2.43 \%$ if it is not included in the model. The strongest contribution to the dependent variable of the passing of the FCAT 2.0 Mathematics Test comes from the White student population (24\%) in Model 1, followed by the Black student population (15\%) in Model 1. (See Appendix II for the Collinearity Statistics explanation) 
Table 52

Coefficients Continued - Relationship of School Climate and FCAT 2.0 Mathematics Scores when controlling Racial and Ethnic Concentration (Whites \& Black)

\begin{tabular}{llccc}
\hline Model & \multicolumn{2}{c}{ Correlations } & \multicolumn{2}{c}{ Collinearity Statistics } \\
\cline { 2 - 4 } & (Constant) & Part & Tolerance & VIF \\
\hline \multirow{2}{*}{1 Whites } & & & \\
& Blacks & .490 & .877 & 1.141 \\
\hline \multirow{2}{*}{ (Constant) } & -.387 & .877 & 1.141 \\
\hline \multirow{2}{*}{2} & & & \\
Whites & .345 & .790 & 1.266 \\
Blacks & -.124 & .612 & 1.633 \\
School Climate (Parent) & .031 & .527 & 1.897 \\
& School Climate (Student) & .254 & .490 & 2.040 \\
& School Climate (Staff) & .156 & .632 & 1.581 \\
\hline
\end{tabular}

Chapter 4 presented the relationship between the scores of FCAT 2.0

Mathematics Test and the racial and ethnic concentrations, ESOL student population, socio-economic status, and school climate. Lastly, Chapter 5 will summarize the findings of the study and discuss the implications of the study for educational policy, theory, and further research. 


\section{CHAPTER 5}

\section{SUMMARY, DISCUSSION, AND RECOMMENDATIONS}

This quantitative study analyzed the relationship between the FCAT 2.0

mathematics scores of public middle school students in Miami-Dade County, Florida and the racial and ethnic concentrations (Whites, Blacks, and Hispanics), ESOL student population, socio-economic status, and school climate for the 2010 - 2011 school year. Data were gathered from various documents published by the Florida Department of Education and Miami-Dade County Public Schools: FLDOE's FCAT School Accountability Report (2010-2011 Edition), FLDOE's 2011 AYP Report (2010-2011 Edition), and MDCPS'School Climate Survey Individual Results (2010-2011 Edition). Multiple Linear Regression was used to analyze the data and test the hypotheses, determining significant relationships between the independent variables and dependent variable.

Miami-Dade County Public Schools have racial and ethnic concentrations, ESOL student populations, different levels of socio-economic statuses, and varying school climate, like many school districts in metropolitan areas. "Miami-Dade County is one of the most ethnically/racially diverse metropolitan areas in the United States and continues to experience a profound demographic transformation that has major implications for educational policies, minority student academic achievement, and the concept of equal educational opportunity" (Moore, 2002, p.209). Even though all school districts are unique, this study on Miami-Dade County can provide insight to school districts with similar characteristics. 
Mathematics achievement has been hindered by various factors such as racial and ethnic concentrations (Whites, Blacks and Hispanics), socio-economic status, ESOL student population, and school climate. These variables all interact with one another, in some cases too much, to create multicollinearity, but the data supports the research findings.

It is evident that Miami-Dade County Public Schools must continue its efforts to improve the performance of students on the FCAT 2.0 Mathematics Test despite the challenges which students may face that are beyond their control. Racial and ethnic concentrations in schools, socio-economic status of students, size of the ESOL student population, and how positive the school climate is hampers the efforts to provide all students with an equal and quality education but it should not restrict the progress of providing it. Every possible effort needs to be made to ensure that all students receive an equal and quality education. The No Child Left Behind Act focuses on closing "the achievement gap with accountability, flexibility and choice, so that no child is left behind" declared that "all men are created equal" (One Hundred Seventh Congress of the United States of America, 2008). Despite the challenges students face, they are all equal, so they should all receive an equal and quality education. If the poor academic performance of students is because of the educational institutions and policies, society fails to adhere to providing all students with an equal and quality education. Thus, all school districts must constantly strive to provide all students with an equal and quality education. 


\section{Summary of Relationship between FCAT 2.0 Math Scores and Racial and Ethnic Concentrations, Socio-Economic Status, ESOL Student Population, and School \\ Climate}

The study postulated the following five research hypotheses regarding the relationship between the FCAT 2.0 mathematics scores, racial and ethnic concentration, socio-economic status, ESOL student population, and school climate for the 2010-2011 school year in the public middle schools in Miami-Dade County.

1. There is a significant negative relationship between the FCAT 2.0 mathematics scores and racial and ethnic concentration of public middle schools in Miami-Dade County when controlling socio-economic status, ESOL student population, and school climate for the 2010-2011 school year. This research hypothesis was not rejected because as stated in Table 5, Table 9, Table 13, Table 17, and Table 21, a statistically significant negative relationship exists between the independent variables and dependent variable, $p<0.001$ since it is less than 0.01 .

To test this hypothesis, several tests were done, grouping the independent variables differently due to multicollinearity. By removing one or more of the highly correlated independent variables, it was possible to analyze the individual contribution of each independent variable to the FCAT 2.0 Mathematics scores. For the Blacks, socioeconomic status, ESOL, and school climate test, these independent variables together have a statistically significant relationship with the FCAT 2.0 Mathematics scores (Table 5). The independent variables that did have a statistically significant relationship with the FCAT 2.0 Mathematics scores were the Economically Disadvantaged (SES) student population $(p<0.001)$ and the positive school climate question of the student survey 
(0.002) in Model 1 and the Economically Disadvantaged (SES) student population ( $p<$ $0.001)$ and the positive school climate question of the student survey (0.002) in Model 2. On the other hand, specific independent variables individually did not have a statistically significant relationship with the FCAT 2.0 Mathematics scores such as the ESOL student population (0.047), the positive school climate question of the parent survey (0.347), and the positive school climate question of the staff survey (0.029) for Model 1 and the Black student population (0.214), the ESOL student population (0.299), the positive school climate question of the parent survey (0.535), and the positive school climate question of the staff survey (0.063) for Model 2 (Table 7). For this test, after squaring the values in the Part column under Correlations in Table 8, the strongest contribution on the dependent variable comes from the Economically Disadvantaged (SES) student population at $20.1 \%$ in Model 1 and $14.2 \%$ in Model 2 .

For the Blacks, Whites, ESOL and school climate test, these independent variables together have a statistically significant relationship with the FCAT 2.0 Mathematics scores (Table 9). The independent variables that did have a statistically significant relationship with the FCAT 2.0 Mathematics scores were the positive school climate question of the student survey $(p<0.001)$ in Model 1 and the White student population (0.001) and the positive school climate question of the student survey ( $p<$ 0.001) in Model 2. On the other hand, specific independent variables individually did not have a statistically significant relationship with the FCAT 2.0 Mathematics scores such as the ESOL student population (0.039), the positive school climate question of the parent survey (0.097), and the positive school climate question of the staff survey (0.026) for Model 1 and the Black student population (0.039), the ESOL student population (0.296), 
the positive school climate question of the parent survey (0.631), and the positive school climate question of the staff survey $(0.047)$ for Model 2 (Table 11). For this test, after squaring the values in the Part column under Correlations in Table 12, the strongest contribution on the dependent variable comes from the positive school climate question of the student survey at $13.69 \%$ in Model 1 and $6.76 \%$ in Model 2.

For the Whites, Hispanics, ESOL and school climate test, these independent variables together have a statistically significant relationship with the FCAT 2.0 Mathematics scores (Table 13). The independent variables that did have a statistically significant relationship with the FCAT 2.0 Mathematics scores were the positive school climate question of the student survey $(p<0.001)$ in Model 1 and the White student population $(p<0.001)$ and the positive school climate question of the student survey $(p<$ 0.001) in Model 2. On the other hand, specific independent variables individually did not have a statistically significant relationship with the FCAT 2.0 Mathematics scores such as the ESOL student population (0.039), the positive school climate question of the parent survey (0.097), and the positive school climate question of the staff survey $(0.026)$ for Model 1 and the Hispanic student population (0.043), the ESOL student population (0.301), the positive school climate question of the parent survey (0.619), and the positive school climate question of the staff survey (0.046) for Model 2 (Table 15). For this test, after squaring the values in the Part column under Correlations in Table 16, the strongest contribution on the dependent variable comes from the positive school climate question of the student survey at $13.69 \%$ in Model 1 , followed by the White student population at 9.36\% in Model 2. 
For the Hispanics, ESOL and school climate test, these independent variables together have a statistically significant relationship with the FCAT 2.0 Mathematics scores (Table 17). The independent variables that did have a statistically significant relationship with the FCAT 2.0 Mathematics scores were the positive school climate question of the student survey $(p<0.001)$ in Model 1 and the ESOL student population $(0.005)$ and the positive school climate question of the student survey $(p<0.001)$ in Model 2. On the other hand, specific independent variables individually did not have a statistically significant relationship with the FCAT 2.0 Mathematics scores such as the On the other hand, specific independent variables individually did not have a statistically significant relationship with the FCAT 2.0 Mathematics scores such as the ESOL student population (0.039), the positive school climate question of the parent survey (0.097), and the positive school climate question of the staff survey (0.026) for Model 1 and the Hispanic student population (0.041), the positive school climate question of the parent survey (0.254), and the positive school climate question of the staff survey (0.102) for Model 2 (Table 19). For this test, after squaring the values in the Part column under Correlations in Table 20, the strongest contribution on the dependent variable comes from the positive school climate question of the student survey at 13.69\% in Model 1 and $12.6 \%$ in Model 2.

For the Whites, ESOL and school climate test, these independent variables together have a statistically significant relationship with the FCAT 2.0 Mathematics scores (Table 21). The independent variables that did have a statistically significant relationship with the FCAT 2.0 Mathematics scores were the positive school climate question of the student survey $(p<0.001)$ in Model 1 and the White student population $(p$ 
$<0.001)$, the positive school climate question of the student survey $(p<0.001)$, and the positive school climate question of the staff survey (0.010) in Model 2. On the other hand, specific independent variables individually did not have a statistically significant relationship with the FCAT 2.0 Mathematics scores such as the ESOL student population (0.039), the positive school climate question of the parent survey (0.097), and the positive school climate question of the staff survey (0.026) for Model 1 and the ESOL student population (0.993) and the positive school climate question of the parent survey $(0.331)$ in Model 2 (Table 23). For this test, after squaring the values in the Part column under Correlations in Table 24, the strongest contribution on the dependent variable comes from the positive school climate question of the student survey at 13.69\% in Model 1, followed by the White student population at $10.2 \%$ in Model 2 .

2. There is a significant negative relationship between the FCAT 2.0 mathematics scores and racial and ethnic concentration when controlling the ESOL student population of the school. This research hypothesis is rejected for Model 1 because as stated in Table 26 and Table 30, no statistically significant relationship exists between the ESOL student population and dependent variable $(0.312>0.01)$. For Model 2 , this research hypothesis is not rejected because as stated in Table 26 and Table 30, a statistically significant relationship exists between the independent variables and the dependent variable, $p<$ 0.001 since it is less than 0.01 .

To test this hypothesis, several tests were done, grouping the independent variables differently due to multicollinearity. By removing one or more of the highly correlated independent variables, it was possible to analyze the individual contribution of each independent variable. For the Whites, Hispanic and ESOL test, these independent 
variables together, Model 2, have a statistically significant relationship with the FCAT 2.0 Mathematics scores (Table 25) but when the ESOL student population is being controlled for, no statistically significant relationship exists with the dependent variable. Additionally, for Model 1 (0.312) and Model 2 (0.351), the ESOL student population did not have a statistically significant relationship with the FCAT 2.0 Mathematics scores (Table 27). In Model 2, the White student population $(p<0.001)$ and the Hispanic student population $(p<0.001)$ did have a statistically significant relationship with the FCAT 2.0 Mathematics scores. For this test, after squaring the values in the Part column under Correlations in Table 28, the strongest contribution on the dependent variable comes from the White student population at $26.8 \%$, followed by the Hispanic student population at $13.2 \%$.

For the Whites, Blacks and ESOL test, these independent variables together, Model 2, have a statistically significant relationship with the FCAT 2.0 Mathematics scores (Table 29) but when the ESOL student population is being controlled for, it has no statistically significant relationship with the dependent variable. Additionally, for Model $1(0.312)$ and Model $2(0.336)$, the ESOL student population did not have a statistically significant relationship with the FCAT 2.0 Mathematics scores (Table 31). In Model 2, the White student population $(p<0.001)$ and the Black student population $(p<0.001)$ did have a statistically significant relationship with the FCAT 2.0 Mathematics scores. For this test, after squaring the values in the Part column under Correlations in Table 32, the strongest contribution on the dependent variable comes from the Black student population at $13.69 \%$, followed by the White student population at $12.5 \%$. 
3. There is a significant negative relationship between the FCAT 2.0 mathematics scores and SES. This research hypothesis is not rejected because as stated in Table 33 and Table 34 there is a statistically significant relationship between the Economically Disadvantaged (SES) student population and the FCAT 2.0 Mathematics scores, $p<$ 0.001 since it is less than 0.01 . For this test, after squaring the values in the Part column under Correlations in Table 36, the Economically Disadvantaged student population has a contribution of $68.89 \%$ on the FCAT 2.0 Mathematics scores.

4. There is a significant negative relationship between the FCAT 2.0 mathematics scores and SES when controlling racial and ethnic concentrations. This research hypothesis is not rejected for Model 1 and Model 2 because as stated in Table 37 and Table 41, there is a statistically significant relationship between the independent variables and dependent variable, $p<0.001$ since it is less than 0.01 .

To test this hypothesis, several tests were done, grouping the independent variables differently due to multicollinearity. By removing one or more of the highly correlated independent variables, it was possible to analyze the individual contribution of each independent variable. For the Whites, Hispanics and socio-economic status test, these independent variables together, Model 2, have a statistically significant relationship with the FCAT 2.0 Mathematics scores (Table 37) as well as when the racial and ethnic concentrations are being controlled in Model 1. The independent variables that did have a statistically significant relationship with the FCAT 2.0 Mathematics scores were the White student population $(p<0.001)$ and the Hispanic student population $(p<0.001)$ in Model 1 and the Hispanic student population $(p<0.001)$ and the Economically Disadvantaged (SES) student population $(p<0.001)$ in Model 2. On the other hand, for 
Model 2, the White student population did not have a statistically significant $(0.080)$ relationship with the FCAT 2.0 Mathematics scores (Table 39). For this test, after squaring the values in the Part column under Correlations in Table 40, the strongest contribution on the dependent variable comes from the White student population at 40.8\% in Model 1, followed by the Economically Disadvantaged (SES) student population at $19.8 \%$ in Model 2 .

For the Whites, Blacks and socio-economic status test, these independent variables together, Model 2, have a statistically significant relationship with the FCAT 2.0 Mathematics scores (Table 41) as well as when the racial and ethnic concentrations are being controlled in Model 1 The independent variables that did have a statistically significant relationship with the FCAT 2.0 Mathematics scores were the White student population $(p<0.001)$ and the Black student population $(p<0.001)$ in Model 1 and the Black student population $(p<0.001)$ and the Economically Disadvantaged (SES) student population $(p<0.001)$ in Model 2 (Table 43). On the other hand, for Model 2, the White student population (0.20) did not have a statistically significant relationship with the FCAT 2.0 Mathematics scores. For this test, after squaring the values in the Part column under Correlations in Table 44, the strongest contribution on the dependent variable comes from the White student population at $24 \%$ in Model, followed by Economically Disadvantaged (SES) student population at $19.4 \%$ in Model 2. .

5. There is a significant negative relationship between the FCAT 2.0 mathematics scores and school climate when controlling racial and ethnic concentrations. This research hypothesis is not rejected for Model 1 and Model 2 because as stated in Table 45 
and Table 49, there is a statistically significant relationship between the independent variables and dependent variable, $p<0.001$ since it is less than 0.01 .

To test this hypothesis, several tests were done, grouping the independent variables differently due to multicollinearity. By removing one or more of the highly correlated independent variables, it was possible to analyze the individual contribution of each independent variable. For the Whites, Hispanics and school climate test, these independent variables together, Model 2, have a statistically significant relationship with the FCAT 2.0 Mathematics scores (Table 45) as well as when the racial and ethnic concentrations are being controlled in Model 1 . The independent variables that did have a statistically significant relationship with the FCAT 2.0 Mathematics scores were the White student population $(p<0.001)$ and the Hispanic student population $(p<0.001)$ in Model 1 and the White student population $(p<0.001)$ and the positive school climate question in the student survey $(p<0.001)$ in Model 2 (Table 47). On the other hand, for Model 2, the Hispanic student population (0.079), the positive school climate question of the parent survey (0.635), and the positive school climate question in the staff survey (0.025) did not have a statistically significant relationship with the FCAT 2.0 Mathematics scores (Table 47). For this test, after squaring the values in the Part column under Correlations in Table 48, the strongest contribution on the dependent variable comes from Model 1, the White student population at $40.8 \%$, followed by the Hispanic student population at $14.5 \%$ in Model 1.

For the Whites, Blacks and school climate test, these independent variables together, Model 2, have a statistically significant relationship with the FCAT 2.0 Mathematics scores (Table 49) as well as when the racial and ethnic concentrations are 
being controlled in Model 1. The independent variables that did have a statistically significant relationship with the FCAT 2.0 Mathematics scores were the White student population $(p<0.001)$ and the Black student population $(p<0.001)$ in Model 1 and the White student population $(p<0.001)$ and the positive school climate question in the student survey $(p<0.001)$ in Model 2 (Table 51). On the other hand, for Model 2, the Black student population (0.071), the positive school climate question of the parent survey (0.647), and the positive school climate question of the staff survey $(0.025) \mathrm{did}$ not have a statistically significant relationship with the FCAT 2.0 Mathematics scores (Table 51). For this test, after squaring the values in the Part column under Correlations in Table 52, the strongest contribution on the dependent variable comes from Model 1, the White student population at $24 \%$, followed by the Black student population at $15 \%$ in Model 2.

Hence, the results of the quantitative study found that all five research hypotheses were not rejected, meaning statistically significant relationships were found between the independent variables and dependent variable. For the second research hypothesis and its two tests, when controlling the ESOL student population (Model 1), there was no statistically significant relationship with the FCAT 2.0 Mathematics scores. On the other hand, for Model 2, combining the White student population, the Hispanic student population and the ESOL student population for Test 1 and the White student population, the Black student population, and the ESOL student population for Test 2, there was a statistically significant relationship with the FCAT 2.0 Mathematics scores, thus not rejecting the research hypothesis. 
Moreover, the Economically Disadvantaged (SES) student population was the strongest correlated variable with the passing of the FCAT 2.0 Mathematics Test, followed by the positive school climate question of the student survey and the White student population. The relationship was that the higher the Economically Disadvantaged (SES) student population variable, the lower number of students who passed the FCAT 2.0 Mathematics Test. This relationship was negative and strong. For the test on the relationship between the dependent variable and the Black student population, socioeconomic status, the ESOL student population, and the school climate, socio-economic status had a correlation of -0.830 (Table 5). For the test on the relationship between the dependent variable and socio-economic status, socio-economic status had a correlation of -0.830 (Table 33). For the test on the relationship between the dependent variable and the White student population, the Hispanic student population, and socio-economic status, socio-economic status had a correlation of -0.830 (Table 37). For the test on the relationship between the dependent variable and the White student population, the Black student population, and socio-economic status, socio-economic status had a correlation of -0.830 (Table 41). The independent variable of socio-economic status is the single most powerful predictor of academic achievement and supports the major finding of the Coleman Report (Coleman, 1966).

Furthermore, the more students agreed that their school climate was positive and helped them learn, the more students passed the FCAT 2.0 Mathematics Test. This relationship was positive and strong. For the test on the relationship between the dependent variable and the Black student population, the ESOL student population, socio-economic status, and school climate, the school climate from the students' 
perception had a correlation of 0.741 (Table 5). For the test on the relationship between the dependent variable and the Black student population, the White student population, the ESOL student population, and school climate, the school climate from the students' perception had a correlation of 0.741 (Table 9). For the test on the relationship between the dependent variable and the White student population, the Hispanic student population, the ESOL student population, and school climate, the school climate from the students' perception had a correlation of 0.741 (Table 13). For the test on the relationship between the dependent variable and the Hispanic student population, the ESOL student population, and school climate, the school climate from the students' perception had a correlation of 0.741 (Table 17). For the test on the relationship between the dependent variable and the White student population, the ESOL student population, and school climate, the school climate from the students' perception had a correlation of 0.741 (Table 21). For the test on the relationship between the dependent variable and the White student population, the Hispanic student population, and school climate, the school climate from the students' perception had a correlation of 0.741 (Table 45). For the test on the relationship between the dependent variable and the White student population, the Black student population, and school climate, the school climate from the students' perception had a correlation of 0.741 (Table 49). The more students agreed that their school climate was positive and helped them learn, the more passed the FCAT 2.0 Mathematics Test, having the second largest relation to the dependent variable. Feeling safe and comfortable and knowing that they are learning helps students succeed. Having a strong positive correlation between the school climate and achievement will only reflect in higher academic achievement and aspirations for the students (Chenoweth, 2007). 
Additionally, the larger the White student population, the more students passed the FCAT 2.0 Mathematics Test. For the test on the relationship between the dependent variable and the Black student population, the White student population, the ESOL student population, and school climate, the White student population had a correlation of 0.668 (Table 9). For the test on the relationship between the dependent variable and the White student population, the Hispanic student population, the ESOL student population, and school climate, the White student population had a correlation of 0.668 (Table 13). For the test on the relationship between the dependent variable and the White student population, the ESOL student population, and school climate, the White student population had a correlation of 0.668 (Table 21). For the test on the relationship between the dependent variable and the White student population, the Hispanic student population, and ESOL student population, the White student population had a correlation of 0.668 (Table 25). For the test on the relationship between the dependent variable and the White student population, the Black student population, and the ESOL student population, the White student population had a correlation of 0.668 (Table 29). For the test on the relationship between the dependent variable and the White student population, the Hispanic student population, and socio-economic status, the White student population had a correlation of 0.668 (Table 37). For the test on the relationship between the dependent variable and the White student population, the Black student population, and socio-economic status, the White student population had a correlation of 0.668 (Table 41). Due to racial and ethnic dimensions in Miami-Dade County, there is no public middle school with the White student population as the majority. But, for students attending public middle schools that have a White student population, they are exposed to 
better educational opportunities and resources. Borman et al. (2004) stated that "access to predominantly White institutions would enhance the social mobility and life chances" for racial and ethnic minority students (p.607). These three variables have a significant relation to the passing of the FCAT 2.0 Mathematics Test. Thus, the results of the data analysis are consistent with the researching findings.

Table 1 and Table 2 provide percentages for each independent variable group tested in this study. The Economically Disadvantaged (SES) student population independent variable, which was the strongest correlated variable with passing of the FCAT 2.0 Mathematics Test, holds the largest percentage for sample population tested in this study at $79.3 \%$ (Table 1). The variable with the second strongest correlation with the passing of the FCAT 2.0 Mathematics Test is the students that agreed that their school climate is positive and helped them learn. This variable actually holds the third largest percentage for sample population tested in this study at $44.1 \%$ (Table 2). Interestingly, the Hispanic student population has the second largest percentage for sample population tested yet this independent variable is not in the top three strongest correlated variables. The third strongest correlated variable with the passing of the FCAT 2.0 Mathematics Test is the White student population. This variable actually holds the smallest percentage, $8.0 \%$, for the sample population tested yet this independent variable was the third strongest correlated variable with the dependent variable (Table 1).

Table 1 and Table 2 show that the data for this study is based on a large population of over 54,000 students and that the top three variables with strongest correlation with the passing of the FCAT 2.0 Mathematics Test (Economically Disadvantaged student population, students that agreed their school climate was positive 
and helped them learn, White student population) represented a significant portion of the population. Economically Disadvantaged (SES) student population and students that agreed their school climate was positive and helped them learn were greater than $44 \%$ of the population while the White student population, although only $8 \%$ of the population, was still a significant portion of the population.

\section{Discussion and Implications for Improving Student Performance on the FCAT 2.0 Mathematics Test}

This quantitative study focused on exploring whether a relationship exists between public middle school students' performance on the FCAT 2.0 Mathematics Test and racial and ethnic concentrations, socio-economic status, ESOL student population, and school climate in Miami-Dade County, Florida. The major findings from this study clearly show that there is a strong relationship between the independent variables of socio-economic status, the positive school climate question on the student survey, and the White student population on the dependent variable. There is a strong negative relationship between the amount of Economically Disadvantaged (SES) students, decreasing the scores on the FCAT 2.0 Mathematics Test. Additionally, there is a strong positive relationship between the amount of students who agreed that their school climate was positive and helped them learn, increasing the scores on the FCAT 2.0 Mathematics

Test. Lastly, there is a strong positive relationship between the White student population and increasing the scores on the FCAT 2.0 Mathematics Test.

\section{Socio-economic Status}

This study on Miami-Dade County Public Schools, being a large and diverse school district, has important implications on similar school districts such as Chicago, 
Los Angeles, and New York. These and other school districts face similar problems, especially those with high levels of Economically Disadvantaged (SES) students. High levels of economically disadvantaged families have a negative relation to the mathematics achievement of public middle school students in Miami-Dade County. There may be just one parent, lack of involvement, interest, support, no adult supervision, absence of books and educational resources at home, and no structure at home, all necessary for students to succeed (Hofferth \& Sandberg, 2001). Low socio-economic status is also connected with other factors such as high levels of racial and ethnic concentrations in neighborhoods and schools, high ESOL population in schools, and negative school climate among many factor that have an adverse relationship to improve the academic achievement of minority populations (Williams, 1999).

This study found that there is a strong relation between being economically disadvantaged (having a low socio-economic status) and the FCAT 2.0 Mathematics scores in Miami-Dade County. Low socio-economic status is composed of various intricate and complex factors such as segregation, poverty, homeownership, parental influence, parental involvement, parents' education, and family structure. Previous studies such as Coleman (1966), Berliner and Biddle (1995), Valencia (1997), Borman et al. (2004), Street (2005) and Cortes Jr. (2010) found that socio-economic status has a negative relationship on students' academic achievement. "Minorities are more likely to live in low income households or in single parent families, their parents are likely to have less education and they often attend underfunded schools" (Ethington \& Wilson, 2010, p.20). 
As the study demonstrated, Miami-Dade County Public Schools has a large student population that comes from low socio-economic status households. "Students who reside in substandard housing and attend schools with limited resources are expected to attain the same level of success as students who attend schools with a plethora of educational resources that are located in middle-class neighborhoods" (Ethington \& Wilson, 2010, pp. 19-20). Despite various educational policies that have been established like Title I, Title VII, Goals 2000, and No Child Left Behind, the needs of Economically Disadvantaged (SES) students continues to not be met, even with the options from school choice: vouchers, magnet programs, and charter schools. Families using the school choice option may leave behind the problem in their child's home public school, but allowing families to abandon the problem is not the same as addressing it (Gersti-Pepin, 2002). As stated by Gersti-Pepin (2002), policymakers create educational policies that appear to make schools better, but the educational policies are not ensuring that all students receive the same quality education.

Meeting the needs of Economically Disadvantaged (SES) students, which include lack of parent support and involvement, bad nutrition, absence of books and educational resources at home, dangerous neighborhoods, lack of good hygiene, no structure, and unstable sleeping patterns among many is difficult due to various outside factors that are intricate and complex (Hofferth \& Sandberg, 2001). There are other factors that include inadequate resources at the schools and insufficient professional development opportunities for teachers, causing teachers to want to teach at schools that equip them with the necessities for students to succeed or leave the field altogether (Ethington \& Wilson, 2010). These outside factors include the economic situation of the family, 
county, state, and nation, politics, parental choices, crime rates, and demographic conditions. All these factors are beyond the control of educators, but these factors are part of low socio-economic status and so greatly relate to students' academic achievement.

Miami-Dade County Public Schools have made efforts to meet the needs of Economically Disadvantaged (SES) students by adopting educational policies such as Title I, Title VII, Goals 2000, and No Child Left Behind. Unfortunately, the funds provided by these educational policies have not been sufficient or used incorrectly to meet the needs of Economically Disadvantaged (SES) students (Gonzalez, 2005). With a county population of $2,496,435$ people, only a little more than half the population of Miami-Dade County, $58.3 \%$, own their home, and $17.1 \%$ are living below the poverty line (U.S. Census Bureau, 2010a). It is difficult to meet the great amount of needs of students living below the poverty line. Thus, educational policies such as Title I, Title VII, Goals 2000, and No Child Left Behind and school choice such as vouchers, magnet programs, and charter schools have had little relation on meeting the need of Miami-Dade County Public School students.

\section{School Climate}

Additionally, this study found that the second strongest relationship comes from the results of the positive school climate question on the student survey. In this study, students, parents, and school staff were surveyed about the climate of the school. School climate, positively or negatively, relates to students' academic achievement and behavior. The study concluded that the more students agreed that the climate at their schools was positive and helped them learn, the higher they scored on the FCAT 2.0 Mathematics 
Test in Miami-Dade County Public Schools. The positive school climate question on the parent survey and on the staff survey did not have such a strong relationship as the positive school climate question of the student survey. This would suggest that ultimately, students decide if their school climate is positive and helps them learn. The image of the school and their experiences there will be reflected on their academic achievement (Carwell, 2012). The students' perception of education has a stronger relationship because they are the ones learning, not their parents or the staff. Regardless, all stakeholders have a relationship with the school climate.

The climate of a school is vital to the students' success. How the stakeholders feel and act towards it, sets the tone in the school. There are several outside factors that relate to the school's climate that are uncontrollable, intricate and complex. "The problems associated with poor climate at many schools with high minority student populations are blamed for shortchanging those students" (Doyal, 2009, p. 22). Doyal (2009) added that "these schools suffer from poor discipline, poor funding, low staff morale, and lower parental involvement, factors that are blamed for a very high teacher attrition rate and a less qualified caliber of teachers" (p. 22). Personal school experiences of stakeholders, inadequate resources at schools and homes, low morale at schools, lack of funding for schools, limited professional development for teachers, absence of educational programs at schools, high levels of low socio-economic status at schools, and limited extracurricular activities relate to the school's climate. All these factors are beyond the educator's control, yet they have a great relationship with the students' success. 
The school climate or environment "plays a major role in motivational declines and in student achievement loss" in the schools (Gordon, 2011, p. 48). Schools should make it a goal for students to feel that the school climate is positive and helps them learn. With this mind set, students will achieve higher. "Students will have more positive selfimages, higher academic achievement, higher operations, and improved social skills when the school's climate and culture are positive" (Carwell, 2012, p. 56). Meeting the needs of the students, parents, and staff in regards to the school they attend, send their child to, or work at should create a positive climate at the school. Educational policies have been passed such as Title I, Title VII, Goals 2000, and No Child Left Behind to meet the needs which will in turn improve school climate.

\section{Racial and Ethnic Concentration}

Furthermore, this study found that the third strongest relationship comes from the White student population. In Miami-Dade County Public Schools, the schools have either a high level of Black concentration or a high level of Hispanic concentration. Borman et al. (2004) stated that "a much lower percentage of students passed the FCAT in Black segregated schools than in White segregated schools" (p. 625). This study concluded that the greater the White student population was at the schools, the higher the students scored on the FCAT 2.0 Mathematics Test in Miami-Dade County Public Schools.

During the 1970s, "Black and Hispanic students were attending college at rates comparable with Whites" (Darling-Hammond, 2011, p. 17). Besides the comparable college attendance rates, "urban schools were spending as much as suburban schools", "paying their teachers as well" and "gaps in educational attainment had closed 
substantially" (Darling-Hammond, 2011, p. 17). This progress was suspended under the presidency of Ronald Reagan due to various educational reforms that did not meet the needs of standardized testing, per-pupil spending, growing enrollment, immigration, poverty, English language instruction and special education (Darling-Hammond, 2011). Not all students and schools were receiving the same quality education and resources.

Despite the efforts of the ruling of the Brown v Board of Education case (1954), Lau v Nichols (1974), the Plyler v Doe case (1982), the Williams $v$ State of California case (2000), the Elementary and Secondary Education Act of 1965, Title I, Title VII, Goals 2000, and the No Child Left Behind Act, an achievement gap has continued to exist between Black, Hispanic and White students. "In 2011... the achievement gap between minority and White students in reading and math is larger than it was in $1988 . .$, (Darling-Hammond, 2011, p.14). These rulings and educational policies need to be revisited and reevaluated to see how they are and are not being followed.

"Education is supposed to be the prime engine for social mobility in America" (Kahlenberg, 2006, p.1). In order for education to serve as the engine for social mobility, it needs to offer all students regardless of their socio-economic or racial and ethnic background a quality education, despite their racial and ethnic identities. This would then truly allow for social mobility. As concluded in the study, social mobility is present in schools with higher enrollment of Whites than other schools. The relationships of racial and ethnic concentrations and low socio-economic status are diminished for Black and Hispanic students attending public middle schools in Miami-Dade County with higher enrollment of White students than other schools. 
While the efforts continue to meet the needs of the students through educational policies, doing so will not only improve academic achievement but it will be reflected onto the community and its future. "Instructional programs that produce learning climates in which all students achieve, regardless of their socio-economic or minority background" should be offered at all schools (Fadael, 2011, pp. $34-35$ ). These educational policies may need to be reviewed to assure that they are being implemented correctly to meet the needs of the Economically Disadvantaged (SES) students. Policy makers and educators need to review the programs that have come about from educational policies and assess if the program outcomes have been a success. Dr. Martin Luther King Jr. stated "the job of the school is to teach so well that family background is no longer an issue" (Rouse \& Barrow, 2006, p.100).

\section{Recommendations for Improving Student Performance on the}

\section{FCAT 2.0 Mathematics Test}

The overall failure of measures, such as Title I, Title VII, Goals 2000, and No Child Left Behind, designed to meet the needs of the students and provide a quality education were techniques that did not attack the root of the needs of the students and the lack of quality education. Almost 60 years since the ruling of the Brown v Board of Education case which stated that separate was not equal and still today, students in schools with high Black concentrations, high Hispanic concentrations, or high concentrations of low socio-economic status are not receiving the same quality education as schools with high White concentrations and high concentrations of high or middle socio-economic status. 
"Schools in segregated minority communities are populated by large numbers of minority students afflicted by pervasive poverty and all of the many problems that are inherent in poverty-stricken communities" (Moore, 2002, p. 219). Poverty-stricken communities consist of low socio-economic status, poor climate and a high minority population, all reflective in the communities' schools.

In order to realize the ideal of offering a quality education to all students, a few steps must be taken to transform the status quo. The current educational policies such as Title I, Title VII, and No Child Left Behind need to be re-evaluated to make sure that their focus is to meet the needs of the students and provide a quality education. Analyzing how their funding is being used will bring to light if funding lacks or is being misused. Also, establishing a rigorous accountability system that truly measures the assistance given by these educational policies will help protect the funds provided and reassure educators, parents, and students that the educational policies are carrying out their purpose and goals. If need be, the passing of new educational policies that are designed to truly meet the needs of all the students regardless of their socio-economic or racial and ethnic background and provide them with the same quality education might help solve this problem.

Researching school districts or metropolitan areas in similar situations to see how they are resolving this problem might help provide a solution (Moore, 2002). These school districts or metropolitan areas need to have concentrations of Blacks, Whites, and Hispanics, as well as English Language Learners. They may have effective practices already in place that may help Miami-Dade County Public Schools meet the needs of their students and provide them all with the same quality education. 
Conducting a district-wide analysis of the educational resources and technology available at each school to compare and contrast the inventory might provide another step toward providing resources to the neediest schools. This would highlight which schools lack resources or have out-of-date or broken resources. As analyzed in the results of the study, schools with high concentration of low socio-economic status had a lower percentage of the students passing the FCAT 2.0 Mathematics Test. Equipping all schools throughout the district with equally modern and high quality educational resources and technology is one step towards providing all students with the same quality education (Cobb \& Glass, 2009).

Moreover, school choice programs, such as vouchers, magnet programs and charter schools, provide parents with the option of being able to send their child to a different school than their public home school, but only leave the problem behind at the home school. If in addition to these programs, more focus was placed on analyzing the problems that exist in public schools and addressing them, it could finally begin improving the academic achievement of the students attending the public schools (GerstiPepin, 2002). Leaving the problems behind and ignoring them will not bring forth a solution.

Students who do not pass the FCAT 2.0 Mathematics Test should be required to take additional classes of mathematics which will help reinforce their mathematical skills. Offering tutoring sessions before the start of the school day, after the end of the school day and on Saturdays to students not passing the FCAT 2.0 Mathematics Test will help students better grasp the mathematical concepts. This extra learning time will allow for re-teaching and reinforcing of the mathematical concepts. 
Additionally, offering after school care led by certified teachers who can provide good classroom management and help students with their homework assignments can help provide students with the structure and attention they may lack at home. Providing adequate assistance with academics and instilling good behavior can help improve the students' academic achievement in mathematics and all subject areas. This holds the potential to improve the FCAT 2.0 Mathematics scores and school climate.

Another suggestion is to continue surveying students, parents and staff to find out the needs of the students at the school and how they could be met. This survey will bring forth the areas in which the students have needs that are not being met, and can potentially improve the students' academic achievement.

Furthermore, offering the Economically Disadvantaged (SES) students the choice of eating breakfast and dinner, as well as lunch, for free or a reduced price on a daily basis. This will help students eat three nutritionally-balanced meals a day and help them stay healthy and focus better in their classes. Reducing illness from poor nutrition can help improve students' academic achievement in mathematics and all subject areas (Cortes, Jr. 2010). This can lead to improvement in the FCAT 2.0 Mathematics scores and school climate.

Another possibility is to establish a lending system of educational resources so that low socio-economic families can have educational resources in their homes that they are not otherwise able to afford for the children. These educational resources range from books to technology and can enhance the child's grasp of knowledge and understanding of concepts in mathematics and all subject areas (Cobb \& Glass, 2009). This can lead to improvement in the FCAT 2.0 Mathematics scores and school climate. 
Also, school climate is essential to the students' success in school. Students, parents, and staff should continue to be surveyed to find out how the school climate can be improved. This can bring to everyone's attention the areas in need of improvement in a school environment. Requesting a response from all schools, staff members, parents, and students can provide a larger perspective for areas in need of improvement, unlike the current survey that looks at only a subsample of the school community. Additionally, having all schools promote a positive self-image and attitude can relate to the students' academic achievement in mathematics and all subject areas (Perkins-Gough, 2008). This can lead to improvements in the FCAT 2.0 Mathematics scores and school climate.

Lastly, another suggestion is hosting parent workshops to inform them about their child's education and gain their support in meeting their children's needs. When parents are knowledgeable of their child's education, they are more likely to be pleased with the school which will relate to their child's academic achievement (Muller, 1995). This effort will also increase parent involvement.

\section{Recommendations for Future Research}

Like many metropolitan areas, Miami-Dade County Public Schools is experiencing demographic changes due to the economy and racial and ethnic concentrations (Miami-Dade County Public Schools, 2013). These changes relate to society, especially the education system. The needs that arise from these changes must be discovered, researched, and met so that education continues to be the way for social mobility. Education policy makers, educational leaders, and educators must work closely together to make sure the students' needs are being met. These are numerous areas in 
need of exploration that will provide insight and direction in addressing the needs of the students.

The study could be replicated in other metropolitan areas such as Chicago, Los Angeles, New York. It can help establish if similar relationships exist between students' mathematics achievement, as measured by the state standardized test, and racial and ethnic concentrations, socio-economic status, ESOL student population, and school climate in their public schools. If relationships exist between these variables, these other metropolitan areas may then need to review how the needs of their students are being met.

This study could be replicated with Miami-Dade County Public Schools to see if a relationship exists with racial and ethnic concentrations, socio-economic status, ESOL student population, school climate, and the scores on the FCAT 2.0 for Reading, Writing, and Science. If these same variables are influencing other subject areas, it will be other areas that need to be addressed as well.

Additionally, conducting a quantitative study that measures homeownership and its relationship on students' performance on the FCAT 2.0 Mathematics Test will bring forth the value of a stable home. Such a relationship might be established if schools collected data and reported it along with the other data used in this study. When students move frequently throughout their childhood, they miss valuable learning time because of the move and then adjusting to their new school and its curriculum.

A mixed-methods study can be conducted that examines the School Improvement Plan (SIP), how aware the faculty and staff are of the schools' goals, how the goals are being reached, along with its relationship of the students passing the FCAT 2.0 
Mathematics Test. When all stakeholders are aware of the ultimate goal(s) of the school, everyone is working together, and all aspects of the school have the opportunity to succeed.

Investigating the level and quality of professional development being given to public middle school teachers will bring forth if staff is equipped with the latest trends, strategies, resources, and manipulatives in education. When the staff is aware of the latest advances in education, they are able to provide their students with an enhanced learning experience which is then reflected on their academic performance.

\section{Conclusion}

The results of this quantitative study found that all five research hypotheses were not rejected. Hence, statistically significant relationships were found between the independent variables and the dependent variable. On the other hand, for the second research hypothesis and its two tests, when controlling the ESOL student population (Model 1), no statistically significant relationship was found with the FCAT 2.0 Mathematics scores, rejecting the research hypothesis (H2; Table 26 and Table 30). In other words, when controlling the ESOL student population, the FCAT 2.0 Mathematics scores increased as the racial and ethnic concentrations increased. In Model 2, combining the White student population, the Hispanic student population and the ESOL student population for test 1 (Table 26) and the White student population and the ESOL student population for test 2 (Table 30 ), there was a statistically significant relationship with the FCAT 2.0 Mathematics scores, thus not rejecting the research hypothesis. In other words, as the racial and ethnic concentrations and the ESOL student population in schools increased, the FCAT 2.0 Mathematics scores decreased. 
Additionally, the results of this quantitative study found three independent variables to have strong correlations with the dependent variable. The three independent variables were Economically Disadvantaged (SES) student population with the strongest correlation, followed by the School Climate Student Survey and the White student population. This study brought forth that Miami-Dade County Public Schools is characterized by high levels of low socio-economic status which relate to various parts of society such as education.

The American Creed consists of the values of liberty, social justice, the rule of law, equal education, economic and political opportunities and primacy of the individual. It is "the moral force goading society to eliminate racial and ethnic discrimination and reduce the degree of inequality - socioeconomic, political, and educational - between the White majority and most minority groups in the nation" (Moore, 2002, p. 231). Even though these values are part of the foundation of the United States, "the ideal of $E$ pluribus Unum - out of many, one", they are encouraged but not completely followed (Moore, 2002, p. 231). Since the ruling of the Brown v Board of Education case that separate facilities were not equal, policies have been passed in the past several decades to reform schools such as Title I, Title VII, Goals 2000 and No Child Left Behind. Each with a different purpose and goal, but in search of the ultimate result of helping students be academically successful. Despite these initiatives, gaps between racial and ethnic groups and low, middle and high socio-economic status groups are still not being fully addressed.

In Miami-Dade County, the majority of the public schools have a high concentration of either Blacks or Hispanics. This is reflective of the county's 
demographics. This study brought forth that the schools with the largest concentrations of Whites had more students passing the FCAT 2.0 Mathematics Test. Moreover, despite the efforts of school choice, the needs of all racial and ethnic and socio-economic groups of students are not being met. Of course, the students who exercise their school choice option have a different educational path. Unfortunately, vouchers, magnet programs, and charter schools are not meeting all the needs of the students. These initiatives were created to help integrate schools and years later, the results of vouchers, magnet programs, and charter schools are yet to be seen. They are just providing an escape for students from their home school. But, the problem is only being left behind and passed on to the other students. Educational policies must be reformed to address the problems present in the traditional public middle schools, focusing on how all students can receive the same quality education regardless of the racial and ethnic concentrations in the individual schools.

School climate was found to be vital in this study. The students' perception of their school climate being positive and helping them learn has a relationship with their scores on the FCAT 2.0 Mathematics Test. The more students agreed that their school climate was positive and helped them learn, the more passed the FCAT 2.0 Mathematics Test. Educational leaders, educators, parents, and students need to focus on what has to be addressed in order to improve the school climate. The students' perspectives are not the only important ones, but also that of educators', parents', and all stakeholders' who need to agree that the school climate is positive and helps students learn. If not, a negative climate will be present and relate to the students' academic achievement. 
Moore (2002) stated

The primary ideas upon which America was built - the essential equality and moral worth of all human beings, the inalienable rights to freedom, social justice, and equal opportunity, and the universality of human nature- will continue to be the moral force pushing the United States to close the gap between our ideals and the realities for numerous minority groups throughout the nation. (p. 236) The question at hand is how this can be accomplished since previous reforms and policies have not been completely successful. Educational policy makers, educational leaders and educators need to find ways to meet the needs of all students and provide them with a universal, high quality education which will in turn reduce the gaps in achievement between the groups. Focusing on Miami-Dade County Public Schools, some negative relationships on the students' scores of the FCAT 2.0 Mathematics Test are racial and ethnic concentration, socio-economic status and school climate. If the needs created by these relationships were to be met, students' academic achievement would improve. Providing all students with the same quality education is not easy due to the variety of needs students have. Regardless, educational policy makers, educational leaders, and educators need to focus on meeting the needs of the students to assure they all receive the same quality education. 


\section{REFERENCES}

$13^{\text {th }}$ Amendment to the U.S. Constitution. (n.d.). Our documents. Retrieved January 24, 2011 from http://www.ourdocuments.gov/doc.php?flash $=$ old \&doc $=40$

Aberger, S., Brown, B., Mantil, A., \& Perkins, A. (2009). Closing the student achievement gap: The overlooked strategy of socioeconomic integration. Retrieved September 9, 2010 from http://a100educationalpolicy.pbworks.com/f/ Closing + the + Achievement+Gap+-+Socioeconomic+Integration.pdf

Ainsworth, J. W. (2002). Why does it take a village? The mediation of neighborhood effects on educational achievement. Social Forces., 81(1), 117-152.

Amato, P. R. (2000). The consequences of divorce for adults and children. Journal of Marriage and Family, 62(4), 1269 - 1287.

Archbald, D. A. (2004). School choice, magnet schools, and the liberation model: An empirical study. American Sociological Association, 77(4), 283-310.

Arora, R. (2005). Race and ethnicity in education. Burlington, VT: Ashgate Publishing.

Bankston, C. L. III, \& Caldas, S. J. (1998). Family structure, schoolmates, and racial inequalities in school achievement. Journal of Marriage and the Family, 60(3), 715-723.

Barrow, L., \& Rouse, C. E. (2008). School vouchers: Recent findings and unanswered questions. Economic Perspectives, 32(3), 2-16.

Bayer, P., McMillan, R., \& Rueben, K. (2001). The causes and consequences of residential segregation: An equilibrium analysis of neighborhood sorting. Working Papers, 885, 1-45.

Berlak, A. (2008). Racial and cultural competence and the adaptive unconscious. In Teel, K. M., \& Obidah, J. E. (2008). Building racial and cultural competence in the classroom. New York, NY: College Teacher Press.

Berliner, D. C., \& Biddle, B. J. (1995). The manufactured crisis. Reading, MA: AddisonWesley Publishing.

Blazer, C. (2007). Literature review on segregation in public schools. Miami-Dade County Public Schools. Retrieved March 29, 2009 from http://drs.dadeschools.net/Reports/ Segregation.pdf

Boozer, M., Krueger, A., Wolkon, S. (1992). Race and school quality since Brown versus Board of Education. Brookings Institutional Press, 1992, 269-338. 
Borman, K. M., McNulty Eitle, T., Michael, D. \& Eitle, D. J. (2004). Accountability in a post-desegregation era: The continuing significance of racial segregation in Florida's schools. American Educational Research Journal, 41(3), 605-631.

Borman, G. D., Stringfield, S. C., \& Slavin, R. E. (2001). Title I: Compensatory education at the crossroads. Mahwah, NJ: Lawrence Erlbaum Associates.

Cai, J., Moyer, J. C., \& Wang, N. (1999). Parental roles in students' learning of mathematics. Research in Middle Level Education Quarterly, 22(3), 1-18.

Carwell, T.L. (2012). The impact of the Stanford Math Intervention Program and school climate on mathematics achievement levels of female middle school student. Jackson, TN: Union University.

Chemerinsky, E. (2005). The segregration and resegregation of American public education: The courts' role (pp. 29-50). In J. C. Boger, \& G. Orfield (Eds). School resegregation: Must the south turn back? Chapel Hill, NC: The University of North Carolina Press.

Clotfelter, C. (2002). Interracial contact in high school extracurricular activities. The Urban Review, 34(1), $25-46$.

Cobb, C. D., \& Glass, G. V. (2009). School choice in a post-desegregation world. Peabody Journal of Education, 84(2), 262-278.

Cohen, J., Pickeral, T., \& McCloskey, M. (2009). Assessing school climate. Education Digest, 74(8), 45-48.

Coleman, J.S. (1935). Does the negro need separate schools?. The Journal of Negro Education, 4(3), 328-335.

Coleman, J. S. (1966).The concept of equality of opportunity. Harvard Educational Review, 38, 7-32.

Conger, D. (2005). Within school segregation in an urban school district. Educational Evaluation and Policy Analysis, 27(3), 225-244.

Cortes, Jr., E. (2010). Quality education as a civil right: Reflections (pp. 93-105). In T. Perry, R. P. Moses, J. T. Wynne, E. Cortes, Jr,. \& L. Delpit (Eds.). Quality education as a constitutional right. Boston, MA: Beacon Press.

Crain, R. (1970). School integration and occupational achievement of Negroes. In Rivkin, S. G. (2000). School desegregation, academic attainment, and earnings. The Journal of Human Resources, 35(2), 333-346. 
Darling-Hammond (2011). Restoring our schools: The quest for equity in the United States. Canadian Education Association, 51(5), 14-18.

Delpit, L. (1995). Other people's children: Cultural conflict in the classroom. New York, NY: The New Press.

Delpit, L. (2010). Cultural responsive pedagogies: Lessons from teachers (pp.167-188). In T. Perry, R. P. Moses, J. T. Wynne, E. Cortes, Jr,. \& L. Delpit (Eds.). Quality education as a constitutional right. Boston, MA: Beacon Press.

Delpit, L., \& Dowdy, J. K. (2002). The skin that we speak: Thoughts on language and culture in the classroom. New York, NY: The New Press.

Diamond, J. B. (2006). Still separate and unequal: Examining race, opportunity, and school achievement in "integrated" suburbs. Journal of Negro Education, 75(3), 495-505.

DiMaria, R.A. (2000). Correlation. Retrieved March 2, 2013 from http://www.hsc.wvu.edu/ Charleston/son/StudentResources/PDF/Class\%205\%20correlation\%20DiMaria.pdf

Doyal, T.S. (2009). Is there a relationship between academic achievement and school climate at the elementary, middle or high school grade level?. Available from ProQuest Dissertations and Theses database. (Proquest ID 1021723760).

Echenique, F., Fryer Jr., R. G., \& Kaufman, A. (2006). Is school segregation good or bad? American Economic Association, 96(2), 265-269.

Education Week. (2004). Title I. Retrieved December 18, 2011 from http://www.edweek.org/ ew/issues/title-i/

Entwisle, D. R., Alexander, K. L, \& Olson, L. S. (1997). Children, schools, and inequality. Boulder, CO: Westview Press.

Ethington, C.A., \& Wilson, T. (2010). Mathematics achievement and African-American students in urban schools. Investigations in Mathematics Learning, 2(2). 19-32.

Fadael, O. (2011). The relationship between school effectiveness and school achievement: A study of middle school performance in Palm Beach County, Florida since the implementation of NCLB. Available from ProQuest Dissertations and Theses database. 
Flores, B.M. (2005). The intellectual presence of the deficit view of Spanish-speaking children in the educational literature during the $20^{\text {th }}$ century (pp.75-98). In P.Pedraza \& M. Rivera (Eds.). Latino education: An agenda for community action research. Mahwah, NJ: Lawrence Eribaum Associates.

Florida Department of Education. (2005). Florida Comprehensive Assessment Test. Retrieved November 27, 2008 from http://fcat.fldoe.org/

Florida Department of Education. (2011a). 2011 AYP report. Retrieved December 18, 2011 from schoolgrades.fldoe.org/xls/1011/AYP1011ALACHUAtoDADE.xls

Florida Department of Education. (2011b). School accountability report. Retrieved December 18, 2011 from http://schoolgrades.fldoe.org/default.asp

Florida Department of Education. (2011c). FCAT 2.0 student performance results: School math demographic report. Retrieved December 18, 2011 from https://app1.fldoe.org/FCATdemographics/Selections.aspx?reportTypeID= 3\&level $=$ School\&subj $=$ Math

Florida Department of Education. (2011d). Understanding FCAT 2.0 reports. Retrieved December 18, 2011 from http://fcat.fldoe.org/fcat2/pdf/11ufrfinal.pdf

Florida Department of Education. (February 2011). 2011 FCAT 2.0 fact sheet. Retrieved May 24, 2011 from http://fcat.fldoe.org/fcat2/pdf/ffs2.pdf

Florida Department of Education. (July 2011). 2011 Guide to calculating school grades. Retrieved August 5, 2011 from http://schoolgrades.fldoe.org/pdf/1011/School GradesTAP2011.pdf

Forster, G. (2008). Lost opportunity: An empirical analysis of how vouchers affected Florida public schools. Tallahassee, FL: Friedman Foundation for Educational Choice.

Freire, P. (1970). Pedagogy of the Oppressed. New York, NY: Herder \& Herder.

Gajendragadkar, S. S. (2006) The constitutionality of racial balancing in charter schools. Columbia Law Review, 106(1), 144-181.

Gersti-Pepin, C. (2002). Magnet schools: A retrospective case study of segregation. The High School Journal, 85(3), 47-52.

Glenwick, D. S., \& Mowrey, J. D. (1986). When parent becomes peer: Loss of intergenerational boundaries in single parent families. Family Relations, 35(1), $57-62$. 
Gonzalez, R.(2005). Standards-based reform and the latino/a community opportunities for advocacy (pp.165-184). In P. Pedraza \& M. Rivera (Eds.). Latino education: An agenda for community action research. Mahwah, NJ: Lawrence Eribaum Associates.

Gordon, K.D.(2011). Middle school transition: How it affects the achievement of Hispanic students relative to ELL status, socioeconomic status, gender and previous test scores. Ann Arbor, MI: ProQuest, LLC.

Gray, L. H. (2005). The 2004 Charles H. Thompson lecture-colloquium presentation: "No Child Left Behind: Opportunities and threats. Journal of Negro Education, 74(2), 95-111.

Guillemette, R. (n.d.). Sputnik and the crisis that followed. Retrieved January 24, 2011 from http://www.centennialofflight.gov/essay/SPACEFLIGHT/Sputnik /SP16.htm

Hallinan, M. T. (2001). Sociological Perspectives on Black-White Inequalities in American Schooling. Sociology of Education, 74, 50-70.

Hardaway, C. R., \& McLoyd, V. C. (2009). Escaping poverty and securing middle class status: How race and socioeconomic status shape mobility prospects for African Americans during the transition to adulthood. Journal of Youth Adolescence, 38, 242-256.

Hart-Shegos, E. (1999). Homelessness and its effects on children. Family Housing Fund, $1-16$.

Haurin, D. R., Parcel, T. L., \& Haurin, R. J. (2001). The impact of homeownership on child outcomes. Joint Center for Housing Studies of Harvard University, 1-25.

Heck, R. (2000). Examining the impact of school quality on school outcomes and improvement: A value-added approach. Educational Administration Quarterly 36(4), 513-522.

HighScope Educational Research Foundation. (2011). HighScope. Retrieved August 5, 2011 from http://www.highscope.org

Hinton, P.R, Brownlow, C., McMurray, I., \& Cozens, B. (2004). SPSS Explained. New York, NY: Routledge.

Hofferth, S. L., \& Sandberg, J. F. (2001). How American children spend their time. Journal of Marriage and Family, 63(2), 295-308. 
Hong, W., \& Youngs, P. (2008). Does high-stakes testing increase cultural capital among low-income and racial minority students? Education Policy Analysis Archives, 16(6), 1-20.

Hoy, W. K., \& Sabo, D. J. (1998). Quality middle schools: Open and healthy. Thousand Oaks, CA: Sage.

Independence Hall Association. (2010a). Constitution of the United States. Retrieved February 20, 2010 from http://www.ushistory.org/documents/constitution.htm

Independence Hall Association. (2010b). Declaration of Independence. Retrieved February 20, 2010 from ttp://www.ushistory.org/declaration/document/index.htm

Jargowsky, P. A., \& Bane, M. J. (1991). Ghetto poverty in the United States. The Urban Underclass, 235, $251-252$.

Kahlenberg, R. D. (2000). A nation at risk: Preserving public education as an engine for social mobility. New York, NY: The Century Foundation Press.

Kahlenberg, R. D. (2006). Helping children move from bad schools to good ones. Education Week, 25(41), 52 - 66.

Kao, G., \& Thompson, J. S. (2003). Racial and ethnic stratification in educational achievement and attainment. Annual Review of Sociology, 29, 417-442

Keefe, J. W., Kelley, E. A., \& Miller, S. K. (1985). School climate: Clear definitions and a model for a larger setting. NASSP Bulletin, 69(484), 70-77.

Keith, V. M., \& Finlay, B. (1988). The impact of parental divorce on children's educational attainment, marital timing, and likelihood of divorce. Journal of Marriage and Family, 50(3), 797 - 809.

Kelly, J. B., \& Emery, R. E. (2003). Children's adjustment following divorce: Risk and resilience perspectives. Family Relations, 52(4), 352-362.

Kerlinger, F.N. (1973). Foundations of behavioural research. New York, NY: Holt, Reinehart and Winston.

Kim, J. S. \& Sunderman, G. L. (2005). Measuring academic proficiency under the No Child Left Behind Act: Implications for educational equity. Educational Researcher, 34(8), 3-13.

Ladner, M. (2009). Florida's lessons for Indiana K-12 reform. Friedman foundation for educational choice, 8-14. 
Ladner, M., \& Lips, D. (2009). Demography as destiny?. Education Next, 9(3), 20-27.

Lee, C. (2004). Racial segregation and educational outcomes in metropolitan Boston. The Civil Rights Project: Harvard University, 1-42.

Levin, H. M. (1998). Educational vouchers: Effectiveness, choice and costs. Journal of Policy Analysis and Management, 17(3), 373-392.

Levy, T. (2010). Charter schools legislation and the element of race. The Western Journal of Black Studies, 34(1), 43-52.

Lindemer, C. L. (2006). The development of a rating scale to measure the quality of preschool literacy environments: A validity study. Akron, $\mathrm{OH}$ : University of Akron.

Little River Elementary School Characteristic. (2004). Miami-Dade County Public Schools. Retrieved May 19, 2010 from http://oada.dadeschools.net/Schoo 1PerformanceData/0304 Profiles/13021.pdf

Lisack, J. P. (1987). The changing face of America: Population, education, and socioeconomic. Office of Manpower Studies, 87(6).

Lubienski, C., \& Weitzel, P. (2009). Choice, integration, and education opportunity: Evidence on competitive incentives for student sorting in charter schools. The Journal of Gender, Race, and Justice, 11 (3), 351- 375.

MacDonald, V.M., \& Monkman, K. (2005). Setting the context: Historical perspectives on Latino/a education (pp.47-74). In P. Pedraza \& M. Rivera (Eds.), Latino education: An agenda for community action research. Mahwah, NJ: Lawrence Erlbaum Associates.

Magnuson, K., \& Waldfogel, J. (2008). Steady gains and stalled progress: Inequality and the Black-White test score gap. New York, NY: Russell Sage Foundation.

Massey, D. S., \& Denton, N. A. (1993). American apartheid: Segregation and the making of the underclass. Boston, MA: Harvard University Press.

Mayer, S. (1991). How much does a high school's racial and socioeconomic mix affect graduation and teenage fertility rates? (pp. 321-341). In C. Jencks \& P. Peterson (Eds.), The Urban Underclass. Washington, D.C.: Brookings Institution.

Mercado, C. I., \& Santamaria, L. J. (2005) A new vision for Latino/a education: A comparative perspective on research agendas (pp.11-46). In P. Pedraza \& M. Rivera (Eds.). Latino education: An agenda for community action research. Mahwah, NJ: Lawrence, Eribaum Associates. 
Meko, D. (2011). Multiple linear regression. Retrieved January 2, 2012 from http://www.ltrr.arizona.edu/ dmeko/notes_11.pdf

Metz, M. H. (1988). Some missing elements in the educational reform movement. Educational Administration Quarterly, 24(3). 336 - 460.

Miami-Dade County (2009). Economic profile of Miami-Dade County Commission Districts.Retrieved October 11, 2012 from http://www.miamidade.gov /EconomicDevelopment /profile.asp

Miami-Dade County Public Schools (2011a). ESOL and related programs. Retrieved December 18, 2011 from http://bilingual.dadeschools.net/BEWL/programs.asp

Miami-Dade County Public Schools (2011b). Title I-Improving the academic achievement of the disadvantaged. Retrieved December 18, 2011 from http://title1.dadeschools.net

Miami-Dade County Public Schools (2013). Office of governmental affairs, grants administration, and community engagement. Retrieved March 1, 2013 from http://gafla.dadeschools.net

Miami-Dade County Public Schools (2011c). Statistical highlights. Retrieved December 18, 2011 from http://drs.dadeschools.net/StatisticalHighlights/SH10-11.pdf

Misco, T., \& Castañeda, M. E. (2009). "Now, what should I do for English language learners?” Reconceptualizing social studies curriculum design for ELLs. Educational Horizons, 182-189.

Miller, G. E., Reynolds, W. M., \& Weiner, I. B. (2003). Handbook of psychology. Volume 7: Educational psychology. Hoboken, NJ: John Wiley \& Sons, Inc.

Moody, J. (2001). Race, school integration, and friendship segregation in America. American Journal of Sociology, 107(3), 679-716.

Moore, J. R. (2002). School segregation and educational performance in a multicultural society: The case of Miami-Dade County, Florida. Miami, FL: Florida International University.

Moses, R. P. (2010). Consitutional property v constitutional people (pp. 70-92). In T. Perry, R. P. Moses, J. T. Wynne, E. Cortes, Jr,. \& L. Delpit (Eds.). Quality education as a constitutional right. Boston, MA: Beacon Press.

Moses, R. P., \& Cobb, Jr., C. E. (2001). Radical equations: Civil rights from Mississippi to the Algreba Project. Boston, MA: Beacon Press. 
Mouly, G. J. (1970). The science of education research. New York: Van Nostrand Reinhold Company.

Mouw, T., \& Entwisle, B. (2006). Residential segregation and interracial friendship in schools. American Journal of Sociology, 112(2), 394-441.

Mulkey, L. M., Crain, R. L., \& Harrington, A. J. (1992). One-parent households and achievement: Economic and behavioral explanations of a small effect. Sociology of Education 65(1), 48 - 65.

Muller, C. (1995). Maternal employment, parent involvement, and mathematics achievement among adolescents. Journal of Marriage and the Family, 57(1), 85100.

Munoz, M. A., Clavijo, K. G., \& Koven, S. G., (1999). Educational equity in a reform environment: The effect of socio-economic status on student achievement. Retrieved from ERIC database. (ED466524)

Newman, I., McNeil, K., \& Frass, J. (April, 2003). Déjà vu: Another call for replications of research, again. Paper presented at the annual meeting of the American Educational Research Association, Chicago, IL.

Noonan, J. (2004). School climate and the safe school: Seven contributing factors. Education Horizon, 83(1), 61-65.

Oakes, J. (2010). Schools that shock the conscience: What Williams $v$ California reveals about the struggle for an education on equal terms fifty years after Brown (pp.4969). In T. Perry, R. P. Moses, J. T. Wynne, E. Cortes, Jr,. \& L. Delpit. (Eds.). Quality education as a constitutional right. Boston, MA: Beacon Press. 49 - 69

One Hundred Seventh Congress of the United States of America. (2008). U.S. Department of Education. Retrieved October 17, 2013 from http://www2.ed.gov/policy/elsec/leg/esea02/beginning.html\#sec1

Orfield, G. (2007). Prologue - Lessons forgotten (pp.1-6). In E. Frankenburg \& G. Orfield (Eds.). Lessons in integration: Realizing the promise of racial diversity in American schools. Charlottesville, VA: University of Virginia Press. 1- 6.

Pallant, J. (2010). SPSS survival manual: A step by step guide to data analysis using SPSS. Philadelphia, PA: Open University Press.

Perkins-Gough, D. (2008). School climate: Urban parents' views. Educational Leadership. 89-90. 
Perry, I. (2010). Reading, writing, and rights: Ruminations on getting the law in line with educational justice (pp.33-48). In T. Perry, R. P. Moses, J. T. Wynne, E. Cortes, Jr,. \& L. Delpit (Eds.). Quality education as a constitutional right. Boston, MA: Beacon Press.

Perry, T. (2010). The historical and contemporary foundations for Robert Moses' call to make quality education a constitutionally guaranteed right (pp. vii-Xv). In T. Perry, R. P. Moses, J. T. Wynne, E. Cortes, Jr,. \& L. Delpit (Eds.). Quality education as a constitutional right. Boston, MA: Beacon Press.

Perry, T., Steele, C., \& Hilliard III, A. (2003). Young, gifted and Black: Promoting high achievement among African-American students. Boston, MA: Beacon Press.

Powell, J.A. (2005). A new theory of integrated education: True integration (pp. 281304). In J. C. Boger \& G. Orfield (Eds). School segregation: Must the south turnback?. Chapel Hill, NC: The University of North Carolina Press.

Race. (2000). State \& County QuickFacts. Retrieved January 3, 2011 from http://quickfacts.census.gov/qfd/meta/long_RHI225209.htm

Raley, R. K. (1991). The effects of family composition on educational attainment: Do the effects vary by the age of the child? American Journal of Economics and Sociology, Inc,. 54(1), 89-105.

Rivkin, S. G. (2000). School desegregation, academic attainment, and earnings. The Journal of Human Resources, 35(2), 333-346.

Romo, H. (1997). Improving ethnic and racial relations in the schools. Charleston, WV: Clearinghouse on Rural Education and Small Schools.

Roscigno, V. J., Tomaskovie-Devey, D., \& Crowley, M. (2006). Education and the inequalities of place. University of North Carolina Press, 84(4), 2121-2145.

Rouse, C. E. \& Barrow, L. (2006). U.S. elementary and secondary schools: Equalizing opportunity or replicating the status quo? The Future of Children, 16(2), 99-123.

Rubie-Davis, C. M., Peterson, E., Irving, E., Widdowson, D., \& Dixon, R. (2010). Expectations of achievement: Student, teacher, and parent perceptions. Research in Education, 83, 36-53.

Rumberger, R. W., \& Palardy, G. J. (2005). Does resegregation matter? (pp.127-145). In J. C. Boger \& G. Orfield (Eds.), School segregation: Must the south turn back?. Chapel Hill, NC: The University of North Carolina Press. 
Sandell, J., \& Plutzer, E. (2005). Families, divorce, and voter turnout in the US. Political Behavior, 27(2), 133-162.

Saporito, S., \& Sohoni, D. (2006). Coloring outside the lines: Racial segregation in public schools and their attendance boundaries. American Sociological Association, 79(2), 81-105.

Sass, T. R. (2006). Charter schools and student achievement in Florida. Education Finance and Policy, 1(1), 91-122.

Sastry, N., \& Pebley, A. R. (2008). Family and neighborhood sources of socioeconomic inequality in children's achievement. Demography, 47(3), 777 - 800.

Schofield, J. W., \& Sagar, H.A. (1977). Peer interaction patterns in an integrated middle school. Sociometry, 40(2), 130 - 138.

School Climate Surveys. (2011). Miami-Dade County Public Schools. Retrieved December 18, 2011 from http://drs.dadeschools.net/SchoolClimateSurvey/201011/Schools_10-11.html

Scott, J. (2005). In school choice and diversity: What the evidence says. New York, NY: Teachers College Press.

State of Florida. (2013). Consitution of the state of Florida. Retrieved September 23, 2013 from http://www.flsenate.gov/Laws/Constitution\#A9

Street, P. (2005). Segregated schools: Educational apartheid in post-civil rights America. New York, NY: Routledge, Taylor, and Fracis Group.

Stretesky, P.B., \& Hogan, M. J. (2005). Segregation and school disorder. The Social Science Journal, 42(3), 405-420.

Sunset Park Elementary School Characteristics. (2005). Miami-Dade County Public Schools. Retrieved May 19, 2010 from http://oada.dadeschools.net/School PerformanceData/04 05/Profiles/15421.pdf

Sweeney, J. (1988). Tips for improving school climate. Arlington, VA: American Association of School Administrators.

Tatum, B. D. (1997). Why are all the black kids sitting together in the cafeteria? New York: Basic Books.

Tedin, K. L., \& Weiher, G. R. (2004). Racial/ethnic diversity and academic quality as components of school choice. Cambridge University Press, 66(4), 1109-1133. 
The Federal Role in Education. (2010). U.S. Department of Education. Retrieved January 24, 2011 from http://www2.ed.gov/about/overview/fed/role.html

The Williams Case. (2011). California Department of Education. Retrieved April 22, 2011 from http://www.cde.ca.gov/eo/ce/wc/wmslawsuit.asp

Thompson, B. (2006). Foundations of behavioral statistics. New York, NY: Guilford Press.

U.S. Census Bureau (2010a). Miami-Dade County, Florida. Retrieved December 18, 2011 from http://quickfacts.census.gov/qfd/states/12/12086.html

U.S. Census Bureau. (2010b). State and county quick facts. Retrieved August 5, 2011 from http://quickfacts.census.gov/qfd/states/00000.html

U.S. Department of Education. (2004). Title I - Improving the academic achievement of the disadvantaged. Retrieved December 18, 2011 from http://www2.ed.gov/ policy/elsec/esea02/pg1.html

Valencia, R. R. (1997). Latino demographic and educational conditions. EST Policy Notes, 8(1), 1-4.

Voting Rights Act. (n.d.). America's historical documents. Retrieved November 4, 2011 from http://www.archives.gov/historical-docs/document.html?doc=18\&title.raw $=$ Voting $\% 20$ Rights $\% 20$ Act

Wacquant, L. J. D. (1996). Red belt, black belt: Racial division, class inequality and the state in the French urban periphery and the American ghetto (pp. 234-274). In E. Mingione (Eds.). Urban Poverty and the Underclass: A Reader.

Wang, M. C. \& Kovach, J. A., (1995). Bridging the achievement gap in urban schools: Reducing educational segregation and advancing resilience - Promoting strategies. Association for Supervision and Curriculum Development.

West, K. C. (1994). A desegregation tool that backfired: Magnet schools and classroom segregation. The Yale Law Journal, 103(8), 2567-2592.

Williams, D. R. (1999). Race, socioeconomic status, and health. Annals New York Academy of Sciences, 896, 173-188.

Willie, C. V. (2005). The continuing spirit of the Brown decision of the Supreme Court. The Negro Educational Review, 56(1), 11-17.

Wilson, W. J. (1997). When work disappears: The world of the new urban poor. New York, NY: Vintage 
Wilson, W. J. (2012). The truly disadvantaged: The inner city, the underclass, and public policy. Chicago, IL: University of Chicago Press.

Wormser, R. (2002). Jim Crow stories. Retrieved January 24, 2011 from http://www.pbs.org/wnet/jimcrow/stories_events_gaines.html

Zamel, V. \& Spack, R. (2006). Teaching multilingual learners across the curriculum: Beyond the ESOL classroom and back again. Journal of Basic Writing, 25(2), 126-152.

Zoloth, B. S. (1976). Alternative measures of school segregation. Land Economics, 52(3), 278-298. 


\section{APPENDIX I}

MIAMI-DADE COUNTY PUBLIC SCHOOLS 2010-2011 SCHOOL YEAR DATA

\begin{tabular}{|c|c|c|c|c|c|c|c|c|c|c|}
\hline School Name & $\%$ White & $\%$ Black & $\begin{array}{c}\% \\
\text { Hispanic }\end{array}$ & $\begin{array}{c}\% \\
\text { Other }\end{array}$ & $\% \mathrm{ELL}$ & $\% \mathrm{SES}$ & $\begin{array}{c}\% \text { Pass } \\
\text { FCAT Math }\end{array}$ & $\begin{array}{l}\text { Climate } \\
\text { Parents }\end{array}$ & $\begin{array}{l}\text { Climate } \\
\text { Students }\end{array}$ & $\begin{array}{c}\text { Climate } \\
\text { Staff }\end{array}$ \\
\hline Allapattah & 1.29 & 60.14 & 38.27 & 0.29 & 5.47 & 89.64 & 32 & 69 & 18 & 50 \\
\hline Andover & 0.91 & 90.97 & 6.66 & 1.28 & 6.02 & 82.12 & 60 & 60 & 42 & 69 \\
\hline Arvida & 19.29 & 12.83 & 64.92 & 2.35 & 3.49 & 52.85 & 82 & 89 & 74 & 94 \\
\hline Brownsville & 0.15 & 73.84 & 25.87 & 0.15 & 5.96 & 94.48 & 35 & - & - & 83 \\
\hline Campbell Drive & 2.85 & 54.62 & 41.85 & 0.41 & 8.02 & 91.44 & 36 & 52 & 43 & 58 \\
\hline Carol City & 0.37 & 86.89 & 11.86 & 0.37 & 2.5 & 91.89 & 39 & 74 & 36 & 77 \\
\hline Centennial & 6.91 & 45.77 & 45.65 & 1.31 & 5.6 & 85.46 & 43 & 76 & 44 & 84 \\
\hline Charles R. Drew & 0 & 95.42 & 4.58 & 0 & 0.87 & 95.64 & 35 & 65 & 42 & 44 \\
\hline Citrus Grove & 1.29 & 4.45 & 93.77 & 0.4 & 20.28 & 94.07 & 35 & 82 & 33 & 73 \\
\hline Country Club & 3.67 & 19.27 & 75.41 & 1.44 & 9.78 & 79.94 & 58 & 81 & 56 & 50 \\
\hline Cutler Ridge & 13.72 & 36.06 & 48.18 & 1.75 & 7.59 & 86.42 & 42 & 72 & 42 & 33 \\
\hline Doral & 9.03 & 12.65 & 76 & 2.32 & 8.77 & 56.77 & 69 & 61 & 46 & 86 \\
\hline $\begin{array}{l}\text { George } \\
\text { Washington } \\
\text { Carver }\end{array}$ & 30.6 & 6.8 & 59.6 & 2.8 & 3.2 & 30.8 & 97 & 92 & 79 & 96 \\
\hline Glades & 12.23 & 2.09 & 83.33 & 1.84 & 8.29 & 66.08 & 77 & 87 & 69 & 95 \\
\hline Hammocks & 10.44 & 7.56 & 79.29 & 2.55 & 8.46 & 65.65 & 68 & 82 & 48 & 80 \\
\hline Henry H. Filer & 1.36 & 0.85 & 97.71 & 0.08 & 30.51 & 90.59 & 63 & 90 & 56 & 84 \\
\hline $\begin{array}{l}\text { Herbert A. } \\
\text { Ammons }\end{array}$ & 17.74 & 12.83 & 65.12 & 3.36 & 0.52 & 48.92 & 93 & 95 & 73 & 97 \\
\hline
\end{tabular}




\begin{tabular}{|c|c|c|c|c|c|c|c|c|c|c|}
\hline School Name & $\%$ White & $\%$ Black & $\begin{array}{c}\% \\
\text { Hispanic }\end{array}$ & $\begin{array}{c}\% \\
\text { Other }\end{array}$ & $\%$ ELL & $\%$ SES & $\begin{array}{c}\% \text { Pass } \\
\text { FCAT Math }\end{array}$ & $\begin{array}{l}\text { Climate } \\
\text { Parents }\end{array}$ & $\begin{array}{l}\text { Climate } \\
\text { Students }\end{array}$ & $\begin{array}{l}\text { Climate } \\
\text { Staff }\end{array}$ \\
\hline Hialeah & 2.17 & 3.18 & 94.65 & 0 & 16.69 & 91.21 & 47 & 72 & 46 & 72 \\
\hline Hialeah Gardens & 2.85 & 1.43 & 95.04 & 0.51 & 13.35 & 83.11 & 64 & 86 & 73 & 94 \\
\hline Highland Oaks & 18.8 & 47.47 & 30.13 & 2.75 & 5.67 & 67.55 & 67 & 76 & 60 & 91 \\
\hline Homestead & 3.82 & 33.89 & 61.22 & 0.46 & 8.09 & 92.98 & 45 & 77 & 46 & 65 \\
\hline Horace Mann & 0.8 & 84.71 & 13.83 & 0.53 & 14.23 & 92.95 & 51 & 84 & 47 & 45 \\
\hline $\begin{array}{l}\text { Howard A. } \\
\text { Doolin }\end{array}$ & 5.47 & 2.21 & 90.89 & 1.3 & 14.45 & 84.38 & 58 & 80 & 46 & 86 \\
\hline $\begin{array}{l}\text { Howard D. } \\
\text { Mcmillan }\end{array}$ & 6.57 & 0.82 & 89.79 & 2.46 & 9.51 & 79.58 & 76 & 89 & 72 & 72 \\
\hline John F. Kennedy & 3.84 & 68.17 & 24.29 & 3.41 & 10.22 & 87.74 & 65 & 74 & 59 & 75 \\
\hline $\begin{array}{l}\text { Jorge Mas } \\
\text { Canosa }\end{array}$ & 10.87 & 5.95 & 81.05 & 1.58 & 7.32 & 69.96 & 67 & 84 & 56 & 87 \\
\hline Jose De Diego & 0.77 & 46.62 & 52.42 & 0 & 9.48 & 93.81 & 33 & 83 & 43 & 40 \\
\hline Jose Marti & 1.77 & 1.09 & 95.92 & 1.22 & 21.74 & 91.58 & 56 & 61 & 47 & 73 \\
\hline Kinloch Park & 2.58 & 0.6 & 96.56 & 0.17 & 26.29 & 90.98 & 57 & 86 & 57 & 84 \\
\hline Lake Stevens & 0.63 & 53.13 & 45.94 & 0 & 7.03 & 90.63 & 61 & 76 & 40 & 92 \\
\hline $\begin{array}{l}\text { Lamar Louise } \\
\text { Curry }\end{array}$ & 6.74 & 1.71 & 87.29 & 4.27 & 4.74 & 62.9 & 84 & 88 & 79 & 96 \\
\hline Lawton Chiles & 5.45 & 40.96 & 51.87 & 1.71 & 3.32 & 75.19 & 49 & 64 & 33 & 35 \\
\hline Madison & 0.31 & 62.1 & 37.6 & 0 & 8.47 & 91.06 & 43 & 48 & 40 & 35 \\
\hline Mays Community & 2.57 & 52.57 & 43.57 & 1.1 & 7.54 & 93.2 & 45 & 65 & 36 & 95 \\
\hline
\end{tabular}




\begin{tabular}{|c|c|c|c|c|c|c|c|c|c|c|}
\hline School Name & $\%$ White & $\%$ Black & $\begin{array}{c}\% \\
\text { Hispanic }\end{array}$ & $\begin{array}{c}\% \\
\text { Other }\end{array}$ & $\%$ ELL & $\%$ SES & $\begin{array}{c}\% \text { Pass } \\
\text { FCAT Math }\end{array}$ & $\begin{array}{l}\text { Climate } \\
\text { Parents }\end{array}$ & $\begin{array}{l}\text { Climate } \\
\text { Students }\end{array}$ & $\begin{array}{l}\text { Climate } \\
\text { Staff }\end{array}$ \\
\hline Miami Edison & 0.81 & 88.24 & 10.34 & 0 & 15.62 & 95.94 & 45 & 84 & 48 & 28 \\
\hline Miami Lakes & 4.11 & 10.67 & 84.06 & 0.77 & 10.28 & 82.78 & 69 & 89 & 43 & 90 \\
\hline Miami Springs & 4.94 & 13.28 & 81.1 & 0.49 & 17.42 & 83.94 & 57 & 73 & 55 & 71 \\
\hline Nautilus & 22.03 & 11.36 & 65.16 & 1.2 & 7.86 & 72.42 & 70 & 77 & 45 & 80 \\
\hline Norland & 0.25 & 94.32 & 4.17 & 0.51 & 2.02 & 82.95 & 52 & 62 & 33 & 76 \\
\hline North Dade & 0.51 & 88.57 & 10.58 & 0 & 2.22 & 88.74 & 42 & 77 & 22 & 64 \\
\hline North Miami & 0.48 & 88.01 & 9.96 & 1.35 & 20.12 & 94.2 & 44 & 74 & 48 & 61 \\
\hline Palm Springs & 2.24 & 1.31 & 95.99 & 0.47 & 20.73 & 89.45 & 66 & 85 & 78 & 91 \\
\hline Palmetto & 40.63 & 12.75 & 39.95 & 5.83 & 3.13 & 27.62 & 83 & 90 & 62 & 94 \\
\hline Parkway & 0.72 & 94.74 & 4.31 & 0.24 & 1.67 & 89.95 & 39 & 62 & 45 & 73 \\
\hline Paul W. Bell & 2.96 & 0.13 & 96.1 & 0.81 & 15.48 & 89.37 & 52 & 85 & 63 & 92 \\
\hline Ponce De Leon & 10.65 & 15.03 & 73.11 & 1.2 & 11.43 & 76.46 & 64 & 84 & 48 & 59 \\
\hline Redland & 10.29 & 36.5 & 51.77 & 0.8 & 5.79 & 88.26 & 42 & 66 & 37 & 50 \\
\hline $\begin{array}{l}\text { Richmond } \\
\text { Heights }\end{array}$ & 7.09 & 49.75 & 40.63 & 1.39 & 4.43 & 82.03 & 55 & 77 & - & 100 \\
\hline Riviera & 5.81 & 1.38 & 91.01 & 1.66 & 13.14 & 82.85 & 57 & 93 & 45 & 77 \\
\hline Rockway & 4.15 & 2.12 & 93.42 & 0.24 & 13.71 & 74.61 & 74 & 83 & 65 & 93 \\
\hline Ruben Dario & 2.01 & 2.13 & 95.51 & 0.35 & 16.55 & 86.64 & 65 & 75 & 45 & 83 \\
\hline
\end{tabular}




\begin{tabular}{lcccccccccc}
\hline School Name & \% White & \% Black & $\begin{array}{c}\text { \% } \\
\text { Hispanic }\end{array}$ & $\begin{array}{c}\text { \% } \\
\text { Other }\end{array}$ & \% ELL & \% SES & $\begin{array}{c}\text { \% Pass } \\
\text { FCAT Math }\end{array}$ & $\begin{array}{c}\text { Climate } \\
\text { Parents }\end{array}$ & $\begin{array}{c}\text { Climate } \\
\text { Students }\end{array}$ & $\begin{array}{c}\text { Climate } \\
\text { Staff }\end{array}$ \\
\hline Shenandoah & 2.69 & 3.14 & 94.08 & 0 & 13.45 & 89.6 & 50 & 87 & 60 \\
South Miami & 19.24 & 12 & 66.67 & 1.71 & 4.76 & 48.1 & 83 & 88 & 67 & 90 \\
Southwood & 31.06 & 22.28 & 42 & 3.17 & 2.23 & 42.81 & 80 & 84 & 54 & 66 \\
Thomas Jefferson & 0.21 & 92.18 & 7.19 & 0.42 & 20.08 & 91.12 & 39 & 68 & 50 & 63 \\
W. R. Thomas & 4.96 & 1.12 & 93.12 & 0.48 & 12.48 & 76.96 & 65 & 91 & 64 & 79 \\
West Miami & 2.61 & 0.17 & 96.95 & 0.17 & 21.86 & 87.46 & 57 & 62 & 33 & 60 \\
Westview & 0.84 & 83.53 & 15.63 & 0 & 10.92 & 93.78 & 43 & 67 & 45 & 67 \\
Zelda Glazer & 3.9 & 0.42 & 94.29 & 1.25 & 7.6 & 69.2 & 74 & 93 & 55 & 100 \\
\hline
\end{tabular}




\section{APPENDIX II}

\section{Relationship between FCAT 2.0 Mathematics Scores and Racial and Ethnic}

\section{Concentration when controlling Socio-Economic Status, ESOL Student Population}

\section{and School Climate}

\section{Blacks, SES, ESOL and School Climate}

Multicollinearity occurs when two or more independent variables are highly

correlated with each other (Hinton, Brownlow, McMurray, \& Cozens, 2004). The

presence of multicollinearity makes it difficult to analyze the individual contribution of each independent variable in predicting the dependent variable. If multicollinearity exists, in the Coefficient Table, under the column of Collinearity Statistics, the Tolerance results would be less than 0.10 and the VIF results would be greater than ten. For this particular test, there was a high correlation between the White student population, the Black student population, and the Hispanic student population; thus, the White student population and the Hispanic student population were left out in order to eliminate multicollinearity (Table 53). 
Table 53

Collinearity Statistics - Relationship of FCAT 2.0 Mathematics Scores and Racial and Ethnic Concentration (Blacks, Whites, Hispanics) when controlling Economically Disadvantaged (SES), ESOL Student Population, and School Climate

\begin{tabular}{clcc}
\hline \multirow{2}{*}{ Model } & & \multicolumn{2}{c}{ Collinearity Statistics } \\
\cline { 3 - 4 } & & & Tolerance \\
\hline \multirow{2}{*}{1} & (Constant) & .466 & 2.147 \\
& Economically Disadvantaged (SES) & .671 & 1.490 \\
& ESOL & .563 & 1.777 \\
& School Climate (Parent) & .450 & 2.224 \\
& School Climate (Student) & .647 & 1.546 \\
& School Climate (Staff) & .006 & 164.940 \\
& Whites & .000 & 2248.333 \\
& Blacks & .001 & 1968.984 \\
\hline & Hispanics & .134 & 7.473 \\
& Economically Disadvantaged (SES) & .463 & 2.160 \\
& ESOL & .521 & 1.921 \\
& School Climate (Parent) & .416 & 2.405 \\
& School Climate (Student) & .586 & 1.708 \\
\hline
\end{tabular}

Table 54 displays the Mean and Standard Deviations for the test of measuring the relationship of racial and ethnic concentration (Blacks), socio-economic status (SES), ESOL student population, and school climate with the FCAT 2.0 Mathematics scores. Each Mean is the measure of the average score for its corresponding data set. It is the average of students passing the FCAT 2.0 Mathematics Test, Black student population, ESOL student population, Economically Disadvantaged (SES) student population and the average of parents, students, and staff agreeing that the school climate is positive and helps learning for all public middle schools in Miami-Dade County. The Standard Deviation is the measure of the average difference of a score from its Mean for its corresponding data set. The larger the Standard Deviation number is, the less grouped the data are around the Mean. From the data in Table 54, the ESOL student population 
has the smallest Standard Deviation (6.74569) while the Black student population has the largest Standard Deviation (34.11801).

Table 54

Descriptive Statistics - Relationship of FCAT 2.0 Mathematics Scores and Racial and Ethnic Concentration (Blacks) when controlling Economically Disadvantaged (SES), ESOL Student Population, and School Climate

\begin{tabular}{lcc}
\hline Total $\%^{\mathrm{a}}$ & Mean & Std. Deviation \\
\hline Passing FCAT Math & 58.05 & 16.015 \\
Blacks & 32.1257 & 34.11801 \\
ESOL & 10.3166 & 6.74569 \\
Economically Disadvantaged (SES) & 79.8648 & 16.27095 \\
School Climate (Parent) & 77.53 & 11.181 \\
School Climate (Student) & 50.72 & 13.865 \\
School Climate (Staff) & 73.75 & 19.056 \\
\hline
\end{tabular}

Note. ${ }^{a} n=59$.

As shown in Table 55, there are two models because Model 1 is controlling the ESOL student population, socio-economic status, and school climate while Model 2 incorporates all the independent variables. For Model 1, there is a strong correlation of $0.922, R$, of the independent variable the Black student population when controlling the ESOL student population, socio-economic status, and school climate with the dependent variable. For Model 2, there is a strong correlation of $0.925, R$, between the independent variables and dependent variable. For Model 1 , the $R^{2}$ is 0.851 , which is the amount of unique variance in the dependent variable that can be explained by the independent variable the Black student population when controlling ESOL student population, socioeconomic status, and school climate. The independent variables explain $85.1 \%$ of the unique variance. For Model 2 , the $R^{2}$ is 0.866 , which is the amount of variance in the dependent variable that can be explained by all the independent variables. The 
independent variables explain $86.6 \%$ of the variance. The Adjusted $R^{2}$ for Model 1 is 0.836 , which adjusts for any bias by correcting the $R^{2}$ s v value, hence the Adjusted $R^{2}$ was used for the study because it is more accurate for explaining variance. Using the Adjusted $R^{2}$, the Black student population when controlling ESOL student population, socio-economic status, and school climate explain $83.6 \%$ of the unique variance. For Model 2, it is 0.844 and all the independent variables explain $84.4 \%$ of the variance. The Standard Error of the Estimate represents "a measure of the variability of the multiple correlation" and is 6.482 for Model 1 and 6.445 for Model 2 in this test (Hinton et al., 2004, pg. 315). The $R^{2}$ Change allows the change to $R^{2}$ to be identified when an independent variable was being added, removed, or controlled. The $R^{2}$ Change is 0.851 for Model 1 and 0.005 for Model 2. The $R^{2}$ Change for Model 1 and Model 2 are not the same as the $R^{2}$ because there are variables being controlled for in this particular test. The F Change is 58.252 for Model 1 and 1.583 for Model 2 which is the test statistic $\left(T S_{\text {calc or }}\right.$ $\left.F_{\text {calc }}\right)$. For Model 1, the first Degree of Freedom, $d f 1$, is five and the second Degree of Freedom, $d f 2$, is 51. For Model 2, the first Degree of Freedom, $d f 1$, is one and the second Degree of Freedom, $d f 2$, is 50 . These are the values in the test that are free to vary. The Significant F Change, $P_{\text {calc }}$, is $p<0.001$ for Model 1, which is statistically significant because it is less than 0.01 . For Model 2, the Significant $F$ Change, $P_{\text {calc }}$, is 0.214 , which is not statistically significant because 0.214 is not less than 0.01 . (Hinton et al., 2004) 
Table 55

Model Summary - Relationship of FCAT 2.0 Mathematics Scores and Racial and Ethnic Concentration (Blacks) when controlling Economically Disadvantaged (SES), ESOL Student Population, and School Climate

\begin{tabular}{lccccccccc}
\hline \multirow{2}{*}{ Model } & $\mathrm{R}$ & \multirow{2}{*}{$\begin{array}{c}\mathrm{R} \\
\text { Square }\end{array}$} & $\begin{array}{c}\text { Adjusted } \\
\text { R Square }\end{array}$ & $\begin{array}{c}\text { Std. Error of } \\
\text { the Estimate }\end{array}$ & $\begin{array}{c}\text { R Square } \\
\text { Change }\end{array}$ & $\begin{array}{c}\mathrm{F} \\
\text { Change }\end{array}$ & df1 & df2 & $\begin{array}{c}\text { Sig. F } \\
\text { Change }\end{array}$ \\
\hline 1 & $.922^{\mathrm{a}}$ & .851 & .836 & 6.482 & .851 & 58.252 & 5 & 51 & .000 \\
\hline 2 & $.925^{\mathrm{b}}$ & .866 & .844 & 6.445 & .005 & 1.583 & 1 & 50 & .214 \\
\hline
\end{tabular}

Note. a. Predictors: (Constant), \% of School Climate (Parent), \% of ESOL student population, \% School Climate (Staff), \% School Climate (Student), \% of Economically Disadvantaged (SES)

b. Predictors: (Constant), \% of School Climate (Parent), \% of ESOL student population, $\%$ School Climate (Staff), \% of Black student population, \% School Climate (Student), \% of Economically Disadvantaged (SES)

Additionally, Table 8 (Chapter 4) displays data that makes it known if multicollinearity was present amongst the independent variables being tested. To test this hypothesis, the White student population and the Hispanic student population were not included because they created multicollinearity. Including those two independent variables would have made it difficult to analyze the individual contribution that each independent variable would make to the dependent variable. If the Tolerance is below 0.1 and the Variance Inflation Factor (VIF) is greater than 10, multicollinearity is present (Pallant, 2010). In testing this hypothesis, with these variables, multicollinearity is not present and it is possible to analyze the individual contribution that each independent variable made to the dependent variable.

\section{Blacks, Whites, ESOL and School Climate}

Due to the presence of multicollinearity, the independent variables of the Hispanic student population and the Economically Disadvantaged (SES) student population were 
removed in order to be able to analyze the individual contribution of each independent variable to the dependent variable (Table 56).

Table 56

Collinearity Statistics - Relationship of FCAT 2.0 Mathematics Scores and Racial and Ethnic Concentration (Blacks, Whites, Hispanics) when controlling Economically Disadvantaged (SES), ESOL Student Population, and School Climate

\begin{tabular}{llcc}
\hline \multirow{2}{*}{ Model } & & \multicolumn{2}{c}{ Collinearity Statistics } \\
\cline { 2 - 4 } & & Tolerance & VIF \\
\hline \multirow{2}{*}{1} & (Constant) & .466 & 2.147 \\
& Economically Disadvantaged (SES) & .671 & 1.490 \\
& ESOL & .563 & 1.777 \\
& School Climate (Parent) & .450 & 2.224 \\
& School Climate (Student) & .647 & 1.546 \\
School Climate (Staff) & .006 & 164.940 \\
& Whites & .000 & 2248.333 \\
Blacks & .001 & 1968.984 \\
& Hispanics & .134 & 7.473 \\
Economically Disadvantaged (SES) & .463 & 2.160 \\
ESOL & .521 & 1.921 \\
School Climate (Parent) & .416 & 2.405 \\
School Climate (Student) & .586 & 1.708 \\
\hline
\end{tabular}

Table 57 displays the Mean and Standard Deviations for the test of measuring the relationship of racial and ethnic concentration (Blacks and Whites), ESOL student population, and school climate with the FCAT 2.0 Mathematics scores. It is the average of students passing the FCAT 2.0 Mathematics Test, Black student population, White student population, ESOL student population, and the average of parents, students, and staff agreeing that the school climate is positive and helps learning for all public middle schools in Miami-Dade County Public Schools. From the data in Table 57, the ESOL student population has the smallest Standard Deviation (6.69547), meaning it is closely 
grouped around the Mean. The Black student population has the largest Standard Deviation (34.03266), meaning it is less grouped around the Mean.

Table 57

Descriptive Statistics - Relationship of FCAT 2.0 Mathematics Scores and Racial and Ethnic Concentration (Blacks, Whites) when controlling ESOL Student Population and School Climate

\begin{tabular}{lcc}
\hline Total $^{\mathrm{a}}{ }^{\mathrm{a}}$ & Mean & Std. Deviation \\
\hline Passing FCAT Math & 57.61 & 16.024 \\
Blacks & 33.1314 & 34.03266 \\
Whites & 6.6620 & 8.50480 \\
ESOL & 10.1430 & 6.69547 \\
School Climate (Parent) & 77.52 & 11.082 \\
School Climate (Student) & 50.72 & 13.865 \\
School Climate (Staff) & 74.36 & 19.068 \\
\hline
\end{tabular}

Note. ${ }^{a} n=59$.

As shown in Table 58, there are two models because Model 1 is controlling the ESOL student population and school climate while Model 2 incorporates all the independent variables. For Model 1 , there is a strong correlation of $0.806, R$, of the independent variables Black student population and White student population when controlling the ESOL student population and school climate with the dependent variable.

For Model 2, there is a strong correlation of $0.879, R$, between the independent variables and dependent variable. For Model 1 , the $R^{2}$ is 0.623 , which means that the Black student population and the White student population when controlling the ESOL student population and school climate explain $62.3 \%$ of the unique variance. For Model 2 , the $R^{2}$ is 0.773 , which means that all the independent variables explain $77.3 \%$ of the unique variance. For Model 1 , the Adjusted $R^{2}$ is 0.650 , less because it adjusts for any bias by correcting the $R^{2}$ value, hence the Adjusted $R^{2}$ was used for the study because it is more 
accurate for explaining variance. Using the Adjusted $R^{2}$, the independent variable explains $65 \%$ of the variance. For Model 2 , the Adjusted $R^{2}$ is 0.745 , less because it adjusts for any bias by correcting the $R^{2}$ value, hence the Adjusted $R^{2}$ was used for the study because it is more accurate for explaining variance. Using the Adjusted $R^{2}$, all the independent variables explain $74.5 \%$ of the variance. The Standard Error of the Estimate is 9.837 in Model 1 and 8.087 in Model 2. The $R^{2}$ Change is .650 for Model 1 and .123 for Model 2. The $R^{2}$ Change for Model 1 and Model 2 are not the same as the $R^{2}$ because there are variables being controlled for in this particular test. The $F$ Change is 24.146 for Model 1 and 13.469 for Model 2 which is the test statistic $\left(T S_{\text {calc or }} F_{\text {calc }}\right)$. For Model 1, the first Degree of Freedom, $d f 1$, is four and the second Degree of Freedom, $d f 2$, is 52 . For Model 2, the first Degree of Freedom, $d f 1$, is two and the second Degree of Freedom, $d f 2$, is 50. The Significant $F$ Change, $P_{\text {calc }}$, is $p<0.001$ for Model 1 and Model 2, which are statistically significant because they are less than 0.01 . (Hinton et al., 2004)

Table 58

Model Summary - Relationship of FCAT 2.0 Mathematics Scores and Racial and Ethnic Concentration (Blacks, Whites) when controlling ESOL Student Population and School Climate

\begin{tabular}{|c|c|c|c|c|c|c|c|c|c|}
\hline \multirow[b]{2}{*}{ Model } & \multirow[b]{2}{*}{$\mathrm{R}$} & \multirow[b]{2}{*}{$\begin{array}{c}\mathrm{R} \\
\text { Square }\end{array}$} & \multirow{2}{*}{$\begin{array}{c}\text { Adjusted } \\
\text { R } \\
\text { Square }\end{array}$} & \multirow{2}{*}{$\begin{array}{l}\text { Std. Error } \\
\text { of the } \\
\text { Estimate }\end{array}$} & \multicolumn{5}{|c|}{ Change Statistics } \\
\hline & & & & & $\begin{array}{l}\text { R Square } \\
\text { Change }\end{array}$ & $\begin{array}{c}\mathrm{F} \\
\text { Change } \\
\end{array}$ & df1 & df2 & $\begin{array}{c}\text { Sig. F } \\
\text { Change }\end{array}$ \\
\hline 1 & $.806^{\mathrm{a}}$ & 65 & .623 & 9.837 & .650 & 24.146 & 4 & 52 & .000 \\
\hline 2 & $.879^{\mathrm{b}}$ & .773 & 745 & 8.087 & .123 & 13.469 & 2 & 50 & .000 \\
\hline
\end{tabular}

Note. a. Predictors: (Constant), \% of School Climate (Parent), \% of ESOL student population, \% School Climate (Staff), \% School Climate (Student) b. Predictors: (Constant), \% of School Climate (Parent), \% of ESOL student population, $\%$ School Climate (Staff), \% of Black student population, \% School Climate (Student), \% of White student population 
Additionally, Table 12 (Chapter 4) displays data that makes it known if multicollinearity was present amongst the independent variables being tested. To test this hypothesis, the Hispanic student population and the Economically Disadvantaged (SES) student population were not included because they created multicollinearity, and thus would have made it difficult to analyze the individual contribution that each independent variable would make to the dependent variable.

\section{Whites, Hispanics, ESOL and School Climate}

Due to the presence of multicollinearity, the independent variables of the Black student population and the Economically Disadvantaged (SES) student population were removed in order to be able to analyze the individual contribution of each independent variable to the dependent variable (Table 59).

Table 59

Collinearity Statistics - Relationship of Racial and Ethnic Concentration (Blacks, Whites, Hispanics) and FCAT 2.0 Mathematics Scores when controlling Economically Disadvantaged (SES), ESOL Student Population, and School Climate

\begin{tabular}{clcc}
\hline \multirow{2}{*}{ Model } & & \multicolumn{2}{c}{ Collinearity Statistics } \\
\cline { 2 - 4 } & & Tolerance & VIF \\
\hline \multirow{2}{*}{1} & (Constant) & .466 & 2.147 \\
& Economically Disadvantaged (SES) & .671 & 1.490 \\
& ESOL & .563 & 1.777 \\
& School Climate (Parent) & .450 & 2.224 \\
& School Climate (Student) & .647 & 1.546 \\
School Climate (Staff) & .006 & 164.940 \\
& Whites & .000 & 2248.333 \\
Blacks & .001 & 1968.984 \\
& Hispanics & .134 & 7.473 \\
Economically Disadvantaged (SES) & .463 & 2.160 \\
ESOL & .521 & 1.921 \\
School Climate (Parent) & .416 & 2.405 \\
School Climate (Student) & .586 & 1.708 \\
\hline
\end{tabular}


Table 60 displays the Mean and Standard Deviations for the test of measuring the relationship of racial and ethnic concentration (Whites and Hispanics), ESOL student population, and school climate with the FCAT 2.0 Mathematics scores. It is the average students passing the FCAT 2.0 Mathematics Test, White student population, Hispanic student population, ESOL student population, and the average of parents, students, and staff agreeing that the school climate is positive and helps learning for all public middle schools in Miami-Dade County Public Schools. From the data in Table 60, the ESOL student population has the smallest Standard Deviation (6.69547), meaning it is closely grouped around the Mean. The Hispanic student population has the largest Standard Deviation (32.03428), meaning it is less closely grouped around the Mean.

Table 60

Descriptive Statistics - Relationship of Racial and Ethnic Concentration (Whites, Hispanics) and FCAT 2.0 Mathematics Scores when controlling ESOL Student Population and School Climate

\begin{tabular}{lcc}
\hline Total $^{\mathrm{a}}$ & Mean & Std. Deviation \\
\hline Passing FCAT Math & 57.61 & 16.024 \\
Whites & 6.6620 & 8.50480 \\
Hispanics & 58.7660 & 32.03428 \\
ESOL & 10.1430 & 6.69547 \\
School Climate (Parent) & 77.52 & 11.082 \\
School Climate (Student) & 50.72 & 13.865 \\
School Climate (Staff) & 74.36 & 19.068 \\
\hline
\end{tabular}

Note. ${ }^{a} n=59$.

As shown in Table 61, there are two models because Model 1 is controlling the ESOL student population and school climate while Model 2 incorporates all the independent variables. For Model 1 , there is a strong correlation of $0.806, R$, of the independent variables White student population and Hispanic student population when 
controlling the ESOL student population and school climate with the dependent variable. For Model 2, there is a strong correlation of $0.879, R$, between the independent variables and dependent variable. For Model 1 , the $R^{2}$ is 0.650 , which means that the White student population and the Hispanic student population when controlling the ESOL student population and school climate explain $65 \%$ of the unique variance. For Model 2, the $R^{2}$ is 0.773 , which means that all the independent variables explain $77.3 \%$ of the variance. For Model 1 , the Adjusted $R^{2}$ is 0.623 , less because it adjusts for any bias by correcting the $R^{2}$ value, hence the Adjusted $R^{2}$ was used for the study because it is more accurate for explaining variance. Using the Adjusted $R^{2}$, the White student population and the Hispanic student population when controlling ESOL student population and school climate explain $62.3 \%$ of the unique variance. For Model 2, the Adjusted $R^{2}$ is 0.744 , less because it adjusts for any bias by correcting the $R^{2}$ value, hence the Adjusted $R^{2}$ was used for the study because it is more accurate for explaining variance. Using the Adjusted $R^{2}$, all the independent variable explains $74.4 \%$ of the variance. The Standard Error of the Estimate is 9.837 in Model 1 and 8.102 in Model 2. The $R^{2}$ Change is .650 for Model 1 and .122 for Model 2. The $R^{2}$ Change for Model 1 and Model 2 are not the same as the $R^{2}$ because there are variables being controlled for in this particular test. The $F$ Change is 24.146 for Model 1 and 13.329 for Model 2 which is the test statistic $\left(T S_{\text {calc }}\right.$ $\left.{ }_{\text {or }} F_{\text {calc }}\right)$. For Model 1, the first Degree of Freedom, $d f 1$, is four and the second Degree of Freedom, $d f 2$, is 52. For Model 2, the first Degree of Freedom, $d f 1$, is two and the second Degree of Freedom, $d f 2$, is 50. The Significant $F$ Change, $P_{\text {calc }}$, is $p<0.001$ for Model 1 and Model 2, which is statistically significant because they are less than 0.01 . (Hinton et al., 2004) 
Table 61

Model Summary - Relationship of Racial and Ethnic Concentration (Whites, Hispanics) and FCAT 2.0 Mathematics Scores when controlling ESOL Student Population and School Climate

\begin{tabular}{|c|c|c|c|c|c|c|c|c|c|}
\hline \multirow[b]{2}{*}{ Model } & \multirow[b]{2}{*}{$\mathrm{R}$} & \multirow[b]{2}{*}{$\begin{array}{c}\mathrm{R} \\
\text { Square }\end{array}$} & \multirow{2}{*}{$\begin{array}{c}\text { Adjusted } \\
\text { R } \\
\text { Square } \\
\end{array}$} & \multirow{2}{*}{$\begin{array}{l}\text { Std. Error } \\
\text { of the } \\
\text { Estimate }\end{array}$} & \multicolumn{5}{|c|}{ Change Statistics } \\
\hline & & & & & $\begin{array}{c}\text { R Square } \\
\text { Change }\end{array}$ & $\begin{array}{c}\mathrm{F} \\
\text { Change }\end{array}$ & df1 & $\mathrm{df} 2$ & $\begin{array}{c}\text { Sig. F } \\
\text { Change }\end{array}$ \\
\hline 1 & $.806^{\mathrm{a}}$ & .650 & .623 & 9.837 & .650 & 24.146 & 4 & 52 & .000 \\
\hline 2 & $879^{b}$ & .773 & .744 & 8.102 & .122 & 13.329 & 2 & 50 & .000 \\
\hline
\end{tabular}

Note. a. Predictors: (Constant), \% of School Climate (Parent), \% of ESOL student population, \% School Climate (Staff), \% School Climate (Student) b. Predictors: (Constant), \% of School Climate (Parent), \% of ESOL student population, $\%$ School Climate (Staff), \% of Hispanic student population, \% School Climate (Student), \% of White student population

Additionally, Table 16 (Chapter 4) displays data that makes it known if

multicollinearity was present amongst the independent variables being tested. To test this hypothesis, the Black student population and the Economically Disadvantaged (SES) student population were not included because they created multicollinearity, and thus would have made it difficult to analyze the individual contribution that each independent variable would make to the dependent variable.

\section{Hispanics, ESOL and School Climate}

Due to the presence of multicollinearity, the independent variables of the Black student population, the White student population, and the Economically Disadvantaged (SES) student population were removed in order to be able to analyze the individual contribution of each independent variable to the dependent variable (Table 62). 
Table 62

Collinearity Statistics - Relationship of Racial and Ethnic Concentration (Blacks, Whites, Hispanics) and FCAT 2.0 Mathematics Scores when controlling Economically

Disadvantaged (SES), ESOL Student Population, and School Climate

\begin{tabular}{clcc}
\hline \multirow{2}{*}{ Model } & & \multicolumn{2}{c}{ Collinearity Statistics } \\
\cline { 3 - 4 } & & Tolerance & VIF \\
\hline \multirow{2}{*}{1} & (Constant) & & \\
& Economically Disadvantaged (SES) & .466 & 2.147 \\
& ESOL & .671 & 1.490 \\
& School Climate (Parent) & .563 & 1.777 \\
& School Climate (Student) & .450 & 2.224 \\
& School Climate (Staff) & .647 & 1.546 \\
\hline \multirow{2}{*}{2} & Whites & .006 & 164.940 \\
& Blacks & .000 & 2248.333 \\
Hispanics & .001 & 1968.984 \\
Economically Disadvantaged (SES) & .134 & 7.473 \\
ESOL & .463 & 2.160 \\
School Climate (Parent) & .521 & 1.921 \\
School Climate (Student) & .416 & 2.405 \\
School Climate (Staff) & .586 & 1.708 \\
\hline
\end{tabular}

Table 63 displays the Mean and Standard Deviations for the test of measuring the relationship of racial and ethnic concentration (Hispanics), ESOL student population, and school climate with the FCAT 2.0 Mathematics scores. It is the average of students passing the FCAT 2.0 Mathematics Test, Hispanic student population, ESOL student population, and the average of the parents, students, and staff agreeing that the school climate is positive and helps learning for all public middle schools in Miami-Dade County Public Schools. From the data in Table 63, the ESOL student population has the smallest Standard Deviation (6.69547), meaning it is closely grouped around the Mean. The Hispanic student population has the largest Standard Deviation (32.03428), meaning it is less grouped around the Mean. 
Table 63

Descriptive Statistics - Relationship of Racial and Ethnic Concentration (Hispanics) when controlling ESOL Student Population, and School Climate with the FCAT 2.0 Mathematics Scores

\begin{tabular}{lcc}
\hline Total $^{\mathrm{a}}{ }^{\mathrm{a}}$ & Mean & Std. Deviation \\
\hline Passing FCAT Math & 57.61 & 16.024 \\
Hispanics & 58.7660 & 32.03428 \\
ESOL & 10.1430 & 6.69547 \\
School Climate (Parent) & 77.52 & 11.082 \\
School Climate (Student) & 50.72 & 13.865 \\
School Climate (Staff) & 74.36 & 19.068 \\
\hline
\end{tabular}

Note. ${ }^{\mathrm{a}} n=59$.

As shown in Table 64, there are two models because Model 1 is controlling the ESOL student population and school climate while Model 2 incorporates all the independent variables. For Model 1 , there is a strong correlation of $0.806, R$, of the independent variable Hispanic student population when controlling the ESOL student population and school climate with the dependent variable. For Model 2, there is a strong correlation of $0.823, R$, between the independent variables and the dependent variable. For Model 1, the $R^{2}$ is 0.650 , which means the Hispanic student population when controlling the ESOL student population and school climate explain $65 \%$ of the unique variance. For Model 2, the $R^{2}$ is 0.678 , which means that all the independent variables explain $67.8 \%$ of the variance. For Model 1 , the Adjusted $R^{2}$ is 0.623 , less because it adjusts for any bias by correcting the $\mathrm{R}^{2}$ value, hence the Adjusted $R^{2}$ was used for the study because it is more accurate for explaining variance. Using the Adjusted $R^{2}$, the Hispanic student population explains $62.3 \%$ of the unique variance when controlling ESOL student population and school climate. For Model 2, the Adjusted $R^{2}$ is 0.646 , less because it adjusts for any bias by correcting the $\mathrm{R}^{2}$ value, hence the Adjusted $R^{2}$ was used 
for the study because it is more accurate for explaining variance. Using the Adjusted $R^{2}$, all the independent variable explains $64.6 \%$ of the variance. The Standard Error of the Estimate is 9.837 in Model 1 and 9.529 in Model 2. The $R^{2}$ Change is .650 for Model 1 and .028 for Model 2. The $R^{2}$ Change for Model 1 and Model 2 are not the same as the $R^{2}$ because there are variables being controlled for in this particular test. The $F$ Change is 24.146 for Model 1 and 4.416 for Model 2 which is the test statistic $\left(T S_{\text {calc or }} F_{\text {calc }}\right)$. For Model 1, the first Degree of Freedom, $d f 1$, is four and the second Degree of Freedom, $d f 2$, is 52. For Model 2, the first Degree of Freedom, $d f 1$, is one and the second Degree of Freedom, $d f 2$, is 51 . The Significant $F$ Change, $P_{\text {calc }}$, is $p<0.001$ for Model 1, making it statistically significant. For Model 2, the Significant $F$ Change is 0.041 making it not statistically significant since it is not less than 0.01. (Hinton et al., 2004)

Table 64

Model Summary - Relationship of Racial and Ethnic Concentration (Hispanics) and FCAT 2.0 Mathematics Scores when controlling ESOL Student Population, and School Climate

\begin{tabular}{|c|c|c|c|c|c|c|c|c|c|}
\hline \multirow[b]{2}{*}{ Model } & \multirow[b]{2}{*}{$\mathrm{R}$} & \multirow[b]{2}{*}{$\begin{array}{c}\mathrm{R} \\
\text { Square }\end{array}$} & \multirow{2}{*}{$\begin{array}{c}\text { Adjusted } \\
\text { R } \\
\text { Square }\end{array}$} & \multirow{2}{*}{$\begin{array}{l}\text { Std. Error } \\
\text { of the } \\
\text { Estimate }\end{array}$} & \multicolumn{5}{|c|}{ Change Statistics } \\
\hline & & & & & $\begin{array}{c}\text { R Square } \\
\text { Change }\end{array}$ & $\begin{array}{c}\text { F } \\
\text { Change }\end{array}$ & df1 & df2 & $\begin{array}{c}\text { Sig. F } \\
\text { Change }\end{array}$ \\
\hline 1 & $.806^{\mathrm{a}}$ & 650 & .623 & 9.837 & 650 & 24.146 & 4 & 52 & .000 \\
\hline 2 & $.823^{\mathrm{b}}$ & .678 & .646 & 9.529 & .028 & 4.416 & 1 & 51 & .041 \\
\hline
\end{tabular}

Note. a. Predictors: (Constant), \% of School Climate (Parent), \% of ESOL student population, \% School Climate (Staff), \% School Climate (Student) b. Predictors: (Constant), \% of School Climate (Parent), \% of ESOL student population, $\%$ School Climate (Staff), \% School Climate (Student), \% of Hispanic student population

Additionally, Table 20 (Chapter 4) displays data that makes it known if multicollinearity was present amongst the independent variables being tested. To test this hypothesis, the White student population, the Black student population and the 
Economically Disadvantaged (SES) student population were not included because they created multicollinearity, and thus would have made it difficult to analyze the individual contribution that each independent variable would make to the dependent variable.

\section{Whites, ESOL and School Climate}

Due to the presence of multicollinearity, the independent variables of the Hispanic student population, the Black student population, and the Economically Disadvantaged (SES) student population were removed in order to be able to analyze the individual contribution of each independent variable to the dependent variable (Table 65).

Table 65

Collinearity Statistics - Relationship of Racial and Ethnic Concentration (Blacks, Whites, Hispanics) and FCAT 2.0 Mathematics Scores when controlling Economically Disadvantaged (SES), ESOL Student Population, and School Climate

\begin{tabular}{clcc}
\hline \multirow{2}{*}{ Model } & & \multicolumn{2}{c}{ Collinearity Statistics } \\
\cline { 2 - 3 } & & Tolerance & VIF \\
\cline { 2 - 3 } 1 & (Constant) & & \\
Economically Disadvantaged & .466 & 2.147 \\
(SES) & .671 & 1.490 \\
& ESOL & .563 & 1.777 \\
School Climate (Parent) & .450 & 2.224 \\
School Climate (Student) & .647 & 1.546 \\
School Climate (Staff) & .006 & 164.940 \\
& Whites & .000 & 2248.333 \\
Blacks & .001 & 1968.984 \\
Hispanics & .134 & 7.473 \\
Economically Disadvantaged & .463 & 2.160 \\
(SES) & .521 & 1.921 \\
ESOL & .416 & 2.405 \\
School Climate (Parent) & .586 & 1.708 \\
\hline School Climate (Student) & & \\
School Climate (Staff) &
\end{tabular}

Table 66 displays the Mean and Standard Deviations for the test of measuring the relationship of racial and ethnic concentration (Whites), ESOL student population, and 
school climate with the FCAT 2.0 Mathematics scores. It is the average of students passing the FCAT 2.0 Mathematics Test, White student population, ESOL student popilation, and the average of parents, students, and staff agreeing that the school climate is positive and helps learning for all public middle schools in Miami-Dade County Public Schools. From the data in Table 66, the ESOL student population has the smallest Standard Deviation (6.69547), meaning it is closely grouped around the Mean. The staff agreeing that the school climate is positive and helps students learn has the largest Standard Deviation (19.068), meaning it is less grouped around the Mean.

Table 66

Descriptive Statistics - Relationship of Racial and Ethnic Concentration (Whites) and FCAT 2.0 Mathematics Scores when controlling ESOL Student Population, and School Climate

\begin{tabular}{lcc}
\hline Total $^{\mathrm{a}}$ & Mean & Std. Deviation \\
\hline Passing FCAT Math & 57.61 & 16.024 \\
Whites & 6.6620 & 8.50480 \\
ESOL & 10.1430 & 6.69547 \\
School Climate (Parent) & 77.52 & 11.082 \\
School Climate (Student) & 50.72 & 13.865 \\
School Climate (Staff) & 74.36 & 19.068 \\
\hline
\end{tabular}

Note. ${ }^{\mathrm{a}} n=59$.

As shown in Table 67, there are two models because Model 1 is controlling the ESOL student population and school climate while Model 2 incorporates all the independent variables. For Model 1 , there is a strong correlation of $0.806, R$, of the independent variable White student population when controlling the ESOL student population and school climate with the dependent variable. For Model 2, there is a strong correlation of $0.867, R$, between the independent variables and the dependent variable. For Model 1 , the $R^{2}$ is 0.650 , which means the White student population when controlling 
the ESOL student population and school climate explain $65 \%$ of the unique variance. For Model 2 , the $R^{2}$ is 0.752 , which means that the independent variables explain $75.2 \%$ of the variance. For Model 1, the Adjusted $R^{2}$ is 0.623 , less because it adjusts for any bias by correcting the $R^{2}$ value, hence the Adjusted $R^{2}$ was used for the study because it is more accurate for explaining variance. Using the Adjusted $R^{2}$, the White student population when controlling the ESOL student population and school climate explain $62.3 \%$ of the unique variance. For Model 2 , the Adjusted $R^{2}$ is 0.728 , less because it adjusts for any bias by correcting the $R^{2}$ value, hence the Adjusted $R^{2}$ was used for the study because it is more accurate for explaining variance. Using the Adjusted $R^{2}$, all the independent variable explains $72.8 \%$ of the variance. The Standard Error of the Estimate is 9.837 in Model 1 and 8.362 in Model 2. The $R^{2}$ Change is 0.650 for Model 1 and 0.102 for Model 2. The $R^{2}$ Change for Model 1 and Model 2 are not the same as the $R^{2}$ because there are variables being controlled for in this particular test. The $F$ Change is 24.146 for Model 1 and 20.977 for Model 2 which is the test statistic $\left(T S_{\text {calc or }} F_{\text {calc }}\right)$. For Model 1 , the first Degree of Freedom, $d f 1$, is four and the second Degree of Freedom, $d f 2$, is 52 . For Model 2, the first Degree of Freedom, $d f 1$, is one and the second Degree of Freedom, $d f 2$, is 51 . The Significant $F$ Change, $P_{\text {calc }}$, is $p<0.001$ for Model 1 and Model 2, which is statistically significant because it is less than 0.01. (Hinton et al., 2004) 
Table 67

Model Summary - Relationship of Racial and Ethnic Concentration (Whites) and FCAT 2.0 Mathematics Scores when controlling ESOL Student Population, and School Climate

\begin{tabular}{|c|c|c|c|c|c|c|c|c|c|}
\hline \multirow[b]{2}{*}{ Model } & \multirow[b]{2}{*}{$\mathrm{R}$} & \multirow[b]{2}{*}{$\begin{array}{c}\mathrm{R} \\
\text { Square }\end{array}$} & \multirow{2}{*}{$\begin{array}{c}\text { Adjusted } \\
\text { R } \\
\text { Square }\end{array}$} & \multirow{2}{*}{$\begin{array}{l}\text { Std. Error } \\
\text { of the } \\
\text { Estimate }\end{array}$} & \multicolumn{5}{|c|}{ Change Statistics } \\
\hline & & & & & $\begin{array}{c}\text { R Square } \\
\text { Change }\end{array}$ & $\begin{array}{c}\mathrm{F} \\
\text { Change }\end{array}$ & df1 & $\mathrm{df} 2$ & $\begin{array}{c}\text { Sig. F } \\
\text { Change }\end{array}$ \\
\hline 1 & $.806^{\mathrm{a}}$ & .650 & .623 & 9.837 & .650 & 24.146 & 4 & 52 & .000 \\
\hline 2 & $867^{b}$ & .752 & .728 & 8.362 & .102 & 20.977 & 1 & 51 & .000 \\
\hline
\end{tabular}

Note. a. Predictors: (Constant), \% of School Climate (Parent), \% of ESOL student population, \% School Climate (Staff), \% School Climate (Student) b. Predictors: (Constant), \% of School Climate (Parent), \% of ESOL student population, $\%$ School Climate (Staff), \% School Climate (Student), \% of White student population

Additionally, Table 24 (Chapter 4) displays data that makes it known if multicollinearity was present amongst the independent variables being tested. To test this hypothesis, the Hispanic student population, the Black student population and the Economically Disadvantaged (SES) student population were not included because they created multicollinearity, and thus would have made it difficult to analyze the individual contribution that each independent variable would make to the dependent variable.

\section{Relationship between Schools' Racial and Ethnic Concentration and FCAT 2.0}

\section{Mathematics Scores when controlling ESOL Student Population}

\section{Whites, Hispanics and ESOL}

For this particular test, there was a high correlation between the White student population, the Black student population, and the Hispanic student population, and so the Black student population was left out in order to eliminate the multicollinearity (Table 68). 
Table 68

Collinearity Statistics - Relationship of Racial and Ethnic Concentration (Blacks, Whites, Hispanics) with the FCAT 2.0 Mathematics Scores when controlling the ESOL Student Population

\begin{tabular}{|c|c|c|c|}
\hline \multirow{2}{*}{\multicolumn{2}{|c|}{ Model }} & \multicolumn{2}{|c|}{ Collinearity Statistics } \\
\hline & & \multirow{2}{*}{ Tolerance } & \multirow[t]{2}{*}{ VIF } \\
\hline & (Constant) & & \\
\hline 1 & ESOL & 1.000 & 1.000 \\
\hline \multirow{5}{*}{2} & (Constant) & & \\
\hline & ESOL & .566 & 1.766 \\
\hline & Whites & .007 & 140.425 \\
\hline & Hispanics & .001 & 1581.642 \\
\hline & Blacks & .001 & 1781.366 \\
\hline
\end{tabular}

Table 69 displays the Mean and Standard Deviations for the test of measuring the relationship of racial and ethnic concentration (Whites and Hispanics) and the FCAT 2.0 Mathematics scores when controlling the ESOL student population. From the data in Table 69, the ESOL student population has the smallest Standard Deviation (6.69547), meaning it is closely grouped around the mean. The Hispanic student population has the largest Standard Deviation (32.03428), meaning it is less grouped around the mean.

Table 69

Descriptive Statistics - Relationship of Racial and Ethnic Concentration (Whites and Hispanics) and FCAT 2.0 Mathematics Scores when controlling ESOL Student Population

\begin{tabular}{lcc}
\hline Total $^{\mathrm{a}}{ }^{\mathrm{a}}$ & Mean & Std. Deviation \\
\hline Passing FCAT Math & 57.61 & 16.024 \\
ESOL & 10.1430 & 6.69547 \\
Whites & 6.6620 & 8.50480 \\
Hispanics & 58.7660 & 32.03428 \\
\hline
\end{tabular}

Note. $a=59$

As shown in Table 70, there are two models because Model 1 is controlling the ESOL student population while Model 2 incorporates all the independent variables 
(Whites, Hispanics, and ESOL). For Model 1, there is a weak correlation of $0.134, R$, of the independent variables White student population and Hispanic student population when controlling ESOL student population with the dependent variable. For Model 2, there is a strong correlation of $0.773, R$, between the independent variables and dependent variable. The $R^{2}$ for Model 1 is 0.018 , which means that the White student population and the Hispanic student population when controlling ESOL student population explain $1.8 \%$ of the unique variance. The $R^{2}$ for Model 2 is 0.598 , which is the amount of variance in the dependent variable that can be explained by all the independent variables. All the independent variables can explain $59.8 \%$ of the variance. The Adjusted $R^{2}$ was used for the study because it is more accurate for explaining variance. The Adjusted $R^{2}$ for Model 1 is 0.001 , less because it adjusts for any bias by correcting the $R^{2 \text { ' }}$ s value. Using the Adjusted $R^{2}$, the White student population and the Hispanic student population explains $0.1 \%$ of the unique variance. The Adjusted $R^{2}$ for Model 2 is 0.576 , less because it adjusts for any bias by correcting the $R^{2}$, s value. Using the Adjusted $R^{2}$, the White student population and the Hispanic student population explain 57.6\%. The Standard Error of the Estimate is 16.018 for Model 1 and 10.432 for Model 2 in this test. The $R^{2}$ Change allows the change to $R^{2}$ be identified when the independent variable is controlled for. For each model, the $R^{2}$ Change is the same as the $R^{2}$ but both models do not have the same value because there was a variable controlled for in this particular test. For Model 1, the $R^{2}$ Change is 0.018 and for Model 2, it is 0.580 . The $F$ Change for Model 1 is 1.042 and for Model 2 is 39.692 which is the test statistic $\left(\mathrm{TS}_{\text {calc }}\right.$ or $\left.\mathrm{F}_{\text {calc }}\right)$. For Model 1, the first Degree of Freedom, $d f 1$, is 1 and the second Degree of Freedom, $d f 2$, is 57. For Model 2, the first Degree of Freedom, $d f 1$, is 2 and the second Degree of 
Freedom, $d f 2$, is 55. The Significant $F$ Change, $P_{\text {calc }}$, is 0.312 for Model 1 , meaning the ESOL student population was not statistically significant because 0.312 is not less than 0.01. The Significant $F$ Change, $P_{\text {calc }}$, is $p<0.001$ for Model 2, making the White student population and Hispanic student population statistically significant because it is less than 0.01. (Hinton et al., 2004)

Table 70

Model Summary - Relationship of Racial and Ethnic Concentration (Whites and Hispanics) and FCAT 2.0 Mathematics Scores when controlling ESOL Student Population

\begin{tabular}{|c|c|c|c|c|c|c|c|c|c|}
\hline \multirow[b]{2}{*}{ Model } & \multirow[b]{2}{*}{$\mathrm{R}$} & \multirow[b]{2}{*}{$\begin{array}{c}\mathrm{R} \\
\text { Square }\end{array}$} & \multirow{2}{*}{$\begin{array}{c}\text { Adjusted } \\
\text { R } \\
\text { Square }\end{array}$} & \multirow{2}{*}{$\begin{array}{l}\text { Std. Error } \\
\text { of the } \\
\text { Estimate }\end{array}$} & \multicolumn{5}{|c|}{ Change Statistics } \\
\hline & & & & & $\begin{array}{c}\text { R Square } \\
\text { Change }\end{array}$ & $\begin{array}{c}\mathrm{F} \\
\text { Change }\end{array}$ & df1 & df2 & $\begin{array}{l}\text { Sig. F } \\
\text { Change }\end{array}$ \\
\hline 1 & $.134^{\mathrm{a}}$ & .018 & .001 & 16.018 & .018 & 1.042 & 1 & 57 & .312 \\
\hline 2 & $.773^{\mathrm{b}}$ & .598 & .576 & 10.432 & .580 & 39.692 & 2 & 55 & .000 \\
\hline
\end{tabular}

Note. a. Predictors: (Constant), \% of ESOL student population

b. Predictors: (Constant), \% of ESOL student population, $\%$ of White student population, $\%$ of Hispanic student population

c. Dependent Variable: \% Passing FCAT Math

Additionally, Table 28 (Chapter 4) displays data that makes it known if multicollinearity was present amongst the independent variables being tested. To test this hypothesis, the Black student population was not included because it created multicollinearity, and thus would have made it difficult to analyze the individual contribution that each independent variable would make to the dependent variable.

\section{Whites, Blacks and ESOL}

For this particular test, there was a high correlation between the White student population, the Black student population, and the Hispanic student population, and so the 
Hispanic student population was left out in order to eliminate the multicollinearity (Table 71).

Table 71

Collinearity Statistics - Relationship of Racial and Ethnic Concentration (Blacks, Whites, Hispanics) with the FCAT 2.0 Mathematics Scores when controlling the ESOL Student Population

\begin{tabular}{clcc}
\hline \multirow{2}{*}{ Model } & & \multicolumn{2}{c}{ Collinearity Statistics } \\
\cline { 3 - 4 } 1 & & Tolerance & VIF \\
\hline \multirow{2}{*}{2} & (Constant) & 1.000 & 1.000 \\
\cline { 2 - 4 } 2 & ESOL & & \\
& ESOL & .566 & 1.766 \\
& Whites & .007 & 140.425 \\
& Hispanics & .001 & 1581.642 \\
& Blacks & .001 & 1781.366 \\
\hline
\end{tabular}

Table 72 displays the Mean and Standard Deviations for the test of measuring the relationship of racial and ethnic concentration (Whites and Blacks) and the FCAT 2.0 Mathematics scores when controlling the ESOL student population. From the data in Table 72, the ESOL student population has the smallest Standard Deviation (6.69547), meaning it is closely grouped around the Mean. The Black student population has the largest Standard Deviation (34.03266), meaning it is less grouped around the Mean.

Table 72

Descriptive Statistics - Relationship of Racial and Ethnic Concentration (Blacks, Whites) with the FCAT 2.0 Mathematics Scores when controlling the ESOL Student Population

\begin{tabular}{lcc}
\hline Total $\%^{\mathrm{a}}$ & Mean & Std. Deviation \\
\hline Passing FCAT Math & 57.61 & 16.024 \\
ESOL & 10.1430 & 6.69547 \\
Whites & 6.6620 & 8.50480 \\
Blacks & 33.1314 & 34.03266 \\
\hline
\end{tabular}

Note. $a=59$. 
As shown in Table 73, there are two models because Model 1 is controlling the ESOL student population while Model 2 incorporates all the independent variables (Whites, Blacks, and ESOL). For Model 1, there is a weak correlation of $0.134, R$, of the independent variables White student population and Black student population when controlling the ESOL student population with the dependent variable. For Model 2, there is a strong correlation of $0.777, R$, between the independent variables and dependent variable. The $R^{2}$ for Model 1 is 0.018 , which is the amount of unique variance in the dependent variable that can be explained by the White student population and the Black student population when controlling the ESOL student population. The White student population and the Black student population when controlling the ESOL student population explain $1.8 \%$ of the unique variance. The $R^{2}$ for Model 2 is 0.604 , which is the amount of variance in the dependent variable that can be explained by all the independent variables. All the independent variables can explain $60.4 \%$ of the variance. The Adjusted $R^{2}$ was used for the study because it is more accurate for explaining variance. The Adjusted $R^{2}$ for Model 1 is 0.001 , less because it adjusts for any bias by correcting the $\mathrm{R}^{2 \text { s }} \mathrm{s}$ value. The Adjusted $R^{2}$, the White student population and the Black student population when controlling the ESOL student population explains $0.1 \%$ of the variance. The Adjusted $R^{2}$ for Model 2 is 0.582 , less because it adjusts for any bias by

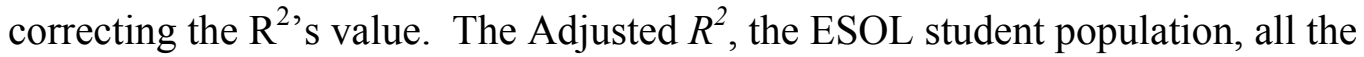
independent variables explain 58.2\%. The Standard Error of the Estimate is 16.018 for Model 1 and 10.361 for Model 2 in this test. The $R^{2}$ Change allows the change to $R^{2}$ to be identified when the independent variable is controlled for. For each model, the $R^{2}$ Change is the same as the $R^{2}$ but both models do not have the same value because there 
was a variable controlled for in this particular test. For Model 1 , the $R^{2}$ Change is 0.018 and for Model 2, it is 0.586 . The $F$ Change for Model 1 is 1.042 and for Model 2 is 40.626 which is the test statistic (TScalc or Fcalc). For Model 1, the first Degree of Freedom, $d f 1$, is 1 and the second Degree of Freedom, $d f 2$, is 57 . For Model 2, the first Degree of Freedom, $d f 1$, is 2 and the second Degree of Freedom, $d f 2$, is 55 . The Significant $F$ Change, $P_{\text {calc }}$, is 0.312 for Model 1, meaning the ESOL student population is not statistically significant because 0.312 is not less than 0.01 . The Significant $F$ Change, $P_{\text {calc }}$, is $p<0.001$ for Model 2, making the ESOL student population, the White student population and the Black student population statistically significant because it is less than 0.01. (Hinton et al., 2004)

Table 73

Model Summary - Relationship of Racial and Ethnic Concentration (Whites and Blacks) and FCAT 2.0 Mathematics Scores when controlling ESOL Student Population

\begin{tabular}{|c|c|c|c|c|c|c|c|c|c|}
\hline \multirow[b]{2}{*}{ Model } & \multirow[b]{2}{*}{$\mathrm{R}$} & \multirow[b]{2}{*}{$\begin{array}{c}\mathrm{R} \\
\text { Square }\end{array}$} & \multirow{2}{*}{$\begin{array}{c}\text { Adjusted } \\
\text { R } \\
\text { Square }\end{array}$} & \multirow{2}{*}{$\begin{array}{l}\text { Std. Error } \\
\text { of the } \\
\text { Estimate }\end{array}$} & \multicolumn{5}{|c|}{ Change Statistics } \\
\hline & & & & & $\begin{array}{c}\text { R Square } \\
\text { Change }\end{array}$ & $\begin{array}{c}\mathrm{F} \\
\text { Change }\end{array}$ & df1 & $\mathrm{df} 2$ & $\begin{array}{c}\text { Sig. F } \\
\text { Change }\end{array}$ \\
\hline 1 & $.134^{\mathrm{a}}$ & .018 & .001 & 16.018 & .018 & 1.042 & 1 & 57 & .312 \\
\hline 2 & $.777^{\mathrm{b}}$ & .604 & .582 & 10.361 & .586 & 40.626 & 2 & 55 & .000 \\
\hline
\end{tabular}

Note. a. Predictors: (Constant), \% of ESOL student population

b. Predictors: (Constant), \% of ESOL student population, $\%$ of White student population, $\%$ of Black student population

c. Dependent Variable: \% Passing FCAT Math

Additionally, Table 32 (Chapter 4) displays data that makes it known if multicollinearity was present amongst the independent variables being tested. To test this hypothesis, the Hispanic student population was not included because it created multicollinearity, and thus would have made it difficult to analyze the individual contribution that each independent variable would make to the dependent variable. 


\section{Relationship between FCAT 2.0 Mathematics Scores and Socio-Economic Status}

Table 74 displays the Mean and Standard Deviations for the test of measuring the relationship of the FCAT 2.0 Mathematics scores and socio-economic status.

Table 74

Descriptive Statistics - Relationship of FCAT 2.0 Mathematics Scores and SocioEconomic Status

\begin{tabular}{lcc}
\hline Total $\%^{\mathrm{a}}$ & Mean & Std. Deviation \\
\hline Passing FCAT Math & 57.61 & 16.024 \\
Economically Disadvantaged (SES) & 80.1490 & 16.10261 \\
\hline
\end{tabular}

Note. $a=59$

As shown in Table 75 , there is a strong correlation of $0.830, R$, of the Economically Disadvantaged (SES) student population with the dependent variable. The $R^{2}$ is 0.688 , which is the amount of variance in the dependent variable that can be explained by the Economically Disadvantaged (SES) student population. The Economically Disadvantaged (SES) student population explains $68.8 \%$ of the variance. The Adjusted $R^{2}$ was used for the study because it is more accurate for explaining variance. The Adjusted $R^{2}$ is 0.683 , less because it adjusts for any bias by correcting the $R^{2}$ s value. Using the Adjusted $R^{2}$, the Economically Disadvantaged (SES) student population explains $68.3 \%$ of the variance. The Standard Error of the Estimate is 9.024 in this test. The $R^{2}$ Change and the $R^{2}$ are the same $(0.688)$ since no variable was controlled in this particular test. The $F$ Change for Model 1 is 125.878 which is the test statistic $\left(T S_{\text {calc }}\right.$ or $\left.F_{\text {calc }}\right)$. The first Degree of Freedom, $d f 1$, is 1 and the second Degree of Freedom, $d f 2$, is 57 . The Significant $F$ Change, $P_{\text {calc }}$, is $p<0.001$, making the 
Economically Disadvantaged (SES) student population statistically significant because it is less than 0.01. (Hinton et al., 2004)

Table 75

Model Summary - Relationship of FCAT 2.0 Mathematics Scores and Socio-Economic Status

\begin{tabular}{lccccccccc}
\hline & & & \multicolumn{6}{c}{ Adjusted Std. Error } & \multicolumn{6}{c}{ Change Statistics } \\
\cline { 5 - 9 } Model & $\mathrm{R}$ & $\begin{array}{c}\mathrm{R} \\
\text { Square }\end{array}$ & $\begin{array}{c}\mathrm{R} \\
\text { of the } \\
\text { Square }\end{array}$ & $\begin{array}{c}\mathrm{R} \\
\text { Estimate }\end{array}$ & $\begin{array}{c}\text { Square } \\
\text { Change }\end{array}$ & $\begin{array}{c}\mathrm{F} \\
\text { Change }\end{array}$ & $\mathrm{df1}$ & $\mathrm{d} 2$ & $\begin{array}{c}\text { Sig. F } \\
\text { Change }\end{array}$ \\
\hline 1 & $.830^{\mathrm{a}}$ & .688 & .683 & 9.024 & .688 & 125.878 & 1 & 57 & .000 \\
\hline
\end{tabular}

Note. a. Predictors: (Constant), Total \% of Economically Disadvantaged student population

b. Dependent Variable: Total \% Passing FCAT Math

Additionally, Table 36 (Chapter 4) displays data that makes it known if

multicollinearity is present amongst the independent variables being tested. Since there is only one independent variable being tested, there is no multicollinearity.

\section{Relationship between FCAT 2.0 Mathematics Scores and Socio-Economic Status}

\section{when controlling Racial and Ethnic Concentrations}

\section{Whites, Hispanics and Socio-Economic Status}

For this particular test, there was a high correlation between the White student population, the Black student population, and the Hispanic student population, and so the Black student population was left out in order to eliminate the multicollinearity (Table 76). 
Table 76

Collinearity Statistics - Relationship of the FCAT 2.0 Mathematics Scores and Socioeconomic Status when controlling Racial and Ethnic Concentration (Blacks, Whites, Hispanics)

\begin{tabular}{|c|c|c|c|}
\hline \multirow{2}{*}{\multicolumn{2}{|c|}{ Model }} & \multicolumn{2}{|c|}{ Collinearity Statistics } \\
\hline & & Tolerance & VIF \\
\hline \multirow{4}{*}{1} & (Constant) & & \\
\hline & Hispanics & .001 & 1502.030 \\
\hline & Blacks & .001 & 1704.048 \\
\hline & Whites & .007 & 136.782 \\
\hline \multirow{5}{*}{2} & (Constant) & & \\
\hline & Hispanics & .001 & 1721.873 \\
\hline & Blacks & .001 & 1961.514 \\
\hline & Whites & .007 & 142.519 \\
\hline & Economically Disadvantaged (SES) & .171 & 5.832 \\
\hline
\end{tabular}

Table 77 displays the Mean and Standard Deviations for the test of measuring the relationship between FCAT 2.0 Mathematics scores and the Economically Disadvantaged (SES) student population when controlling racial and ethnic concentrations (Whites and Hispanics). From the data in Table 77, the White student population has the smallest Standard Deviation (8.50480), meaning it is closely grouped around the Mean. The Hispanic student population has the largest (32.03428), meaning it is less grouped around the Mean. 
Table 77

Descriptive Statistics - Relationship of FCAT 2.0 Mathematics Scores and SocioEconomic Status when controlling Racial and Ethnic Concentration (Whites \& Hispanics)

\begin{tabular}{lcc}
\hline Total $\%{ }^{\mathrm{a}}$ & Mean & Std. Deviation \\
\hline Passing FCAT Math & 57.61 & 16.024 \\
Whites & 6.6620 & 8.50480 \\
Hispanics & 58.7660 & 32.03428 \\
Economically Disadvantaged (SES) & 80.1490 & 16.10261 \\
\hline
\end{tabular}

Note. $a=59$.

As shown in Table 78, there are two models because Model 1 is controlling the racial and ethnic concentrations (Whites and Hispanics) while Model 2 incorporates all the independent variables (Whites, Hispanics, and Economically Disadvantaged). For Model 1 , there is a strong correlation of $0.769, R$, of the socio-economic status when controlling the White student population and the Hispanic student population with the dependent variable. For Model 2 , there is a strong correlation of $0.889, R$, between all the independent variables and the dependent variable. The $R^{2}$ for Model 1 is 0.592 , which is the amount of the unique variance in the dependent variable that can be explained by socio-economic status when controlling the White student population and the Hispanic student population, explaining 59.2\% of the variance. The $R^{2}$ for Model 2 is 0.790 , which is the amount of variance in the dependent variable that can be explained by all the independent variables. All the independent variables can explain $79.0 \%$ of the variance. The Adjusted $R^{2}$ was used for the study because it is more accurate for explaining variance. The Adjusted $R^{2}$ for Model 1 is 0.577 , less because it adjusts for any bias by correcting the $\mathrm{R}^{2 \text {, }}$ s value. Using the Adjusted $R^{2}$, socio-economic status explains $57.7 \%$ of the variance when controlling the White student population and the Hispanic 
student population. The Adjusted $R^{2}$ for Model 2 is 0.778 , less because it adjusts for any bias by correcting the $R^{2}$,s value. Using the Adjusted $R^{2}$, all independent variables explain $77.8 \%$. The Standard Error of the Estimate is 10.421 for Model 1 and 7.544 for Model 2 in this test. For each model, the $R^{2}$ Change is the same as the $R^{2}$ but both models do not have the same value because there was a variable controlled for in this particular test. For Model 1, the $R^{2}$ Change is 0.592 and for Model 2, it is 0.198 . The $F$ Change for Model 1 is 40.563 and for Model 2 is 51.872 which is the test statistic $\left(T S_{\text {calc }}\right.$ or $\left.F_{\text {calc }}\right)$. For Model 1, the first Degree of Freedom, $d f 1$, is two and the second Degree of Freedom, $d f 2$, is 56. For Model 2, the first Degree of Freedom, $d f 1$, is one and the second Degree of Freedom, $d f 2$, is 55. The Significant $F$ Change, $P_{\text {calc }}$, is $p<0.001$ for Model 1, meaning that socio-economic status, when controlling the White student population and Hispanic student population, was statistically significant because it is less than 0.01 . The Significant $F$ Change, $P_{\text {calc }}$, is $p<0.001$ for Model 2, meaning that the White student population, the Hispanic student population, and the Economically Disadvantaged (SES) student population were statistically significant because it is less than 0.01 . (Hinton et al., 2004) 
Table 78

Model Summary - Relationship of FCAT 2.0 Mathematics Scores and Socio-Economic Status when controlling Racial and Ethnic Concentration (Whites \& Hispanics)

\begin{tabular}{|c|c|c|c|c|c|c|c|c|c|}
\hline \multirow[b]{2}{*}{ Model } & \multirow[b]{2}{*}{$\mathrm{R}$} & \multirow[b]{2}{*}{$\begin{array}{c}\mathrm{R} \\
\text { Square }\end{array}$} & \multirow{2}{*}{$\begin{array}{c}\text { Adjusted } \\
\text { R } \\
\text { Square }\end{array}$} & \multirow{2}{*}{$\begin{array}{l}\text { Std. Error } \\
\text { of the } \\
\text { Estimate }\end{array}$} & \multicolumn{5}{|c|}{ Change Statistics } \\
\hline & & & & & $\begin{array}{l}\text { R Square } \\
\text { Change }\end{array}$ & $\begin{array}{c}\mathrm{F} \\
\text { Change }\end{array}$ & df1 & $\mathrm{df} 2$ & $\begin{array}{c}\text { Sig. F } \\
\text { Change }\end{array}$ \\
\hline 1 & $.769^{\mathrm{a}}$ & .592 & .577 & 10.421 & .592 & 40.563 & 2 & 56 & .000 \\
\hline 2 & $.889^{b}$ & .790 & .778 & 7.544 & .198 & 51.872 & 1 & 55 & .000 \\
\hline
\end{tabular}

Note. a. Predictors: (Constant), \% of Hispanic student population, $\%$ of White student population

b. Predictors: (Constant), \% of Hispanic student population, $\%$ of White student population, $\%$ of Economically Disadvantaged student population

c. Dependent Variable: \% Passing FCAT Math

Additionally, Table 40 (Chapter 4) displays data that makes it known if

multicollinearity was present amongst the independent variables being tested. To test this hypothesis, the Black student population was not included because it created multicollinearity, and thus would have made it difficult to analyze the individual contribution that each independent variable would make to the dependent variable.

\section{Whites, Blacks and Socio-Economic Status}

For this particular test, there was a high correlation between the White student population, the Black student population, and the Hispanic student population, and so the Hispanic student population was left out in order to eliminate the multicollinearity (Table 79). 
Table 79

Collinearity Statistics - Relationship of the FCAT 2.0 Mathematics Scores and Socioeconomic Status when controlling Racial and Ethnic Concentration (Blacks, Whites, Hispanics)

\begin{tabular}{|c|c|c|c|}
\hline \multirow{2}{*}{\multicolumn{2}{|c|}{ Model }} & \multicolumn{2}{|c|}{ Collinearity Statistics } \\
\hline & & \multirow[t]{2}{*}{ Tolerance } & \multirow[t]{2}{*}{ VIF } \\
\hline \multirow{4}{*}{1} & (Constant) & & \\
\hline & Hispanics & .001 & 1502.030 \\
\hline & Blacks & .001 & 1704.048 \\
\hline & Whites & .007 & 136.782 \\
\hline \multirow{5}{*}{2} & (Constant) & & \\
\hline & Hispanics & .001 & 1721.873 \\
\hline & Blacks & .001 & 1961.514 \\
\hline & Whites & .007 & 142.519 \\
\hline & Economically Disadvantaged (SES) & .171 & 5.832 \\
\hline
\end{tabular}

Table 80 displays the Mean and Standard Deviations for the test of measuring the relationship between FCAT 2.0 Mathematics scores and the Economically Disadvantaged (SES) student population when controlling racial and ethnic concentration (Whites and Blacks). From the data in Table 80, the White student population has the smallest Standard Deviation (8.50480), meaning it is closely grouped around the Mean. The Black student population has the largest Standard Deviation (34.03266), meaning it is less grouped around the Mean.

Table 80

Descriptive Statistics - Relationship of FCAT 2.0 Mathematics Scores and SocioEconomic Status when controlling Racial and Ethnic Concentration (Whites \& Blacks)

\begin{tabular}{lcc}
\hline Total $\%{ }^{\mathrm{a}}$ & Mean & Std. Deviation \\
\hline Passing FCAT Math & 57.61 & 16.024 \\
Whites & 6.6620 & 8.50480 \\
Blacks & 33.1314 & 34.03266 \\
Economically Disadvantaged (SES) & 80.1490 & 16.10261 \\
\hline
\end{tabular}

Note. $a=59$. 
As shown in Table 81, there are two models because Model 1 is controlling the racial and ethnic concentrations (Whites and Blacks) while Model 2 incorporates all the independent variables (Whites, Blacks, and Economically Disadvantaged). For Model 1, there is a strong correlation of $0.773, R$, of socio-economic status when controlling the White student population and the Black student population with the dependent variable. For Model 2, there is a strong correlation of $0.890, R$, between all the independent variables with the dependent variable. The $R^{2}$ for Model 1 is 0.597 , which is the amount of the unique variance in the dependent variable that can be explained by socio-economic status when controlling the White student population and the Black student population. The White student population and the Black student population explain $59.7 \%$ of the variance. The $R^{2}$ for Model 2 is 0.791 , which is the amount of variance in the dependent variable that can be explained by all the independent variables. The independent variables can explain $79.1 \%$ of the variance. The Adjusted $R^{2}$ was used for the study because it is more accurate for explaining variance. The Adjusted $R^{2}$ for Model 1 is

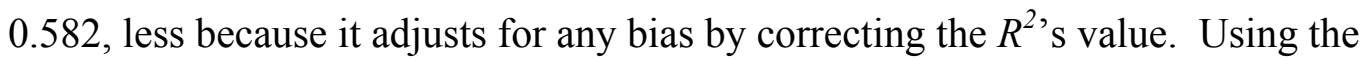
Adjusted $R^{2}$, socio-economic status explains $58.2 \%$ of the variance when controlling the White student population and the Black student population. The Adjusted $R^{2}$ for Model 2 is 0.780 , less because it adjusts for any bias by correcting the $R^{2}$, s value. Using the Adjusted $R^{2}$, all the independent variables explain 78.0\%. The Standard Error of the Estimate is 10.355 for Model 1 and 7.517 for Model 2 in this test. The $R^{2}$ Change allows the change to $R^{2}$ be identified when the independent variable is controlled for. For each model, the $R^{2}$ Change is the same as the $R^{2}$ but both models do not have the same value because there was a variable controlled for in this particular test. For Model 1, the $R^{2}$ 
Change is 0.597 and for Model 2, it is 0.195 . The $F$ Change for Model 1 is 41.445 and for Model 2 is 51.275 which is the test statistic $\left(T S_{\text {calc }}\right.$ or $\left.F_{\text {calc }}\right)$. For Model 1, the first Degree of Freedom, $d f 1$, is two and the second Degree of Freedom, $d f 2$, is 56. For Model 2, the first Degree of Freedom, $d f 1$, is one and the second Degree of Freedom, $d f 2$, is 55 . These are the values in the test that are free to vary. The Significant $F$ Change, $P_{\text {calc }}$, is $p$ $<0.001$ for Model 1, meaning that socio-economic status when controlling the White student population and Black student population were statistically significant because it is less than 0.01 . The Significant $F$ Change, $P_{\text {calc }}$, is $p<0.001$ for Model 2, meaning that the White student population, Black student population, and the Economically Disadvantaged (SES) student population were statistically significant because it is less than 0.01. (Hinton et al., 2004)

Table 81

Model Summary - Relationship of FCAT 2.0 Mathematics Scores and Socio-Economic Status when controlling Racial and Ethnic Concentration (Whites \& Blacks)

\begin{tabular}{lccccccccc}
\hline & & & \multicolumn{6}{c}{ Adjusted Std. Error } & \multicolumn{6}{c}{ Change Statistics } \\
\cline { 5 - 10 } Model & $\mathrm{R}$ & $\begin{array}{c}\mathrm{R} \\
\text { Square }\end{array}$ & $\begin{array}{c}\mathrm{R} \\
\text { of the } \\
\text { Square }\end{array}$ & $\begin{array}{c}\mathrm{R} \\
\text { Estimate }\end{array}$ & $\begin{array}{c}\text { Square } \\
\text { Change }\end{array}$ & $\begin{array}{c}\mathrm{F} \\
\text { Change }\end{array}$ & $\mathrm{df1}$ & $\mathrm{df} 2$ & $\begin{array}{c}\text { Sig. F } \\
\text { Change }\end{array}$ \\
\hline 1 & $.773^{\mathrm{a}}$ & .597 & .582 & 10.355 & .597 & 41.445 & 2 & 56 & .000 \\
\hline 2 & $.890^{\mathrm{b}}$ & .791 & .780 & 7.517 & .195 & 51.275 & 1 & 55 & .000 \\
\hline
\end{tabular}

Note. a. Predictors: (Constant), $\%$ of Black student population, $\%$ of White student population b. Predictors: (Constant), \% of Black student population, $\%$ of White student population, $\%$ of Economically Disadvantaged student population

c. Dependent Variable: \% Passing FCAT Math

Additionally, Table 44 (Chapter 4) displays data that makes it known if multicollinearity was present amongst the independent variables being tested. To test this hypothesis, the Hispanic student population was not included because it created 
multicollinearity, and thus would have made it difficult to analyze the individual

contribution that each independent variable would make to the dependent variable.

\section{Relationship between School Climate and FCAT 2.0 Mathematics Scores when}

\section{controlling Racial and Ethnic Concentrations}

\section{Whites, Hispanics and School Climate}

For this particular test, there was a high correlation between the White student population, the Black student population, and the Hispanic student population thus, the Black student population were left out in order to eliminate the multicollinearity (Table 82).

Table 82

Collinearity Statistics - Relationship of the FCAT 2.0 Mathematics Scores and School Climate when controlling Racial and Ethnic Concentration (Blacks, Whites, Hispanics)

\begin{tabular}{|c|c|c|c|}
\hline \multirow{2}{*}{\multicolumn{2}{|c|}{ Model }} & \multicolumn{2}{|c|}{ Collinearity Statistics } \\
\hline & & Tolerance & VIF \\
\hline \multirow{4}{*}{1} & (Constant) & & \\
\hline & Hispanics & .001 & 1502.030 \\
\hline & Blacks & .001 & 1704.048 \\
\hline & Whites & .007 & 136.782 \\
\hline \multirow{7}{*}{2} & (Constant) & & \\
\hline & Hispanics & .001 & 1721.630 \\
\hline & Blacks & .000 & 2046.945 \\
\hline & Whites & .006 & 142.519 \\
\hline & School Climate (Parent) & .523 & 1.912 \\
\hline & School Climate (Student) & .452 & 2.211 \\
\hline & School Climate (Staff) & .629 & 1.590 \\
\hline
\end{tabular}

Table 83 displays the Mean and Standard Deviations for the test of measuring the relationship between school climate and FCAT 2.0 Mathematics scores when controlling racial and ethnic concentration (Whites and Hispanics). From the data in Table 83, the White student population has the smallest Standard Deviation (8.50480), meaning it is 
closely grouped around the Mean. The Hispanic student population has the largest Standard Deviation (32.03428), meaning it is less grouped around the Mean.

Table 83

Descriptive Statistics - Relationship of School Climate and FCAT 2.0 Mathematics Scores when controlling Racial and Ethnic Concentration (Whites \& Hispanics)

\begin{tabular}{lcc}
\hline Total $\%^{\mathrm{a}}$ & Mean & Std. Deviation \\
\hline Passing FCAT Math & 57.61 & 16.024 \\
Whites & 6.6620 & 8.50480 \\
Hispanics & 58.7660 & 32.03428 \\
School Climate (Parent) & 77.52 & 11.082 \\
School Climate (Student) & 50.72 & 13.865 \\
School Climate (Staff) & 74.36 & 19.068 \\
\hline
\end{tabular}

Note. $a=59$.

As shown in Table 84, there are two models because Model 1 is controlling the racial and ethnic concentrations (Whites and Hispanics) while Model 2 incorporates all the independent variables (Whites, Hispanics, and school climate). For Model 1, there is a strong correlation of $0.769, R$, of socio-economic status when controlling the White student population and the Hispanic student population with the dependent variable. For Model 2, there is a strong correlation of $0.876, R$, between all the independent variables and the dependent variable. The $R^{2}$ for Model 1 is 0.592 , which is the amount of the unique variance in the dependent variable that can be explained by socio-economic status when controlling the White student population and the Hispanic student population. The White student population and the Hispanic student population explain $59.2 \%$ of the variance. The $R^{2}$ for Model 2 is 0.767 , which is the amount of variance in the dependent variable that can be explained by all the independent variables. The independent variables can explain $76.7 \%$ of the variance. The Adjusted $R^{2}$ was used for the study 
because it is more accurate for explaining the variance. The Adjusted $R^{2}$ for Model 1 is 0.576 , less because it adjusts for any bias by correcting the $R^{2}$ s value. Using the Adjusted $R^{2}$, the socio-economic status explains $57.6 \%$ of the variance when controlling the White student population and the Hispanic student population. The Adjusted $R^{2}$ for Model 2 is 0.744 , less because it adjusts for any bias by correcting the $R^{2 \text {, }}$ value. Using the Adjusted $R^{2}$, all the independent variables explain $74.4 \%$. The Standard Error of the Estimate is 10.428 for Model 1 and 8.110 for Model 2 in this test. The $R^{2}$ Change allows the change to $R^{2}$ be identified when the independent variable is controlled for. For each model, the $R^{2}$ Change is the same as the $R^{2}$ but both models do not have the same value because there were variables controlled for in this particular test. For Model 1, the $R^{2}$ Change is 0.592 and for Model 2, it is 0.175 . The $F$ Change for Model 1 is 39.114 and for Model 2 is 12.764 which is the test statistic $\left(T S_{\text {calc }}\right.$ or $\left.F_{\text {calc }}\right)$. For Model 1, the first Degree of Freedom, $d f 1$, is two and the second Degree of Freedom, $d f 2$, is 54. For Model 2, the first Degree of Freedom, $d f 1$, is three and the second Degree of Freedom, $d f 2$, is 51 . The Significant $F$ Change, $P_{\text {calc }}$, is $p<0.001$ for Model 1, meaning that socio-economic status when controlling the White student population and the Hispanic student population was statistically significant because it was less than 0.01 . The Significant $F$ Change, $P_{\text {calc }}$, is $p<0.001$ for Model 2, meaning that the White student population, Hispanic student population, and the School Climate were statistically significant because it is less than 0.01. (Hinton et al., 2004) 
Table 84

Model Summary - Relationship of School Climate and FCAT 2.0 Mathematics Scores when controlling Racial and Ethnic Concentration (Whites \& Hispanics)

\begin{tabular}{|c|c|c|c|c|c|c|c|c|c|}
\hline \multirow[b]{2}{*}{ Model } & \multirow[b]{2}{*}{$\mathrm{R}$} & \multirow[b]{2}{*}{$\begin{array}{c}\mathrm{R} \\
\text { Square }\end{array}$} & \multirow{2}{*}{$\begin{array}{c}\text { Adjusted } \\
\text { R } \\
\text { Square }\end{array}$} & \multirow{2}{*}{$\begin{array}{l}\text { Std. Error } \\
\text { of the } \\
\text { Estimate }\end{array}$} & \multicolumn{5}{|c|}{ Change Statistics } \\
\hline & & & & & $\begin{array}{l}\text { R Square } \\
\text { Change }\end{array}$ & $\begin{array}{c}\mathrm{F} \\
\text { Change }\end{array}$ & df1 & $\mathrm{df} 2$ & $\begin{array}{c}\text { Sig. F } \\
\text { Change }\end{array}$ \\
\hline 1 & $.769^{\mathrm{a}}$ & .592 & .576 & 10.428 & .592 & 39.114 & 2 & 54 & .000 \\
\hline 2 & $.876^{\mathrm{b}}$ & .767 & .744 & 8.110 & .175 & 12.764 & 3 & 51 & .000 \\
\hline
\end{tabular}

Note. a. Predictors: (Constant), $\%$ of Hispanic student population, $\%$ of White student population

b. Predictors: (Constant), \% of Hispanic student population, $\%$ of White student population, $\%$ of School Climate (Parent), $\%$ of School Climate (Student), $\%$ of School Climate (Staff)

c. Dependent Variable: \% Passing FCAT Math

Additionally, Table 48 (Chapter 4) displays data that makes it known if

multicollinearity was present amongst the independent variables being tested. To test this hypothesis, the Black student population was not included because it created multicollinearity, and thus would have made it difficult to analyze the individual contribution that each independent variable would make to the dependent variable.

\section{Whites, Blacks and School Climate}

For this particular test, there was a high correlation between the White student population, the Black student population, and the Hispanic student population thus, the Hispanic student population were left out in order to eliminate the multicollinearity (Table 85). 
Table 85

Collinearity Statistics - Relationship of the FCAT 2.0 Mathematics Scores and School Climate when controlling Racial and Ethnic Concentration (Blacks, Whites, Hispanics)

\begin{tabular}{|c|c|c|c|}
\hline \multirow{2}{*}{\multicolumn{2}{|c|}{ Model }} & \multicolumn{2}{|c|}{ Collinearity Statistics } \\
\hline & & Tolerance & VIF \\
\hline \multirow{4}{*}{1} & (Constant) & & \\
\hline & Hispanics & .001 & 1502.030 \\
\hline & Blacks & .001 & 1704.048 \\
\hline & Whites & .007 & 136.782 \\
\hline \multirow{7}{*}{2} & (Constant) & & \\
\hline & Hispanics & .001 & 1721.630 \\
\hline & Blacks & .000 & 2046.945 \\
\hline & Whites & .006 & 142.519 \\
\hline & School Climate (Parent) & .523 & 1.912 \\
\hline & School Climate (Student) & .452 & 2.211 \\
\hline & School Climate (Staff) & .629 & 1.590 \\
\hline
\end{tabular}

Table 86 displays the Mean and Standard Deviations for the test of measuring the relationship between school climate and FCAT 2.0 Mathematics scores when controlling racial and ethnic concentration (Whites and Blacks). From the data in Table 86, the White student population has the smallest Standard Deviation (8.50480), meaning it is closely grouped around the Mean. The Black student population has the largest Standard Deviation (34.03266), meaning it is less grouped around the Mean.

Table 86

Descriptive Statistics - Relationship of School Climate and FCAT 2.0 Mathematics Scores when controlling Racial and Ethnic Concentration (Whites \& Blacks)

\begin{tabular}{lcc}
\hline Total $\%{ }^{\mathrm{a}}$ & Mean & Std. Deviation \\
\hline Passing FCAT Math & 57.61 & 16.024 \\
Whites & 6.6620 & 8.50480 \\
Blacks & 33.1314 & 34.03266 \\
School Climate (Parent) & 77.52 & 11.082 \\
School Climate (Student) & 50.72 & 13.865 \\
School Climate (Staff) & 74.36 & 19.068 \\
\hline
\end{tabular}

Note. $a=59$. 
As shown in Table 87, there are two models because Model 1 is controlling the racial and ethnic concentrations (Whites and Blacks) while Model 2 incorporates all the independent variables (Whites, Blacks, and school climate). For Model 1, there is a strong correlation of $0.773, R$, of socio-economic status when controlling the Whites student population and the Black student population with the dependent variable. For Model 2, there is a strong correlation of $0.876, R$, between all the independent variables and the dependent variable. The $R^{2}$ for Model 1 is 0.597 , which is the amount of the unique variance in the dependent variable that can be explained by socio-economic status when controlling the White student population and the Black student population. The White student population and the Black student population explain 59.7\% of the variance. The $R^{2}$ for Model 2 is 0.767 , which is the amount of variance in the dependent variable that can be explained by all the independent variables. The independent variables can explain $76.7 \%$ of the variance. The Adjusted $R^{2}$ was used for the study because it is more accurate for explaining variance. The Adjusted $R^{2}$ for Model 1 is 0.582 , less because it adjusts for any bias by correcting the $R^{2}$ s s value. Using the Adjusted $R^{2}$, socio-economic status explains $58.2 \%$ of the variance when controlling the White student population and the Black student population. The Adjusted $R^{2}$ for Model 2 is 0.745 , less because it adjusts for any bias by correcting the $R^{2}$, s value. Using the Adjusted $R^{2}$, all the independent variables explain 74.5\%. The Standard Error of the Estimate is 10.362 for Model 1 and 8.097 for Model 2 in this test. The $R^{2}$ Change allows the change to $R^{2}$ be identified when the independent variable is controlled for. For each model, the $R^{2}$ Change is the same as the $R^{2}$ but both models do not have the same value because there were variables controlled for in this particular test. For Model 1 , the $R^{2}$ Change is 0.597 
and for Model 2, it is 0.171 . The $F$ Change for Model 1 is 39.965 and for Model 2 is 12.480 which is the test statistic $\left(T S_{\text {calc }}\right.$ or $\left.F_{\text {calc }}\right)$. For Model 1, the first Degree of

Freedom, $d f 1$, is two and the second Degree of Freedom, $d f 2$, is 54. For Model 2, the first Degree of Freedom, $d f 1$, is three and the second Degree of Freedom, $d f 2$, is 51 . The Significant $F$ Change, $P_{\text {calc }}$, is $p<0.001$ for Model 1, meaning that socio-economic status when controlling the White student population and Black student population were statistically significant because it is less than 0.01 . The Significant $F$ Change, $P_{\text {calc }}$, is $p<$ 0.001 for Model 2, meaning that the White student population, Black student population, and the School Climate were statistically significant because it is less than 0.01. (Hinton et al., 2004)

Table 87

Model Summary - Relationship of School Climate and FCAT 2.0 Mathematics Scores when controlling Racial and Ethnic Concentration (Whites \& Blacks)

\begin{tabular}{lccccccccc}
\hline & & & \multicolumn{6}{c}{ Adjusted Std. Error } & \multicolumn{5}{c}{ Change Statistics } \\
\cline { 5 - 9 } Model & $\mathrm{R}$ & $\mathrm{R}$ & \multirow{2}{*}{$\begin{array}{c}\mathrm{R} \\
\text { Square }\end{array}$} & $\begin{array}{c}\mathrm{R} \\
\text { Square the } \\
\text { Estimate }\end{array}$ & $\begin{array}{c}\text { Square } \\
\text { Change }\end{array}$ & $\begin{array}{c}\mathrm{F} \\
\text { Change }\end{array}$ & df1 & df2 & $\begin{array}{c}\text { Sig. F } \\
\text { Change }\end{array}$ \\
\hline 1 & $.773^{\mathrm{a}}$ & .597 & .582 & 10.362 & .597 & 39.965 & 2 & 54 & .000 \\
\hline 2 & $.876^{\mathrm{b}}$ & .767 & .745 & 8.097 & .171 & 12.480 & 3 & 51 & .000 \\
\hline
\end{tabular}

Note. a. Predictors: (Constant), $\%$ of Black student population, $\%$ of White student population

b. Predictors: (Constant), \% of Black student population, $\%$ of White student population, Total $\%$ of School Climate (Parent), \% of School Climate (Student), \% of School Climate (Staff)

c. Dependent Variable: \% Passing FCAT Math

Additionally, Table 52 (Chapter 4) displays data that makes it known if

multicollinearity was present amongst the independent variables being tested. To test this hypothesis, the Black student population was not included because it created 
multicollinearity, and thus would have made it difficult to analyze the individual contribution that each independent variable would make to the dependent variable. 
VITA

\section{MARILYS GALINDO}

Born, Hialeah, Florida

\section{EDUCATION}

$2008-2013$

Ed.D., Curriculum and Instruction

Florida International University

Miami, Florida

$2008-2011$

$2008-2010$

Ed.S., Curriculum and Instruction

Florida International University

Miami, Florida

M.S., Educational Leadership and Administration

Florida State University

Tallahassee, Florida

$2006-2007$

M.S., Curriculum, Instruction, and Technology

Nova Southeastern University

Davie, Florida

$2003-2006$

B.S., Early Childhood Education

Florida International University

Miami, Florida

EXPERIENCE

2013 - Present

Instructional Designer

Palm Beach State College

Lake Worth, Florida

2011 - Present

Adjunct Professor / Faculty Supervisor

University of Phoenix

$2012-2013$

Curriculum Specialist / Teacher

St. Vincent Ferrer School

Delray Beach, Florida

$2011-2012$

Teacher

Jesse S. Bobo Elementary School

Spartanburg, South Carolina

$2006-2010$

Department Chair / Teacher

Shenandoah Middle School

Miami, Florida 